\title{
June 2004 \\ Progress Report on the Federal Building and Fire Safety Investigation of the World Trade Center Disaster
}

\section{Volume 2}

Contains Appendices A, B, and C 

NIST Special Publication 1000-5

\section{June 2004 Progress Report on the Federal Building and Fire Safety Investigation of the World Trade Center Disaster}

\section{Volume 2}

Contains Appendices A, B, and C

June 2004

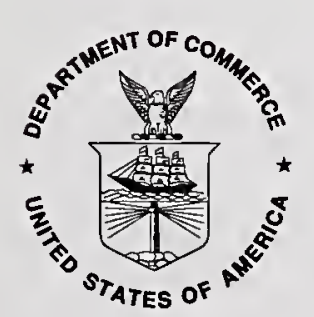

U.S. Department of Commerce

Donald L. Evans, Secretary

Technology Administration

Phillip J. Bond, Under Secretary for Technology 


\section{Disclaimer}

Certain commercial entities, equipment, products, or materials are identified in this document in order to describe a procedure or concept adequately or to trace the history of the procedures and practices used. Such identification is not intended to imply recommendation, endorsement, or implication that the entities, products, materials, or equipment are necessarily the best available for the purpose. Nor does such identification imply a finding of fault or negligence by the National Institute of Standards and Technology.

\section{Disclaimer}

The policy of NIST is to use the International System of Units (metric units) in all publications. In this document, however, units are presented in metric units or the inch-pound system, whichever is prevalent in the discipline.

\section{Use in Legal Proceedings}

No part of any report resulting from a NIST investigation into a structural failure or from an investigation under the National Construction Safety Team Act may be used in any suit or action for damages arising out of any matter mentioned in such report (15 USC 281a; as amended by P.L. 107-231).

National Institute of Standards and Technology Special Publication 1000-5

Natl. Inst. Stand. Technol. Spec. Publ. 1000-5, 1,054 pages (June 2004)

CODEN: NSPUE2 


\section{MASTER TABLE OF CONTENTS}

\section{Volume 1}

Table of Contents

List of Acronyms and Abbreviations

Metric Conversion Table

Preface

Executive Summary

Chapter 1

Interim Findings and Accomplishments

Chapter 2

Progress on the World Trade Center Investigation

Chapter 3

Update on Safety of Threatened Buildings (WTC R\&D) Program

Chapter 4

Update on WTC Dissemination and Technical Assistance Program

\section{Volume 2}

Table of Contents

List of Acronyms and Abbreviations

Metric Conversion Table

Appendix A

Interim Report on the Analysis of Building and Fire Codes and Practices

Appendix B Interim Report on Development of Structural Databases and Reference Models for the WTC Towers 
Appendix C Interim Report on Analysis of Aircraft Impact into the WTC Towers

\section{Volume 3}

Table of Contents

List of Acronyms and Abbreviations

Metric Conversion Table

Appendix D

Interim Report on Preliminary Stability Analysis of the WTC Towers

Appendix E

Interim Report on Contemporaneous Structural Steel Specifications

Appendix F

Interim Report on Inventory and Identification of Steels Recovered from the

WTC Buildings

\section{Volume 4}

Table of Contents

List of Acronyms and Abbreviations

Metric Conversion Table

Appendix G

Interim Report on Significant Fires in WTC 1, 2, and 7 Prior to September 11, 2001

Appendix $\mathrm{H}$

Interim Report on Evolution of WTC Fires, Smoke, and Damage based on Image Analysis

Appendix I

Interim Report on Assessment of Sprayed Fireproofing in the WTC

Towers-Methodology 


\section{Volume 5}

Table of Contents

List of Acronyms and Abbreviations

Metric Conversion Table

Appendix $J$

Interim Report on Experiments to Support Fire Dynamics and Thermal

Response Modeling

Appendix K

Interim Report on Subsystem Structural Analysis of the WTC Towers

Appendix L

Interim Report on WTC 7

Appendix $M$

Interim Report on 2-D Analysis of the WTC Towers Under Gravity Load and Fire

\section{Volume 6}

Table of Contents

List of Acronyms and Abbreviations

Metric Conversion Table

Appendix $\mathbf{N}$

Interim Report on Analysis of First-Person Accounts from Survivors of the WTC Evacuation on September 11, 2001

Appendix 0

Interim Report on Telephone Interviews

Appendix $\mathbf{P}$

Interim Report on Emergency Communications

Appendix Q

NIST's Working Hypothesis for Collapse of the WTC Towers 
This page intentionally left blank. 


\section{LIST OF ACRONYMS AND ABBREVIATIONS}

AAPOR American Association of Public Opinion Research

$\mathrm{ABC}$

American Broadcasting Company

$\mathrm{ACI}$

American Concrete Institute

AISC

American Institute of Steel Construction

AISI

American Iron and Steel Institute

ALE

Arbitrary-Lagrangian-Evlerian

$\mathrm{AMCBO}$

Association of Major City/County Building Officials

ANSI

American National Standards Institute

ANSYS

finite element model

ARA

Applied Research Associates, Inc.

ASCE

American Society of Civil Engineers

ASHRAE American Society of Heating, Refrigerating and Air-Conditioning Engineers, Inc.

ASME

American Society of Mechanical Engineers

ASTM

ASTM International

AWS

American Welding Society

BOCA

Building Officials and Code Administrators

$\mathrm{BOCA} / \mathrm{BBC}$

BOCA Basic Building Code

BPAT

Building Performance Assessment Team

BPS

Building Performance Study

BSI

British Standards Institution

$\mathrm{C} / \mathrm{F}$

cancer free

CATI

computer-assisted telephone interviews

CBR

chemical, biological, and radiological

CBS

Columbia Broadcasting System

CERF

Civil Engineering Research Foundation

CFD

computational fluid dynamics

CIB

International Council for Research and Innovation in Building and Construction

CII

Construction Industry Institute

$\mathrm{CNN}$

Cable News Network 
CPP Cermak Peterka Peterson, Inc.

$\mathrm{CPU} \quad$ central processing unit

CRT cathode-ray tube

CTB\&UH Council on Tall Buildings and Urban Habitat

CTE coefficients of thermal expansion

$\mathrm{DC} / \mathrm{F} \quad$ BlazeShield $\mathrm{DC} / \mathrm{F}$ fire protective insulation

DL dead load

DTAP dissemination and technical assistance program

EMS Emergency Medical Service

EMT Emergency Medical Team

ER\&S Emory Roth \& Sons

FBI Federal Bureau of Investigation

FCA Flux cored arc

FDNY New York City Fire Department

FDS Fire Dynamics Simulator

FE finite element

FEA finite element analysis

FEM finite element model

FEMA Federal Emergency Management Agency

FMRC Factory Mutual Research Corp.

FSI Fire-Structure Interface

FVM Finite Volume Method

GFI Government Furnished Information

GG glass over glass

$\mathrm{GHz} \quad$ gigahertz

GMS, LLP Gilsanz Murray Steficek, LLP

HAZ heat affected zone

HNSE Hugo Nue Schnutzer East

HRR heat release rate

HVAC heating, ventilating, and air conditioning

IAQ indoor air quality

IBC International Building Code 
ICBO International Conference of Building Officials

ICC International Code Council

IMTI Integrated Manufacturing Technology

JFK John F. Kennedy International Airport

JIS Japan Industrial Standard

LERA Leslie E. Robertson Associates

LES Large Eddy Simulation

LL live load

LSTC Livermore Software Technology Corporation

MBC BOCA National Building Code

MCC Municipal Code of Chicago

MPI Message Passing Interface

NBC National Broadcasting Company

NBFU National Board of Fire Underwriters

NCSBCS National Conference of States on Building Codes \& Standards, Inc.

NCST National Construction Safety Team

NEMA National Electrical Manufacturers Association

NFPA National Fire Protection Association

NIBS National Institute of Building Sciences

NIST National Institute of Standards and Technology

NYC New York City

NYCBC New York City Building Code

NYCDOB New York City Department of Buildings

NYPD New York City Police Department

NYSBC New York State Building Construction Code

P.L. Public Law

PANYNJ Port Authority of New York and New Jersey

PAPD Port Authority Police Department

PC\&F Pacific Car and Foundry

PDM Pittsburg-Des Moines

PONYA Port of New York Authority

R\&D research and development 
RWDI Rowan Williams Davis and Irwin, Inc.

SBCCI Southern Standard Building Code

SDL superimposed dead load

SDO standards development organization

SEAoNY Structural Engineers Association of New York

SFPE Society of Fire Protection Engineering

SFRM spray-on fire resistant material or sprayed fire resistive materials

SHCR Skilling, Helle, Christiansen, \& Robertson

SI

metric

SLB short legs back-to-back

SMA Shielded Metal Arc

SOD Special Operations Division

SOM Skidmore, Ownings \& Merrill

SPH Smoothed Particle Hydrodynamics

SQL Structured Query Language

SWMB Skilling, Ward, Magnussen, and Barkshire

TL Truss Lower Chord

TM Truss Middle Chord

TU Truss Upper Chord

UBC Uniform Building Code

UL Underwriters' Laboratories, Inc.

USC United States Code

USM United States Mineral Products Co.

VCBT Virtual Cybernetic Building Testbed

WABC WABC-TV New York

WCBS WCBS-TV New York

WF wide flange (a type of structural steel shape now usually called a W-shape). ASTM A 6 defines them as "doubly-symmetric, wide-flange shapes with inside flange surfaces that are substantially parallel."

WNBC NBC4 New York

WNYW FOX5 New York

WPIX WPIX-TV New York

WTC World Trade Center 
WTC $1 \quad$ World Trade Center Tower 1

WTC 2 World Trade Center Tower 2

WTC $7 \quad$ World Trade Center Building 7 


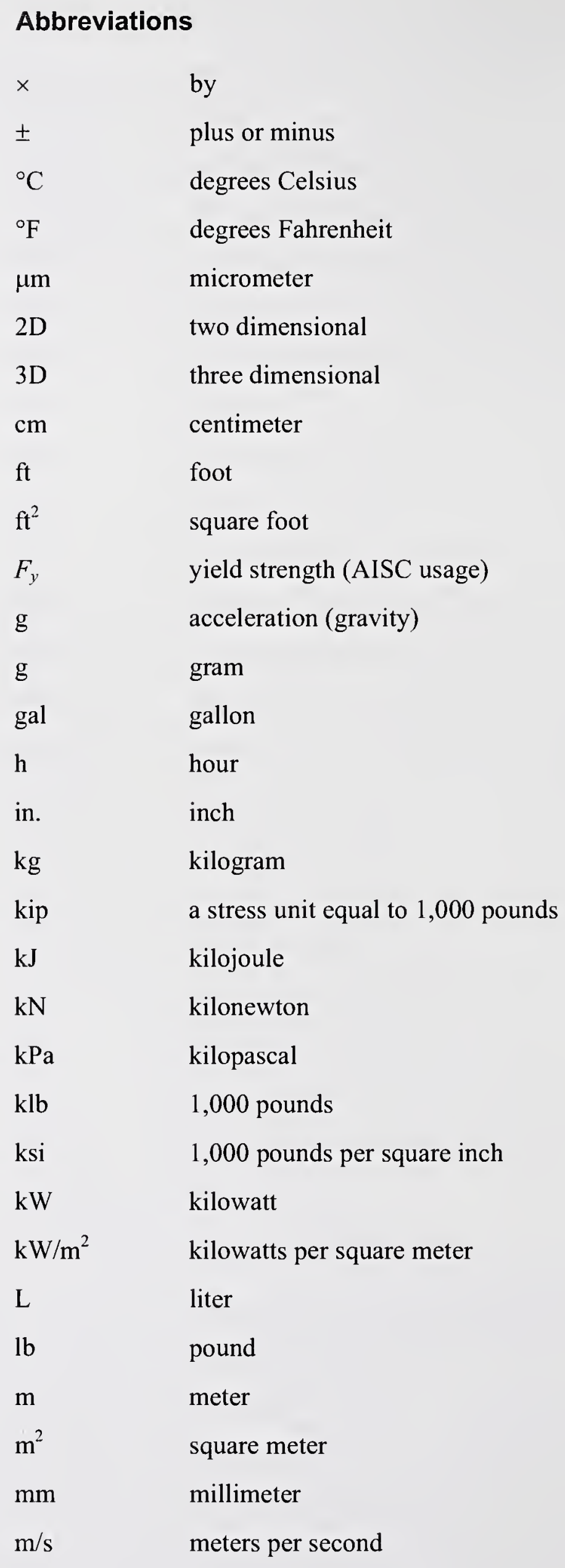




$\begin{array}{ll}\text { min } & \text { minute } \\ \text { MJ } & \text { megajoule } \\ \mathrm{MPa} & \text { megapascal } \\ \mathrm{mph} & \text { miles per hour } \\ \mathrm{ms} & \text { microsecond } \\ \mathrm{Msi} & \text { millions pounds per square inch } \\ \mathrm{MW} & \text { megawatt } \\ \mathrm{N} & \text { newton } \\ \mathrm{Pa} & \text { pascal } \\ \text { pcf } & \text { pounds per cubic foot } \\ \text { plf } & \text { pounds per linear foot } \\ \text { psf } & \text { pounds per square foot } \\ \text { psi } & \text { pounds per square inch } \\ \mathrm{s} & \text { second }\end{array}$


This page intentionally left blank. 


\section{Metric Conversion TAble}

To convert from

to

\section{AREA AND SECOND MOMENT OF AREA}

square foot $\left(\mathrm{ft}^{2}\right)$

square inch $\left(\mathrm{in}^{2}\right)$

square inch $\left(\mathrm{in}^{2}\right)$

square yard $\left(\mathrm{yd}^{2}\right)$

\section{ENERGY (includes WORK)}

kilowatt hour $\left(\mathrm{kW}{ }^{*} \mathrm{~h}\right)$

quad (1015 BtuIT)

therm (U.S.)

ton of TNT (energy equivalent)

watt hour $\left(W^{*} h\right)$

watt second $\left(\mathrm{W}^{*} \mathrm{~s}\right)$

\section{FORCE}

dyne (dyn)

kilogram-force (kgf)

kilopond (kilogram-force) (kp)

kip ( 1 kip=1000 lbf)

kip ( 1 kip=1000 lbf)

pound-force (lbf)

\section{FORCE DIVIDED BY LENGTH}

pound-force per foot $(\mathrm{lbf} / \mathrm{ft})$

pound-force per inch (lbf/in)

\section{HEAT FLOW RATE}

calorieth per minute (calth/min)

calorieth per second (calth/s)

kilocalorieth per minute (kcalth/min)

kilocalorieth per second (kcalth/s) square meter $\left(\mathrm{m}^{2}\right)$

square meter $\left(\mathrm{m}^{2}\right)$

square centimeter $\left(\mathrm{cm}^{2}\right)$

square meter $\left(\mathrm{m}^{2}\right)$

joule (J)

joule (J)

joule (J)

joule (J)

joule (J)

joule (J)

newton (N)

newton $(\mathrm{N})$

newton $(\mathrm{N})$

newton $(\mathrm{N})$

kilonewton $(\mathrm{kN})$

newton $(\mathrm{N})$

newton per meter $(\mathrm{N} / \mathrm{m})$

newton per meter $(\mathrm{N} / \mathrm{m})$

watt (W)

watt (W)

watt (W)

watt (W)
Multiply by

9.290304 E-02

6.4516 E-04

$6.4516 \mathrm{E}+00$

8.361274 E-01

$3.6 \mathrm{E}+06$

$1.055056 \mathrm{E}+18$

$1.054804 \mathrm{E}+08$

$4.184 \mathrm{E}+09$

$3.6 \mathrm{E}+03$

$1.0 \mathrm{E}+00$

1.0 E-05

$9.80665 \mathrm{E}+00$

$9.80665 \mathrm{E}+00$

$4.448222 \mathrm{E}+03$

$4.448222 \mathrm{E}+00$

$4.448222 \mathrm{E}+00$

$1.459390 \mathrm{E}+01$

$1.751268 \mathrm{E}+02$

$6.973333 \mathrm{E}-02$

$4.184 \mathrm{E}+00$

$6.973333 \mathrm{E}+01$

$4.184 \mathrm{E}+03$ 
To convert from

to

Multiply by

\section{LENGTH}

foot $(\mathrm{ft})$

inch (in)

inch (in)

micron (m)

yard (yd)

\section{MASS and MOMENT OF INERTIA}

kilogram-force second squared per meter $\left(\mathrm{kgf} * \mathrm{~s}^{2} / \mathrm{m}\right)$

pound foot squared $\left(\mathrm{lb}^{*} \mathrm{ft}^{2}\right)$

pound inch squared $\left(\mathrm{lb}^{*}\right.$ in $\left.^{2}\right)$

ton, metric ( $\mathrm{t})$

ton, short (2000 lb)

\section{MASS DIVIDED BY AREA}

pound per square foot $\left(\mathrm{lb} / \mathrm{ft}^{2}\right)$

pound per square inch

(not pound force) $\left(\mathrm{lb} / \mathrm{in}^{2}\right.$ )

\section{MASS DIVIDED BY LENGTH}

pound per foot $(\mathrm{lb} / \mathrm{ft})$

pound per inch (lb/in)

pound per yard (lb/yd) meter $(\mathrm{m})$

$3.048 \mathrm{E}-01$

meter $(\mathrm{m})$

$2.54 \mathrm{E}-02$

centimeter $(\mathrm{cm})$

$2.54 \mathrm{E}+00$

meter $(\mathrm{m})$

$1.0 \mathrm{E}-06$

meter $(\mathrm{m})$

$9.144 \mathrm{E}-01$
$9.80665 \mathrm{E}+00$

kilogram meter squared $\left(\mathrm{kg}^{*} \mathrm{~m}^{2}\right)$

$4.214011 \mathrm{E}-02$

kilogram meter squared $\left(\mathrm{kg}^{*} \mathrm{~m}^{2}\right)$

kilogram (kg)

2.926397 E-04

$1.0 \mathrm{E}+03$

kilogram (kg)

$9.071847 \mathrm{E}+02$ kilogram per square meter $\left(\mathrm{kg} / \mathrm{m}^{2}\right)$

kilogram per square meter $\left(\mathrm{kg} / \mathrm{m}^{2}\right)$
$4.882428 \mathrm{E}+00$

$7.030696 \mathrm{E}+02$ kilogram per meter $(\mathrm{kg} / \mathrm{m})$

kilogram per meter $(\mathrm{kg} / \mathrm{m})$

kilogram per meter $(\mathrm{kg} / \mathrm{m})$
$1.488164 \mathrm{E}+00$

$1.785797 \mathrm{E}+01$

$4.960546 \mathrm{E}-01$

\section{PRESSURE or STRESS (FORCE DIVIDED BY AREA)}

$\begin{array}{lll}\text { kilogram-force per square centimeter }\left(\mathrm{kgf} / \mathrm{cm}^{2}\right) & \text { pascal }(\mathrm{Pa}) & 9.80665 \mathrm{E}+04 \\ \text { kilogram-force per square meter }\left(\mathrm{kgf} / \mathrm{m}^{2}\right) & \text { pascal }(\mathrm{Pa}) & 9.80665 \mathrm{E}+00 \\ \text { kilogram-force per square millimeter }\left(\mathrm{kgf} / \mathrm{mm}^{2}\right) & \text { pascal }(\mathrm{Pa}) & 9.80665 \mathrm{E}+06 \\ \text { kip per square inch }(\mathrm{ksi})\left(\mathrm{kip} / \mathrm{in}^{2}\right) & \text { pascal }(\mathrm{Pa}) & 6.894757 \mathrm{E}+06 \\ \text { kip per square inch }(\mathrm{ksi})\left(\mathrm{kip} / \mathrm{in}^{2}\right) & \text { kilopascal }(\mathrm{kPa}) & 6.894757 \mathrm{E}+03 \\ \text { pound-force per square foot }\left(\mathrm{lbf} / \mathrm{ft}^{2}\right) & \text { pascal }(\mathrm{Pa}) & 4.788026 \mathrm{E}+01 \\ \text { pound-force per square inch }(\mathrm{psi})\left(\mathrm{lbf} / \mathrm{in}^{2}\right) & \text { pascal }(\mathrm{Pa}) & 6.894757 \mathrm{E}+03 \\ \text { pound-force per square inch }(\mathrm{psi})\left(\mathrm{lbf} / \mathrm{in}^{2}\right) & \text { kilopascal }(\mathrm{kPa}) & 6.894757 \mathrm{E}+00 \\ \text { psi (pound-force per square inch) }\left(\mathrm{lbf} / \mathrm{in}^{2}\right) & \text { pascal }(\mathrm{Pa}) & 6.894757 \mathrm{E}+03 \\ \text { psi (pound-force per square inch) }\left(\mathrm{lbf} / \mathrm{in}^{2}\right) & \text { kilopascal }(\mathrm{kPa}) & 6.894757 \mathrm{E}+00\end{array}$




\section{To convert from}

TEMPERATURE

degree Celsius $\left({ }^{\circ} \mathrm{C}\right)$

degree centigrade

degree Fahrenheit $\left({ }^{\circ} \mathrm{F}\right)$

degree Fahrenheit $\left({ }^{\circ} \mathrm{F}\right)$

kelvin $(\mathrm{K})$

\section{TEMPERATURE INTERVAL}

degree Celsius $\left({ }^{\circ} \mathrm{C}\right)$

degree centigrade

degree Fahrenheit $\left({ }^{\circ} \mathrm{F}\right)$

degree Fahrenheit $\left({ }^{\circ} \mathrm{F}\right)$

degree Rankine $\left({ }^{\circ} \mathrm{R}\right)$

\section{VELOCITY (includes SPEED)}

foot per second ( $\mathrm{ft} / \mathrm{s}$ )

inch per second (in/s)

kilometer per hour $(\mathrm{km} / \mathrm{h})$

mile per hour $(\mathrm{mi} / \mathrm{h})$

mile per minute ( $\mathrm{mi} / \mathrm{min})$

\section{VOLUME (includes CAPACITY)}

cubic foot $\left(\mathrm{ft}^{3}\right)$

cubic inch $\left(\mathrm{in}^{3}\right)$

cubic yard $\left(\mathrm{yd}^{3}\right)$

gallon (U.S.) (gal)

gallon (U.S.) (gal)

liter (L)

ounce (U.S. fluid) (fl oz)

ounce (U.S. fluid) (fl oz) to

\section{Multiply by}

kelvin $(\mathrm{K})$

$\mathrm{T} / \mathrm{K}=\mathrm{t} /{ }^{\circ} \mathrm{C}+273.15$

degree Celsius $\left({ }^{\circ} \mathrm{C}\right)$

degree Celsius $\left({ }^{\circ} \mathrm{C}\right)$

kelvin (K)

degree Celsius $\left({ }^{\circ} \mathrm{C}\right)$

$t^{\circ} \mathrm{C} \approx \mathrm{t} /$ deg. cent.

$\mathrm{t} /{ }^{\circ} \mathrm{C}=\left(\mathrm{t} /{ }^{\circ} \mathrm{F} 232\right) / 1.8$

$\mathrm{T} / \mathrm{K}=\left(\mathrm{t} /{ }^{\circ} \mathrm{F}+459.67\right) / 1.8$

$\mathrm{t} /{ }^{\circ} \mathrm{C}=\mathrm{T} / \mathrm{K} 2273.15$ kelvin $(\mathrm{K})$

degree Celsius $\left({ }^{\circ} \mathrm{C}\right)$

degree Celsius $\left({ }^{\circ} \mathrm{C}\right)$

kelvin $(\mathrm{K})$

kelvin $(\mathrm{K})$

meter per second $(\mathrm{m} / \mathrm{s})$

meter per second $(\mathrm{m} / \mathrm{s})$

meter per second $(\mathrm{m} / \mathrm{s})$

kilometer per hour $(\mathrm{km} / \mathrm{h})$

meter per second $(\mathrm{m} / \mathrm{s})$

$$
\begin{aligned}
& \text { cubic meter }\left(\mathrm{m}^{3}\right) \\
& \text { cubic meter }\left(\mathrm{m}^{3}\right) \\
& \text { cubic meter }\left(\mathrm{m}^{3}\right) \\
& \text { cubic meter }\left(\mathrm{m}^{3}\right) \\
& \text { liter }(\mathrm{L}) \\
& \text { cubic meter }\left(\mathrm{m}^{3}\right) \\
& \text { cubic meter }\left(\mathrm{m}^{3}\right) \\
& \text { milliliter }(\mathrm{mL})
\end{aligned}
$$

3.048 E-01

$2.54 \mathrm{E}-02$

2.777778 E-01

$1.609344 \mathrm{E}+00$

$2.68224 \mathrm{E}+01$ 
This page intentionally left blank.

xviii 


\section{TABLE OF CONTENTS}

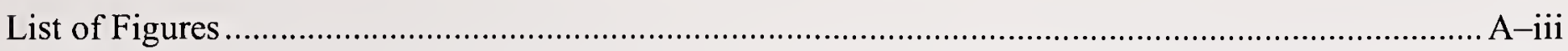

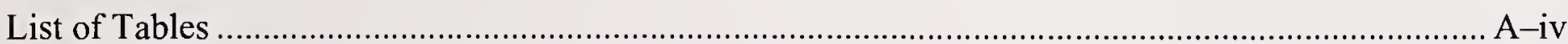

\section{Appendix A}

Interim Report on the Analysis of Building and Fire Codes and Practices..................... A-1

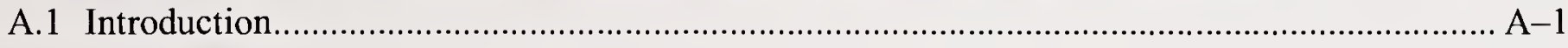

A.1.1 The New York City Building Code .................................................................... A-3

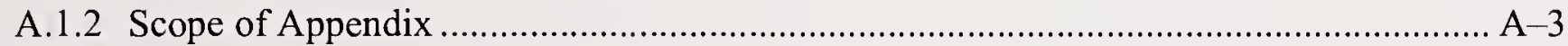

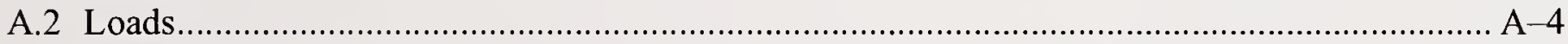

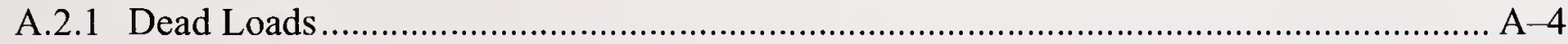

A.2.2 Live Loads ...................................................................................................... A-6

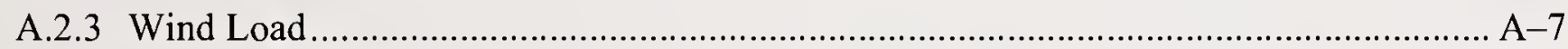

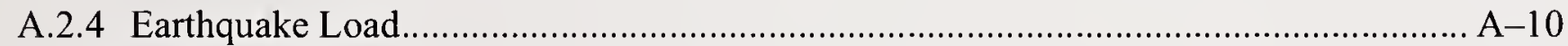

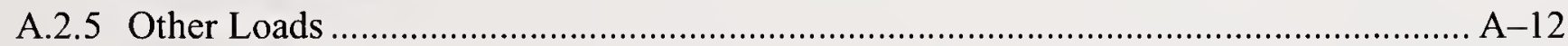

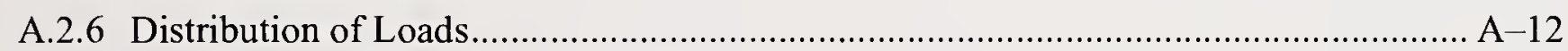

A.3 Materials, Design, and Construction............................................................................... A-13

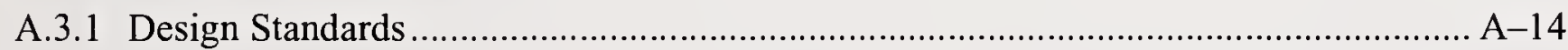

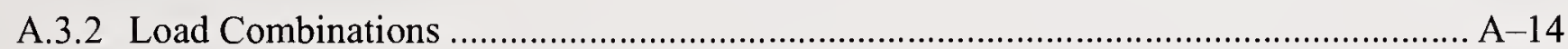

A.3.3 Alteration of Existing Buildings...................................................................... A-16

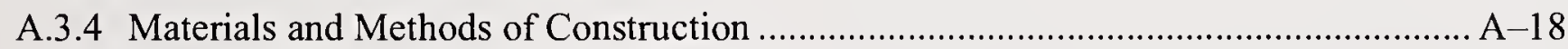

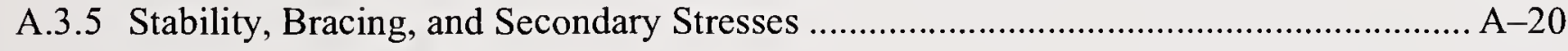

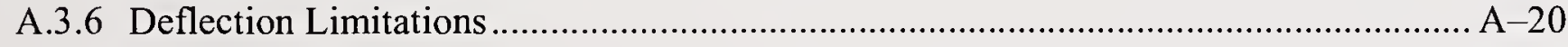

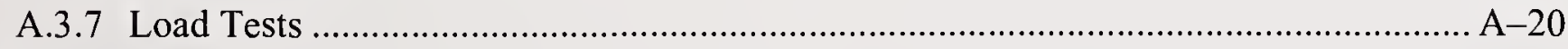

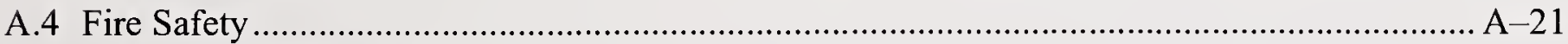

A.4.1 Fire Protection .............................................................................................. A-21

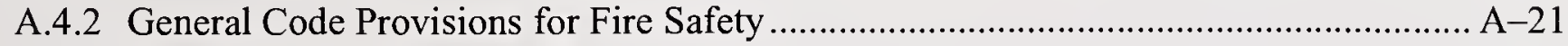

A.4.3 Occupancy Classification .................................................................................. A-22

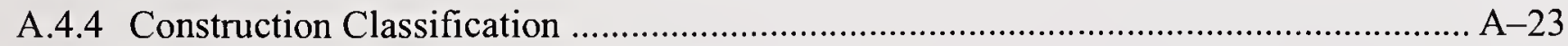

A.4.5 Fire Resistance of Structural Elements................................................................ A-24

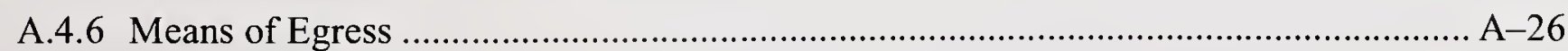

A.5 Preliminary Findings................................................................................................. A-29 


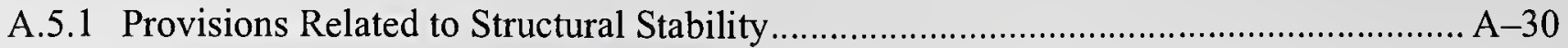

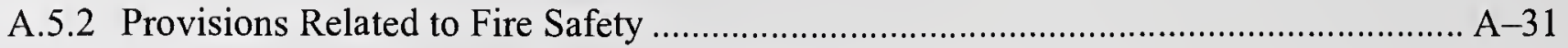

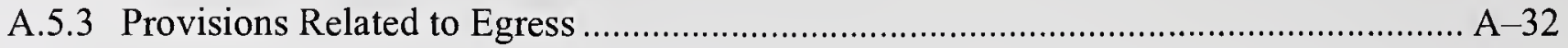

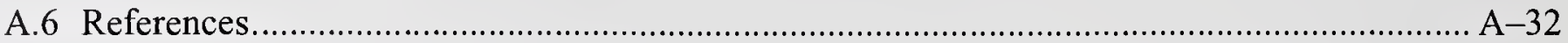




\section{LIST OF FIGURES}

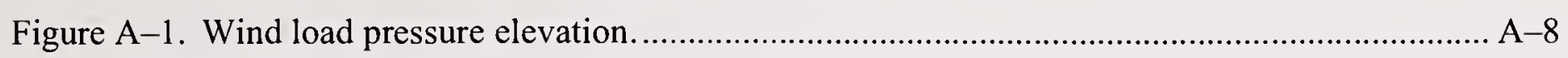

Figure A-2. Wind load pressure versus elevation................................................................ A-10 


\section{LIST OF TABLES}

Table A-1. Examples of dead loads given in NYC Building Code and BOCA Code.

A-5

Table A-2. Examples of minimum uniformly distributed live loads ............................................ A-6

Table A-3. Reduced live load for beams and girders............................................................... A-9

Table A-4. Design standards for concrete and steel.................................................................. A-14

Table A-5. Compliance requirements for alterations.............................................................. A -17

Table A-6. Excerpts of inspection requirements for materials and assemblies in 1968 New York

City Building Code.

Table A-7. Excerpts of inspection requirements for methods of construction in 1968 New York City Building Code.

Table A-8. Summary of fire safety provisions for business occupancy in high-rise buildings $(>75 \mathrm{ft})$. 


\section{Appendix A \\ INTERIM REPORT ON THE ANALYSIS OF BUILDING AND FIRE CODES AND PRACTICES}

\section{A.1 INTRODUCTION}

As stated in Chapter 2, one of the objectives of the National Institute of Standards and Technology (NIST) Investigation of the World Trade Center (WTC) disaster is to determine the procedures and practices that were used in the design, construction, operation, and maintenance of the WTC buildings. (For other objectives refer to http://wtc.nist.gov.) Since WTC 1, 2, and 7 were designed according to the New York City Building Code, it is important to understand how this code compared with contemporaneous building codes. This appendix summarizes the structural and fire provisions of the 1968 New York City Building Code and compares them with a number of building codes that existed when WTC 1, 2, and 7 were designed, as well as the 2001 edition of the New York City Building Code.

As a result of devastating fires in major cities of the U.S. such as Boston, New York, Chicago, and Baltimore in the late 1800 s, the first model building code was developed by the fire insurance industry to minimize future fire losses. The National Board of Fire Underwriters (predecessor of the American Insurance Association) published the National Building Code in 1905. Subsequently, the Pacific Coast Building Officials Conference (predecessor of the International Conference of Building Officials) issued the Uniform Building Code (UBC) in 1927, the Southern Building Code Congress International Inc. published its Southern Standard Building Code (SBCCI) in 1946, and the Building Officials and Code Administrators, Inc. (BOCA) published the Basic Building Code in 1950. In the mid-1980s, the Basic Building Code was changed to the BOCA National Building Code (NBC). These regionally used model building codes were revised annually to incorporate developments in new materials and construction methods, and new additions were published every three years.

It should be pointed out that provisions in these model building codes establish minimum requirements to safeguard life, health and property and public welfare by means of regulations pertaining to the design, construction, and quality of materials, use and occupancy, and maintenance of buildings. When buildings are designed, constructed, and maintained according to building code requirements, they are considered to have met minimum requirements. While building code regulations address a number of objectives demanded by society, the primary objectives of building codes are structural stability and fire safety.

Before the issuance of the International Building Code (IBC) in 2000 , which was published by the International Code Council (an amalgamation of the three regional code organizations), most local and state building codes in the U.S. were patterned after one of the three model building codes, UBC, SBCCI, or NBC. These model codes evolved in the mid-20th century to incorporate regional differences in construction materials and practices. When adopted by local jurisdictions, the model building code becomes a legal document and code provisions become mandatory laws. A number of major cities in the U.S. have developed their own building codes to meet their specific needs, such as San Francisco for earthquake resistant design and New York City for high-rise buildings design. 
The National Fire Protection Association (NFPA) in the early 1900s initiated the development of a "life safety code" for safety of building occupants. This code, while not a building code, is frequently used as a supplement to the building codes. In 2002, NFPA also published a model building code known as the NFPA Building Construction and Safety Code (NFPA 5000).

The Port of New York Authority (PONYA) (whose name was changed to the Port Authority of New York and New Jersey [PANYNJ] in 1972) is an interstate agency that was established in 1921 under a clause in the U.S. constitution that permits compacts between states. As an interstate agency, construction projects of the Port Authority are not required to comply with any building code. With respect to design and construction of the WTC towers, however, in 1963 the Port Authority instructed its consultants to prepare their designs of WTC 1 and WTC 2 to comply with the New York City Building Code (Levy 1963). Although it was not specifically stated in the letter to the architect, the 1938 edition of the Code was in effect at that time. In areas where the Code was not explicit or where technological advances made portions of the 1938 Code obsolete, the Port Authority directed the architect and consulting engineers to propose designs "based on acceptable engineering practice." The Port Authority also required the design professionals to inform the Planning Division of the WTC when such situations occurred. The Port Authority established a special WTC office that reviewed and approved plans, issued variances, and conducted inspections during construction instead of the city agencies and employees that would normally perform these duties.

The Port Authority further stated that all design concepts would be reviewed before the final design by the Chief Engineer of the Port Authority and by the appropriate New York City agencies. According to correspondence in 1975 from the architect-of-record for the WTC project, the New York City Building Department reviewed the design drawings of WTC 1 and WTC 2 in 1968 (Solomon 1975).

In 1965, the Port Authority instructed the architect and consulting engineers to revise their designs for WTC 1 and WTC 2 to comply with the second and third drafts of the New York City Building Code then being finalized and to undertake any design modifications necessary to comply with the new code provisions (Levy 1965). The new New York City Building Code (NYC BC 1968) was enacted by the City Council on October 22, 1968, approved by the Mayor on November 6, 1968, and became effective on December 6, 1968.

The Port Authority intended to lease space in WTC 1 and WTC 2 to tenants who would adapt their spaces to their own needs through a tenant alteration process. To maintain structural integrity and fire safety, the Port Authority issued a set of requirements for the alteration process. The first edition of the Tenant Construction Review Manual was issued in 1971, shortly after the first tenants occupied WTC 1 in December 1970 and before initial occupancy of WTC 2 in 1972. The manual contained the technical criteria to be used in planning alterations (architectural, mechanical, electrical, fire protection, and so forth) to Port Authority facilities. Included were applicable standards to be used by tenants and their agents and review criteria to be used by the Engineering Department of the Port Authority. Alteration designs were to be completed by registered design professionals, and at the completion of the work, asbuilt drawings were to be submitted to the Port Authority. The 1968 New York City Building Code was referenced, and specific code provisions were referenced in various checklists. The review manual was updated in 1979, 1984, 1990, and 1997, at which times changes that had been made to the New York City Building Code were incorporated. In 1998, the manual was replaced by the Architectural and Structural Design Guidelines, Specifications, and Standard Details, which dealt specifically with alterations to WTC 1 and WTC 2. 
Unlike WTC 1 and WTC 2, which were developed and owned by the Port Authority, WTC 7 was developed on land owned by the Port Authority, but the building was owned by Seven World Trade Company and Silverstein Development Corporation, General Partner. It was designed and constructed as a "Tenant Alteration" project of the Port Authority. When WTC 7 was designed in the mid-1980s, the 1968 New York City Building Code with amendments was in effect. The Project Specifications for WTC 7 issued in 1984 required that the structural steel be designed in accordance with the then current New York City Building Code.

\section{A.1.1 The New York City Building Code}

The New York City Building Code is part of the Administrative Code of New York City. It is amended from time to time by Local Laws to improve safety requirements or to incorporate technological advances. New York City Council Members, at the request of any person or group, can introduce a bill to the Council for the purpose of amending the Building Code requirements. When passed by the Council and approved by the Mayor, the bill becomes a Local Law. Seventy-nine Local Laws were adopted between 1969 and 2002 that modified the 1968 Building Code. For example, Local Laws 5, 16, and 86 made important modifications to fire protection and life safety features of the 1968 Building Code.

To aid the implementation of and to clarify building code requirements, New York City issues "rules." These rules are initiated typically by City Government offices such as the Department of Buildings and the Department of Environment. These rules do not require enactment by the City Council, and new rules issued by the Building Commissioner can be put into effect expeditiously. The rules are part of the Building Code, and are required to be complied with for design, construction, and maintenance of buildings.

The 1968 New York City Building Code includes "Reference Standards." These include standard test methods published by the ASTM International, or design standards published by other consensus-based organizations. These reference standards may include modifications to the provisions in the published standards, or they may be stand-alone requirements developed by New York City.

\section{A.1.2 Scope of Appendix}

The 1968 New York City Building Code (NYCBC 1968) is compared with four other codes. They are: the 1964 New York State Building Construction Code (NYSBC 1964); the 1965 BOCA Basic Building Code (BOCA/BBC 1965); the 1967 Municipal Code of Chicago Relating to Buildings (MCC 1967); and the 2001 edition of the New York City Building Code (NYCBC 2001)

The 1964 New York State Building Construction Code was selected for comparison, as it would have been a governing building code outside the New York City limits. The 1965 BOCA Basic Building Code was selected, as it was typically adopted by local jurisdictions in the northeastern region of the U.S. The 1968 New York City Building Code is compared with the 1967 Municipal Code of Chicago to see whether there are any substantial differences in the structural and fire safety requirements of the two codes. In the late 1960s and early 1970s, several tall buildings were built in Chicago including the Sears Tower (110 stories) and the John Hancock Tower (100 stories). The 2001 edition of the New York City Building Code is compared with the 1968 version to examine the extent to which Local Laws have 
modified the code provisions, and in most cases, is only addressed in areas where changes have occurred between the two versions.

A provision by provision comparison was made between the 1968 New York City Building Code and these four codes. The code provisions that were compared are limited to the requirements related to structural stability, active and passive fire safety, and emergency egress. This appendix presents a summary of substantial differences noted in the comparison. This summary focuses on the following topics:

- Loads to be considered in the design of buildings;

- Requirements for materials, design, and construction;

- Fire protection requirements; and

- Egress requirements.

With respect to structural stability, no Local Law other than Local Law 17 (seismic provisions for new construction) has been adopted that modified the structural requirements of the 1968 New York City Building Code. Hence comparison between the structural requirements of the 1968 and 2001 New York City Building Code is not discussed here, with the exception of earthquake loads.

\section{A.2 LOADS}

A key aspect of any structural design is the loading that the structure is intended to support. Building codes provide minimum values for the different types of loads that are considered in typical building designs. The designer is permitted to use larger values for these loads, but is not permitted to use smaller values without approval by the building official. This section compares the specified loads in the codes that were compared. Similarities and differences are noted.

\section{A.2.1 Dead Loads}

Dead loads refer to loads that are permanently present in a building. They include, for example, the weight of the structural components, the weights of permanent partitions, the weights of floor and wall finishes, and the weights of service equipment that is part of the building (elevator equipment, plumbing, electrical, heating, air conditioning, and ventilation systems). Weights of the structural components are computed from the sizes of the members and the densities of the material, and codes typically provide default density values for different materials. The dead loads of partitions and walls are typically prescribed in terms of weight per unit area of wall, and the weight per unit length of wall or partition is determined from these prescribed values and the heights of the partitions or walls. Floor finishes and ceilings are typically specified in terms of a uniform load per unit area of floor or ceiling. Table A-1 gives examples of the minimum values of dead load prescribed in Referenced Standard RS 9-1 in the 1968 New York City Building Code and in Appendix J of the 1965 BOCA Basic Building Code. There are no corresponding provisions in the 1964 New York State Building Construction Code or the 1967 Municipal Code of Chicago. Typically, the designer is permitted to use weights based on available 
data that are greater than the specified minimum values, but the designer is not permitted to use lower values without approval of the Code Official.

Table A-1. Examples of dead loads given in NYC Building Code and BOCA Code.

\begin{tabular}{|c|c|c|}
\hline & NYC & BOCA \\
\hline \multicolumn{3}{|c|}{ Walls and Partitions } \\
\hline Hollow concrete block -8 in. thick & $53 \mathrm{psf}$ & $50 \mathrm{psf}$ \\
\hline Clay tile, nonload bearing -8 in. thick & 34 psf & $36 \mathrm{psf}$ \\
\hline Plaster partition, metal studs \& lath, gypsum plaster both sides & $18 \mathrm{psf}$ & $18 \mathrm{psf}$ \\
\hline \multicolumn{3}{|c|}{ Floor Finishes } \\
\hline Resilient flooring & $2 \mathrm{psf}$ & $2 \mathrm{psf}$ \\
\hline Hardwood flooring $7 / 8$ in. thick ( 1 in. for BOCA) & $4 \mathrm{psf}$ & 4 psf \\
\hline Cement, 1 in. thick & $12 \mathrm{psf}$ & $12 \mathrm{psf}$ \\
\hline \multicolumn{3}{|l|}{ Ceilings } \\
\hline Suspended acoustical tile & $2 \mathrm{psf}$ & - \\
\hline Suspended metal lath and gypsum plaster & 9 psf & $10 \mathrm{psf}$ \\
\hline \multicolumn{3}{|c|}{ Miscellaneous Materials } \\
\hline Marble & $168 \mathrm{pcf}^{\mathrm{B}}$ & $168 \mathrm{pcf}$ \\
\hline Concrete (normal density stone or gravel) & $144 \mathrm{pcf}$ & $144 \mathrm{pcf}$ \\
\hline Reinforced concrete (normal density) & $150 \mathrm{pcf}$ & $150 \mathrm{pcf}$ \\
\hline
\end{tabular}

a. Note that the units in the 1968 New York City Building Code are given incorrectly as "psf."

According to the 1968 New York City Building Code, weights from service equipment (plumbing stacks, piping, heating, ventilating, and air conditioning (HVAC), etc.) are to be included in the dead load (C26-901.2) ${ }^{1}$. The weight of equipment that is part of the occupancy of a given area is to be considered as live load (see next section). The 1964 New York State Building Construction Code and the 1967 Municipal Code of Chicago do not have a provision in this regard. The 1965 BOCA Basic Building Code has a similar provision but without citing specific types of service equipment as in the New York City Code.

The 1968 New York City Building Code requires that weights of partitions be considered in two ways: (1) using line loads at locations shown on plans or (2) using the equivalent uniform load given in Reference Standard RS 9-1. The stipulated equivalent uniform load depends on the partition weight, for example, if a partition weighs 201 plf to 350 plf, it may be taken into account by designing for a uniform load of 20 psf. The uniform loading approach, however, is not permitted in certain situations for which actual partition weights must be used. Equivalent uniform loads must be used in areas where the locations of partitions are not shown on plans, or in areas where partitions can be relocated. The 1964 New York State Building Construction Code does not have a specific provision in this regard. The 1967 Municipal Code of Chicago prescribes a minimum partition load of $20 \mathrm{psf}$. The BOCA Basic Building Code requires consideration of the actual weight of the partitions or an equivalent uniform load of at least 20 psf.

1 Refers to section number in the 1968 New York City Building Code. 


\section{A.2.2 Live Loads}

Live loads are those resulting from the use and occupancy of the building, and include loads such as weights of occupants, furniture, filing cabinets, safes, mechanical equipment, and other items that the structure is called upon to support. Live loads are specified in terms of weight per unit of floor (or roof) area or in terms of concentrated loads. The values specified in codes are based largely on load survey data, experience, and judgment.

\section{Floor Live Loads}

In general, values of minimum uniformly distributed live loads specified in codes are organized on the basis of use or occupancy of spaces and there is no consistency in the names of these use categories. Thus comparison between codes is not straightforward. Table $\mathrm{A}-2$ gives some examples of minimum uniformly distributed live loads for floors. It is seen that there is general agreement in the values of these selected minimum uniform live loads specified by the four codes.

Table A-2. Examples of minimum uniformly distributed live loads

\begin{tabular}{|l|c|c|c|c|}
\hline & $1968 \mathrm{NYC}$ & $\mathbf{1 9 6 4} \mathbf{N Y S}$ & $\mathbf{1 9 6 7}$ Chicago & 1965 BOCA \\
\hline Office space & $50 \mathrm{psf}$ & $50 \mathrm{psf}$ & $50 \mathrm{psf}$ & $50 \mathrm{psf}$ \\
\hline Restaurant & $100 \mathrm{psf}$ & $100 \mathrm{psf}$ & - & $100 \mathrm{psf}$ \\
\hline Lobbies & $100 \mathrm{psf}$ & $100 \mathrm{psf}$ & $100 \mathrm{psf}$ & $100 \mathrm{psf}$ \\
\hline Stairways & $100 \mathrm{psf}$ & $100 \mathrm{psf}$ & $75-100 \mathrm{psf}^{\mathrm{a}}$ & $100 \mathrm{psf}$ \\
\hline Rest rooms & $40 \mathrm{psf}$ & $60 \mathrm{psf}$ & - & - \\
\hline Hospital operating room & $60 \mathrm{psf}$ & $60 \mathrm{psf}$ & $40 \mathrm{psf}$ & $60 \mathrm{psf}$ \\
\hline School classroom & $40 \mathrm{psf}$ & $60 \mathrm{psf}$ & $40 \mathrm{psf}$ & - \\
\hline
\end{tabular}

a. Depends on occupancy, for example, 75 psf for business, 100 psf for schools.

The codes also specify concentrated live loads placed so as to result in maximum stresses.

\section{Live Load Reduction}

There is a low likelihood that the full design floor live loads will be present on all floors of a building at the same time. In addition, the likelihood that the complete area on any one floor is loaded with the design load decreases as the floor area increases. To account for these factors, building codes permit "live-load reductions" in calculating the design loads for primary members (columns and girders) that support the roof and floors. The codes use several methods for live-load reduction (CTB\&UH 1980):

1. Percentage Method-In this method, the live load reduction increases by a certain percentage with increasing numbers of floors, with a limit on the maximum value of reduction (typically 50 percent). 
2. Tributary Area Method-The live load is reduced as the accumulated tributary area that is supported by a member is increased. The limiting value depends on the ratio of live load to dead load. The type of occupancy affects whether a reduction is permitted.

3. Live Load to Dead Load Ratio - The permitted reduction depends on the ratio of live load to dead load, provided that the dead load is greater than the live load.

The 1968 New York City Building Code uses the tributary area method and permits the percentage method as an alternative for columns, piers, and walls. The 1964 New York State Building Construction Code and the 1967 Municipal Code of Chicago use the tributary area method for beams and girders and the percentage method for columns and walls. The 1965 BOCA Basic Building Code uses a tributary method that is similar to the New York State Code.

Figure A-1 compares the reduced live load for columns, walls, and piers on the basis of the percentage method for three of the codes. It is seen that the permitted reductions are similar with the exception of the roof and top floor, where the 1968 New York City Building Code and the 1967 Municipal Code of Chicago are more conservative (less reduction permitted) than the 1964 New York State Building Construction Code.

Table A-3 compares the reduced live loads for beams and girders for the different codes. For the 1968 New York City Building Code, the reduced value of live load for a given contributory area depends on the live load to dead load ratio, with lower values permitted for lower live load to dead load ratios. For the 1964 New York State Building Construction Code and the 1965 BOCA Basic Building Code, the values shown in the table are based on a reduction factor of $0.08 \% / \mathrm{ft}^{2}$. The lowest reduced value, however, is limited to 40 percent or

$$
100 \% \frac{3.33 \frac{L}{D}-1}{4.33 \frac{L}{D}}
$$

whichever is larger, where $L / D$ is the live load to dead load ratio. As the ratio of live load to dead load increases, less live load reduction is permitted. A comparison of the values in Table A-3 shows that the 1967 Municipal Code of Chicago did not permit as large a reduction in live load for the same contributory area as the other codes.

\section{A.2.3 Wind Load}

The effect of wind on buildings is taken into account by the building codes by specifying a uniform pressure to be applied horizontally to a building. These pressures are to be applied in any direction so as to obtain the most critical loading condition. 


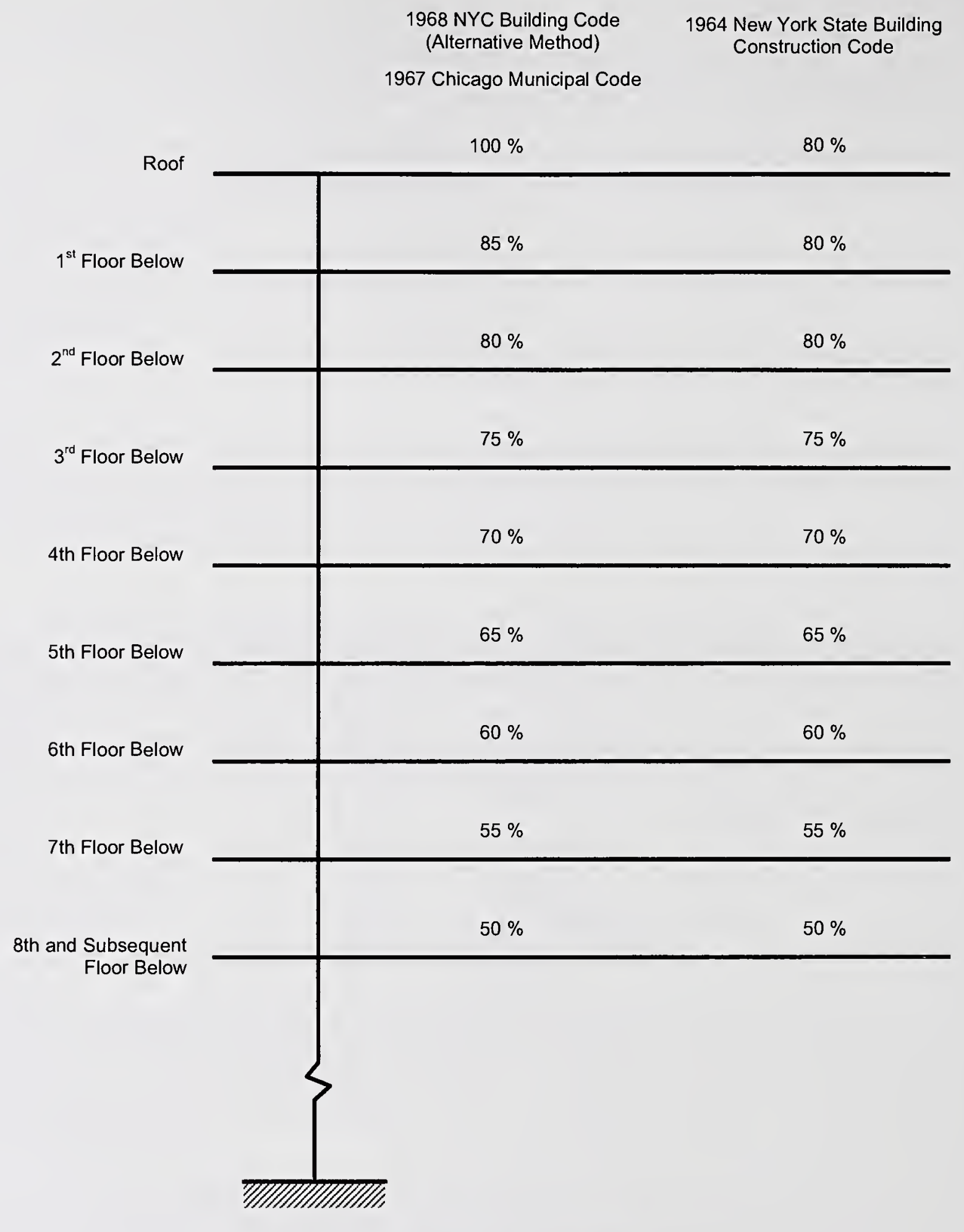

Figure A-1. Wind load pressure elevation. 
Table A-3. Reduced live load for beams and girders.

\begin{tabular}{|c|c|c|c|}
\hline $\begin{array}{c}\text { Contributary Area } \\
\text { (ft }^{2} \text { ) }\end{array}$ & $\begin{array}{c}\text { 1968 NYC } \\
\text { Building Code }\end{array}$ & $\begin{array}{c}\text { 1967 Chicago } \\
\text { Municipal Code }\end{array}$ & $\begin{array}{c}\text { 1956 NY State and } \\
\text { 1965 BOCA Codes }\end{array}$ \\
\hline 100 or less & $100 \%$ & $100 \%$ & $100 \%$ \\
\hline $100-149$ & $100 \%$ & $95 \%$ & $100 \%$ \\
\hline $150-199$ & $80 \%$ to $85 \%^{\mathrm{a}}$ & $95 \%$ & $84 \%$ to $88 \%^{\mathrm{b}}$ \\
\hline $200-299$ & $80 \%$ to $85 \%^{\mathrm{a}}$ & $90 \%$ & $76 \%$ to $84 \%^{\mathrm{b}}$ \\
\hline $300-449$ & $60 \%$ to $75 \%^{\mathrm{a}}$ & $85 \%$ & $64 \%$ to $76 \%^{\mathrm{b}}$ \\
\hline $450-599$ & $50 \%$ to $70 \%^{\mathrm{a}}$ & $85 \%$ & $52 \%$ to $64 \%^{\mathrm{b}}$ \\
\hline 600 and more & $40 \%$ to $65 \%^{\mathrm{a}}$ & $85 \%$ & $40 \%$ to $52 \%^{\mathrm{b}}$ \\
\hline
\end{tabular}

a. Permitted value depends on live load to dead load ratio; less reduction permitted with higher ratio.

b. The lowest value is limited to 40 percent or 100 percent $(3.33 \mathrm{~L} / \mathrm{D}-1) /(4.33 \mathrm{~L} / \mathrm{D})$, whichever is greater.

The pressure due to wind varies with the square of the wind speed, and wind speed increases with height. Thus building codes specify minimum design wind pressures that increase with elevation. The variations of pressure with height, however, are not the same among the building codes compared. Figure A-2 compares the specified wind pressure versus height relationships for the four codes that were compared. Several observations are noted:

- For buildings up to $600 \mathrm{ft}$ in height, the $1964 \mathrm{New}$ York State Building Construction Code prescribes the largest wind pressures.

- The 1967 Municipal Code of Chicago prescribes the lowest wind pressures for buildings up to $900 \mathrm{ft}$ in height.

- The 1968 New York City Building Code and the 1965 BOCA Basic Building Code provide similar wind pressures for buildings up to $700 \mathrm{ft}$ in height; for taller buildings the BOCA Code specifies larger pressures.

For a building height of 1,370 ft (the approximate heights of WTC 1 and WTC 2), the wind pressure distribution specified by the 1965 BOCA Basic Building Code would result in the largest shear force and overturning moment at the base of the building.

The 1968 New York City Building Code permits the designer to use wind pressure values, other than specified minimums, on the basis of wind tunnel tests and with approval of the building official. The following wording is provided in Section 6 of Reference Standard RS 9-5, "Minimum Design Wind Pressures."

In lieu of the design wind pressures established in sections 1 and 2 of this reference standard, and subject to review and approval of the commissioner, design wind pressures may be approximated from suitably conducted model tests. The tests shall be predicated on a basic wind velocity of $80 \mathrm{mph}$ at the $30 \mathrm{ft}$ level, and shall simulate and include all factors involved in considerations of wind pressure, including pressure and suction effects, shape factors, functional effects, gusts, and internal pressures and suctions. 


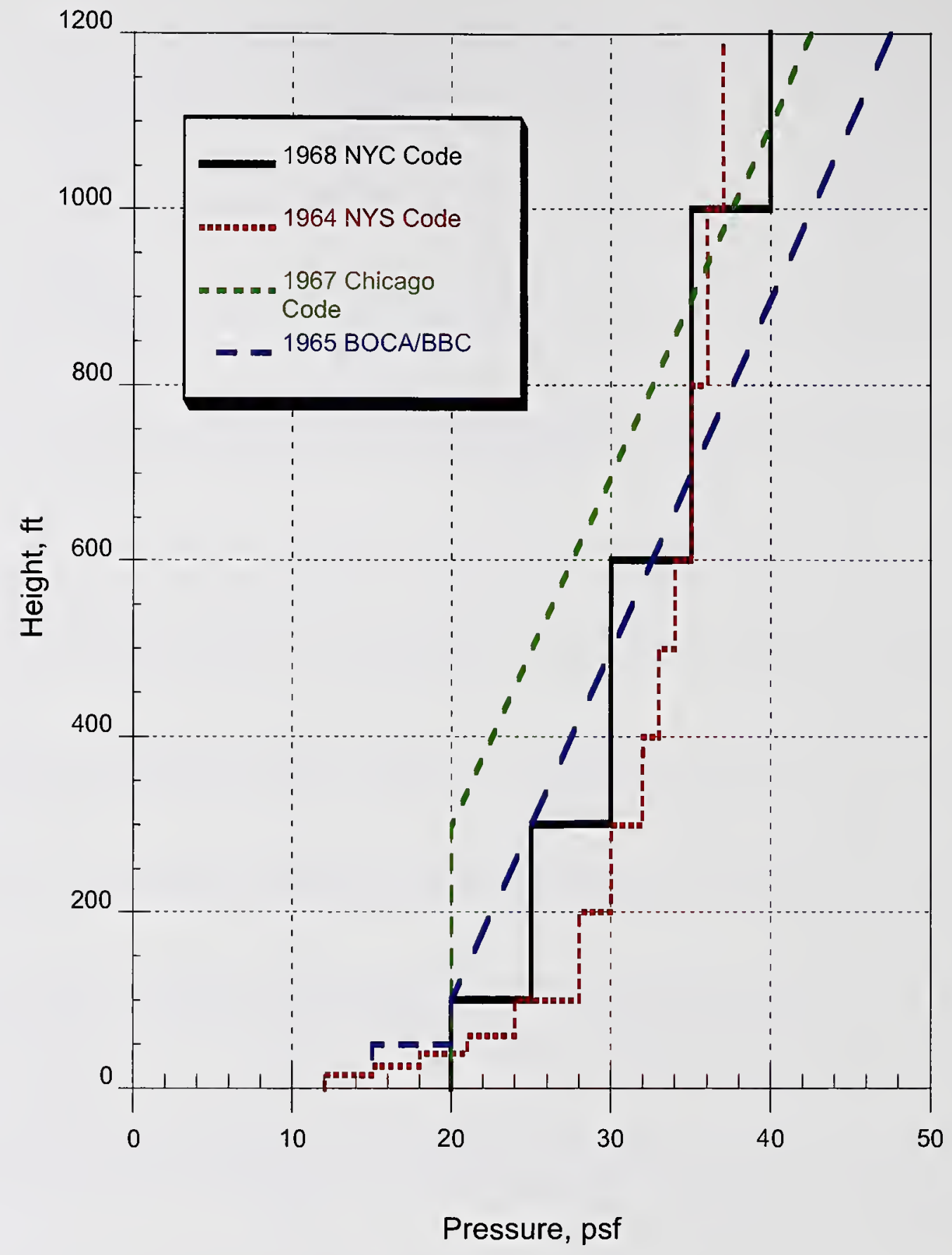

Figure A-2. Wind load pressure versus elevation.

Thus the 1968 New York City Building Code presumes a wind with a speed of 80 mph measured $30 \mathrm{ft}$ above the ground. The 1964 New York State Building Construction Code, on the other hand, states that the prescribed wind loads "are based on a design wind speed of $75 \mathrm{mph}$ at a height of $30 \mathrm{ft}$ above grade level." Both the 1965 BOCA Basic Building Code and the 1967 Municipal Code of Chicago do not specify the design wind speed.

\section{A.2.4 Earthquake Load}

The 1968 New York City Building Code does not have provisions for earthquake loads. Among the contemporaneous codes that were compared, only the 1965 BOCA Basic Building Code has earthquake 
load provisions. These are contained in Appendix K-11 of that Code and were adapted from the 1962 edition of the Uniform Building Code.

The 2001 edition of the New York City Building Code contains seismic design provisions from the 1988 edition of the Uniform Building Code (UBC 1988), including the 1990 Accumulative Supplement. These provisions were put into effect in 1996 as a result of Local Law17 (passed in 1995). Significant modifications to the 1988 Uniform Building Code were made, and described in Reference Standard RS 9-6.

One modification is to the paragraph on "Minimum Seismic Design," which is modified to read:

The following types of construction shall, at a minimum, be designed and constructed to resist the effects of seismic ground motions as provided in this section:
new structures on new foundations;
new structures on existing foundations; and
enlargements in and of themselves on new foundations.

Buildings classified in New York City occupancy group J-3 and not more than three stories in height need not conform to the provisions of this section. The Commissioner may require that the following types of construction be designed and constructed to incorporate safety measures as necessary to provide safety against the effects of seismic ground motions at least equivalent to that provided in a structure to which the provisions of the section are applicable:

new buildings classified in occupancy group $\mathrm{J}-3$ and which are three stories or less in height; and

enlargements in and of themselves where the costs of such enlargement exceeds sixty percent of the value of the building.

In the subdivision on "Criteria Selection" the following paragraph was added:

Seismic Zone. The seismic zone factor, $Z$, for buildings, structures and portions thereof in New York City shall be 0.15 . The seismic zone factor is the effective zero period acceleration for $\mathrm{S}_{1}$ type rock.

Other significant amendments include consideration of soil liquefaction that is not to be found in the Uniform Building Code. 


\section{A.2.5 Other Loads}

The 1968 New York City Building Code has provisions dealing with types of loadings not considered in the other codes that were compared. Two examples are "thermal forces" and "shrinkage." Paragraph C26-905.7 deals with thermal forces and includes the following requirement:

...For exterior exposed frames, arches, or shells regardless of plan dimensions, the design shall provide for the forces and/or movements resulting from an assumed expansion and contraction corresponding to an increase or decrease in temperature of forty degrees $\mathrm{F}$ for concrete or masonry construction and sixty degrees $\mathrm{F}$ for metal construction....

Paragraph C26-905.8 on shrinkage includes the following requirement:

The design of reinforced concrete components shall provide for the forces and/or movements resulting from shrinkage of the concrete in the amount of 0.0002 times the length between contraction joints for standard weight concrete, and 0.0003 times the length between contraction joints for lightweight concrete....

\section{A.2.6 Distribution of Loads}

Another topic that is contained only in the 1968 (and 2001) New York City Building Code is the distribution of loads, which is covered in Article 7 of Sub-chapter 9. Section C26-906.1 deals with vertical loads and states:

"Distribution of vertical loads to supporting members shall be determined on the basis of a recognized method of elastic analysis or system of coefficients of approximation. Elastic or inelastic displacements of supports shall be considered and, for the distribution of dead loads, the modulus of elasticity of concrete or composition [composite] sections shall be reduced to consider plastic flow. Secondary effects, due to warping of the floors shall be considered."

Section C26-906.2 deals with distribution of horizontal forces. Because this section provides important information in the design assumptions to be used in the design of high-rise buildings, several key sections are repeated here,

The following provisions shall apply to superstructure framing only, and shall not apply to structures wherein horizontal loads are transmitted to the foundation by staycables, arches, non-rectangular frames, or by frames, trusses, or shear walls not oriented in vertical planes.

(a) Distribution of horizontal loads to vertical frames, trusses and shear walls. - Horizontal loads on the superstructure shall be assumed to be distributed to vertical frames, trusses, and shear walls by floor and roof systems acting as horizontal diaphragms. The proportion of the total horizontal load to be resisted by any given vertical frame, truss, or shear wall shall be determined on the basis of relative rigidity, considering the eccentricity of the applied load with respect to the center of resistance of the frames, trusses, or shear walls. For vertical trusses, web deformations shall be considered in evaluating the rigidity. 
(b) Distribution of horizontal loads within rigid frames of tier buildings. (1) ASSUMPTIONS. - The distribution of horizontal loads within rigid frames of tier buildings may be determined on the basis of a recognized method of elastic analysis or, subject to limitations in paragraph two of this subdivision, may be predicated on one or more of the following simplifying assumptions:

a. Points of inflection in beams or columns are at their midspan and midheight, respectively. The story shear is distributed to the columns in proportion to their stiffnesses.

b. The change in length of columns due to axial effects of the horizontal loads may be neglected.

c. Vertical column loads due to horizontal forces are taken by the exterior columns only, or are resisted by the columns in proportion to the column distances from the neutral axis of the bent.

(2) LIMITATIONS. -

a. For buildings over $300 \mathrm{ft}$ in height, the change in length of the columns, due to the effects of the horizontal loads, shall be evaluated or the framing proportioned to produce regular movements of the successive joints at each floor so that warping of the floor system may be neglected.

b. Simplifying assumptions used in design shall be subject to approval by the commissioner for any of the following conditions or circumstances:

1. For buildings over $300 \mathrm{ft}$ in height or for buildings with a heightwidth ratio greater than five.

2. At two-story entrances or intermediate floors.

3. Where offsets in the building occur.

4. Where transfer columns occur.

5. In any similar circumstances of irregularities or discontinuities in the framing.

\section{A.3 MATERIALS, DESIGN, AND CONSTRUCTION}

Subchapter 10 of the 1968 New York City Building Code is entitled "Structural Work" and it provides minimum requirements for materials, design, and construction of all structural elements in buildings. This summary reviews design standards, materials, load combinations, and load tests. 


\section{A.3.1 Design Standards}

Design standards refer to those documents that are used to proportion the structural elements and their connections. The principal structural materials in the WTC were concrete and steel, and the design standards are those produced by the American Concrete Institute (ACI) and the American Institute of Steel Construction (AISC). The ACI produces the standard known as ACI 318, Building Code Requirements for Reinforced Concrete, ${ }^{2}$ and the AISC produced the following:

- Specification for the Design, Fabrication and Erection of Structural Steel for Buildings (AISC 1963)

- Specifications for Structural Steel Buildings-ASD and Plastic Design (AISC 1989)

- Load and Resistance Factor Design Specifications for Structural Steel Buildings (AISC 1993)

Table A -4 summarizes the concrete and steel design standards adopted by the codes that were compared. The 1964 New York State Building Construction Code is a performance standard and does not adopt design standards by reference. Thus at the time the WTC Towers were being designed, the other two codes (Chicago and BOCA) referenced the same concrete and steel design standards as the New York City code.

Table A-4. Design standards for concrete and steel.

\begin{tabular}{|l|c|c|c|c|}
\hline & $\mathbf{1 9 6 8}$ NYC Code & 2001 NYC Code & $\begin{array}{c}\text { 1967 Chicago } \\
\text { Code }\end{array}$ & $\begin{array}{c}\text { 1965 BOCA } \\
\text { Code }\end{array}$ \\
\hline Concrete & ACI 318-63 & ACI 318-89 & ACI 318-63 & ACI 318-63 \\
\hline Steel & AISC 1963 & AISC 1989 & AISC 1963 & AISC 1963 \\
\hline
\end{tabular}

The 1963 edition of ACI 318 permits reinforced concrete members to be designed by either the working stress (or allowable stress) method or by the ultimate strength method. The 1963 AISC specification, on the other hand, is based on allowable stress design. The design method affects the loads used in the design calculations.

\section{A.3.2 Load Combinations}

The loads prescribed by the codes are used in different combinations to assess the governing design condition. The codes distinguish between sustained loads and loads of short duration or infrequent occurrence. For allowable stress design, two approaches are used for dealing with these two categories of loads, as will be discussed. For ultimate strength design, the prescribed loads are multiplied by specified load factors. In either case, the designer considers all applicable load combinations and determines the most critical condition, which becomes the design basis for a particular element.

2 In 1999, the title was changed to Building Code Requirements for Structural Concrete. 


\section{Allowable Stress Design}

The 1968 New York City Building Code defines two categories of loads:

1. Basic loads, which include dead load, live load, and reduced live load where applicable; and

2. Loads of infrequent occurrence, which include wind load, thermally induced load, shrinkage induced load, and unreduced live load where live load reduction is permitted.

Stresses in structural elements cannot exceed the allowable values specified in the referenced design standards under the following load combinations:

- The sum of the basic loads multiplied by a factor equal to 1 ;

- The factored sum of one or more basic loads and one load of infrequent occurrence, where the load factor equals 0.75 ;

- The factored sum of one or more basic loads plus two or more loads of infrequent occurrence, where the load factor equals 0.6 .

The 2001 New York City Building Code is similar with the exception that it includes earthquake load as another load of infrequent occurrence.

The other Codes that were compared use a different approach for dealing with loads of infrequent occurrence. The 1964 New York State Building Construction Code states that stress due to wind load may be ignored if it less than $1 / 3$ of the stress due to dead load plus imposed load excluding wind load. If the stress due to wind load exceeds this limit, the allowable stress for the material is permitted to be increased by $1 / 3$.

The 1967 Municipal Code of Chicago uses a similar approach and states: "For combined stresses due to dead, live, and wind load, the allowable stresses in materials may be increased $1 / 3$, provided the section thus determined is at least as strong as that required for dead and live load alone. Snow load shall be considered a live load."

The 1965 BOCA Basic Building Code is similar except that wind load or earthquake load is considered along with dead load and live load (including snow load). The same $1 / 3$ increase in allowable stress is permitted under wind or earthquake load. The BOCA Code also explicitly states that wind load is permitted to be neglected if it results in stress less than $1 / 3$ the stress due to dead load plus live load.

\section{Ultimate Strength Design}

In the 1960 s, ultimate strength design was standardized only for reinforced concrete. As shown in Table A-4, the three codes from the 1960s referenced ACI 318-63, which include the following load combinations to establish the design loads (U) for structural members:

1. For structures where wind and earthquake loads may be neglected, $\mathrm{U}=1.5 \mathrm{D}+1.8 \mathrm{~L}$. 
2. For structures where wind load must be included, $U=1.25(\mathrm{D}+\mathrm{L})$ or $\mathrm{U}=0.9 \mathrm{D}+1.1 \mathrm{~W}$, whichever produces the most unfavorable condition for the member.

3. For structures where earthquake loading is included, $\mathrm{E}$ shall be substituted for $\mathrm{W}$ in condition 2.

4. In structures where effects of shrinkage and temperature are included, the effects of such items shall be considered on the same basis as the effects of dead load.

The 2001 New York City Building Code refers to ACI 318-99, which includes many more load combinations to be considered. These are as follows:

1. For all structures, $\mathrm{U}=1.4 \mathrm{D}+1.7 \mathrm{~L}$.

2. For structures where wind load must be included, $U=0.75[1.4 \mathrm{D}+1.7 \mathrm{~L}+1.7 \mathrm{~W})]$ or $\mathrm{U}=0.9 \mathrm{D}+1.3 \mathrm{~W}$, whichever produces the most unfavorable condition for the member.

3. For structures where resistance to earthquakes must be included, the load combinations of condition 2 are used with 1.1 E substituted for W.

4. For structures where resistance to earth pressure $(\mathrm{H})$ must be included, $\mathrm{U}=1.4 \mathrm{D}+1.7 \mathrm{~L}+1.7 \mathrm{H}$ or $0.9 \mathrm{D}+1.7 \mathrm{H}$, whichever produces the most unfavorable condition.

5. For structures where resistance to fluid pressure $(\mathrm{F})$ must be included, $\mathrm{U}=1.4 \mathrm{D}+1.7 \mathrm{~L}+1.4 \mathrm{~F}$ or $0.9 \mathrm{D}+1.7 \mathrm{~F}$, whichever produces the most unfavorable condition.

6. For structures where resistance shrinkage and temperature $(\mathrm{T})$ must be included, $\mathrm{U}=0.75(1.4 \mathrm{D}+1.4 \mathrm{~T}+1.7 \mathrm{~L})>1.4(\mathrm{D}+\mathrm{T})$.

7. For structures where resistance to impact must be taken into account, such effects shall be included with live load $\mathrm{L}$.

\section{A.3.3 Alteration of Existing Buildings}

The compared codes have provisions to address code compliance when existing buildings are altered. The provisions of all codes, other than the 1964 New York State Building Construction Code, are broadly similar. In general, whether the altered building or only the alternations need to comply with code requirements depends on the ratio of alterations to the total building expressed either in terms of cost or dimensions. When the ratio is low, even the alterations may not have to be in compliance with the code, provided stipulated conditions are met. The 1964 New York State Building Construction Code, however, requires that any addition or alteration regardless of building value shall be made in conformity with that code. It is silent as to the structure being altered. Table A-5 summarizes code provisions related to alterations. 
Table A-5. Compliance requirements for alterations.

\begin{tabular}{|c|c|}
\hline Code & Provisions \\
\hline $\begin{array}{l}1968 \text { New York City } \\
\text { Building Code }\end{array}$ & $\begin{array}{l}\text { Alterations exceeding } 60 \text { percent of building value (in any } 12 \text {-month period): The } \\
\text { entire building shall be made to comply with the requirement of the code. } \\
\text { Alterations between } 30 \text { percent and } 60 \text { percent of building value: Only those } \\
\text { portions of the building altered shall be made to comply with the requirements of the } \\
\text { code. } \\
\text { Alteration under } 30 \text { percent of building value: Those portions altered may, at the } \\
\text { option of the owner, be altered in accordance with the requirement of the code, or } \\
\text { altered in compliance with their previously required condition and with the same or } \\
\text { equivalent materials and equipment, provided the general safety and public welfare are } \\
\text { not thereby endangered. }\end{array}$ \\
\hline $\begin{array}{l}2001 \text { New York City } \\
\text { Building Code }\end{array}$ & $\begin{array}{l}\text { Same as } 1968 \text { Code, except that wording for alterations less than } 30 \text { percent of } \\
\text { building values was changed to: "those portions of the building altered may, at the } \\
\text { option of the owner, be altered in accordance with the requirements of this code, or } \\
\text { altered in compliance with the applicable laws in existence prior to December sixth, } \\
\text { nineteen hundred sixty-eight, provided the general safety and public welfare are not } \\
\text { thereby endangered." } \\
\text { In addition, certain alterations are required to conform to the code regardless of } \\
\text { magnitude or cost. These include, among others: } \\
\text { Alterations to standpipes, sprinklers, or interior fire alarm and signal systems; } \\
\text { Alterations to equipment for heating or storing water; } \\
\text { Sprinkler, alarm protection, and emergency lighting requirements for places of } \\
\text { assembly. }\end{array}$ \\
\hline $\begin{array}{l}1964 \text { New York State } \\
\text { Building Construction } \\
\text { Code }\end{array}$ & $\begin{array}{l}\text { Addition or alteration: Any addition or alteration, regardless of cost, made to a } \\
\text { building shall be made in conformity with applicable regulations of the code. }\end{array}$ \\
\hline $\begin{array}{l}1967 \text { Municipal Code } \\
\text { of Chicago }\end{array}$ & $\begin{array}{l}\text { More than } 50 \text { percent: Such buildings and structures shall be made to conform to all } \\
\text { requirements of the code that are applicable to new buildings and structures. } \\
25 \text { percent to } 50 \text { percent: All new constructions shall conform to the requirements of } \\
\text { the code for new buildings or structures of like area, height and occupancy. } \\
25 \text { percent or less: Certain exceptions can be made that allow the use of materials that } \\
\text { conform to the strength and fire resistance for the materials with which the building is } \\
\text { constructed. Otherwise, all new construction shall conform to the requirements of this } \\
\text { code for a new building. }\end{array}$ \\
\hline $\begin{array}{l}1965 \text { BOCA Basic } \\
\text { Building Code }\end{array}$ & $\begin{array}{l}\text { "In the reconstruction, repair, extension or alteration of existing buildings, the } \\
\text { allowable working stresses used in design shall be as follows: } \\
\text { 1. Building extended: If altered by an extension in height or area, all existing } \\
\text { structural parts affected by the addition shall be strengthened where necessary and all } \\
\text { new structural parts shall be designed to meet the requirements for buildings hereafter } \\
\text { erected. } \\
\text { 2. Building repaired: When the uncovered structural parts are found unsound, such } \\
\text { parts shall be made to conform to the requirements for buildings hereafter erected. } \\
\text { 3. Existing live load: When an existing building heretofore approved is altered or } \\
\text { repaired within the limitation prescribed in Section } 106.3 \text { (alteration under } 50 \text { percent) } \\
\text { and } 106.4 \text { (alteration under } 25 \text { percent), the structure may be designed for the loads and } \\
\text { stresses applicable at the time of erection, provided that public safety is not } \\
\text { endangered. } \\
\text { 4. Posted live load: May be posted for original approved live loads." }\end{array}$ \\
\hline
\end{tabular}




\section{A.3.4 Materials and Methods of Construction}

The compared codes have requirements for the materials and construction methods. Each code makes distinctions in materials and methods that depend on the nature of inspection and conformance with standards.

The 1968 New York City Building Code prescribes testing and inspection requirements for all materials, assemblies, forms, and methods of construction. A distinction is made between materials and methods subject to "controlled inspection" and those that are not subject to controlled inspection. Materials and methods subject to controlled inspections "shall be inspected and/or tested to verify compliance with code requirements." In general, activities related to controlled inspections "shall be made and witnessed by or under the direct supervision of an architect or engineer retained by or on behalf of the owner or lessee, who shall be, or shall be acceptable to, the architect or engineer who prepared or supervised the preparation of the plans." On the other hand, materials and methods not designated for controlled inspection "shall be inspected and/or tested to verify compliance with code requirements by the person superintending the use of the material or its incorporation into the work..."

The 1968 New York City Building Code provides tables to indicate which materials and methods are subject to controlled inspections and which are not. Table A-6 includes excerpts from the requirements for inspection of materials and assemblies. A footnote to the table in the code states that "All structural materials and assemblies subject to controlled inspection shall be tested and/or inspected at their place of manufacture and evidence of compliance with the provisions of this subchapter shall be provided as stipulated in sub-articles 1003.0 through 1011.0." Table A-7 is an excerpt of the inspection requirements for methods of construction. A footnote to the companion table in the code states that "All construction operations designated for controlled inspection shall be inspected by the architect or engineer designated for controlled inspection during the performance of such operation."

The 1968 New York City Building Code required that the installation of "sprayed-on fire protection" of structural members (except those encased in concrete) be subjected to controlled inspection requirements, as defined above. There were, however, no specific provisions on what testing was required.

The 1964 New York State Building Construction Code and the 1965 BOCA Basic Building Code make distinctions between "controlled" and "ordinary" materials in reference to establishing allowable stresses. For example BOCA defines "controlled materials" as those that are "certified by an accredited authoritative agency as meeting accepted engineering standards for quality." Ordinary materials are those that do not conform to the requirements for controlled materials.

The 1967 Municipal Code of Chicago specifies that all materials and methods used in the design and construction of buildings shall be classified as "controlled materials" or "ordinary materials." According to the Chicago Code, "controlled materials" means a building, structure, or part thereof, which has been designed or constructed under the following conditions: (a) All controlled materials must be selected or tested to meet the special strength, durability and fire resistance requirements upon which the design is based. (b) The design, preparation of working drawings, including details and connections, the checking and approval of all shop and field details and the inspection of the work during construction shall be under the supervision of a registered architect or structural engineer (Section 69-3.1). 
Table A-6. Excerpts of inspection requirements for materials and assemblies in 1968 New York City Building Code.

\begin{tabular}{|c|c|c|}
\hline Material & Elements Subject to Controlled Inspection & $\begin{array}{l}\text { Elements Not Subject to Controlled } \\
\text { Inspection }\end{array}$ \\
\hline Steel & None & All structural elements and connections \\
\hline Concrete & $\begin{array}{l}\text { Materials for all structural elements } \\
\text { proportioned on the basis of calculated } \\
\text { stresses } 70 \text { percent or greater, of basic } \\
\text { allowable stresses. See Section } 1004.0 \text { for } \\
\text { specific requirements relating to "quality } \\
\text { control of materials and batching." }\end{array}$ & $\begin{array}{l}\text { (1) All materials for all structural elements } \\
\text { proportioned on the basis of calculated stresses } \\
\text { less than } 70 \text { percent or greater of basic allowable } \\
\text { values. } \\
\text { (2) Concrete materials for: } \\
\text { (a) Short span floor and roof construction } \\
\text { proportioned as per section } 1004.8 \text {. } \\
\text { (b) Walls and footings for buildings in } \\
\text { occupancy group J-3. } \\
\text { (3) Metal reinforcement. }\end{array}$ \\
\hline
\end{tabular}

Table A-7. Excerpts of inspection requirements for methods of construction in 1968 New York City Building Code.

\begin{tabular}{|l|l|l|}
\hline Material & \multicolumn{1}{|c|}{$\begin{array}{c}\text { Operations Subject to Controlled } \\
\text { Inspection }\end{array}$} & \multicolumn{1}{c|}{$\begin{array}{c}\text { Operations Not Subject to Controlled } \\
\text { Inspection }\end{array}$} \\
\hline Steel & $\begin{array}{l}\text { (1) Welding operations and the tensioning of } \\
\text { high strength bolts in connections where the } \\
\text { calculated stresses in the welds or bolts are 50 } \\
\text { percent or more of basic allowable values. } \\
\text { (2) Connection of fittings to wire cables for } \\
\text { suspended structures, except where cables } \\
\text { together with their attached fittings are proof- } \\
\text { loaded to not less than 50 percent of ultimate } \\
\text { capacity. }\end{array}$ & $\begin{array}{l}\text { (1) Welding operations and the tensioning of } \\
\text { high strength bolts in connections where the } \\
\text { calculated stresses in the welds or bolts are less } \\
\text { than 50 percent of basic allowable values. } \\
\text { (2) All other fabrication and erection operations } \\
\text { not designated for controlled inspection. }\end{array}$ \\
\hline Concrete & $\begin{array}{l}\text { Except for those operations specifically } \\
\text { designated in this table as not subject to } \\
\text { controlled inspection, for all concrete, the } \\
\text { operations described in section 1004.5(a) shall } \\
\text { be subject to controlled inspection." }\end{array}$ & $\begin{array}{l}\text { (1) All operations relating to the constriction of } \\
\text { members and assemblies (other than prestressed } \\
\text { concrete) which involve the placement of a total } \\
\text { of less than 50 cubic yards of concrete and } \\
\text { wherein said concrete is used at levels of } \\
\text { calculated stress 70 percent or less of basic } \\
\text { allowable values. } \\
\text { (2) placing and curing of concrete for all: } \\
\text { (a) short span floor and roof construction as per } \\
\text { section 1004.8. } \\
\text { (b) Walls and footings for buildings in } \\
\text { occupancy group J-3. } \\
\text { (3) Size and location of reinforcement for walls } \\
\text { and footings in occupancy group J-3. } \\
\text { (4) All other operations not described in } \\
\text { Sections C26-1004.5(a). }\end{array}$ \\
\hline
\end{tabular}




\section{A.3.5 Stability, Bracing, and Secondary Stresses}

The 1968 and 2001 New York City Building Code are the only codes of those compared that include provisions for stability, bracing, and secondary stresses. The provisions are the same in the two editions of the code. Stability, in this case, refers to resistance to sliding or overturning of the building on its foundation. The New York City Building Code requires a factor of safety of 1.5 against failure by sliding or overturning. The required stability is to be provided solely by the dead load plus any permanent anchorage that is provided. Bracing refers to lateral support to prevent buckling of compression members (columns and walls). The New York City Building Code requires that the bracing be proportioned to resist a load of at least 2 percent of the total design compression load in the braced member plus any transverse shear load on the bracing member. Secondary stresses refer to stresses associated with transverse deflection of a member. In trusses, for example, secondary stresses arise because joints are not true pins and some bending is introduced, which results in transverse displacements of the individual elements. The New York City Building Code requires that secondary stresses in trusses be considered in designing the size of the individual elements.

\section{A.3.6 Deflection Limitations}

All five codes contain limits on vertical deflections of floor and roof assemblies. Except for the New York City Building Codes (both the 1968 and 2001 versions), the deflection limits relate to crack formation of plastered building components. The deflection is limited 1/360 of the span for plastered members and $1 / 240$ of the span for non-plastered members. The New York City Building Codes refer to the reference standards for deflection limits in addition to the $1 / 360$ of the span limit. For concrete members, ACI 318-63 specifies limits for both short- and long-term deflections of beams and one-way slabs. For steel members, the 1963 AISC Specification specifies deflection limits to avoid damage to plastered ceilings and to limit deflections of flat roofs.

\section{A.3.7 Load Tests}

Building codes generally allow load tests to ascertain the adequacy of load carrying capacity of structural members. Specifically building codes allow load tests or tests of in-place materials:

- To verify adequacy of structural design for a member or an assembly,

- To verify adequacy of partially completed construction,

- To prequalify structural members or assemblies before used in service,

- To verify adequacy of questionable completed structure, and

- To determine concrete strength by means of core tests.

The New York City Building Codes have provisions to cover all five categories. The New York State Code has provisions for (1) and (4). The Chicago Municipal Code has provisions for (1), (4) and (5). The BOCA/Basic Building Code has provisions for (1) and (2). 


\section{A.4 FIRE SAFETY}

\section{A.4.1 Fire Protection}

As mentioned in A.1, in 1965, the Port Authority directed that the design of the WTC towers be updated to conform to the second and third drafts of the 1968 New York City Building Code then under development. However, since it was not known which proposals in the second and third drafts would be adopted into the final 1968 code, the strategy was to identify any proposed design provision that differed from the 1938 code requirement as a variance to be specifically approved by the Port Authority (Kyle 1966a and Kyle 1966b). The Port Authority established the World Trade Department, a special Port Authority office, to review and approve plans, to issue variances, and to conduct inspections during construction.

The 1968 New York City Building Code contained detailed fire safety provisions on a number of topics not addressed in the other codes of the time, most of which appeared in these other codes at later times. For example, while the contemporaneous codes contained requirements for flame spread ratings for interior finish materials, the 1968 New York City Building Code also included requirements for "smoke developed" ratings that did not appear in other codes until later.

As stated in Section A.1.1, the New York City Building Code is amended by "Local Laws" (LL) and refined or interpreted by administrative orders issued by the Building Commissioner. While there were some 79 Local Laws adopted between 1969 and 2002 that modified the 1968 code, those that contained significant modifications to fire protection and life safety requirements include LL54/1970, LL5/1973, LL26/1975, LL55/1976, LL33/1978, LL41/1978, LL84/1979, LL86/1979, LL16/1984 and LL16/1987. Of particular importance in this group are LL5/1973 (and LL86/1979 that changed the compliance dates for LL5/1973) and LL16/1984 because some of their provisions applied retroactively to existing office buildings.

\section{A.4.2 General Code Provisions for Fire Safety}

Fire safety of building construction is generally regulated through limits placed on the height and the area per floor as a function of the type and degree of fire resistance of materials used in the structural elements. These material characteristics are categorized as types of construction, e.g., Type I through V, and the associated limits are contained in "heights and areas" tables that are a cornerstone of most (prescriptive) building codes, worldwide.

The intent of building height limits is to restrict taller buildings to non-combustible structural members with the greatest fire resistance (as measured in the ASTM E 119 test method). The primary concern with combustible structural members is that they can become ignited by an exposing fire and can continue to burn (often in concealed spaces) even after the exposing fire has been extinguished, leading to collapse.

The other important height factor is the definition of a high-rise building. This is generally based on the height above which fire department ladders will not reach, requiring that fires be fought from inside. An interior attack is limited to hand-held hoses supplied from standpipes and working from interior stairways. Traditionally, high-rise buildings have been defined as those that exceed $75 \mathrm{ft}$ or 6 stories 
above grade in height, but some newer codes increase this height to $100 \mathrm{ft}$, as modern fire department ladders are longer.

The intent of area limits is generally to limit property risk and to limit the size (area involved on any floor) of the fire to that which can be dealt with by the fire department with the number of people and equipment typical of an initial response.

\section{A.4.3 Occupancy Classification}

The building codes define categories of occupancy (which may have more than one sub-class). The group designations vary in different codes, the ones presented here are those used in the New York City Building Code. These are:

- High Hazard (Group A)

- Storage (Groups B-1 and B-2)

- Mercantile (Group C)

- Industrial (Group D-1 and D-2)

- Business (Group E)

- General Assembly (Group F-1 through F-4)

- Educational (Group G)

- Institutional (Groups H-1 and H-2)

- Residential (Groups J-1 through J-3)

- Miscellaneous (Group K)

Building codes use occupancy as a surrogate for risk factors that determine the level of performance needed. For example, occupancy is determined by a combination of factors such as types and quantity of combustible contents, common ignition sources, and typical occupant characteristics. Business occupancies (which includes office buildings) are considered among the lowest risk because they typically contain grades of furniture that constitute relatively low combustible loads, few ignition sources, and a population that is predominately adult, in good physical and mental condition (e.g., not using alcohol), and not sleeping. The most risky occupancies are High Hazard, in which are found highly flammable, toxic, or explosive materials, and Institutional (e.g., hospitals and prisons) in which occupants are likely to be incapable of unassisted egress. 


\section{A.4.4 Construction Classification}

The model building codes classify building constructions into different "Types." Although there are some variations in categories, they are reasonably consistent. ${ }^{3}$ The main categories are Type 1 (fire resistive), Type 2 (non-combustible), Type 3 (combustible), Type 4 (heavy timber) and Type 5 (ordinary).

Types 1 and 2 are constructed with non-combustible exterior and interior bearing walls and columns. Fire resistance ratings (see A.4.5) are greatest for Type 1, and Type 2 is any (non-combustible) construction not meeting Type I requirements. Type 3 is where exterior bearing walls are non-combustible and interior bearing walls and some columns may employ approved combustible materials. Type 4 is known as heavy timber, which utilizes large, solid cross section wooden members such as in post and beam construction. Type 5 is traditional wood frame construction. Common non-combustible structural elements use steel or reinforced concrete. Combustible structural elements are usually made of solid- or engineered-wood and laminates.

Combustibility of the materials in a structural element is determined in ASTM E 136 in which the material is placed in a furnace at $750^{\circ} \mathrm{C}\left(1,380^{\circ} \mathrm{F}\right)$, which is a "typical" fire temperature. Some minor surface burning (e.g., from paint or coatings) is allowed in the first $30 \mathrm{~s}$ but there cannot be any significant energy release as indicated by more than $30^{\circ} \mathrm{C}\left(54^{\circ} \mathrm{F}\right)$ increase in the furnace temperature, and the test specimen cannot lose more than half its initial mass. Materials that pass are designated noncombustible and the rest are combustible.

Within each construction type, there are several sub-categories determined by the fire resistance ratings of the columns, beams, and floor supports. In some codes these sub-categories are identified by letters following the type (e.g., 1B or $3 \mathrm{~A}$ ) or by a set of three numbers that represent the fire resistance required (in hours) of the columns, beams, and floors, respectively (e.g., Type $1[3,3,2]$ ).

For unsprinklered office buildings, the following construction classes are permitted in the five building codes reviewed.

- Type 1A and 1B-NYC BC 68, NYS BC 64, BOCA/BBC 65 (Unlimited height)

- Type 1A, 1B, 1C, 1D-NYC BC 01 (Height limited to $75 \mathrm{ft}$ )

- Type 1A only-Chicago BC 67 (Unlimited height)

It is noted that the 1938 New York City Building Code did not include Type 1B construction for office occupancies. The reasons for the inclusion of Type 1B construction for office occupancies into the 1968 New York City Building Code are not recorded (recordkeeping in the codes and standards development process was very poor prior to the Hydrolevel vs. ASME Supreme Court decision in 1982). The codes then and now tend to follow each other as champions of changes to one code usually try to change all of the codes. The 1950 edition of the Basic Building Code (BOCA) included a Type 1B construction class with unlimited height and area for business and low hazard storage occupancies without sprinklers. Among other model codes, the Standard Building Code (1946-47 edition, SBCCI) had a Type 2

3 Construction type definitions varied among the model codes until an effort was expended in the 1970s by the Board for the Coordination of the Model Codes (BCMC) to eliminate unnecessary differences. 
construction similar to Type 1B for business occupancies and buildings more than $80 \mathrm{ft}$ in height, the National Building Code (1934 edition, NBFU) had a semi-fireproof similar to Type 1B for buildings above $75 \mathrm{ft}$, and the Uniform Building Code (1927 edition, ICBO) had a Type 2 similar to Type 1B for buildings above $75 \mathrm{ft}$.

The Basic Building Code (BOCA) would be expected to have the strongest influence on New York City since BOCA was the regional code used in the Northeast U.S. This may be why Type 1B construction was included in the 1968 New York City Building Code.

Mandatory sprinkler requirement for new high-rise buildings was first introduced in the New York City Building Code in 1984 (by Local Law 16), in BOCA in 1984, and in the Chicago building code (which allows a compartmentation alternative) in 1975. Before Local Law 16 was adopted, the 1968 New York City Building Code permitted Type 1A, 1B, 1C, and 1D construction for sprinklered office buildings of unlimited height. In the 2001 New York City Building Code, the minimum permitted construction classification for office buildings of unlimited height is Type $1 \mathrm{C}$.

\section{A.4.5 Fire Resistance of Structural Elements}

The structural elements of a building are protected against failure in fire for a specified period as determined in the ASTM E 119 test. The intent of the fire rating requirements is for the structure as a minimum to withstand design loads (including fire) without local structural collapse until occupants can escape and the fire service can complete search and rescue operations.

Fire resistance requirements in the building codes are greatest for structural members that are essential to the stability of the building as a whole. These include columns and other major gravity load carrying members that connect directly to columns such as girders and trusses.

For various construction classes, the building codes specify different fire resistance ratings. The building codes reviewed specify fire resistance ratings for high-rise office occupancies as follows:

- Type $1 \mathrm{~A}$

- Columns: $4 \mathrm{~h}$ (supporting more than one floor)

- Beams: $3 \mathrm{~h}$ (floor construction)

- Type 1B

- Columns: $3 \mathrm{~h}$ (supporting more than one floor)

- Beams: 2 h (floor construction).

- Type 1C (for sprinklered buildings only)

- Columns: $2 \mathrm{~h}$ (supporting more than one floor)

- Beams: $1 \frac{1 / 2}{h}$ (floor construction). 
The choice among permitted construction classes for a particular building is made by the architect and/or the owner. Thus, an unsprinklered high-rise office building that was designed according to the 1968 version of the New York City Building Code could follow either Type 1A or 1B, and if designed subsequent to the passage of Local Law 16/1984 a high-rise office building would have to be sprinklered but it could follow Type $1 \mathrm{C}$ as a minimum classification. Similar reductions in the minimum required fire resistance ratings for sprinklered buildings are found in all national model building codes over this period as requirements for fire sprinklers, especially in high-rise buildings, have become common.

Type 1B, and eventually Type $1 \mathrm{C}$, construction was permitted for high-rise office occupancies because this occupancy is considered low risk. Most other use groups in high-rise buildings were restricted to Type $1 \mathrm{~A}$, which is the construction type with the maximum structural fire protection defined in these codes.

\section{Compartmentation and Sprinklers}

Section 6 of Local Law 5 adopted by New York City in 1973, required the subdivision of unsprinklered space in new office occupancies and in existing offices over $100 \mathrm{ft}$ in height by fire rated partitions. Local Law 5 was challenged in the courts and was eventually upheld, although the original compliance dates were amended by Local Law 86 (1979) so that full compliance was required by February 7, 1988.

After the passage of Local Law 5, the Port Authority implemented a program to retrofit sprinklers and to offer tenants the option of sprinklering or compartmentation consistent with Local Law 5 provisions. Sprinklering of WTC 1 and WTC 2 was undertaken in three phases: Phase 1 was the sprinklering of below grade spaces completed with the original construction. Phase 2 was begun after Local Law 5 was adopted and included the installation of sprinkler risers and other infrastructure, and the installation of sprinklers in corridors, storage rooms, lobbies, and smaller tenant spaces for tenants not selecting the compartmentation option. Phase 3 involved sprinklering the remaining tenant spaces, initially as tenants changed, and later on negotiated schedules. This process was underway when in 1984 Local Law 16 was adopted, which required sprinklers in new high-rise buildings including offices. Thus all floor spaces by February 8, 1988, had to either be subdivided in accordance with the compartmentation requirement or sprinklered. A 1997 report states that there were four floors and the sky lobbies (all in WTC 1) left to be sprinklered, and that the installation of sprinklers at these floors was underway (Coty 1997). In an October 1999 report, it is stated that sprinklering of the tenant floors was completed and sprinklering of the sky lobbies was "currently underway" (PANYNJ 1999).

\section{Summary}

Table A-8 summarizes key fire safety requirements for business occupancy in high-rise buildings (greater than $75 \mathrm{ft}$ ) as stipulated in the codes that were compared. In addition, the provisions from the $1938 \mathrm{New}$ York City Building Code are provided for comparison. It is seen that, overall, the 1968 New York City Building Code was in accord with contemporaneous codes. Exceptions are the permitted construction classes and minimum fire ratings, which were more restrictive in the 1967 Municipal Code of Chicago. 
Table A-8. Summary of fire safety provisions for business occupancy in high-rise buildings ( $>75 \mathrm{ft}$ ).

\begin{tabular}{|c|c|c|c|c|c|c|}
\hline & 1938 NYC & 1968 NYC & 2001 NYC & 1964 NYS & $1967 \mathrm{MCC}$ & 1965 BOCA \\
\hline Detection & $\begin{array}{l}\text { No } \\
\text { requirement }\end{array}$ & $\begin{array}{l}\text { Smoke } \\
\text { detectors to } \\
\text { shut down } \\
\text { HVAC fans to } \\
\text { prevent } \\
\text { smoke } \\
\text { recirculation }\end{array}$ & $\begin{array}{l}\text { Class E fire } \\
\text { alarm system } \\
\text { with voice } \\
\text { commu- } \\
\text { nication }\end{array}$ & $\begin{array}{l}\text { Fire alarm } \\
\text { system } \\
\text { required; fire } \\
\text { detection or } \\
\text { sprinkler } \\
\text { system is } \\
\text { alternative }\end{array}$ & Not required & $\begin{array}{l}\text { Fire alarm } \\
\text { system } \\
\text { required if not } \\
\text { sprinklered }\end{array}$ \\
\hline $\begin{array}{l}\text { Suppression } \\
\text { (Sprinklers) }\end{array}$ & $\begin{array}{l}\text { No } \\
\text { Requirement }\end{array}$ & $\begin{array}{l}\text { Below grade } \\
\text { only }\end{array}$ & $\begin{array}{l}\text { Required if } \\
\text { gross floor area } \\
>100,000 \mathrm{ft}^{2}\end{array}$ & $\begin{array}{l}\text { Below grade } \\
\text { only }\end{array}$ & Not required & $\begin{array}{l}\text { Not required } \\
\text { until } 1984\end{array}$ \\
\hline $\begin{array}{l}\text { Permitted } \\
\text { Construction } \\
\text { Class }\end{array}$ & $1 \mathrm{~A}$ & $1 \mathrm{~A}, 1 \mathrm{~B}$ & $\begin{array}{l}1 \mathrm{~A}, 1 \mathrm{~B}, 1 \mathrm{C} \\
\text { with } \\
\text { sprinklers }\end{array}$ & $1 \mathrm{~A}, 1 \mathrm{~B}$ & $1 \mathrm{~A}$ & $1 \mathrm{~A}, 1 \mathrm{~B}$ \\
\hline $\begin{array}{l}\text { Fire } \\
\text { Separation } \\
\text { (Compart- } \\
\text { mentation) }\end{array}$ & $\begin{array}{l}3 \mathrm{~h} \text { shaft } \\
\text { enclosures; } \\
1 \mathrm{~h} \text { tenant } \\
\text { separations } \\
\text { (demising } \\
\text { walls) }\end{array}$ & $\begin{array}{l}2 \text { h shaft } \\
\text { enclosures; } \\
1 \text { h tenant } \\
\text { separations }\end{array}$ & $\begin{array}{l}2 \mathrm{~h} \text { shaft } \\
\text { enclosures; } \\
1 \mathrm{~h} \text { tenant } \\
\text { separations; } \\
\text { unsprinklered } \\
\text { requires } \\
\text { compart- } \\
\text { mentation if } \\
>7,500 \mathrm{ft}^{2} \text { or } \\
>15,000 \mathrm{ft}^{2} \\
\text { with smoke } \\
\text { detectors }\end{array}$ & $\begin{array}{l}2 \mathrm{~h} \text { shaft } \\
\text { enclosures; } \\
1 \text { hr tenant } \\
\text { separations }\end{array}$ & $\begin{array}{l}2 \mathrm{~h} \text { hoistways; } \\
1 \mathrm{~h} \text { shaft } \\
\text { enclosures; } \\
2 \mathrm{~h} \text { tenant } \\
\text { separations } \\
\text { every } \\
10,000 \mathrm{ft}^{2}\end{array}$ & $\begin{array}{l}2 \text { h shaft } \\
\text { enclosures; } \\
3 / 4 \text { h tenant } \\
\text { separations }\end{array}$ \\
\hline $\begin{array}{l}\text { Minimum fire } \\
\text { resistance } \\
\text { ratings: }\end{array}$ & & & & & & \\
\hline $\begin{array}{l}\text { Ext. and int. } \\
\text { bearing walls } \\
\text { and columns } \\
\text { supporting }>1 \\
\text { floor }\end{array}$ & $4 \mathrm{~h}$ & $3 \mathrm{~h}$ & $2 \mathrm{~h}$ & $3 \mathrm{~h}$ & $4 \mathrm{~h}$ & $3 \mathrm{~h}$ \\
\hline $\begin{array}{l}\text { Floors } \\
\text { including } \\
\text { beams }\end{array}$ & $3 \mathrm{~h}$ & $2 \mathrm{~h}$ & $11 / 2 h$ & $2 \mathrm{~h}$ & $3 \mathrm{~h}$ & $2 \mathrm{~h}$ \\
\hline
\end{tabular}

\section{A.4.6 Means of Egress}

The basic concept of occupant egress implemented in building codes involves the provision of a properly designed means of egress that is continuous and unobstructed from any point in the building to the outside. Proper design includes the width of the spaces and doors, direction of door swing, lighting and marking, protection from the fire and its effects, and geometry of stairs or ramps. Limits on travel distances to reach a means of egress and on common paths of travel, dead ends, and the provision of alternative means of egress if the primary path is blocked by fire are also basic concepts of egress design. 
The means of egress described in building codes consists of three parts. The exit access is a corridor, aisle, balcony, gallery, room, porch, or portion of a roof over which an occupant must travel to reach the exit. The exit is a door leading to the outside or through a protected passageway to the outside, a smokeproof tower, protected stairway, exit passageway, enclosed ramp, escalator, or moving walkway within a building. The exit discharge is the door to the outside, although some codes allow not more than half the exits to discharge onto a floor with an unobstructed path to the outside, and which is protected by sprinklers and a 2-h fire resistance separation from floors below.

Another concept found in the context of Means of Egress systems is that of defense in place. This is normally associated with occupancies where the occupants cannot escape such as hospitals or prisons, but may also be applied to refuge areas (sometimes called areas of rescue assistance) where people with disabilities await assistance or to areas in which occupants are being held temporarily while they await their turn to evacuate in a phased evacuation. Defense in place usually involves providing some protection against exposure to fire, heat, and smoke for the time needed to move these people to a safe place.

\section{Egress System Design}

The objective of the egress system design is to allow unimpeded evacuation of the building population without exposure to fire or smoke. Prescriptive building code regulations address this by specifying a population density (people per unit floor area) for each building use group, called the "occupant load factor." When multiplied by the floor area, the occupant load is obtained on which the egress system design is based (unless there is reason to believe that the actual load will be greater or the owner desires a greater allowance).

The means of egress is then designed to accommodate that occupant load on the basis of an egress width per occupant served, also specified in the building code. Values are specified for stairs and for other egress components, sprinklered and unsprinklered, and with special values for high hazard and institutional building occupancies to allow for higher egress speeds (high hazard) and greater number of wheelchairs or evacuation in patient beds (institutional), respectively.

The width of the egress system at each floor is sized to accommodate the number of occupants on that floor only. There is an additional requirement that the egress system width cannot become narrower in the direction of egress travel and beyond any convergence of two or more egress systems the capacity cannot be less than the sum of the capacities. These requirements are intended to account for the accumulation of flows from multiple floors.

For very tall buildings, it was recognized that the accumulating flow from a large number of floors would result in congestion in the stairways and a reduction of flow speeds. Widening stairways to increase the capacity has an economic consequence. Thus the concept of phased evacuation was developed where occupants are evacuated first from the three floors closest to the fire, while others wait their turn. Such systems require a voice communication system to manage the process by voice messages from a fire command center staffed by the fire service, and (e.g., in New York City) fire wardens on each floor directing the flow. 


\section{Prescriptive Egress Specifications}

Traditional (prescriptive) building codes specify the design of egress systems by first, estimating the number of occupants in an area to be evacuated, second, determining the (combined) width of the exit system needed for that number of occupants, and third, dividing that width among the number of exits needed to achieve the travel distance limits. These codes further establish some minimum requirements for the number and width of exits and exit components. These minimum requirements seem to derive from a 1935 National Bureau of Standards (now NIST) publication titled "Design and Construction of Building Exits" (NBS 1935). A survey of buildings showed that the nominal 44-in. (2 units of width) exit stair was in common use, and a majority of buildings provided two such stairs. This report recommended that these be adopted as minimum requirements in building codes. This report also recommended the values for occupant load and capacity allowances discussed below.

For the most part, the egress design factors found in all of the model building codes are identical. In the IBC and NFPA 5000 model codes, design occupant densities (loads) range from $500 \mathrm{ft}^{2}$ (gross) per occupant (aircraft hangers, warehouses) to $5 \mathrm{ft}^{2}$ (net) per occupant (assembly, standing space). Common values are $100 \mathrm{ft}^{2}$ (gross) per occupant (business, industrial) or $200 \mathrm{ft}^{2}$ (gross) per occupant (residential). By multiplying occupant loads by estimated floor area, the number of people to be evacuated is obtained. These same values have appeared in the building codes for a long time.

The means of egress provisions in the (1968 through 2001) New York City Building Code use the "unit width" method of computing egress capacity. This method was previously found in all the model codes but was changed to the "inches per person" method in the late 1980s (e.g., the NFPA 101 Life Safety Code changed to the "inches per person" method in its 1988 edition). The major reason for the change was that the capacity of elements of the egress system was measured in $22 \mathrm{in}$. increments (called a unit of exit width) with remaining fractions only credited in half units (12 in. or more). Thus the "inches per person" method allows egress credit for exit elements that may have non-standard dimensions. The New York City Building Code (1968 through 2001) requires at least two exits per floor for business occupancy (Group E) in buildings taller than $60 \mathrm{ft}$ and it permits 80 people per (22 in.) unit of exit width and 60 people per unit width on stairs. These are identical to the values found in the contemporaneous codes (1965 BOCA and 1968 NFPA 101) reviewed. For example, for a floor space of $30,000 \mathrm{ft}^{2}, 5$ unit widths of stairs would be needed. Thus three 44 in. wide stairs (the minimum permitted width) would meet the New York City Building Code requirement. New York City further permits scissor stairs (an arrangement where two stairs are intertwined in a single shaft) with openings located at least $15 \mathrm{ft}$ apart (C26.602.3), which are prohibited in most other building codes.

Both the IBC 2000 and NFPA 5000 model codes, as well as most building codes based on them (but not 2001 NYC), now determine the capacity of the egress system by specifying the width per person for egress system components. With the exception of hazardous and health care occupancies, both the IBC (without sprinkler protection) and the NFPA 5000 Code (sprinklered or not) specify the same egress system width of 0.3 in. per occupant in stairways and 0.2 in. per occupant elsewhere. The IBC reduces egress capacity where sprinklered to 0.2 in. per occupant in stairs and $0.15 \mathrm{in}$. elsewhere. The egress capacity of the exit system is the smallest capacity of any component. For example, a 34 in. (clear width) door leading into a 44 in. (clear width) stair have capacities of 170 and 147 occupants, respectively. Thus the exit capacity is the smaller of the two, or 147 occupants. The minimum number of exits specified in both model codes is two for populations up to 500 , three from 501 to 1,000 , and four if over 1,000 . 
Finally, building codes specify maximum travel distances to an exit by occupancy and presence of sprinklers, and the same values are found in all the codes, including New York City. For example, in the 1968 New York City Building Code, the maximum travel to an exit for business occupancy is $200 \mathrm{ft}$ for unsprinklered construction and $300 \mathrm{ft}$ for sprinklered construction. The IBC 2000 code specifies $200 \mathrm{ft}$ (unsprinklered) and $250 \mathrm{ft}$ (sprinklered) for most occupancies, except for business which is allowed $300 \mathrm{ft}$ if sprinklered. The NFPA 5000 code specifies travel distances without sprinklers of $100 \mathrm{ft}$ (for hotels, apartments, and mercantile), $50 \mathrm{ft}$ (for health care and educational), or $200 \mathrm{ft}$ (for business, industrial, and assembly). When fully sprinklered, these increase to $200 \mathrm{ft}$ (for hotel, apartments, educational), $250 \mathrm{ft}$ (for mercantile, industrial, assembly) and $300 \mathrm{ft}$ (business). While most buildings will require two or more exits, the travel distance requirement only applies to the distance from any point to the closest (single) exit. The distance to any other exit(s) is unregulated.

\section{Elevators}

Currently there are no U.S. building codes that permit elevators to be used as a means of occupant egress in emergencies, and ASME A17.1 (ASME 2000) requires signs at all elevators warning that they shall not be used in fires. There are some recent exceptions to this, but these are limited to special cases. For example, NFPA 5000 permits protected elevators as a secondary means of egress for air traffic control towers and the City of Las Vegas accepted elevators as a primary means of occupant egress from Stratosphere Tower based on a performance-based design (Bukowski 2003).

U.S. building codes (including New York City) require accessible elevators as part of a means of egress that may be used by the fire service to evacuate people with disabilities. These elevators must comply with the emergency operation requirements of ASME A17.1 (Phase II emergency operation by the fire service), be provided with emergency power, be accessible from an area of refuge or a horizontal exit (unless the building is fully sprinklered), and operate in a smoke protected hoistway. Phase II operation involves the use of an elevator by a firefighter for fire service access or for rescue of people with disabilities performed under manual control (with the use of a special key).

\section{A.5 PRELIMINARY FINDINGS}

The 1968 New York City Building Code was compared with contemporaneous building codes to determine whether there were significant differences in code provisions. In addition, the 2001 New York City Building Code was also compared to examine the changes resulting from the adoption of Local Laws and rules. The comparison was limited to provisions related to structural stability, fire safety, and egress. In general, it was found that the majority of the provisions were similar among the four codes that were compared. It was also found that the New York City Building Code was more advanced in certain areas than the other three contemporaneous codes (1964 New York State Building Construction Code, 1967 Municipal Code of Chicago, and 1965 BOCA Basic Building Code). The following summarizes the major findings of the code comparison. 


\section{A.5.1 Provisions Related to Structural Stability}

\section{Dead Load}

The New York City Building Codes (both 1968 and 2001 editions) allow lower than 20 psf for uniformly distributed partition loads for partitions that weigh less than 200 plf, while the other codes compared prescribed a minimum uniform partition load of $20 \mathrm{psf}$. As a reference, a $10 \mathrm{ft}$ high partition made of $1 / 2$ in. thick gypsum wallboard on both sides of 2 by 4 wood studs spaced at 16 in. on center weighs about 60 plf. Except for the partition load provision, other dead load provisions in the five codes compared are similar.

\section{Live Load}

The five codes compared had similar minimum live load provisions. They all permit live load reduction for the design of columns and floor framing members. The amount of reduction allowed varies among the codes. While the 1967 Chicago Municipal Code allowed only a maximum of 15 percent reduction for floor-framing members (beams and girders), other codes allowed as much as 60 percent reduction (see Table A-3). The amount of reduction allowed for columns is about the same for all five codes (see Fig. A-1).

\section{Wind Load}

The general trends of the specified wind pressure distributions along the height of a building in the five codes compared are similar. However, specific design wind pressure values vary as much as $10 \mathrm{psf}$ at specific heights. For tall buildings, like the WTC towers, the 1965 BOCA Basic Building Code would produce the largest shear force and bending moment at the base of the building.

The 1968 New York City Building Code allows determination of design wind pressure based on wind tunnel tests with approval by the Building Commissioner.

\section{Earthquake Load}

In the 1960 s, only the BOCA Basic Building Code had the earthquake design provisions, which were based on the Uniform Building Code. The 2001 New York City Building Code contains the earthquake design provisions that are based on the 1997 Uniform Building Code.

\section{Others Loads}

The 1968 New York City Building Code is the only code among the contemporaneous codes compared that has provisions to consider loads due to thermal expansion/contraction of structural members and shrinkage of reinforced concrete members. The New York City Building Code also included language on the distribution of loads among structural members in a building. 


\section{Referenced Design Standards}

The 1968 New York City Building Code and the other contemporaneous codes compared, except the 1964 New York State Building Construction Code, make reference to the same national design standards for steel and reinforced concrete.

\section{Building Alterations}

All codes compared, with the exception of the 1964 New York State Building Construction Code, had similar provisions on whether alterations were required to comply with the current building code. In general, alterations need to comply with the current code when the alteration is a significant portion of the building size or value (see Table A-5). The New York State code, on the other hand, required any alteration to comply with the code.

\section{Construction Inspection}

The codes that were compared include provisions related to inspection of materials and methods during construction. The specific requirements, however, are not similar. The 1968 New York City Building Code distinguishes between "controlled inspection" that require supervision by a design professional and those not so designated as controlled, which can be tested by the person superintending the use of the material. The New York City Building Code required controlled inspection of sprayed-on fire protection, but it did not specify required tests.

\section{Bracing}

Only the New York City Building Code among the codes compared included provisions on bracing of compression members. The New York code requires that members designed to brace compression members (for example, columns), be proportioned to resist 2 percent of the design compression load in the member being braced.

\section{A.5.2 Provisions Related to Fire Safety}

\section{Construction Types}

The building codes compared classify building constructions into different types depending on the combustibility of the construction materials. The New York City Code uses two types, noncombustible and combustible, whereas modern model codes have adopted five types: fire resistive (Type 1); noncombustible (Type 2); combustible (Type 3); heavy timber (Type 4); and ordinary (Type 5). These types are typically sub-divided into classes such as Type $1 \mathrm{~A}$ and Type $1 \mathrm{~B}$.

The cornerstone of fire safety of construction is the "height and area" table that defines the limiting floor and area and building height for different construction classifications (1 A, 1B, and so forth) and 
occupancy groups. In the case where a building could be assigned to more than one construction classification, the codes are silent on which classification should be used, and the selection of the building classification is at the discretion of the owner/architect.

\section{Compartmentation}

In 1973, Local Law 5 was adopted by New York City, which required that large, open floors in existing office building over $100 \mathrm{ft}$ in height be subdivided by 1-hour separations into areas not greater than $7,500 \mathrm{ft}^{2}$. Areas could be increased to $15,000 \mathrm{ft}^{2}$ with 2-hour separations and smoke detectors. Unlimited floor areas were permitted where fully sprinklered.

\section{Sprinklers}

In 1985, Local Law 16 was adopted in New York City, which limited Type 1B construction to buildings of $75 \mathrm{ft}$ or less unless they were fully sprinklered, for which there were no height or floor area limitations.

\section{A.5.3 Provisions Related to Egress}

The 1968 New York City Building Code contained similar requirements to the other contemporaneous codes, which were compared, for the number and capacity of exits and stairs and for the design occupant load. The New York City Code permitted scissor stairs (two stairs in one shaft separated by a fire-rated partition) with doors located at least $15 \mathrm{ft}$ apart, whereas other building codes prohibited scissor stairs.

\section{A.6 REFERENCES}

ASME 2000. Safety Code for Elevators and Escalators ASME 17.1, American Society of Mechanical Engineers, New York, NY.

BOCA/BBC 1965. BOCA Basic Building Code, Fourth Edition, Building Officials Conference of America, Chicago, IL.

Bukowski, R.W. 2003. Protective Elevators for Egress and Access During Fires in Tall Buildings, Proceedings of the CIB-CTBUH Conference on Tall Buildings, Kuala Lumpur, Malaysia.

October 20-23.

Coty, Eric H. (Rolf Jensen \& Associates). 1997. Included as Attachment A to World Trade Center Code Compliance Evaluation compiled by PANYNJ October 15, 1999, March 14.

CTB\&UH (Council on Tall Buildings and Urban Habitat). 1980. Monograph on Planning and Design of Tall Buildings, Volume CL-Tall Building Criteria and Loading, American Society of Civil Engineers, Reston, VA.

IBC 2000. International Building Code, International Code Council, Falls Church, VA. 
Kyle, John M. (Chief Engineer, Port Authority). 1966a. Memorandum to Guy F. Tozzoli (Director, World Trade Department), May 9.

Kyle, John M. (Chief Engineer, Port Authority). 1966b. Memorandum to Guy F. Tozzoli (Director, World Trade Department), June 2.

Levy, Malcolm. 1963. Port of New York Authority Letter to Minoru Yamasaki (Architect, Minoru Yamasaki \& Associates), May 15.

Levy, Malcolm. 1965. Port of New York Authority Letter to Minoru Yamasaki (Architect, Minoru Yamasaki \& Associates), September 29.

MCC (Municipal Code of Chicago). 1967. Municipal Code of Chicago Relating to Buildings (As Amended to and including January 1, 1967), Index Publishing Corp., Chicago, IL.

NBS 1935. Design and Construction of Building Exits, National Bureau of Standards Miscellaneous Publication M151, U.S. Government Printing Office, Washington, DC.

NFPA (National Fire Protection Association). 1966. Life Safety Code, NFPA 101, Quincy, MA.

NFPA (National Fire Protection Association). 2003. Building Construction and Safety Code, NFPA 5000, Quincy, MA.

NYCBC 1968. Building Code-Local Law No. 76 of the City of New York, New York, NY

NYCBC 2001. Building Code of the City of New York, 2001 Edition, Gould Publications, Binghamton, NY.

NYSBC 1964. State Building Construction Code Applicable to General Building Construction, Building Code Bureau, State of New York, New York, NY, December 1.

PANYNJ (Port Authority of New York and New Jersey). 1999. World Trade Center - Code Compliance Evaluation, October 15.

Solomon, Joseph H. (Emery Roth \& Sons). 1975. Letter to Malcolm P. Levy (General Manager, World Trade Center Operations), February 18.

UBC 1988. Uniform Building Code, International Conference of Building Officials, Whittier, CA. 
This page intentionally left blank.

$$
\text { A-34 }
$$




\section{TABLE OF CONTENTS}

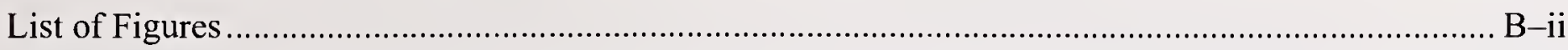

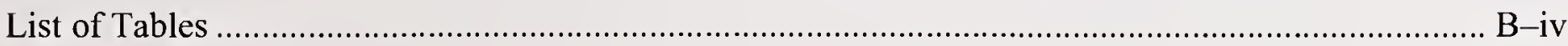

\section{Appendix B}

Interim Report on Development of Structural Databases and Reference Models for

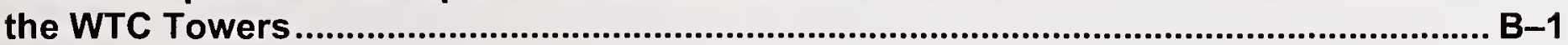

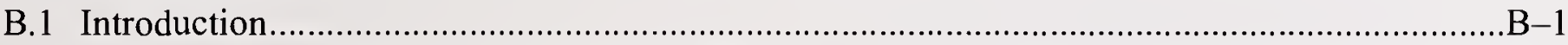

B.1.1 Description of WTC Structural System .......................................................................

B.2 Development of Structural Databases for the Towers …...................................................

B.2.1 Description of WTC Structural Documents ...............................................................

B.2.2 Overview of the WTC Structural Database (WTC-DB) .......................................... -9

B.2.3 Methodology for the WTC-DB Development .........................................................

B.2.4 Modifications to Database Elements ..............................................................................

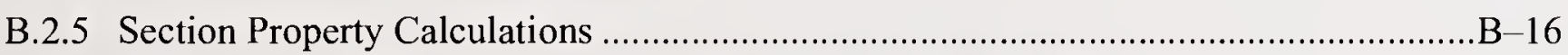

B.3 Development of Reference Structural Analysis Models for the Towers .................................

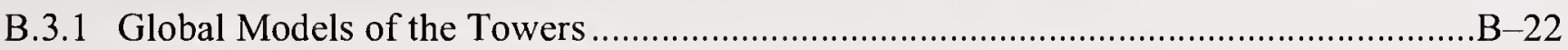

B.3.2 Typical Truss-Framed Floor Model--Floor 96A …............................................

B.3.3 Typical Beam-Framed Floor Model-Floor 75B ............................................... 44

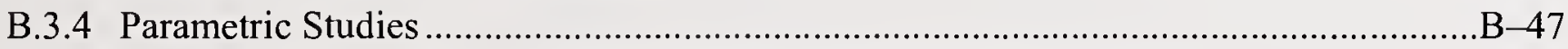

B.4 Review of the Structural Databases and Reference Models of the Towers ..............................

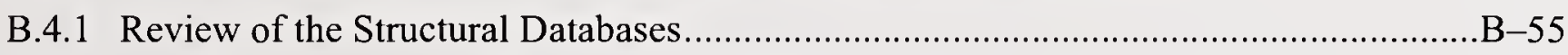

B.4.2 Review of the Reference Structural Models ............................................................56 


\section{LIST OF FIGURES}

Figure B-1. Typical WTC tower architectural floor plan …......................................................... B-2

Figure B-2. Typical WTC exterior wall, foundation to floor 9...................................................... B-3

Figure B-3. Typical WTC tower hat truss elevation ........................................................................ B-4

Figure B-4. Typical WTC floor truss framing zones. ................................................................... B-5

Figure B-5. Part plan of floor 96 of WTC 1, components of typical truss framing system.................. B-6

Figure B-6. Part section typical truss floor panel................................................................................ B-7

Figure B-7. Drawing Book 3 flowchart: WTC 1 and WTC 2 core columns ................................... B-10

Figure B-8. Core column reinforcement. …................................................................................ B-13

Figure B-9. Column section at original column strap detail ....................................................... B-15

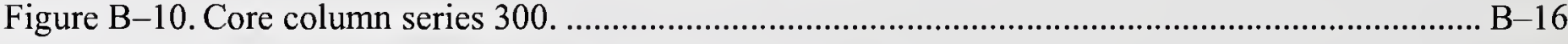

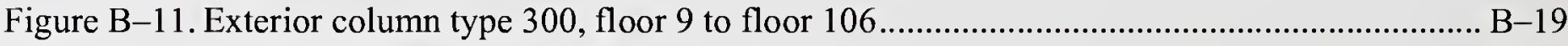

Figure B-12. Column type 6000 with tapered spandrel .................................................................... B-20

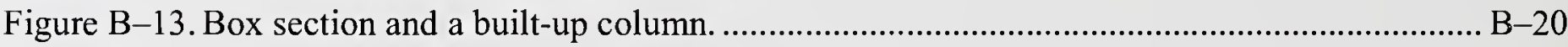

Figure B-14. Global model coordinate axis location. .................................................................. B-24

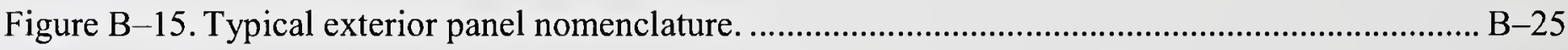

Figure B-16. Rendered isometric views of the WTC 1 model........................................................ B-28

Figure B-17. Frame view of the WTC 2 model: exterior wall elevation and interior section ................ B-29

Figure B-18. Frame view and rendered view of the WTC 1 model.................................................... B-31

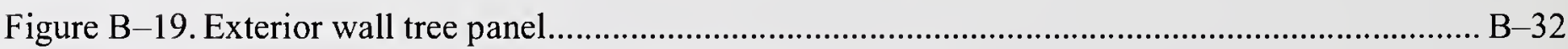

Figure B-20. Exterior wall tree: as-built cross sections for level E ............................................ B-34

Figure B-21. Frame view and rendered view of an exterior wall tree. ........................................... B-34

Figure B-22. Typical WTC tower exterior wall panel. ................................................................ B-35

Figure B-23. As-modeled plan of the WTC 1 hat truss. .................................................................. B-37

Figure B-24. Rendered 3-D model of the WTC 1 hat truss............................................................. B-37

Figure B-25. Typical truss-framed floor panels arrangement........................................................... B-39

Figure B-26. Typical truss-framed floor model (floor 96A) ......................................................... B-40

Figure B-27. Typical primary truss cross-section ........................................................................ B-41

Figure B-28. Typical bridging truss cross-section ...................................................................... B-42

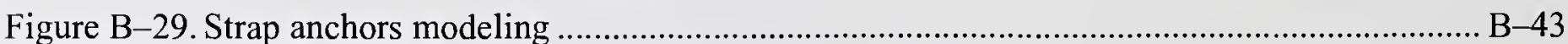

Figure B-30. Typical beam-framed floor arrangement........................................................... B-45

Figure B-31. Typical beam-framed floor model (floor 75B)....................................................... B-45 
Figure B-32. Horizontal truss modeling, slab not shown..................................................... B 46

Figure B-33. Shell element and frame models of typical exterior wall panel................................. B 48

Figure B-34. Column and spandrel rigidity of typical exterior wall panel. ..................................... B-49

Figure B-35. Shell element and frame models of typical exterior wall corner panel.......................... B-51

Figure B-36. Column and spandrel rigidity of typical exterior wall corner panel........................... B-51

Figure B-37. Detailed and simplified model of the exterior wall corner panel................................ B-52

Figure B-38. Deflection of typical truss-framed floor model due to lateral loading.......................... B-54

Figure B-39. Deflection of equivalent floor model due to lateral loading ................................... B-54

Figure B-40. Deflections of the north and south faces of the floor for the detailed and equivalent floor models.

B-55 


\section{LIST OF TABLES}

Table B-1. Modifications to members of the WTC database (WTC-DB) …................................... B-9

Table B-2. Approximate size of the reference structural models (rounded)................................... B-30

Table B-3. Lateral displacement for the shell and frame models of typical exterior wall panel with varied column and spandrel rigidities.

B-50

Table B-4. Lateral displacement for the shell and frame models of typical exterior wall corner panel with varied column and spandrel rigidities. 


\section{Appendix B \\ INTERIM REPORT ON DEVELOPMENT OF STRUCTURAL DATABASES AND REFERENCE MODELS FOR THE WTC TOWERS}

\section{B.1 INTRODUCTION}

The objectives of this project are to (1) develop structural databases for the primary structural components of the World Trade Center towers, (WTC 1 and WTC 2), (2) use the databases to develop reference structural analysis models that capture the intended behavior of each of the two towers, and (3) perform linear, static structural analyses to establish the baseline performance of each of the two towers under design gravity and wind loads. This appendix focuses on the tasks related to the first two objectives. The appendix reports on the work conducted by the firm of Leslie E. Robertson Associates (LERA), the firm responsible for the original structural engineering of the WTC towers, for the development of the structural databases and reference models. It also outlines the comprehensive review process for the structural databases and reference models that includes the rigorous in-house NIST review and third-party review by the firm of Skidmore, Owings, and Merrill (SOM).

Section B.1 presents an introduction and a brief description of the structural system of the towers. Section B.2 presents an outline and methodology used for the development of the structural databases for both towers from the original computer printouts of the structural documents, along with the relational databases that are used for the development of the reference structural models. Section B.3 presents the development of the reference structural analysis models for WTC 1 and WTC 2, including global tower models, typical floor models, and parametric studies needed for the development of the global models. Finally, Section B.4 outlines the in-house and third-party review process for the structural databases and reference models.

\section{B.1.1 Description of WTC Structural System}

\section{Global Structural System}

WTC 1 and WTC 2 each consisted of a 110-story above grade structure and 6-story below grade structure. The buildings, which were each approximately $207 \mathrm{ft}$ by $207 \mathrm{ft}$ square in plan and with story heights of typically $12 \mathrm{ft}$, rose to heights of $1,368 \mathrm{ft}$ (WTC 1) and 1,362 ft (WTC 2) above ground. The exterior walls of the towers supported gravity loads and all lateral loads, and were constructed of steel closely spaced, built-up columns and deep spandrels. The core contained columns that supported the remainder of the gravity loads of the towers. The core area was approximately $135 \mathrm{ft}$ by $87 \mathrm{ft}$ in plan (refer to Fig. B-1). The distances between the rectangular core and the square exterior wall were approximately $36 \mathrm{ft}$ and $60 \mathrm{ft}$. The areas outside of the core were free of columns and the floors were supported by truss-framing in the tenant areas and beam-framing in the mechanical rooms and other areas.

The primary structural systems for the towers included exterior columns, spandrel beams, and bracing in the basement floors, core columns, core bracing at the mechanical floors, core bracing at the main lobby atrium levels, hat trusses, and the floor systems. 


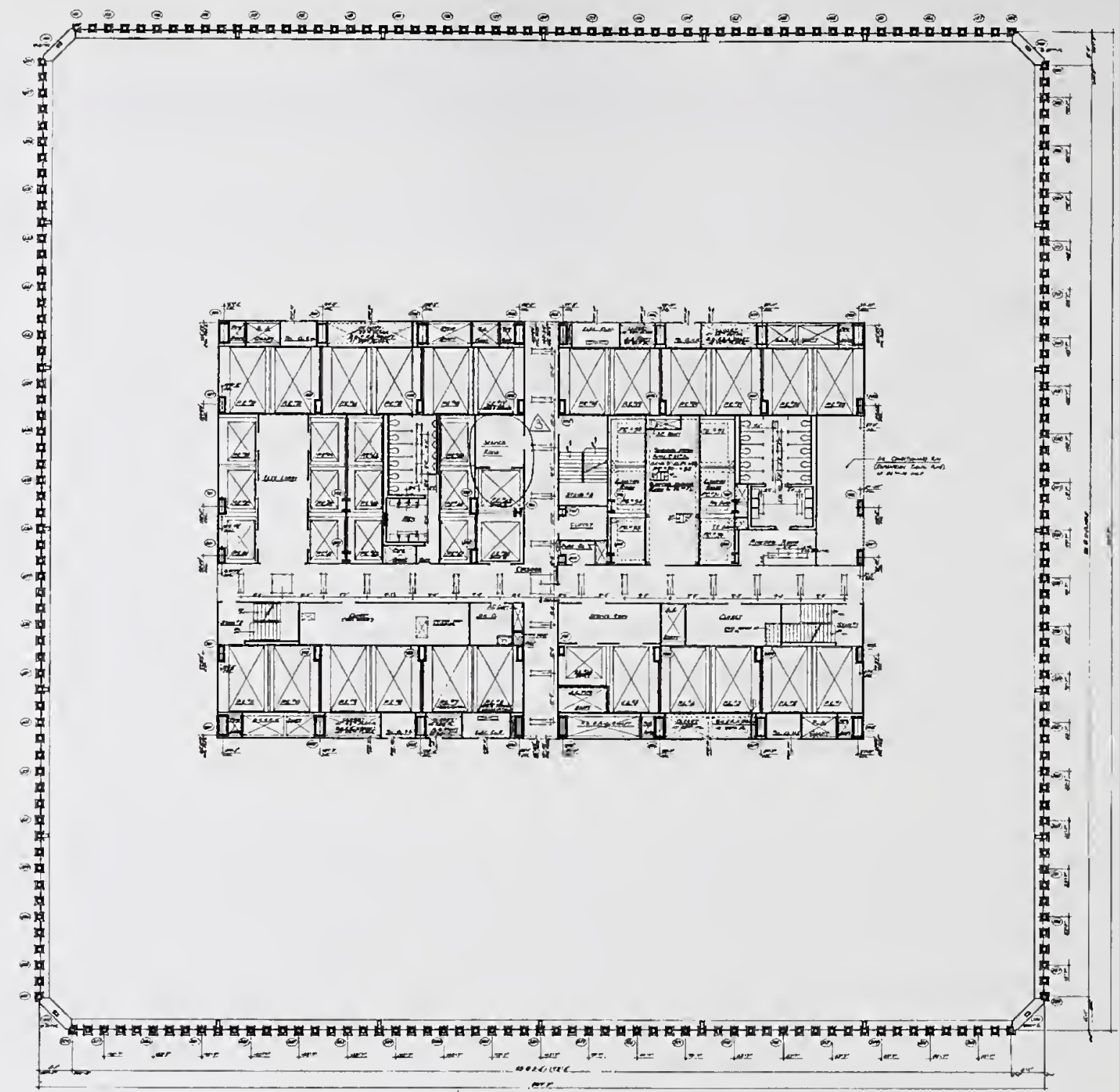

Drawing used with permission from PANYNJ.

Figure B-1. Typical WTC tower architectural floor plan (floor 26, WTC 2).

The exterior wall columns from the foundation level up to Elevation $363 \mathrm{ft}$ were spaced $10 \mathrm{ft} 0 \mathrm{in}$. on center, built-up of steels plates, and connected by spandrels. Bracing existed in the plane of the exterior wall between the Concourse Level and the foundation, (see Fig. B-2). Between Elevation $363 \mathrm{ft}$ and floor 7 , the single exterior wall columns spaced $10 \mathrm{ft} 0 \mathrm{in}$. on center transitioned to three columns spaced at $3 \mathrm{ft} 4$ in. on center as shown in Fig. B-2 (see also Fig. B-19).

The exterior wall columns above floor 7 that were spaced $3 \mathrm{ft} 4 \mathrm{in}$. on center, were built-up of steel plates, and were connected to each other by spandrel plates, typically 52 in. deep. The exterior columns and spandrels were pre-assembled into exterior wall panels, typically 3 -columns wide by 3 -stories tall (refer to Fig. B-22).

The core columns were typically built-up box members at the lower floors and transitioned into rolled structural steel shapes at the upper floors. The core columns were typically spliced at 3 -story intervals at 


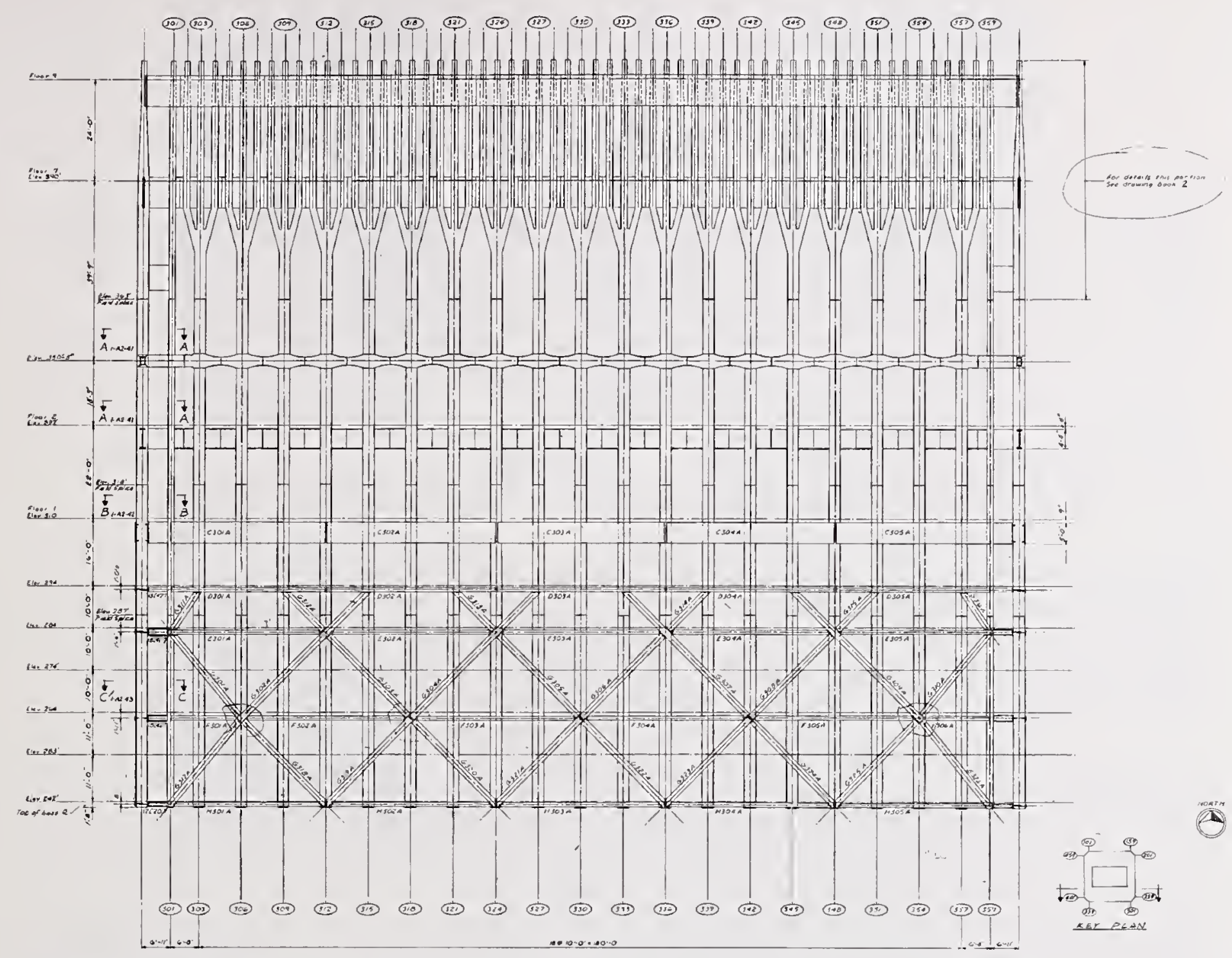

Drawing used with permission from PANYNJ.

Figure B-2. Typical WTC exterior wall, foundation to floor 9.

$3 \mathrm{ft}$ above floor level. Diagonal bracing of the core columns existed at the lobby atrium levels, the mechanical levels, and in the area of the hat truss.

At the top of each tower, hat trusses interconnected the core columns with the exterior wall panels and provided a base for the antennae. The vertical members of the hat trusses were wide flange core columns. The diagonals were primarily wide flange rolled sections with the exception of the end diagonals interconnecting the core to the exterior walls which were built-up box sections. The majority of the horizontal members in the hat truss system were wide flange and built-up box section floor beams. The members of the hat trusses were shown in the SA/B-400 series elevations (refer to Fig. B-3). 


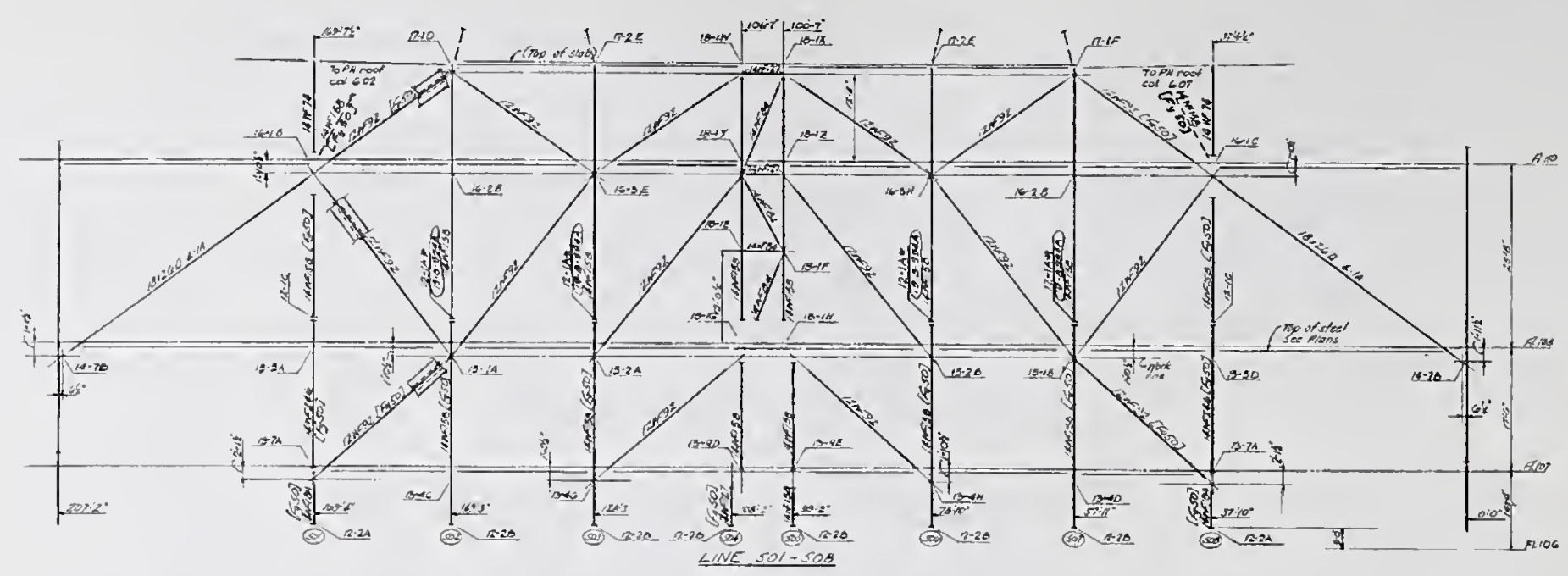

Drawing used with permission from PANYNJ.

Figure B-3. Typical WTC tower hat truss elevation (Drawing SA 401).

\section{Floor Structural System}

In the typical WTC tower floor plan, the area inside the core was framed with rolled structural steel shapes acting compositely with formed concrete slabs. The area outside the core was framed in either trusses (typical on tenant floors) or in rolled structural steel shapes (typical on mechanical floors).

Truss-Framed Floors - The majority of the floors of the WTC towers were tenant floors where the areas outside of the core were constructed of steel trusses acting compositely with concrete slabs cast over metal deck. The trusses consisted of double angle top and bottom chords with round bar webs and were designed to act compositely with the concrete slab. Composite action was achieved by the shear connection provided by the web bar extending above the top chord and into the slab. Two trusses were placed at every other exterior column line, resulting in a $6 \mathrm{ft} 8 \mathrm{in}$. spacing between truss pairs. The typical floor consisted of three truss zones: a long span zone, a short span zone, and a two-way zone, (see Fig. B-4).

The floor trusses were pre-assembled into floor panels as defined in the contract drawings. The span of the trusses was about $36 \mathrm{ft}$ in the short direction and $60 \mathrm{ft}$ in the long direction. The floor panels included primary trusses, bridging trusses, deck support angles, metal deck, and strap anchors, all of which were defined by the contract drawings and specifications.

The floor truss panel types are indicated in the structural plans (see Fig. B-5) and the plans refer in turn to Drawing Book 7 for information regarding the components of the floor truss panels and to Drawing Book $\mathrm{D}$ for damper information. Drawing Book 7 provided panel by panel layout plans and elevations of each referenced truss. The section through a floor panel after the concrete was placed is illustrated in Fig. B-6.

Beam-Framed Floors - The typical locations of the beam-framed floors were the mechanical floors, the mechanical mezzanines, and the floors above the mezzanines (e.g., floors 41,42 , and 43). These floors were constructed using rolled structural steel shapes. The beam framing for the typical floor system was W27 beams in the long span region and W16 beams in the short span region. Typically, beam spacing was $6 \mathrm{ft} 8 \mathrm{in}$. The steel beams acted compositely with the normal weight concrete slab on metal deck. 


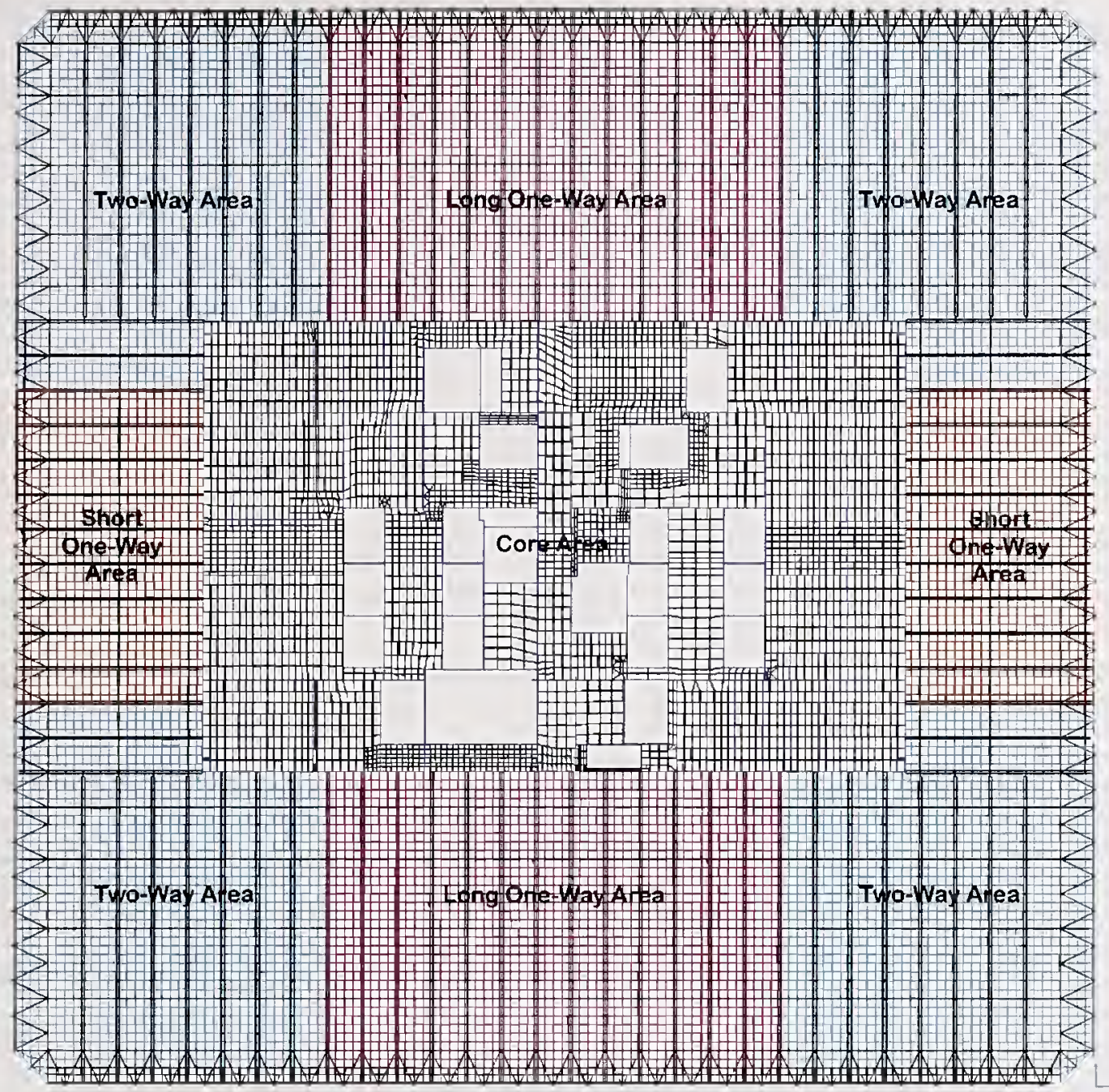

Figure B-4. Typical WTC floor truss framing zones.

The deck spanned in the direction of the primary beams and was supported typically at $6 \mathrm{ft} 8 \mathrm{in}$. intervals by a 4C5.4 deck support channel. A 2 in. concrete topping slab was placed on top of the structural slab. The core area was framed similar to the core of the truss-framed floors, but the steel beams were typically larger, and the concrete slab was 6 in. deep. The beam-framed floors above the mechanical mezzanine had a $73 / 4$ in. normal weight concrete slab on $11 / 2$ in. metal deck, while the core slab was 8 in. normal weight concrete.

Beam-framing was added to truss-framed floors at levels which supported escalators or stairs in the areas outside of the core. The escalator floors occurred typically in the two levels directly above the mechanical rooms.

\section{B.2 DEVELOPMENT OF STRUCTURAL DATABASES FOR THE TOWERS}

This section outlines the development of the electronic databases for the major structural components of the WTC towers from original computer printouts of the structural documents. The structural databases are used to develop the reference structural models of the towers as outlined in Section B.3. Included in this section are an overview of the WTC towers' structural design documents, a description of the structural database contents, methodology for the development of the database, and a description of the relational database. 


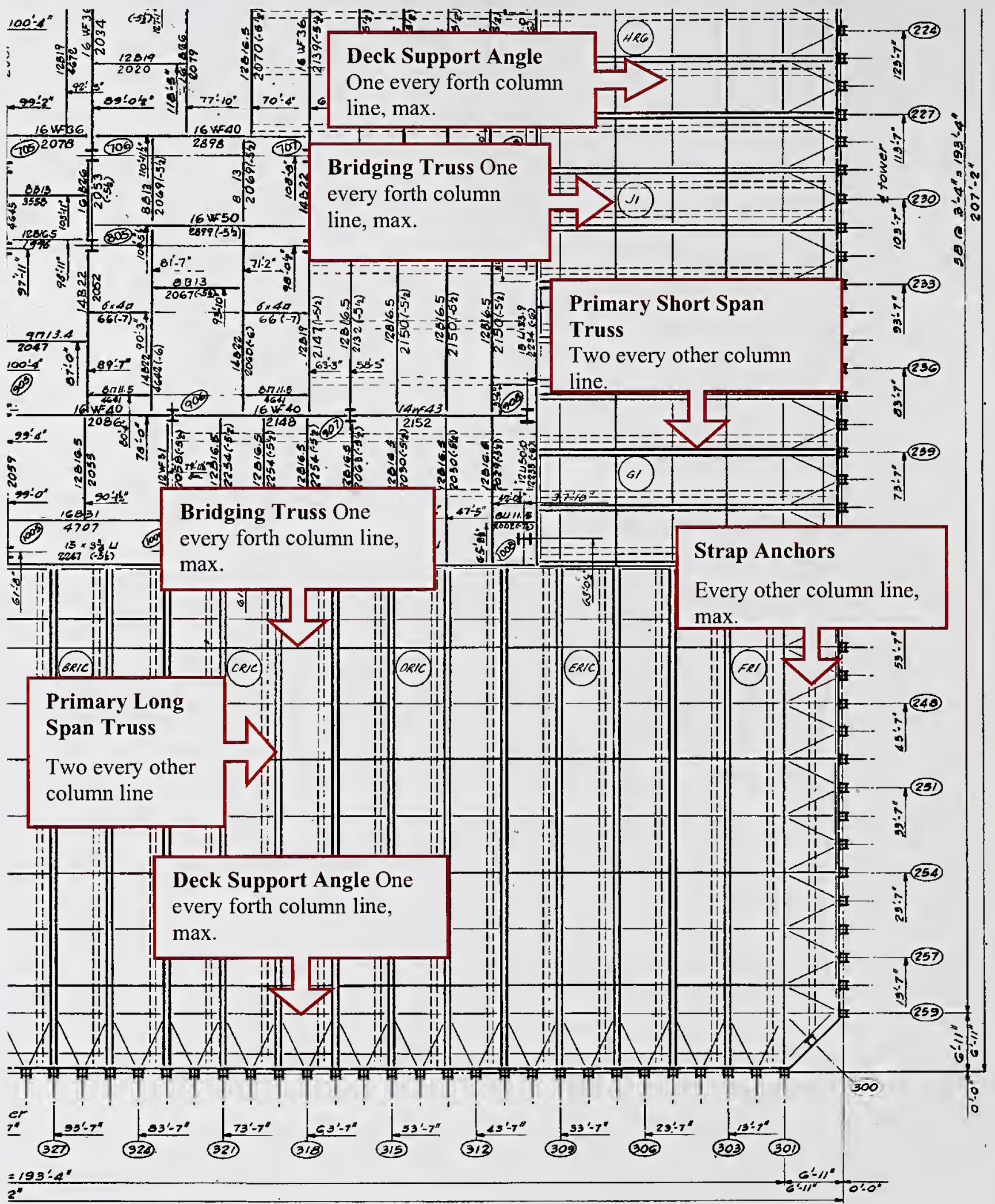

Original drawing used with permission from PANYNJ.

Figure B-5. Part plan of floor 96 of WTC 1 (Drawing SA-104), components of typical truss framing system. 


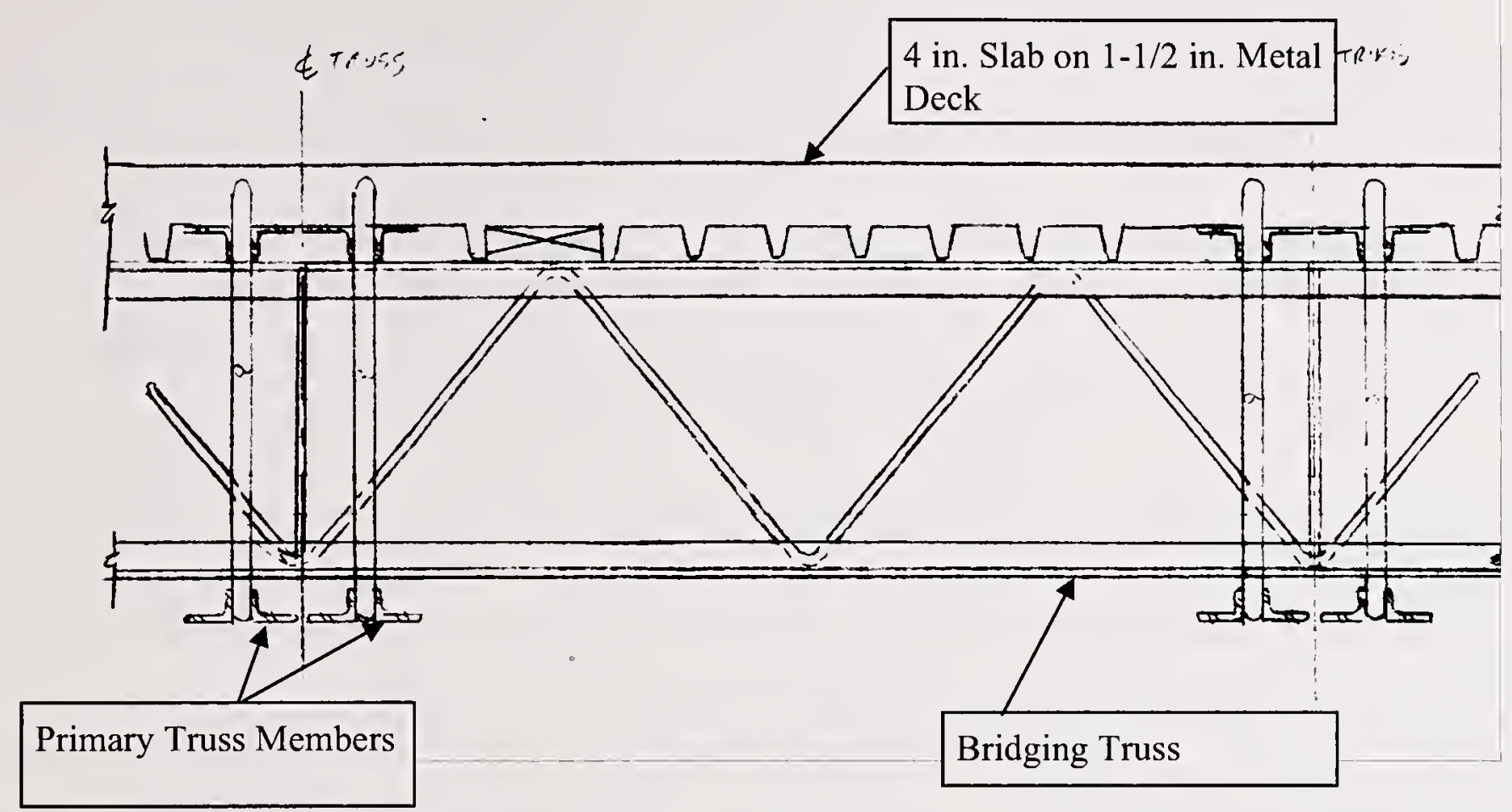

Original drawing used with permission from PANYNJ.

Figure B-6. Part section typical truss floor panel.

\section{B.2.1 Description of WTC Structural Documents}

The WTC structural drawings were issued in two main formats: large-size sheets containing plan and elevation information and smaller book-sized drawings containing details and tabulated information. Throughout the WTC drawings, Tower A or WTCA denotes WTC 1 (north tower) and Tower B or WTCB denotes WTC 2 (south tower). The large size drawings always make reference to the structural drawing books through their notes, sections, and detail references. The structural drawing books for WTC 1 and WTC 2 include the following:

- Book 1 contains exterior wall information to elevation $363 \mathrm{ft}$. (Dates: 02/1967 to 12/1968, Approx. 213 pages).

- Book 2 contains exterior wall information elevation $363 \mathrm{ft}$ to floor 9. (Dates: 04/1967 to 12/1967, Approx. 62 pages).

- Book 3 contains core column information. (Dates: 03/1967 to 09/1969, Approx. 137 pages).

- Book 4 contains exterior wall information floor 9 to floor 110 . (Dates: 04/1967 to 10/1972, Approx. 1,080 pages).

- Book 5 contains the beam schedule. (Dates: 05/1967 to 08/1969, Approx. 292 pages).

- Book 6 contains connection details and core bracing. (Dates: 08/1967 to 05/1969, Approx. 1,060 pages). 
- Book 7 contains truss floor panel information. (Dates: 10/1967 to 07/1969, Approx. 345 pages).

- Book 8 contains concrete notes and details. (Dates: 03/1968 to 07/1974, Approx. 926 pages).

- Book 9 contains roof area column splice details. (Dates: 05/1970 to 04/1971, Approx. 440 pages).

- Book 18 contains strap anchor and core truss seat information. (Dates: 10/1968 to 11/1969, Approx. 219 pages).

- Book 19 contains revisions after fabrication. (Dates: 08/1968 to 05/1975, Approx. 374 pages).

- Book 20 contains structural steel details. (Dates: 07/1968 to 03/1971, Approx. 41 pages).

- Book D contains damper details. (Dates: 03/1969 to 09/1971, Approx. 43 pages).

The remaining number books (Books 10,11,12, and 13) contain information about the sub-grade structure. Books 14, 15, 16, and 17 were never used.

Until fabrication was begun, the above drawings and drawing books (with the exception of Book 19) for the project were modified in keeping with the requests for changes by contractor(s) and early tenant modifications. The drawings were modified up until such time as the fabrication of elements commenced. At that time, Book 19 was introduced. It contained the information regarding 'revisions after fabrication'.

LERA believes that the original structural drawings represent significantly accurate 'as-built' drawings for the towers. As tenant modification requests became large in scope, they became separate projects (e.g., the Fiduciary Trust Vault Project, see Section B.2.4). Tenant structural modifications designed by LERA were then documented in a single book of quarter-size plans referred to as the 'WTC Tenant Structural Modifications Book'. Later tenant modifications were mostly archived on a job-by-job basis without a central accounting for all the changes. NIST has in its possession complete copies of all the drawings, drawing books, and modifications to the towers performed by LERA. In some instances modifications were made by the Port Authority of New York and New Jersey (PANYNJ) Engineering, such as additions to the mechanical levels. In other instances, tenant modifications were performed by other engineers. For these instances, LERA does not have record of the work completed. According to the PANYNJ, no record of structural work could be found so far for the additions to the mechanical floors made by the PANYNJ Engineering, and it is likely that they were lost with the collapse of the towers. Modifications made by other engineering firms include openings or closings of floor slabs and local reinforcement of floor segments to accommodate new loads. For these modifications, NIST has access to the documents related to the work.

The few modifications made by LERA to the components compiled in the WTC structural databases that will have an effect the global behavior of the towers are listed in Table B-1. 
Table B-1. Modifications to members of the WTC database (WTC-DB).

\begin{tabular}{|c|c|c|c|c|c|c|c|}
\hline Item & Description & Tower & Element & Floor & Element Effected & $\begin{array}{l}\text { WTC-DB } \\
\text { Modified }\end{array}$ & Archived \\
\hline 1 & $\begin{array}{l}\text { Core column } \\
\text { reinforcing }\end{array}$ & $\begin{array}{l}\text { WTC 1 } \\
\text { and } \\
\text { WTC 2 }\end{array}$ & Numerous & $98-106$ & Core columns & Book 3 & Book 19 \\
\hline 2 & $\begin{array}{l}\text { Fiduciary Bank } \\
\text { Vault }\end{array}$ & WTC 2 & $\begin{array}{l}\text { Col. 508B and } \\
\text { Col. 1008B }\end{array}$ & $45-97$ & Core columns & Book 3 & LERA P209 \\
\hline 3 & $\begin{array}{l}\text { Bombing of } 26 \\
\text { February } 1993 \\
\text { repair }\end{array}$ & WTC 1 & $\begin{array}{l}\text { Col. } 324 \text {, } \\
\text { bracing } \\
\text { G313A and } \\
\text { G304A }\end{array}$ & B-2 level & $\begin{array}{l}\text { Perimeter } \\
\text { column and } \\
\text { bracing }\end{array}$ & NA & $\begin{array}{l}\text { LERA } \\
\text { P1003118 }\end{array}$ \\
\hline 4 & EXCO stair & WTC 1 & Col. 901A & 26 & Core column & NA & $\begin{array}{l}\text { LERA } \\
\text { P1003249 }\end{array}$ \\
\hline
\end{tabular}

\section{B.2.2 Overview of the WTC Structural Database (WTC-DB)}

The original WTC design documents used the concept of limiting the need for repetition in documenting the data shared between different elements with similar characteristics. The drawing book schedules refer to subsequent tables for information common to several lines of the same schedule. In an effort to minimize the amount of repeated information and thereby the data checking of the digital WTC-DB, the drawing book data within the databases created for this project were linked in a similar manner. In order to accurately follow the original flow of the drawing book links, flowcharts of the drawing books to be digitized were developed for this project. These flowcharts were used to organize the links of the digitized data within the relational database. An example of such flowcharts for Drawing Book 3 (core columns) is illustrated in Fig. B-7.

The WTC-DB contains the computer and hand-tabulated data for the major structural components from the original Drawing Books 1 through 5, including exterior walls, core columns, and beam schedule for the towers. Where information from Drawing Books 1 through 5 was modified by Drawing Book 19 and would affect the towers' modeling, the information is included in the database. In addition, some information from Drawing Books 6 (core bracing schedule) and 9 (beams in the hat truss region) has been included in the database files as it was utilized in the finite element modeling of the towers.

The drawing book tables are first digitized and stored in Microsoft Excel format files. The Excel files include several worksheets that describe the evolution of the data from the drawing book to the final database format, as well as additional information and notes for interpreting the data.

The WTC relational database links the Excel files and allows users to view and select data through query commands. The primary benefit of the relational database format is the ability to programmatically query the database for data required in assembling the structural models of the towers. The query routine allows multiple users the ability to review, extract, and export the basic data in any required form. The data can be manipulated using Structured Query Language (SQL) according to the desired output, for example the structure of the user's finite element model input file. 


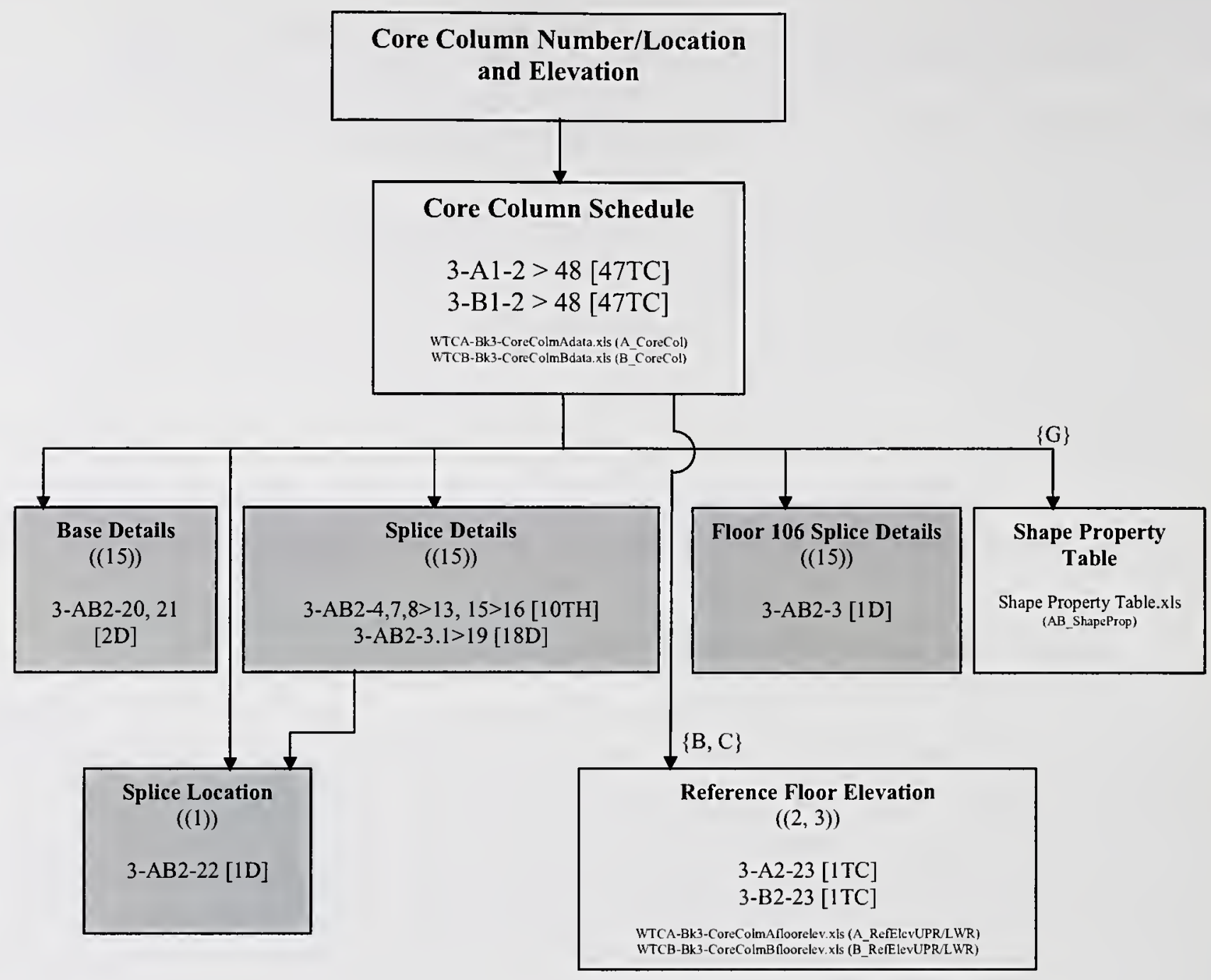

NOTES:

1. 4-AB-* Denotes Drawing Book 4, Tower $\mathrm{A}, \mathrm{B}$ or $\mathrm{AB}$, and page number

2. $[* T C]$ Number of pages and type, where page types include:

TC - Computer generated tables; TH - Hand written tables; D - Diagrams

3. *.xls Excel spreadsheet file name; $(\mathrm{AB} * * *)$ database heading

4. $\left(\left({ }^{*}\right)\right)$ Reference note key from original $\bar{D}$ rawing Book information table.

5. $\{*\}$ Relational database link (i.e. Excel column number) from previous *.xls file.

6. Figures of columns and panels are shown from inside of building looking out, unless otherwise noted.

\section{Figure B-7. Drawing Book 3 flowchart: WTC 1 and WTC 2 core columns, foundation to} floor 106.

\section{B.2.3 Methodology for the WTC-DB Development}

\section{Data Entry}

The tabulated portions of WTC Drawing Books 1, 2, 3, 4, 5, 6, and 9 were first scanned and stored in TIFF image format files. The image files containing the tabulated information were then opened in an Optical Character Recognition (OCR) program that converted the information into a text file. The OCR program was modified to allow for the filtration of unnecessary characters during the documents conversion process. In other words, the user could direct the program to block specific characters that are 
not on the actual page. As an example, if after reviewing a table, one recognizes that it uniformly contains numbers and only the characters "A, B, -", and "/" then the remaining characters can be frozen out by the software. This reduced the misinterpretation, as an example, of a ' $\mathrm{Z}$ ' for a ' 2 ', or an ' $\mathrm{O}$ ' for a 'zero'.

The raw text file was then opened in a word processing program, where it was compared with the original hardcopy drawing books. As needed, data columns were adjusted, and obvious errors were individually corrected. The 'cleaned' text file was then imported into a Microsoft Excel spreadsheet with column headings and proper alignment. When importing into Excel, "text" was the cell format used for handling of the scanned information to avoid the misinterpretation of fractions as dates (e.g., 3/8 as March 8). An Excel macro was written at this stage to convert the text fractions into number fractions. The final product of this stage was an Excel file that contains the information from the drawing book table.

\section{Quality Control}

Checking began during the OCR data entry process, where the files being entered and the OCR software interpretation were viewed simultaneously. This was considered a first check. Once the Excel file was complete, the file entered the 'second check' process.

The 'Second Check'-An engineer not involved during the OCR process performed a second, sample checking of the database in a random but methodical manner. For approximately once in four pages, every cell of data in the page was compared with the original drawing books. Discrepancies of the files were then either re-entered using OCR or were individually corrected to agree with the original books.

The 'Cross-Check Rectify' Check-After completing the 'second check,' the files were compared with the database provided by a consultant for the leaseholder of the WTC towers as part of an insurance litigation concerning the towers (provided to LERA as Government Furnished Information [GFI]) using a cross-check macro formula worksheet. Once compared, conflicting information appeared in a yellow highlighted cell displaying both sets of compared information in the "Calculation" macro formula worksheet. The cell was then reviewed and confirmed with the WTC drawing books. If errors were from the developed worksheet, data was rectified, and the yellow highlight in the 'Calculation' worksheet was then removed by comparing the files again. If errors were from the GFI worksheet, raw GFI data was not modified, but the cell was highlighted in blue to note that it has been reviewed. The files were then compared again, and the cell color in the 'Calculation' worksheet changed to blue. The process was repeated to remove all the yellow cells so that only blue highlighted cells remain. The worksheet 'ComparisonORIGINAL' was retained for the record of the original comparison, and the updated worksheet 'ComparisonFINAL' was retained for the record of the final comparison.

Final Review-Finally, the files were reviewed for completeness, formatting, and data units. A final check was made to find any numbers that may have been input as text letters. Following this review, the worksheet was used to develop the member section properties.

\section{Cross Section Property Calculations}

The next step was to calculate the cross section properties for the members included in the database. The section properties calculated included cross sectional area $(A)$, moment of inertia $(I)$, section modulus $(S)$, 
plastic section modulus $(Z)$, radius of gyration $(r)$, and torsional constant $(J)$ for both the major and minor axes (where applicable). The Section Designer function of SAP2000 Version 8 was used to calculate the cross section properties since it enables the program to perform more precise code checks, as the dimensions of each plate element that is part of the section would be input into the finite element model.

The current rolled shape database in SAP2000 represents the modern day rolling practices. The rolled shapes used in the construction of the WTC towers were from a different era and thus, had different properties in comparison to present day shapes. Therefore, a rolled shape database consistent with the time of construction was developed in this project. See Section B.2.5 for further discussion about the rolled shape database.

\section{Relational Database Development}

As discussed earlier, the original WTC drawing books were designed to avoid repeating identical information. The drawing book schedules, therefore, refer to other tables for information common to several lines of the same schedule. In keeping with the nature of the original drawing books and to minimize the data in the digital WTC-DB, the drawing book and section property data were linked using Microsoft Access.

The assembly of the relational database began with the mapping of the original WTC drawing book into flowcharts (see, e.g., Fig. B-7). The digitized drawing book data with the corresponding cross sectional member properties from the Excel-format files were then imported into the Microsoft Access database program and partitioned into tables. The tables were then joined using the links cataloged in the flowcharts. These tables were developed to provide the input files for the finite element modeling of the towers as illustrated in Section B.3.1.

\section{B.2.4 Modifications to Database Elements}

The majority of the original members and elements defined within the WTC-DB could be fully defined by the original data in the drawing books. As outlined in Table B-1, however, some modifications were made that are described in the following sections. Of the items outlined in Table B-1, items 1 and 2 have been included within the database.

\section{Core Column Reinforcing at Floors 98 to 106}

A number of core columns in both WTC 1 and WTC 2 were reinforced at floors 98 to 106 . Book 19, pages 19-AB-974.1 through 4, shows that core columns 501, 508, 703, 803, 904, 1002, 1006, and 1007 from floors 98 to 106 in both towers were reinforced with steel plates. Three methods were used to attach the reinforcing plates to the wide flange columns: (1) the plates were welded to the flanges; (2) the plates were welded to the webs; and (3) the plates, which were parallel to the web, were welded to the flange ends. The plate information (width, thickness, length, and yield strength) was incorporated into the database tables of Book 3. Since the plates varied from floor to floor, the original column (defined over a three-story height) was split into typically three floor-by-floor sections and the designation of the column was appended to include either U(upper), M(middle), or L(lower) designation (refer to Fig. B-8). For floors 104 and 106, the columns are two-story columns. Hence, the columns at these floors had only $\mathrm{U}$ and $\mathrm{L}$ designations. The section property calculations included the contributions of the reinforcing 
plate at each level. For the built-up section property data, the reinforcing plate was considered to be applied to the column for its floor-to-floor height.

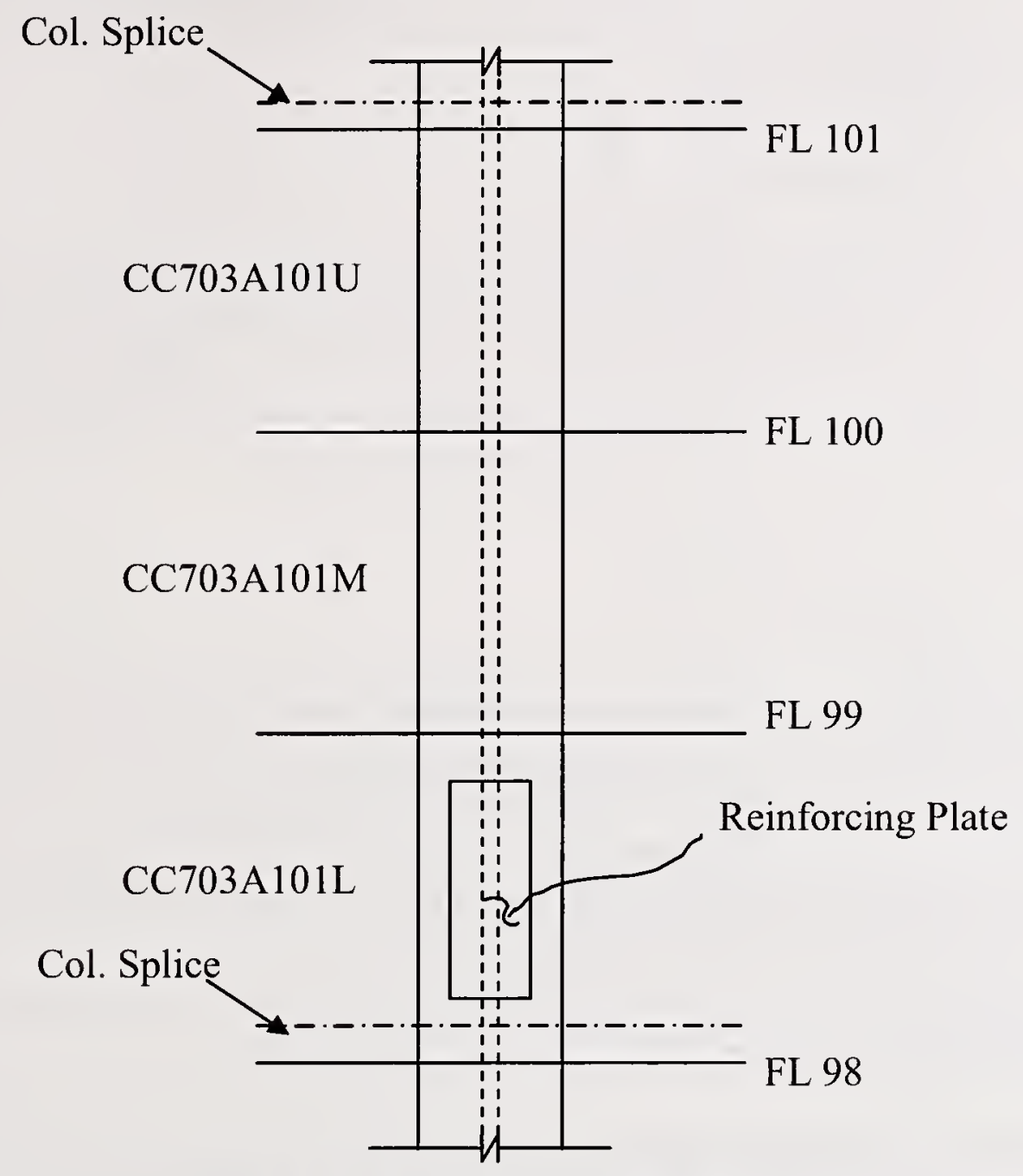

Figure B-8. Core column reinforcement.

\section{Core Column Reinforcing Due to Construction of Fiduciary Trust Vault}

The Fiduciary Trust Company added a concrete vault at floor 97 of WTC 2, which required reinforcing two corner core columns at the north end of the core. This work is included in the WTC Towers A and B Structural Renovation Drawings Reference Manual. The Fiduciary Trust Structural Drawing 765-S-A-4 shows that WTC 2 core columns 508 and 1008 were reinforced with steel plates from floors 45 to 97 . The reinforcement consisted of plates welded to the flanges of the built-up box columns (floors 45 to 83 ) and the flanges of the rolled shape columns (floors 83 to 97). These reinforcing plate modifications and the reinforcing plates yield strength, $F_{Y}$, were added to the original Book 3 data contained in the WTC-DB. The database included plates that extended long enough such that they substantially affect the member properties of the column, e.g., the added plates increase the capacity of the columns. Where the plates appeared to reinforce only the column splice, they were not included in the database.

The reinforcing plate data were tabulated and incorporated into the database in the same manner as the plates discussed in the previous section, except that a second length designation was added to differentiate the length of the plates on the north and south faces of the columns, i.e., the column designation "LN" refers to the length of the plates on the north face of the column. Again, when calculating the built-up 
column properties, the plate was assumed to be continuous along the floor-to-floor height of the column. When the length of the reinforcing plate shown in the drawing was greater than the floor height, the plate was attributed to the two column segments. Where the plate extended over the entire height of the segment, the length was tabulated as the height of the column segment. The remaining length of plate was attributed to the other column segment.

\section{Repair Due to the Bombing of February 26, 1993}

The 1993 bombing resulted in structural damage to WTC 1, centered at exterior column 324 (south wall), B-2 level. The face of the column towards the explosion was slightly bowed, and the splice in the column developed a hairline crack. The column was reinforced locally to account for the loss of steel area. The bracing on either side was replaced with equivalent sections and attached in a similar manner as the originals. No modification to the WTC-DB has been made for this repair.

\section{Tenant Alteration for an Interoffice Stair}

A tenant alteration was provided for an interoffice stair between floors 25 and 26 in WTC 1 . This work, adjacent to core column 901A, was performed by an engineering firm (other than LERA) and unknowingly resulted in the loss of a core column bracing strap (refer to Fig. B-9), leaving the column unbraced about its minor axis for two stories. The PANYNJ alerted LERA to the issue and asked LERA to review. The situation was reviewed by LERA, and the column stability was found to be adequate. No modification to the WTC-DB has been made for this modification. The effect of removing the strap is accounted for in the global model of WTC 1, see Section B.3.1.

\section{Drawing Book Data Discrepancies}

In the original WTC drawing book data, the following discrepancies were discovered by LERA:

- Book 1 page 1-B-15. For member number G311A, the inch portion of the length is listed as $3-1 / 18$. Based on the comparison to similar bracing types in the area, this dimension was modified to be $3-1 / 8$ in. in the WTC-DB.

- Book 3 page 3-A1-10. For core column $601 \mathrm{~A}$ between floors 86 to 89 and 89 to 92 , the column type is listed as 213 . Type 213 is a column type which by definition has reinforcing plates, but for this location, no plate data was provided in the schedule. This, in combination with comparisons to similar columns in plan, led to modifying the column type to 111 . This also applies to column 601B, page 3-B1-10 between floors 86 to 89 and 89 to 92 . 

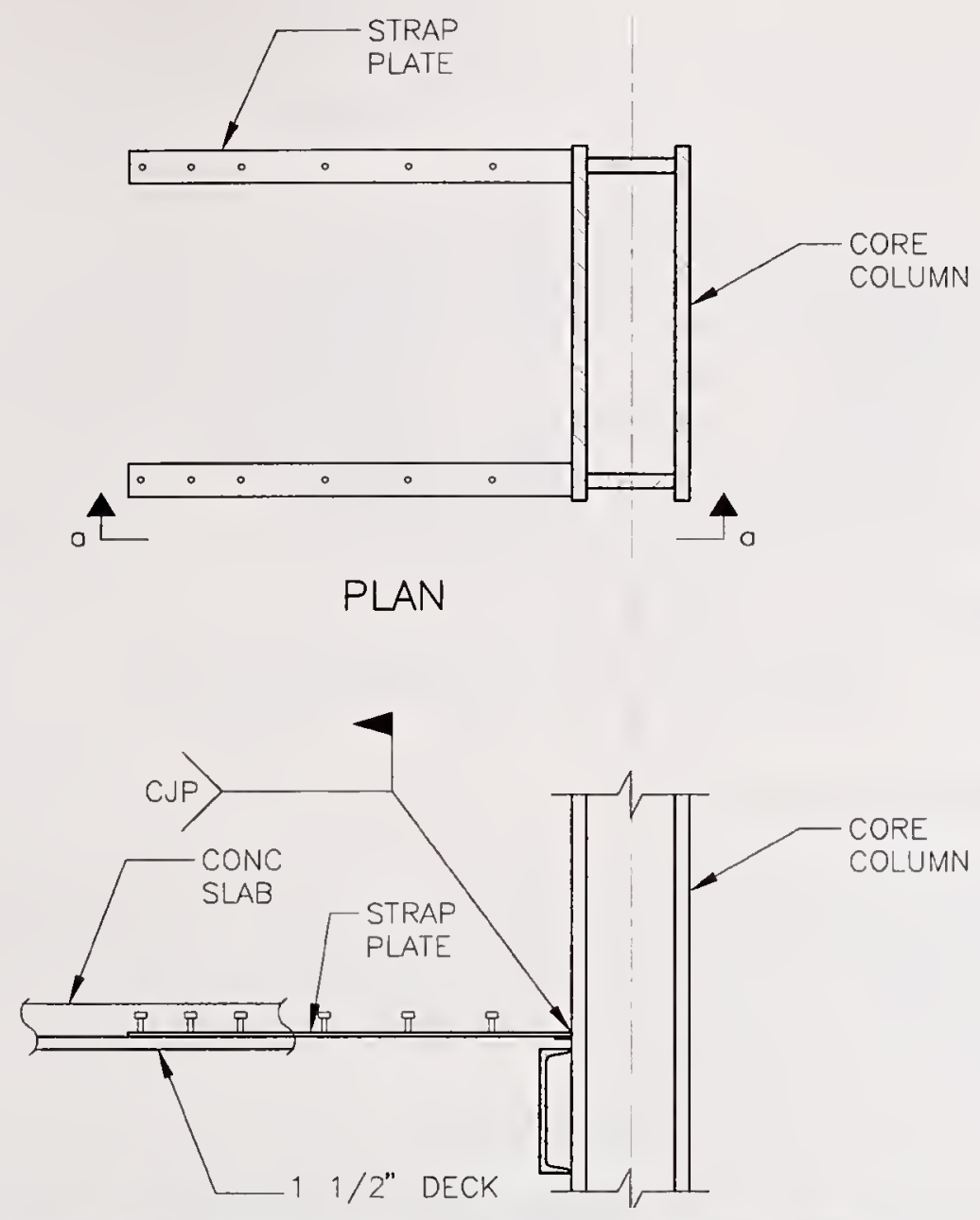

Figure B-9. Column section at original column strap detail (taken from drawing book 18, page 18-AB2-12).

- Book 3 page 3-B1-48. For column $1008 \mathrm{~B}$ between floors 63 to 66 , the yield strength, $F_{Y}$, is listed as $6 \mathrm{ksi}$ in the table. Based on the yield strength of the columns above and below these floors, the yield strength was modified to be $36 \mathrm{ksi}$. For the same column number and floor segments, the lower splice detail number is listed as " $01 \mathrm{G}$." Based on the lower splice detail number of the columns above and below these floors, the number was modified to be "301G."

- Book 3 page 3-B1-9. For core column 508B between floors 21 to 24 , the length of plate 1 , $W 1$, is tabulated as 11.25 in. However, length $B$ for this column is 22 in. and thickness $t 2$ is 5.5 in. $W 1$ equals $B$ minus two times $t 2$ (see Fig. B-10). Hence, assuming $t 2$ was listed correctly in the table, $W I$ was modified to be 11 in.

- Book 1 page 1-B-23 and 1-B2-19. The details for column types 1024, 1025, 5024, and 6025 listed in the tables are not explicitly shown in the drawing book. For these members, column shapes are assumed to be as shown in the typical details in page 1-B-19 for the 1000 series columns, $1-\mathrm{B}-24$ for the 5000 series column, and the $1-\mathrm{B}-27$ for the 6000 series column.

- Book 3 page 3-AB2-6. The column type 216 does not appear to be assigned to any member in the drawing book. 


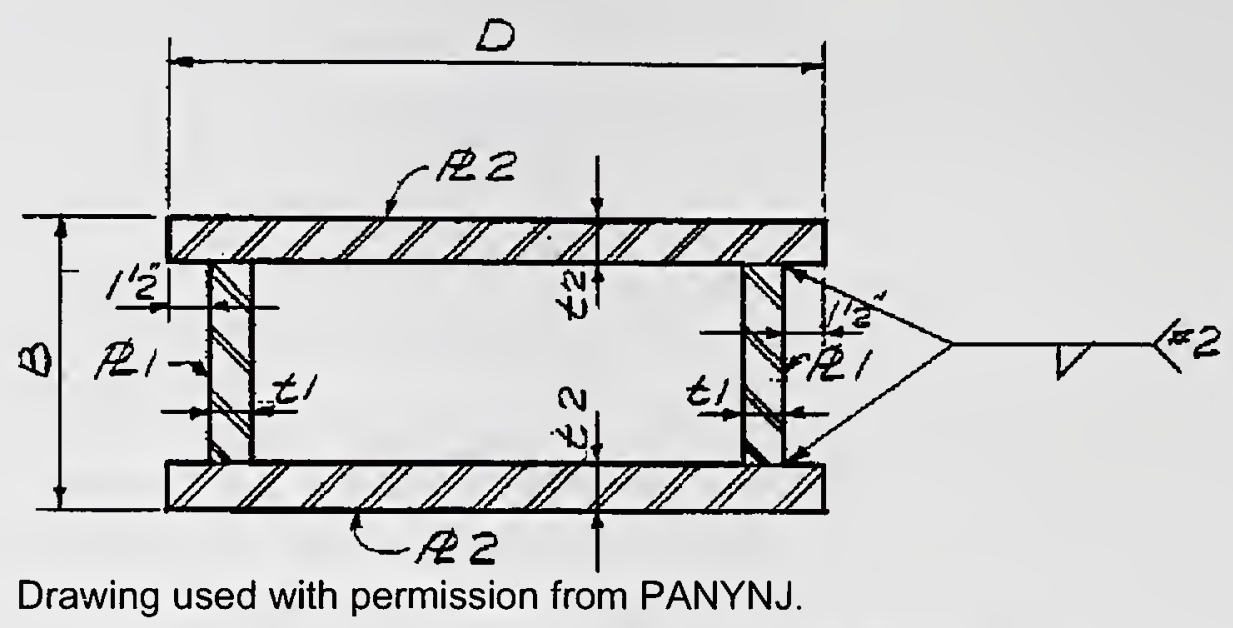

Figure B-10. Core column series $\mathbf{3 0 0}$.

\section{B.2.5 Section Property Calculations}

SAP2000 Section Designer was typically used to calculate section properties for built-up sections. The sections were "built-up" within SAP2000 by defining plate dimensions and offsets from 0-0 location. Section orientations were defined with the $\mathrm{X}-\mathrm{X}$ axis horizontal to the bottom of the original drawing book page as the detail is shown in the drawing book.

During the process of calculating properties there was an exception to this orientation rule. Core column members CC1007A104L, CC1002A104L, CC703A106L, CC1007B104L, CC1002B104L, and CC703B106L consist of a wide flange shape and web reinforcing plates. These members were input into SAP2000 rotated 90 degrees from the orientation shown in the details to utilize the default orientation of the wide flange section in Section Designer. Once the properties were calculated, the sections were placed in the WTC-DB following the orientation of the detail (i.e., the axis was shifted back 90 degrees).

When rolled shapes were used to create built-up sections, the rolled shapes database developed for this project was used to build the sections in SAP Section Designer as explained later in this section. The 200 series core columns (wide flange rolled columns reinforced with plates) are examples of members whose properties were calculated in this manner.

\section{Member Designations}

For member section property calculations and assembly of the finite element models, the members were named using the following general member designations. The member designations are listed in the Microsoft Excel files.

First character:

- $\quad$ Book 1-below tree-B

- Book 2-exterior wall tree-T

- Book 3 - core columns-C 
- Book 4-exterior columns and spandrels-E

Second character:

- C-column

- S-spandrel and below grade exterior wall spandrel, strut, or bracing

Third to fifth character: (third to sixth character for 4 digit column e.g., 1004)

- Column number

Sixth character:

- A-WTC 1

- $\quad \mathrm{B}-\mathrm{WTC} 2$

Seventh character and above:

- Upper splice level-for core columns

- U(upper), M(middle), or L(lower)—column segment where reinforcing plates are added

- $\mathrm{T}$ or B-top or bottom of nonprismatic columns

- Detail letter (lowercase) - (where more than one section is calculated)

- $\mathrm{F}$ or $\mathrm{C}$ - face or center of nonprismatic spandrel

- Elevation-below tree spandrel elevations

\section{Column Member Multiple Section Property Calculation}

In the database, the following three types of column members had different cross sections along the length of the members:

- Exterior wall tree at level C in Drawing Book 2 (two different cross sections)

- Exterior wall tree at level E in Drawing Book 2 (three different cross sections)

- Exterior column type 300 (floor 9 to 106) in Drawing Book 4 (two different cross sections)

For these three member types, the section properties of the different cross sections were calculated and listed in the database tables. In an effort to minimize repeated information, the raw input data for all sections were only shown in the rows that correspond to the first cross section. For the second and third (if any) cross sections, the calculated data followed in the rows below. The constant raw data such as the column number were not repeated in these rows of the table, and thus the corresponding cells were left blank. Since the column number was used as a link for the development of the relational database, only 
the row containing the raw input data and the first cross section properties was returned in a query, and thus, the user must refer back to the Microsoft Access 'Tables' for the remaining section property information. The section names of the different cross sections along the member length were distinguished by the last one to two characters, which identified the cross sections where the section properties were calculated.

For example, exterior column EC339 (mechanical floors) tapers over a portion of the length of the member (refer to Fig. B-11). The section properties above and below the spandrel were calculated. The column section above the spandrel was called EC339, while the column section below the spandrel was called EC339cc. The suffix 'cc' denoted the section below the spandrel. Note that the raw dimensional data for EC339cc were not shown in the table, as the information was the same as for EC339.

\section{Spandrel Member Multiple Section Property Calculation}

In the database, the exterior columns below elevation $363 \mathrm{ft}$ in column series 5000,6000, and 7000 in Drawing Book 1 had corresponding spandrels shown in the details in Book 1. There were two types of spandrels for these members, tapered built-up box shapes and built-up I shapes. For the tapered built-up box shapes, the section properties of the different cross sections were calculated and listed in the database tables. The data were listed in the database files as described for columns with multiple cross sections. The section names of the different spandrel cross sections along the member length were distinguished by the last three to four characters, which identified the cross sections where the section properties were calculated.

For these exterior columns, there are spandrels at two elevations, $332 \mathrm{ft}$ and $350 \mathrm{ft}$. At elevation $350 \mathrm{ft}$, the spandrels tapered, and as a result two cross section properties were calculated. The first section was at the face of the exterior column, and the corresponding section name had a Suffix F (face). The second section was at the center of the spandrel in between two exterior columns, and the corresponding section name had a Suffix C (center). The elevations and locations of the cross sections of the spandrels were shown in the figures in the "Cross Section" worksheets in the database Excel files.

For example, four different section properties were calculated for exterior column 6009 in WTC 1 . The first section was the exterior column itself, and the section name was BC6009A. The other three sections, BS6009AB332, BS6009AT350C, and BS6009AT350F were for the spandrel sections. The suffix B332 in BS6009AB332 denoted the bottom spandrel at elevation $332 \mathrm{ft}$. Suffixes T350C and T350F in BS6009AT350C and BS6009AT350F, respectively denoted the top spandrel at elevation $350 \mathrm{ft}$, and the "C" or "F" identified the locations where the section properties were calculated, see Fig. B-12.

\section{Section Property Calculation Comparisons}

For all the members whose section properties were included in the GFI database, the cross sectional properties in the GFI data were compared with the data contained within the WTC-DB. Most section property results compared with good accuracy between GFI and the WTC-DB (within 1 percent). It was found that results from the calculations of the torsional constant, $J$, however, did vary. LERA in-house 


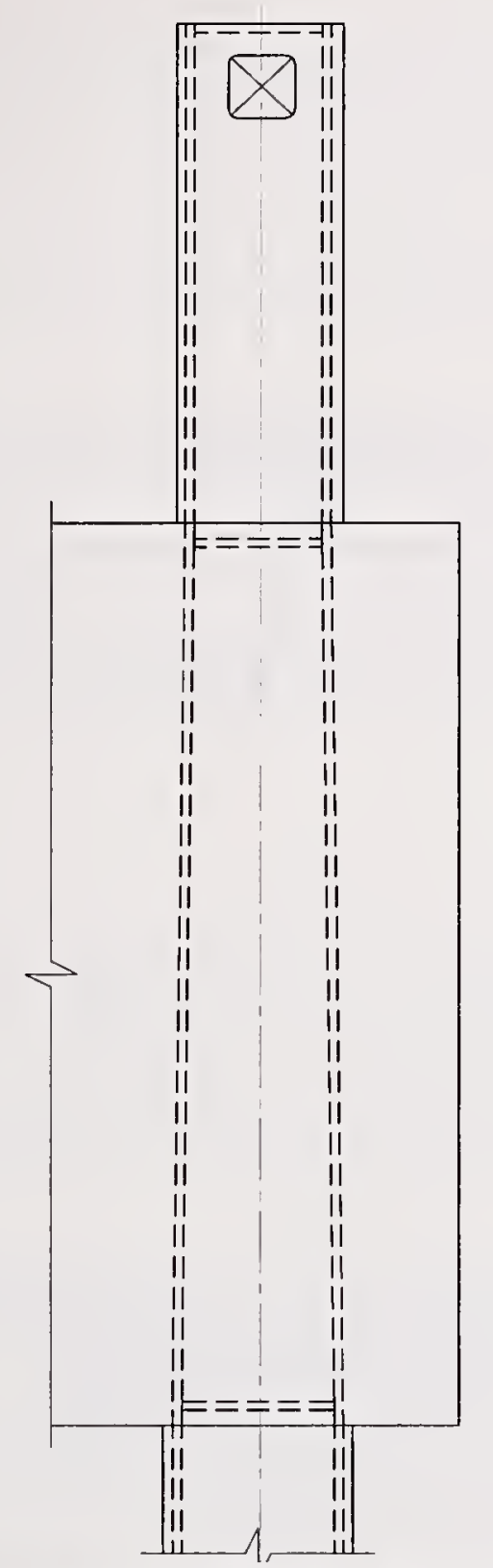

Figure B-11. Exterior column type 300, floor 9 to floor 106 (taken from
drawing book 4, page 4-AB2-18).

programs were then used to confirm the accuracy of the $J$ calculation. For core columns in WTC 1, SAP2000 generated values used in the WTC-DB were on average 8 percent larger than $J$ values calculated using a LERA in-house program, while the results provided by the GFI database were on average 13 percent greater than LERA in-house program $J$ calculations.

It was found that for box sections, $J$ values calculated by the above equation matched the $J$ values given by SAP Tube Section. However, for the same tube section, the $J$ values given by SAP Section Designer were greater than $J$ given by SAP Tube Section, even while all other properties were equivalent. According to Computers and Structures, Inc., the developer of SAP2000; the $J$ values given by SAP Section Designer are more accurate as SAP Section Designer uses a finite element method to calculate the $J$ values while an approximate equation is used in SAP Tube Section. 


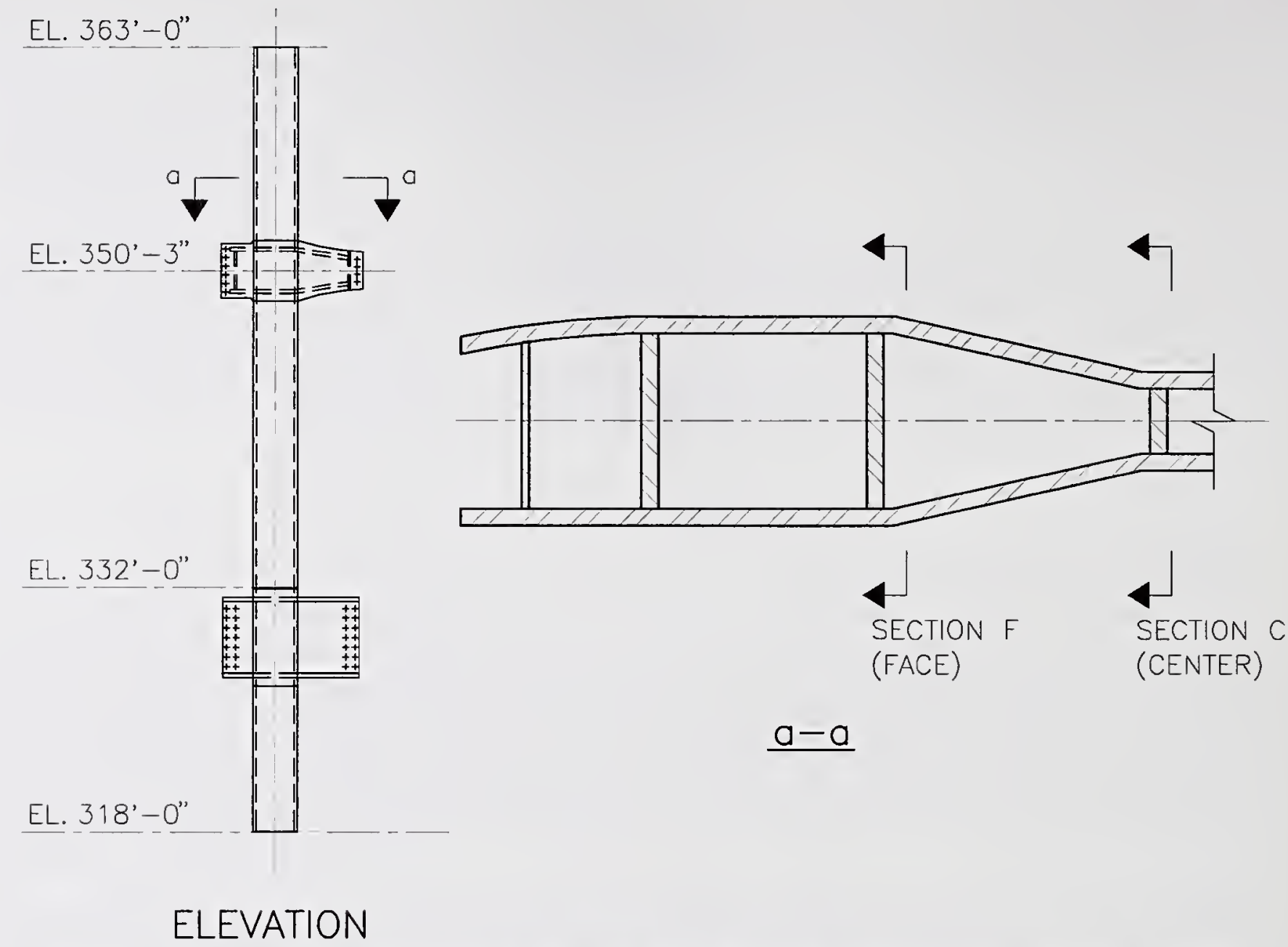

Figure B-12. Column type 6000 with tapered spandrel (taken from drawing book 1 , pages 1-A2-27 and 28).

The approximate equation used to calculate $J$ values by the LERA in-house program for a built-up column or box section as shown in Fig. B-13 is as follows:

$$
J=\frac{2(b h)^{2}}{\frac{b}{t_{f}}+\frac{h}{t_{w}}}
$$

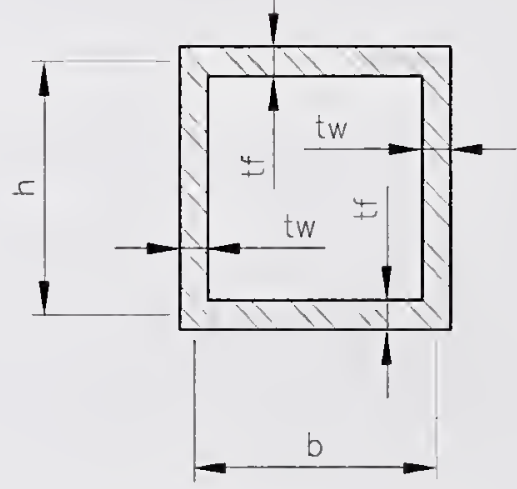

(a)

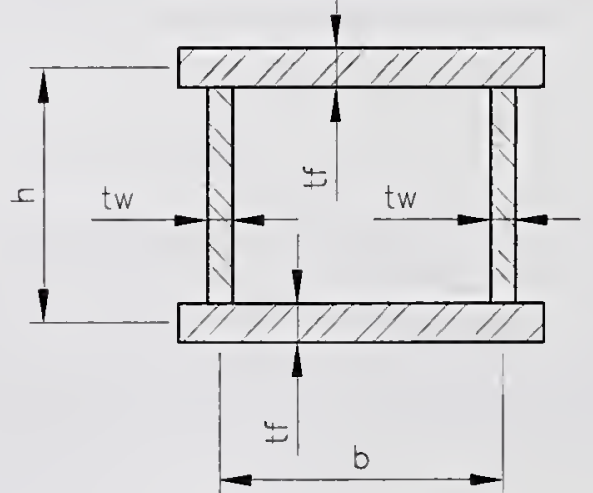

(b)

Figure B-13. Box section and a built-up column. 
In order to minimize the complexity of the model, where the member cross-section was of the type illustrated in Fig. B-13 (a), box column members were defined in SAP Tube Section. The remaining built-up box columns (similar to Fig. B-13 b) were defined in SAP Section Designer.

For members whose properties are not given in the GFI database, hand calculations or calculations by LERA in-house program were carried out to verify the results from SAP2000 Section Designer for at least one section for each member type.

In summary, it was found that SAP2000 Section Designer provided section properties in close agreement to LERA calculated properties. In most cases these properties also closely matched with the properties listed in the GFI database. In the cases where SAP2000 results disagreed with the GFI database, the results were reviewed and it was concluded that the SAP2000 calculation provided the correct properties. Therefore the section property results calculated using SAP2000 were used in the WTC-DB and the development of the finite element models of the towers.

\section{Rolled Shape Database}

While the majority of the primary members of the WTC towers' super-structure were built-up members, rolled shapes were also used. The rolled shapes specified in the drawings in a number of cases are no longer produced and therefore, are not included in the rolled shape database embedded within SAP2000. Therefore, a rolled shape database was developed using the old nomenclature and section properties. The result was a file named 'Shape Property Table.xls' and it contains three worksheets, 'Database', 'Excel Format', and 'WF Shape Properties from SAP'. The following is a discussion of their contents.

Data contained in 'Database' and 'Excel Format'-Drawing Books 3, 4, and 5 include reference to specific rolled shapes. The referenced shape names were extracted from the above books and assembled into a single reference database for rolled shapes. Most of the section properties were obtained from the Manual of Steel Construction, American Institute of Steel Construction (AISC), Sixth Edition, 1963 (AISC 6th Edition) with few exceptions where cross sections were not included in this edition. Examples of these exceptions include the following:

- Section properties of 14WF455 to 14WF730 were obtained from the Manual of Steel Construction-Load and Resistance Factor Design, American Institute of Steel Construction, Third Edition, 2001 (AISC-LRFD 3rd Edition).

- Section properties of $6 \mathrm{CH} 12,6 \mathrm{CH} 15.1,12 \mathrm{CH} 40,12 \mathrm{CH} 45$, and $12 \mathrm{CH} 50$ were obtained from the MC-shapes table in the AISC-LRFD 3rd Edition.

- Section properties of 18WF69 were obtained from the Iron and Steel Beams 1873 to 1952, the American Institute of Steel Construction, 1968. 16WF342 was assumed to have the same section properties of $16 \mathrm{H} 342$ tabulated in Iron and Steel Beams 1873 to 1952, the American Institute of Steel Construction, 1968.

- For $7 \times 5$ tube, $Z_{x}, Z_{y}$, and $J$ were obtained from the AISC-Allowable Stress Design (ASD), 1989, 9th Edition. 
- For $2 \mathrm{~L} 31 / 2 \times 3 \times 1 / 2$ in. long leg back to back, the combined properties were taken from SAP's embedded rolled shape database.

Data contained in 'WF Shape Properties from SAP'-For the rolled wide flange shapes, an additional database was created in SAP2000 based on the tabulated shape dimensions from the AISC Manuals as discussed above. Computers and Structures, Inc. provided an MS Excel file named 'Proper.xls' with a macro that allowed the accurate calculation of the section properties for use within SAP2000. This information was then used by SAP2000 Section Designer to calculate section properties for built-up members comprised of wide flange sections and added plates.

For calculation of the properties with 'Proper.xls', dimensions of the webs and flanges, as well as the size of the fillet, were input into the spreadsheet. The macro then calculated the section properties based on the input information. The results were shown to be in good agreement with the original tabulated properties.

\section{B.3 DEVELOPMENT OF REFERENCE STRUCTURAL ANALYSIS MODELS FOR THE TOWERS}

This section outlines the development of the reference structural analysis models for each of the two towers. Included in this section are descriptions of the structural models, modeling techniques, parametric studies utilized in the development of the models, and a description of the methodology used in exporting data from the relational database presented in Section B.2 into the global models.

The main types of the models developed are as follows:

- Two global models of the major structural components and systems for the towers, one each for WTC 1 and WTC 2; and

- One model each of the typical truss-framed floor and typical beam-framed floor (mechanical level) within the impact and fire regions.

The models are all linear elastic, three dimensional structural analysis models developed using Computers and Structure, Inc.'s SAP2000 Software, Version 8. The models will be used to establish the baseline performance of each of the two towers under gravity and wind loads in the third phase of this project. In addition, these models serve as a reference for significantly more detailed models to be developed independently in other parts of the NIST investigation for the aircraft impact analysis (Project 2) and thermal-structural response and collapse initiation analyses (Project 6).

\section{B.3.1 Global Models of the Towers}

Three-dimensional structural analysis computer models of the 110-story above grade structure and 6-story below grade structure for each of the two towers were developed. The global models for the towers consist of the major structural components and systems required to establish the baseline performance of the towers under gravity and wind loads.

In establishing the modeling techniques for the global models, parametric studies were performed to evaluate the behavior of typical portions of the structure (Section B.3.4). In addition, once the models 
were completed, order-of-magnitude checks were performed for gravity load, wind load, and eigenvalue results to check the accuracy of the models. More refined checks will be done in the third phase of this project on baseline performance analysis.

\section{Components and Systems in the Towers Global Models}

The models included all primary structural elements in the towers including exterior columns, interior (core) columns, exterior wall bracing in the basement floors, core bracing at the mechanical floors, core bracing at the main lobby atrium levels, spandrel beams, hat trusses, and rigid and flexible diaphragms representing the floor systems as developed in Section B.3.4 of this report.

\section{Coordinate System, Nomenclature, and Models Assembly Overview}

The extent of the data required to assemble the tower models dictated that the relational database capability of the WTC-DB be used (see Section B.2.3). The methodology for the development of the models using the relational database is described in this section.

Coordinate System - The coordinate system for the model geometry was based on the column layout from the original drawings. Figure $\mathrm{B}-14$ shows the location of the $\mathrm{X}$ and $\mathrm{Y}$ axes for the global models and the floor models. The $\mathrm{Z}$ coordinates were based on actual elevations of the towers. The original column numbers were used throughout the models for member identification.

Nomenclature-A standard nomenclature for joints, frame names, and section names for use in the models was established. The nomenclature enables the user to know quickly where in the building a section is located by viewing any given piece of the model. Joint names generally included the column number, tower letter, and floor level. Frame element names generally included the joint name at the ' $j$ ' end (second node). Section names were based on the section as described in the drawing book and were repeated for each steel yield strength assigned for that section. Alternatively, where the section was unique to a particular member in the building, sections were named based on the frame member.

As an example, most nodes (or joints) in the tower models were named according to the following format:

- Column number

- Tower letter (A for WTC 1 and B for WTC 2)

- Floor level

- S for column splice nodes only

- $\quad \mathbf{J}$ for spandrel splice nodes only 


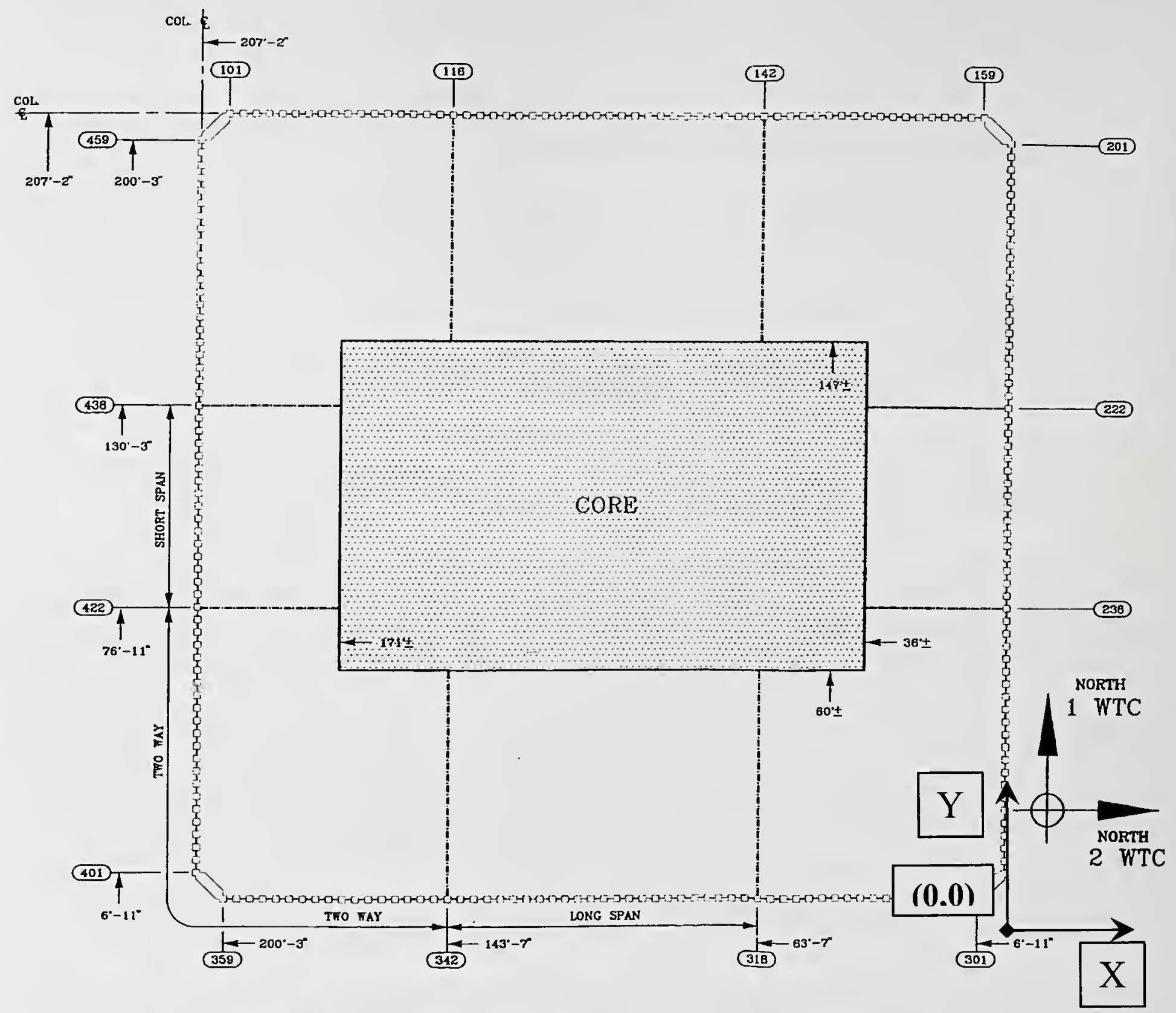

Original drawing used with permission from PANYNJ.

Figure B-14. Global model coordinate axis location.

Figure B-15 illustrates the detailed frame and joint nomenclature for a typical exterior wall panel.

Model Assembly Overview-An overview of the assembly of the data into the tower model is described herein along with an expanded section on the programmatic assembly of the models.

Following a basic study of modeling techniques and testing of SAP2000, Version 8 input format and capabilities, it was determined that the best approach was to divide the model into six main parts and thenassemble them into a unified model. Manipulation of these individual parts was more efficient than attempting to build the whole model simultaneously. 


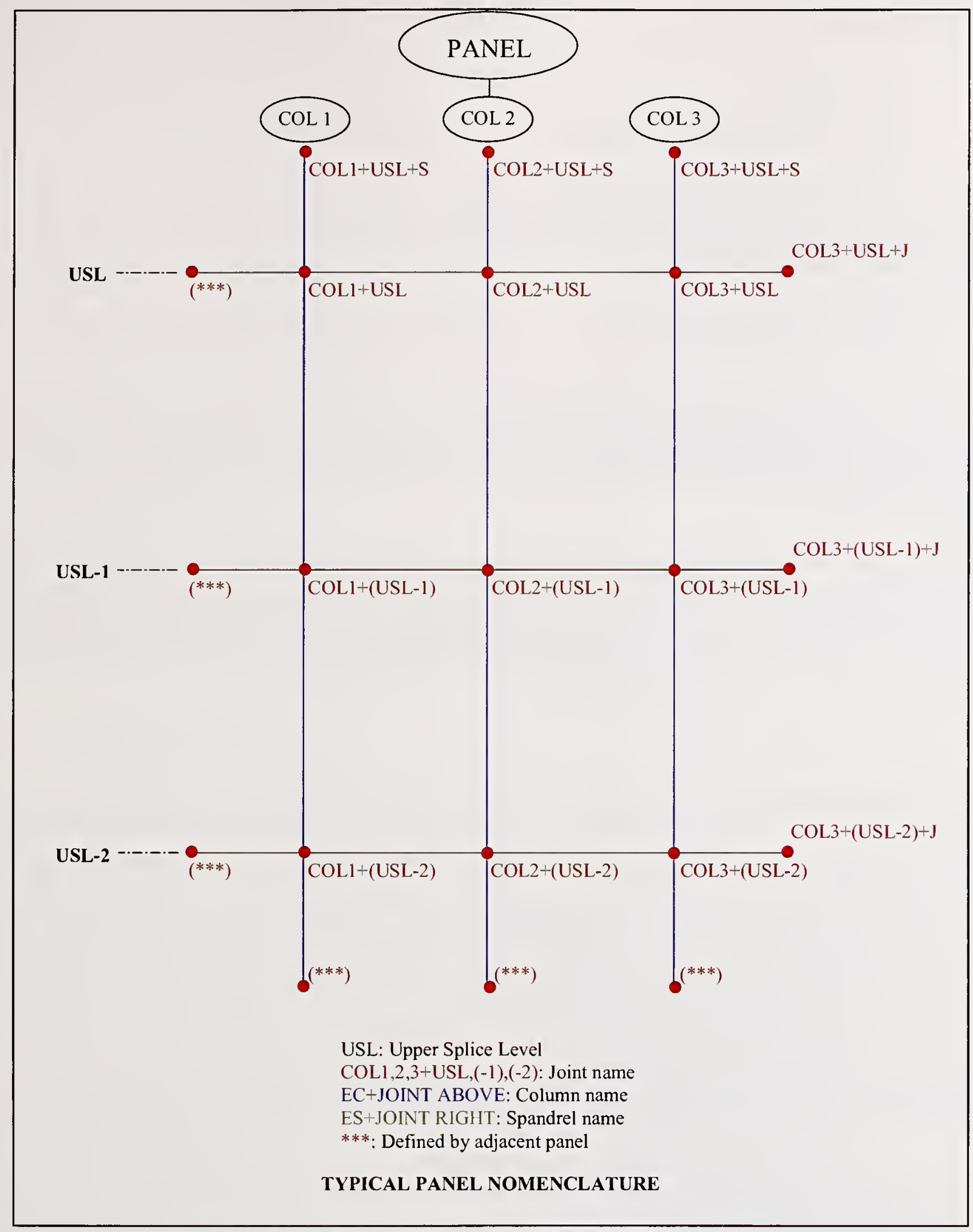

Figure B-15. Typical exterior panel nomenclature. 
The six initial models were:

- Core columns

- Exterior wall, foundation to floor 7

- Exterior wall trees (floors 7 to 9)

- Exterior wall, floors 9 to 106

- Exterior wall, floors 107 to 110

- Hat truss

For the core columns and exterior wall at floors 9 to 106; most of the analysis input files were generated from queries of the WTC-DB. The other four parts of the model were assembled primarily in a more conventional manner.

Core columns and exterior wall panels (floors 9 to 106) were the greatest data-intensive challenges in the model development. Both areas included a large number of frame members and section and material property variations. The query files were used to gather the necessary data, and then simple computer programming was used to convert the data into the SAP input file format. Four main input tables for the SAP input file were developed programmatically:

- Joint coordinates table

- Connectivity-frame/cable table

- Frame section properties tables

- Frame section properties 1 - general

- Frame section properties 5-nonprismatic

- Section designer properties 04-shape I/wide flange

- Section designer properties 05—shape channel

- Section designer properties 11 -shape plate

- Frame assignments table

The remaining data is added directly in the SAP model:

- Material properties

- Frame local axis

- Joint restraint 
- Insertion point

- Constraint

- Gravity and wind load assignments

After the joint coordinates, connectivity, frame section properties, and frame assignments were complete for the six parts, the individual models were combined into a unified model. Rigid diaphragms, flexible diaphragms, core bracings, gravity loads, wind loads, and masses were then added to the unified model. After assembly of the model, the assignment of properties for selected model elements was spot-checked and the model was executed to verify its performance.

The development of the WTC 1 and WTC 2 models has been separate and consecutive endeavors. The lessons learned in the assembly of the WTC 1 model were applied to the development of the WTC 2 model. While there were only minor differences in the basic structural systems of the two towers, there were significant differences in section properties, material properties, and additional column transfers at the lower levels in WTC 2.

Isometric views of the complete WTC 1 model are illustrated in Fig. B-16. Elevations of the complete WTC 2 model are illustrated in Fig. B-17. A summary of the size of the global models of WTC 1 and WTC 2 is presented in Table B-2. The following presents the details of each of the six parts used in the development of the unified global models for WTC 1 and WTC 2.

\section{Core Columns Modeling}

Core column coordinates were tabulated based on the structural drawings. Column locations were typically referenced at their centerlines. Columns on lines 500 and 1000, however, were located in plan drawings along most of their height according to the face of the column to which the floor trusses frame (i.e., WTC 1 north face for 500 columns and south face for 1000 columns). The centerline of these columns was based on their dimensions given in the drawing books. Where these column centerlines varied along the height of the towers (typically $11 / 2 \mathrm{in}$. between three-story pieces), a representative location was chosen to define the column node. Thus, the column coordinate at floor 106 was used as a constant along the tower height because at this level, these columns align with the hat truss above.

The spandrel centerline elevation was selected as the representative floor elevation for exterior columns and used also for core columns. If there were no spandrels in exterior panels, reference elevations were used for the core columns.

There were over 5000 nodes in the core column model. This amount of data required that the Interactive Database input table be set up using a macro. These data were converted to text file format and later imported into SAP. Built-up sections were defined as Section Designer sections, and wide flange shapes were defined directly from "SectionWF1.pro" file (see Section B.2.5). All section names were identical to those in the database. Around 1280 Section Designer sections were defined in this model and imported through Interactive Database function of SAP2000 to the model. 

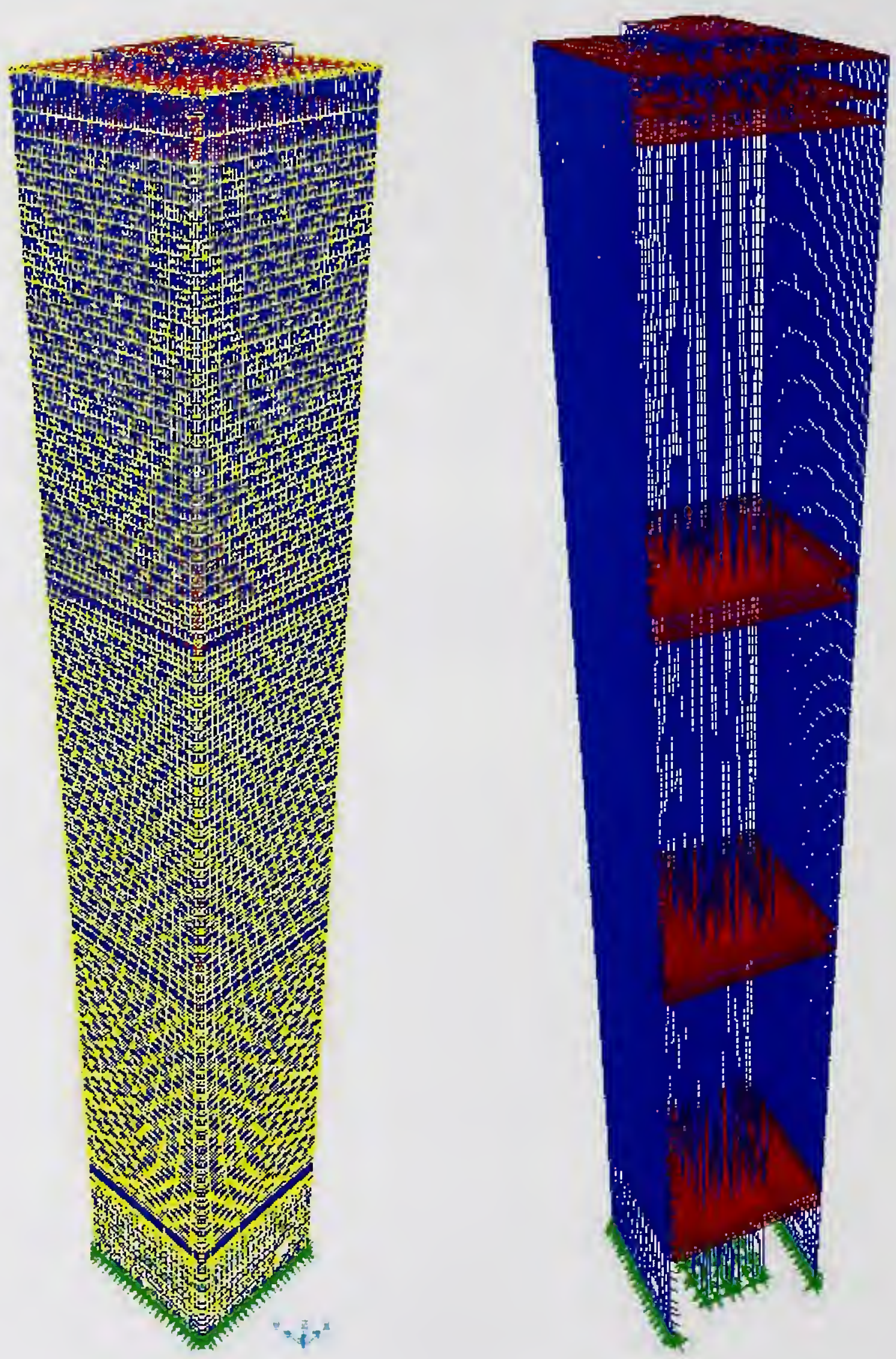

Figure B-16. Rendered isometric views of the WTC 1 model. 

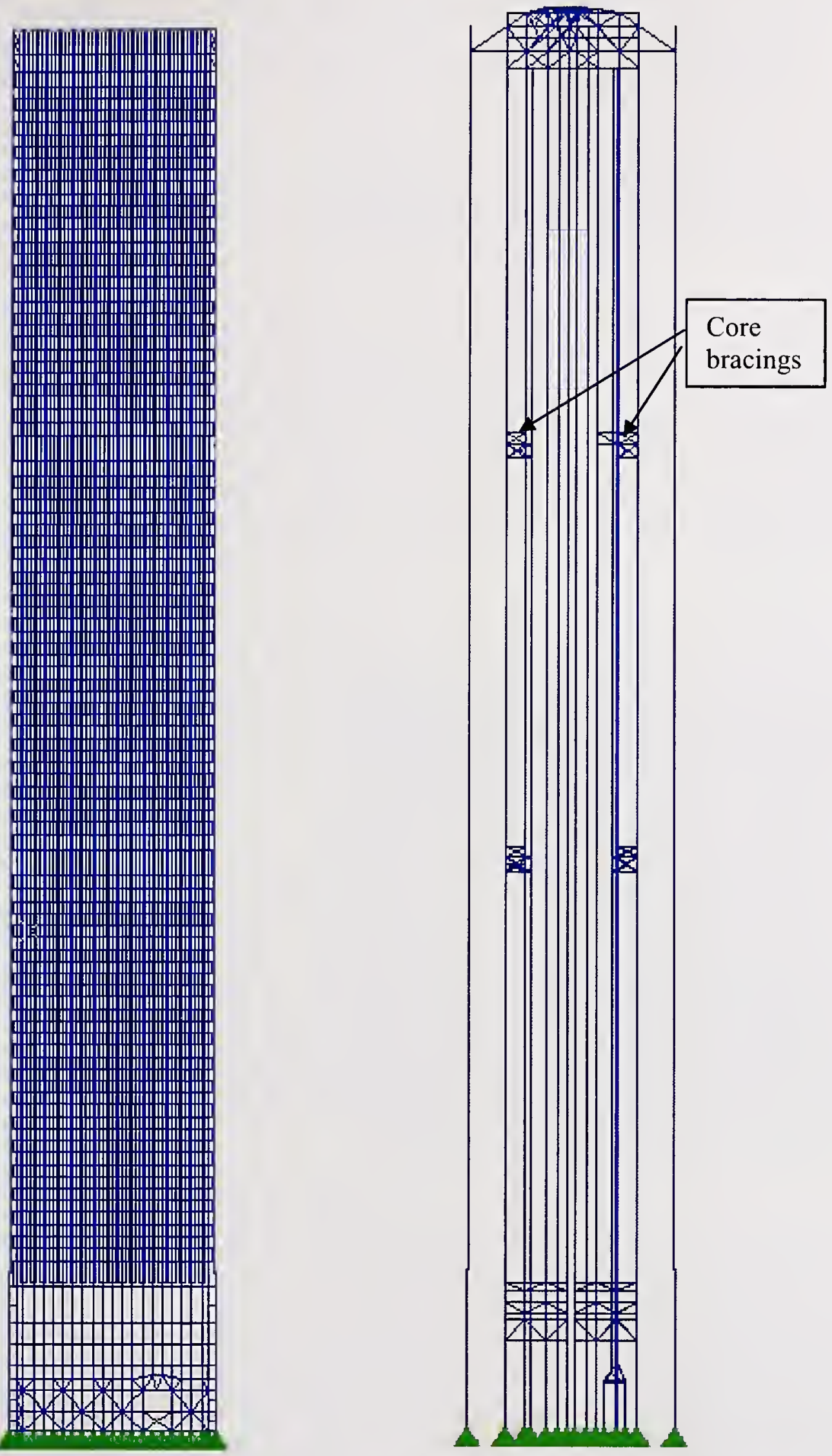

Figure B-17. Frame view of the WTC 2 model: exterior wall elevation and interior section illustrating the core columns, core bracing, and hat truss. 
Table B-2. Approximate size of the reference structural models (rounded).

\begin{tabular}{|l|c|c|c|c|c|}
\hline \multicolumn{1}{|c|}{ Model } & $\begin{array}{c}\text { Number of } \\
\text { Joints }\end{array}$ & $\begin{array}{c}\text { Degrees of } \\
\text { Freedom }\end{array}$ & $\begin{array}{c}\text { Number of } \\
\text { Frame Elements }\end{array}$ & $\begin{array}{c}\text { Number of } \\
\text { Shell Elements }\end{array}$ & $\begin{array}{c}\text { Total Number } \\
\text { of Elements }\end{array}$ \\
\hline${\text { WTC 1 } \text { global model }^{\mathrm{a}}}$ & 53,700 & 218,700 & 73,900 & 10,000 & 83,900 \\
\hline WTC 2 global model $^{\mathrm{a}}$ & 51,200 & 200,000 & 73,700 & 4,800 & 78,500 \\
\hline Typical truss-framed model & 28,100 & 166,000 & 27,700 & 14,800 & 42,500 \\
\hline Typical beam-framed model & 6,500 & 35,700 & 7,500 & 4,600 & 12,100 \\
\hline
\end{tabular}

a. Model does not include floors except for flexible diaphragms at 17 floors as explained later.

The core columns were defined as frame members spanning from node to node at the representative floor elevations. Splices in core columns occurred typically $3 \mathrm{ft}$ above the floor level. In the models, however, the splice was considered to occur at the floor level, and nodes were only defined at these levels (i.e., typically at spandrel centerlines). Most three-story column pieces are unique, as tabulated in WTC-DB (Drawing Book 3). A section for each three-story piece was defined and then assigned to each of the three frame members that make up that column. Using the SAP shading feature to graphically show the section on the model, each frame was rotated to its proper orientation based on the structural drawings.

In the as-designed drawings, there were strap anchors connecting the core columns to the concrete floor slab to provide lateral bracing for the column. At floor 26 of WTC 1 the straps at column 901 were removed during a renovation project that was engineered by a firm other than LERA (see Section B.2.4). The loss of the straps at this location has been included in the model by releasing the column from the diaphragm in the direction of the straps.

\section{Exterior Wall, Foundation to Floor 7 Modeling}

The models of the exterior wall up to elevation $363 \mathrm{ft}$ were developed manually, assigning joints and members connectivity as shown in the drawings. The elevation drawings show that below elevation $363 \mathrm{ft}$, columns were typically spaced at $10 \mathrm{ft}$ and braced with spandrels and diagonals. Joints were defined at all locations where diagonals braced the columns. However, when coordinates were not given in the drawings, joint coordinates were determined based on the geometry of the diagonal. Details in WTC Drawing Book 1 show that the column-diagonal intersections had continuity. Joints at elevation $253 \mathrm{ft}$ (level B-5) were defined only where the diagonals connect to the columns, since the tower floor did not frame into the exterior spandrels at that floor.

Where noted in elevation drawings, spandrel centerline elevations were used to define joint coordinates. Additionally, joints were defined at the spandrel splice midway between two columns at elevation $350 \mathrm{ft}$ 3 in. (floor 3 ) and at elevation $329 \mathrm{ft} 3$ in. (floor 2) to allow for section type transitions.

The majority of the elements at these levels were defined as Section Designer sections, except for box shapes which were defined as "Box/Tube". Channel shapes were defined directly from "SectionWF1.pro" file (see Section B.2.5). All section names were identical to those in the database. Around 200 sections were defined in this model using the Interactive Database function of SAP2000, which was used to import data into SAP2000.

Typical columns were connected from bottom to top and typical spandrels were connected from left to right. Frame names followed the nomenclature description presented earlier. The SAP2000 program 
allows assignment of rigid zone factors to frame end offsets to account for the overlap of cross sections. At the intersection of columns and spandrels, 100 percent rigidity for the column and the spandrels were assigned due to the large size of both columns and spandrels. Using the SAP shading feature to graphically show the section on the model, each frame was rotated to its proper orientation based on the structural drawings.

Refer to Fig. B-18 for a frame view and rendered view of the exterior wall (foundation to floor 9) of the WTC 1 model. The figure also shows the core columns and core bracings.

\section{Exterior Wall Trees (Floor 7 to 9) Modeling}

The panels of the exterior wall between elevation $363 \mathrm{ft}$ and elevation $418 \mathrm{ft} 11$ 1/2 in. are called exterior wall trees. At the exterior wall trees, the typical exterior wall columns transitioned from a spacing of $10 \mathrm{ft}$ to a spacing of $3 \mathrm{ft} 4 \mathrm{in}$. A typical exterior wall tree panel is shown in Fig. B-19. Each panel was divided into five different levels; level B, C, D, E, and F. For each panel in the model, the three exterior columns from above elevation $418 \mathrm{ft} 111 / 2$ in. continued down to level $\mathrm{D}$. At that level, the three columns were connected by a horizontal rigid element to become one member, which extended down to elevation $363 \mathrm{ft}$.
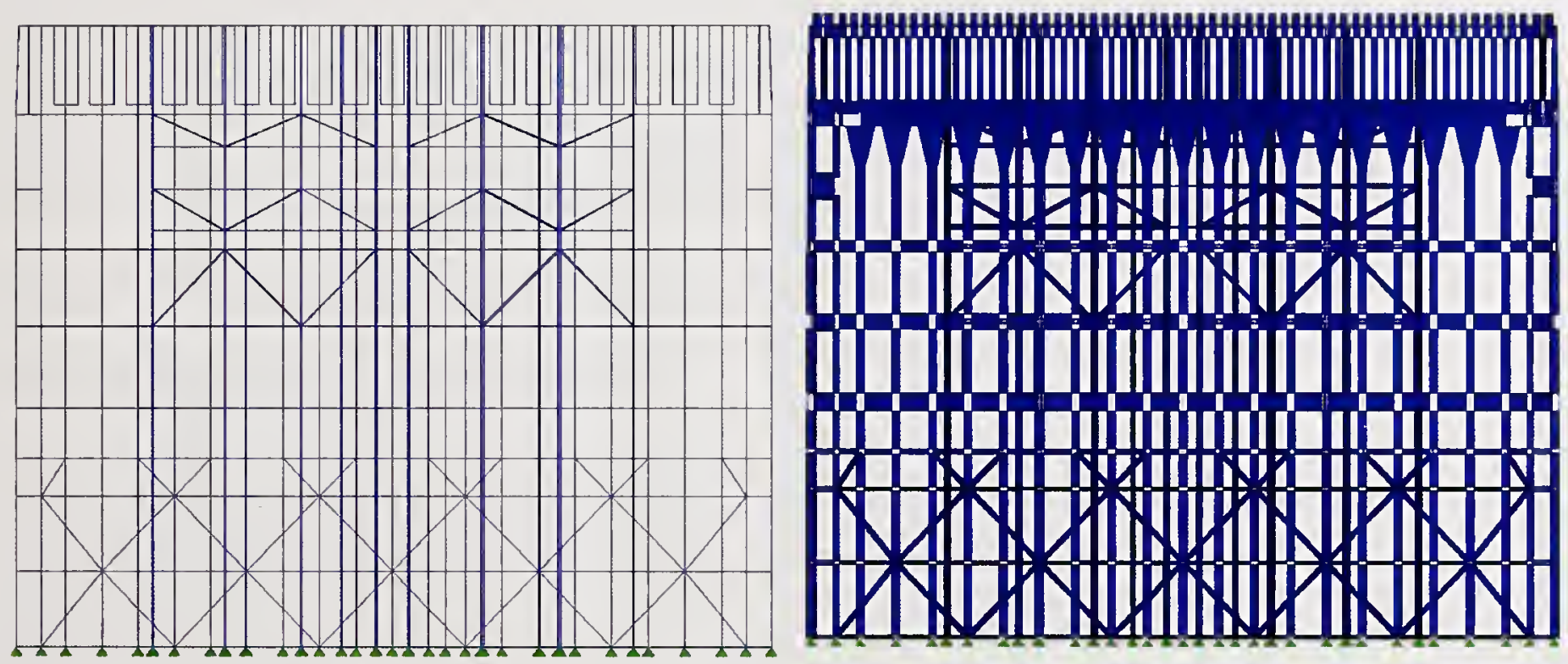

Figure B-18. Frame view and rendered view of the WTC 1 model (foundation to floor 9).

In the model, the tree was also the location where the column insertion point transitioned from the inside face (at the spandrel) of the upper column to the centerline of the lower column. Between levels B and D (see Fig. B-19), the location of the spandrel transitioned from $61 / 2$ in. offset from the exterior column reference line to the center of this reference line. Within the floor 9 spandrel, the exterior columns taper; however, in the model, the tapering of the columns was not included because frame end length offsets were assigned to the columns to account for the rigidity of the spandrels.

Through the height of level C, the box-shaped columns tapered (Fig. B-19). In the model, non-prismatic members were used to model the tapering columns. The columns start to taper at the bottom of the 
spandrel at level B, and cease to taper at the top of the spandrel at level D. The dimensions of the columns at the spandrel edges were defined in the drawing book. In the model, the column extended from the centerline of the spandrel at level B to $1 \mathrm{ft}$ below the top of the spandrel at level D (see discussion for level $\mathrm{D}$ below). Therefore in order to obtain the correct section properties along the length, the dimensions of the section at the joints were interpolated based on the dimensions of the section at the spandrel edges shown in the drawing book. The section properties of the tapering column were assumed to vary linearly between the two sections. Frame end length offsets were assigned to the columns to account for the rigidity of the spandrel at level B and the one foot dimension at level D.

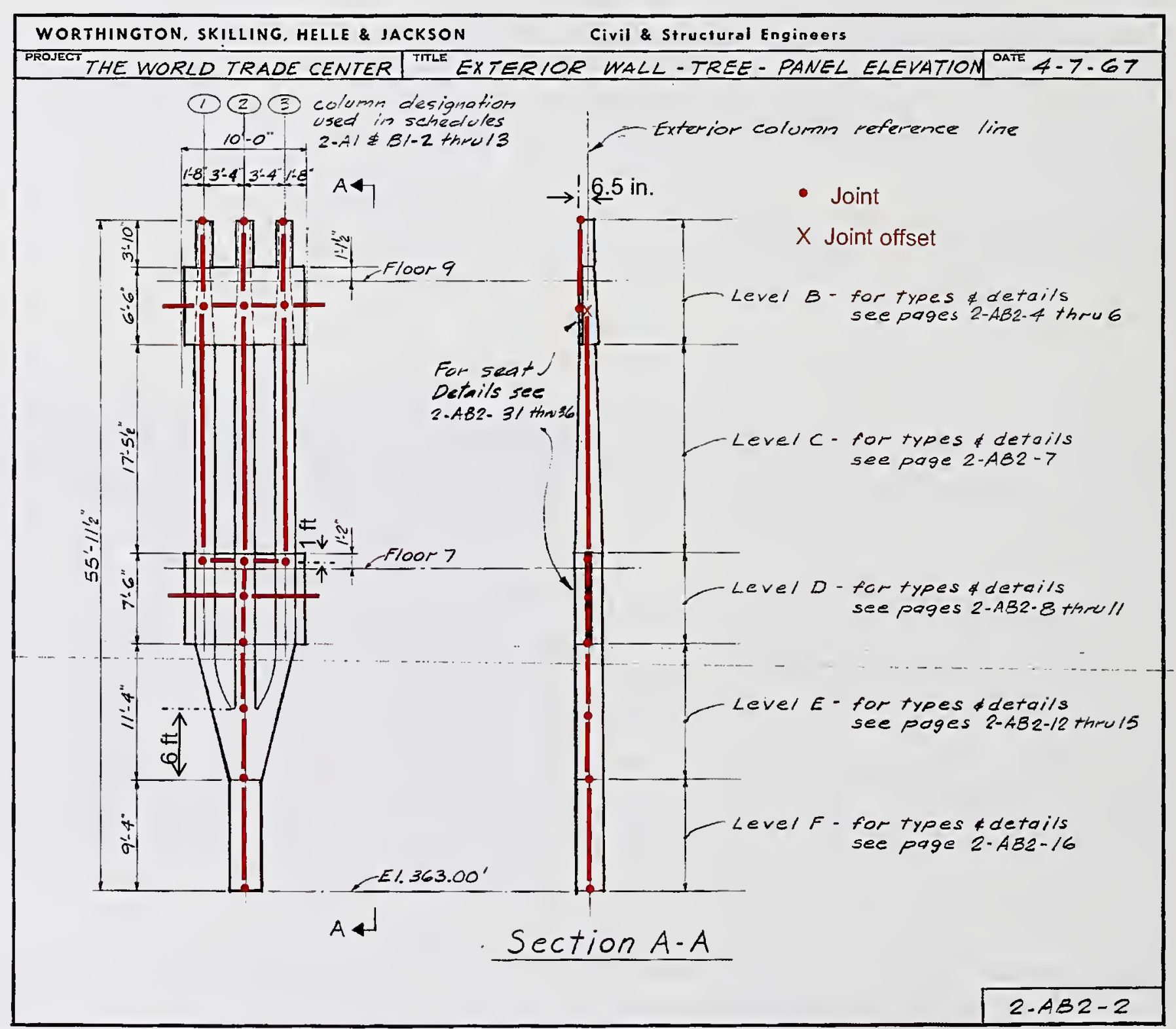

Original drawing used with permission from PANYNJ.

Figure B-19. Exterior wall tree panel (taken from Drawing Book 2, page 2-AB2-2).

At level D, two transitions occurred in the model. The first transition was for the exterior columns, where the three columns coming down from level $\mathrm{C}$ were connected by a horizontal rigid element to become one member at the bottom of the tree. This frame member consisted of the three exterior columns and the spandrel plate. Another horizontal member of the same section properties with the spandrel plate was also defined and connected between the neighboring exterior wall trees. This member connected the 
neighboring exterior wall trees and provided lateral bracing for the columns. Frame end length offsets were assigned to the spandrel to account for the overlap of the spandrel plate with the frame member, which also included the spandrel plate. The transition of the three members into one member was assumed to occur at one foot below the top of the spandrel at level D to account for the fact that the spandrel becomes engaged with the exterior columns after being connected to the exterior columns for a certain distance. Hence, the joints were defined at one foot below the top of the spandrel at level D.

There was a second transition at level D (Fig. B-19). The nodes for the exterior wall columns were typically defined at $61 / 2$ in. offset from the exterior column reference line. But for the joints at and below level $\mathrm{D}$ in the exterior wall tree, the joint coordinates were defined along the exterior column reference line. As a result, for the column member that framed between the nodes at levels B and D, a joint offset of $61 / 2 \mathrm{in}$. was assigned at the top of the member, while no offset was assigned at the bottom. The column therefore remained a vertically straight element while being connected to nodes that were not aligned vertically.

At level E, the exterior columns tapered and had two different types of cross section (Fig. B-20). For each panel, the exterior column transitioned from Section b-b in Fig. B-20 into a box-shaped column (Section $\mathrm{c}-\mathrm{c}$ in Fig. B-20). The location of the transition between the different types of cross section varied for different column types from $5 \mathrm{ft} 8 \mathrm{in}$. to $6 \mathrm{ft} 4$ in. measured from the bottom of level $\mathrm{E}$. In the model, the transition was assumed to be at $6 \mathrm{ft}$ measured from the bottom of level E. For each panel, the exterior column at level $\mathrm{E}$ was modeled as two nonprismatic members. The top section of the first nonprismatic member consisted of three box-shaped columns and a middle plate, while the bottom section was a box-shaped column (Section c-c in Fig. B-20). The properties were assumed to vary linearly between the two sections. The second nonprismatic member was a tapering box shaped column (Section c-c in Fig. B-20), and again, the properties were assumed to vary linearly between the two sections. At level F, the exterior wall tree columns were prismatic box-shaped columns.

The final model of a typical tree is illustrated in Fig. B-21.

\section{Exterior Wall (Floor 9 to 106) Modeling}

In plan, column and spandrel members connected at nodes located at the outside face of the spandrel, $61 / 2$ in. from the exterior column reference line (see Fig. B-22). The columns were offset horizontally, or 'inserted' at this node, using an insertion point located at the centerline of plate T3. Insertion points were not adjusted for spandrel thickness. With this modeling, gravity and wind loads can be applied at the spandrel location.

In elevation, the columns and spandrel members connected at the spandrel centerline, typically $121 / 2$ in. below the reference floor elevation (Fig. B-22). The spandrels were then located correctly without the need for offsets to be defined. The effect of applying loads at both the spandrel centerlines and the reference floor elevations was studied, and it was found that it has a negligible difference in spandrel stresses.

For typical exterior wall panels (i.e., three columns wide by three stories high), nodes at five elevations were defined. The models included nodes at the three representative floor levels (defined at the spandrel centerlines) as well as the upper and lower column splices. Diaphragms were assigned to all nodes at floor levels where concrete slabs exist, to represent the high in-plane stiffness of the concrete floor slabs. 


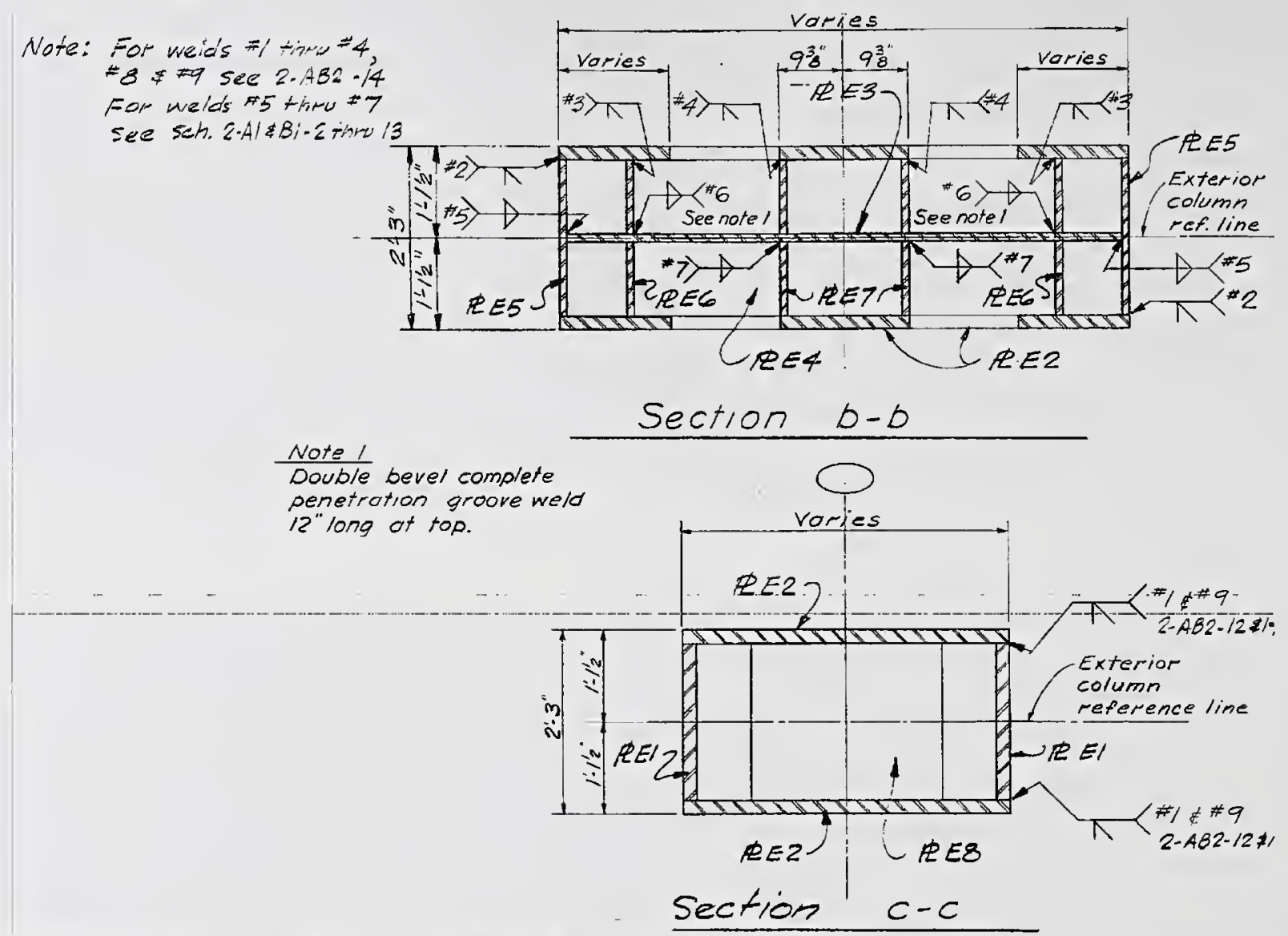

Original drawing used with permission from PANYNJ.

Figure B-20. Exterior wall tree: as-built cross sections for level E (taken from Drawing Book 2, page 2-AB2-13).

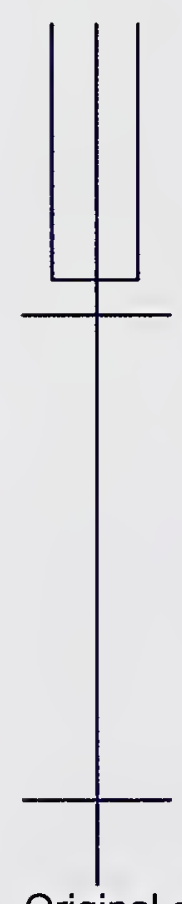

Original drawing used with permission from PANYNJ.

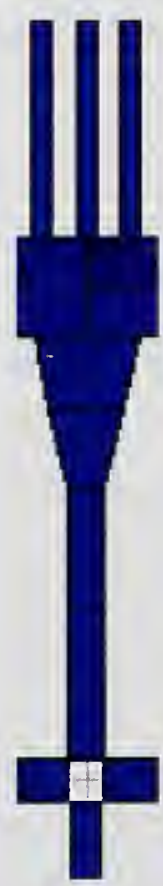

Figure B-21. Frame view and rendered view of an exterior wall tree. 


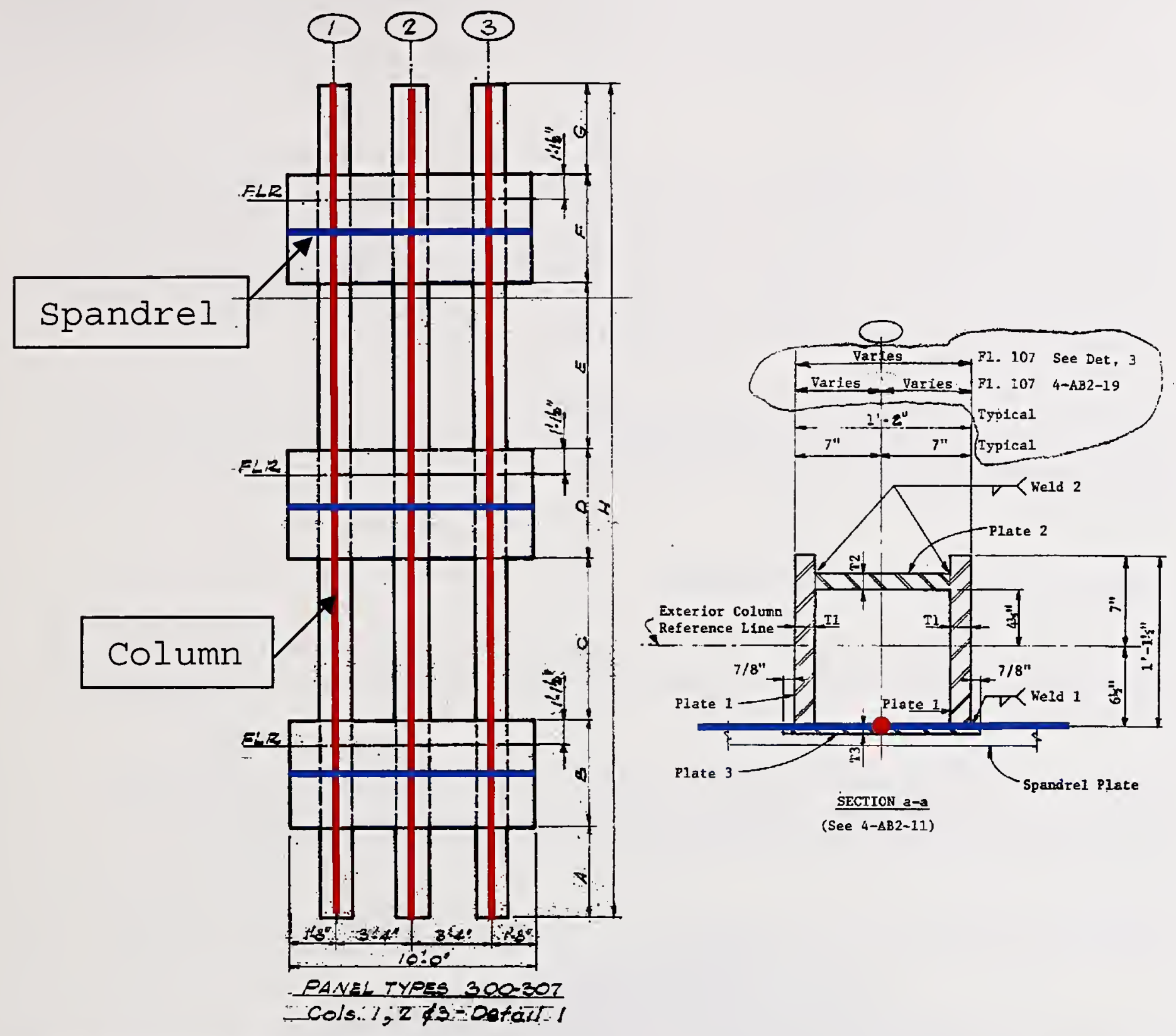

Original drawing used with permission from PANYNJ.

\section{Figure B-22. Typical WTC tower exterior wall panel.}

The SAP2000 program allows assignment of rigid zone factors to frame end offsets to account for the overlap of cross-sections. In the global model, 50 percent rigidity for the column and 100 percent rigidity for the spandrels were assigned for the typical exterior wall panels to match the lateral deflection of the detailed shell model of the panel based on the parametric study results (see Section B.3.4). It was also found that, due to the relatively large depth of the spandrels and the close spacing between the columns, the spandrels contribute to the axial stiffness of the columns in the panels. This contribution was estimated to range from 20 percent to 28 percent increase in the vertical stiffness of the panels. Therefore, a frame property multiplier for the exterior wall column's cross-sectional area was used to provide a 25 percent increase in columns' axial stiffness (see Section B.3.4). 
For exterior wall corner panels, 25 percent rigidity for the column and 50 percent rigidity for the spandrels were assigned based on the parametric study results (see Section B.3.4). Also, an area modifier was used to provide a 25 percent increase in the axial stiffness of the two continuous columns of the comer panels (Section B.3.4). No modifier was used for the $100,200,300$, and 400 series intermittent columns.

Exterior column types were defined in Drawing Book 4. A few types (100 series typical, 300 series at mechanical floors, and 400 to 500 series at corners) repeated extensively throughout the building, with steel yield strengths that vary from $36 \mathrm{ksi}$ to $100 \mathrm{ksi}$. Since SAP does not allow for the assignment of material properties at the member assignment stage, the number of different steel strengths was determined for each exterior column type, and sections were defined for each. The section name included the section number and the yield strength as tabulated in the drawing books.

Typical spandrels and corner panels were defined as rectangular shape and Section Designer section with stiffener, respectively. The top and bottom stiffener of each corner spandrel were included in both the parametric study and the global models. The detail shows that the stiffeners were 6 in. plates of thickness matching plate $\mathrm{T} 2$ in the corner column.

\section{Exterior Wall (Floor 107 to 110) Modeling}

Spandrel depths varied at floors 108 and 110. A weighted average of spandrel depth was determined in order to define the average centerline elevation of the spandrels and, therefore, the node elevation for the entire floor.

For the $7 \times 5$ structural tube sections that were used in these floors, sections from the current AISC Manual were assigned, and modification factors of 1.04 were applied to the section properties. The modifiers were used to match the section properties from the 6th Edition AISC Manual.

The exterior wall members from floors 107 to 110 were typically rolled shapes with $F_{y}=42 \mathrm{ksi}$ or $F_{y}=50 \mathrm{ksi}$. Where not shown in the drawings as $F_{y}=50 \mathrm{ksi}, F_{y}=42 \mathrm{ksi}$ was used.

\section{Hat Truss Modeling}

In both WTC 1 and WTC 2, a truss system referred to as a 'hat truss' was constructed between floor 107 and the roof. The hat truss system was intended to support the load of the antenna on top of the tower and to interconnect the exterior walls to the core. The hat truss was made up of eight trusses spanning perpendicular to the long-direction of the core and six trusses spanning perpendicular to the shortdirection of the core (refer to Figs. B-23 and B-24).

Frame members between floors 107 and 110 were assigned to the model according to plan and elevation drawings of the hat truss. Node locations were set to coincide with the centerline of spandrels at the exterior wall. Columns, diagonals, and beams were included in the model. All columns and diagonals shown in drawings SA/B-400 through SA/B-404 were included in the model. Floor beams that did not participate in the hat truss system were not included in the model, unless they were used to transfer truss chords or core columns. Flexible floor diaphragms were used in this area. 
Coordinates were generally not given at floor 109 , as this level does not contain a complete concrete floor slab. The geometry of the diagonals, columns, and beams was used to determine the location of the node where the diagonal would intersect floor 109. Unless otherwise noted in the drawings, diagonals and

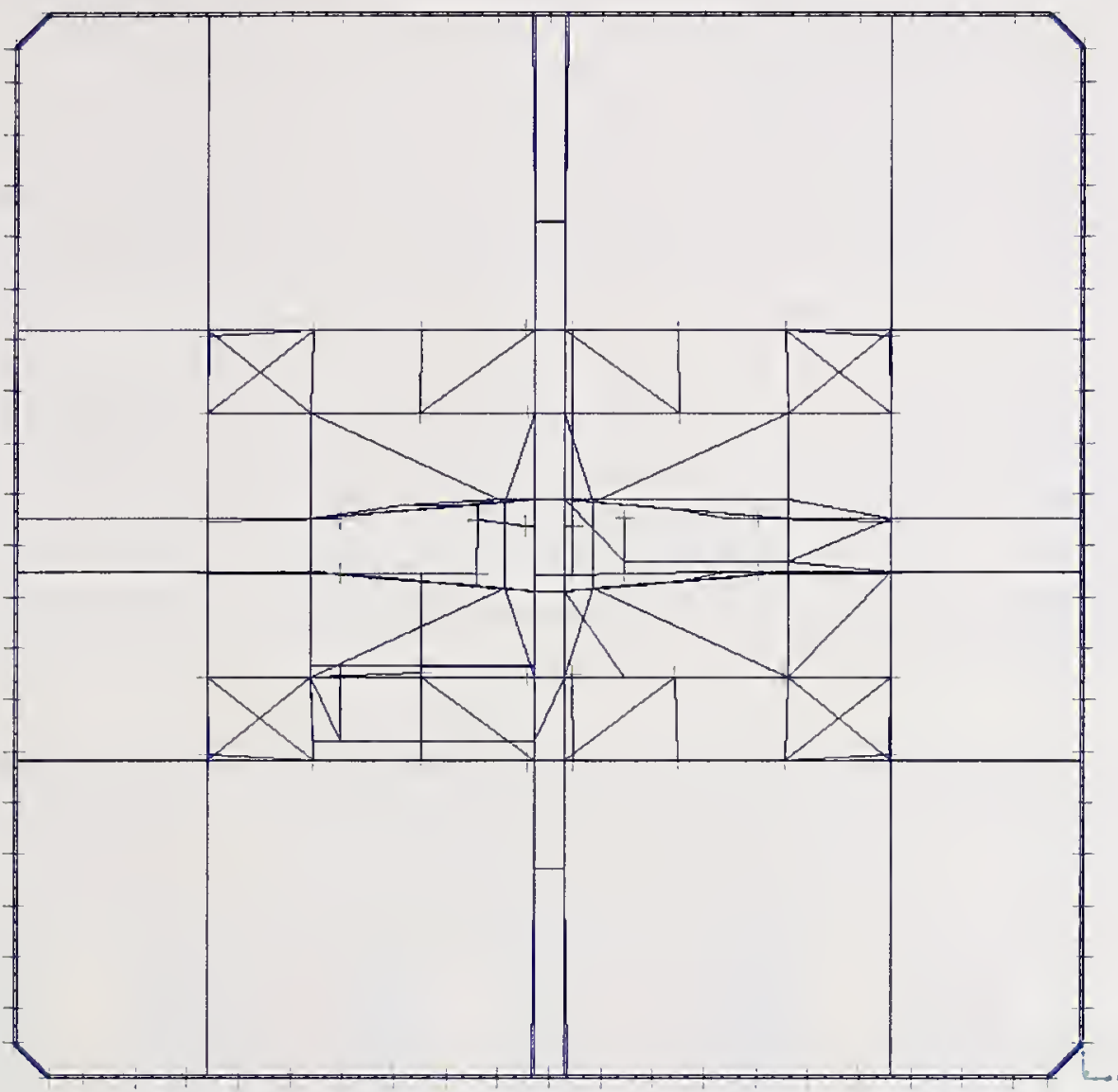

Figure B-23. As-modeled plan of the WTC 1 hat truss.

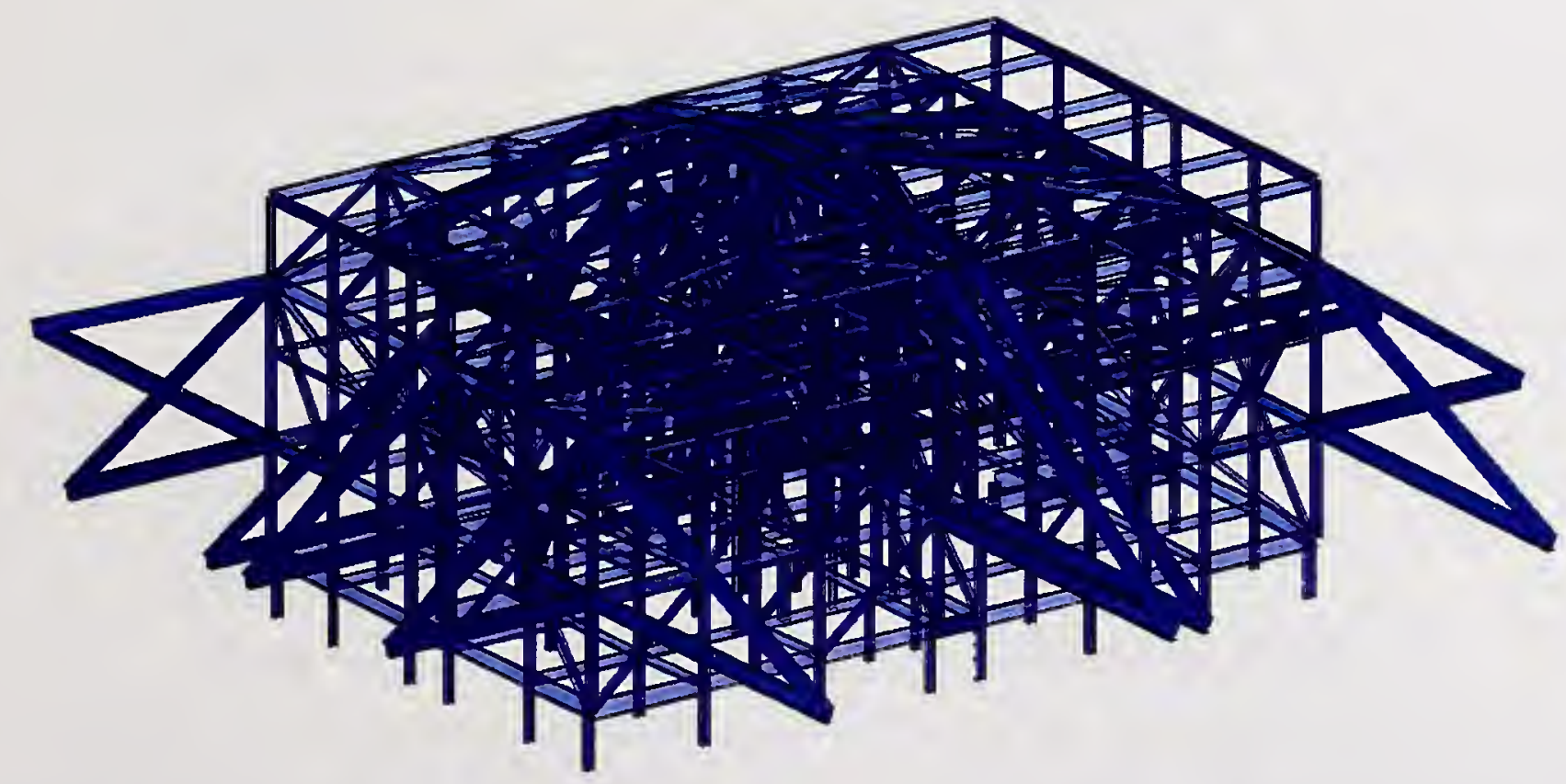

Figure B-24. Rendered 3-D model of the WTC 1 hat truss (prior to assembly in the unified model). 
columns were assumed to be non-composite and floor beams were assumed to be composite. Hat truss diagonals, main chords, and main columns were modeled with continuous joints. Hat truss beams, however, had pinned ends.

\section{Flexible and Rigid Floor Diaphragm Modeling}

For most floors, rigid diaphragms provide for a sufficiently accurate representation of the flow of forces and deformations for global structural response. This is a customary engineering practice. In cases where the flow of forces and deformations would be affected significantly by the use of rigid diaphragms, the floors were modeled as flexible diaphragms.

The floor models described in Sections B.3.2 and B.3.3 were used to develop the flexible diaphragm stiffness utilized within the global models. Section B.3.4 outlines the study for the determination of the in-plane diaphragm stiffness of the detailed floor models, using that in-plane stiffness to arrive at an equivalent shell element floor model. The equivalent shell element floor was used to represent the inplane floor stiffness in the global model. The shell elements attached to all exterior wall columns and core columns.

Flexible diaphragms were used at the floors of the towers in the core of the atrium area, in the mechanical floors, and in the floors of the hat trusses. The floors modeled using flexible diaphragms are floors 3,4 , 5, 6, 7, 9 (atrium levels); 41, 42, 43, 75, 76, 77 (mechanical levels); 107, 108, 109, 110, and roof (hat truss region) of both towers.

\section{Initial Verification of Global Models}

Several steps were taken to verify the model input. SAP2000 Version 8 offers a 'shading' option once a model has been built with frame section assignments. This allows the user to view the members as the program has interpreted their input. The shading option was helpful for using section-designed shapes, and for verifying the orientation (i.e., local axes) of members. Note that shading is not correct when two Section Designer sections are used in non-prismatic members, so orientations for these sections were verified by reviewing their local axis member properties. The work was independently reviewed by engineers not associated with the initial model development.

Once the models were completed, checks for gravity loads, wind loads, and eigenvalue results were performed. The overall performance of the tower models under these loads was found to be reasonable by checking deformations, stresses, reactions, etc. More refined checks will be done as part of the third phase of this project on baseline performance analysis. The natural periods will be calculated using mass properties estimated from realistic loads on the towers as part of the baseline analysis. Calculated natural periods will be compared with the measured periods of WTC 1 .

\section{B.3.2 Typical Truss-Framed Floor Model-Floor 96A}

In order to select the typical truss-framed floor within the expanded impact and fire zones of both towers, the drawings for floors 80 to 100 were reviewed to identify structural similarities. It was found that floor 96 of WTC 1 (96A) represented the typical truss-framed floor in the expanded region for WTC 1 
(floors $89 \mathrm{~A}$ to $103 \mathrm{~A}$ ). The lone exception in this region of WTC 1 was floor 92 which had an increased dead load capacity required for the support of secondary water lines.

Floor 96A was also representative of the typical truss-framed floor in the expanded region for WTC 2 (floors 74B-88B). Specifically, floor 96A was similar to the truss framing at floor $74 \mathrm{~B}$ and floors $84 \mathrm{~B}$ through $88 \mathrm{~B}$. Floors $78 \mathrm{~B}$ and $79 \mathrm{~B}$ were sky lobby and upper escalator floors, respectively. Both contained long span trusses which were similar to floor 96A, but also contained beam-framed floor construction in the entire short span area (where the escalators were located). Floors $80 \mathrm{~B}$ through $83 \mathrm{~B}$ had beam framing in place of a single truss panel in the short span area, while the remaining area contained trusses which were similar to floor 96A.

Based on the above discussion, floor 96 of WTC 1 was selected as the overall representative truss-framed floor for the majority of the expanded impact and fire zone in both towers and is described in the following sections (see Fig. B-25). An isometric view of the typical truss-framed floor model is illustrated in Fig. B-26. Table B-2 includes a summary of the size of the 96A floor model. The following presents the major structural systems and components of the truss-framed floor model.

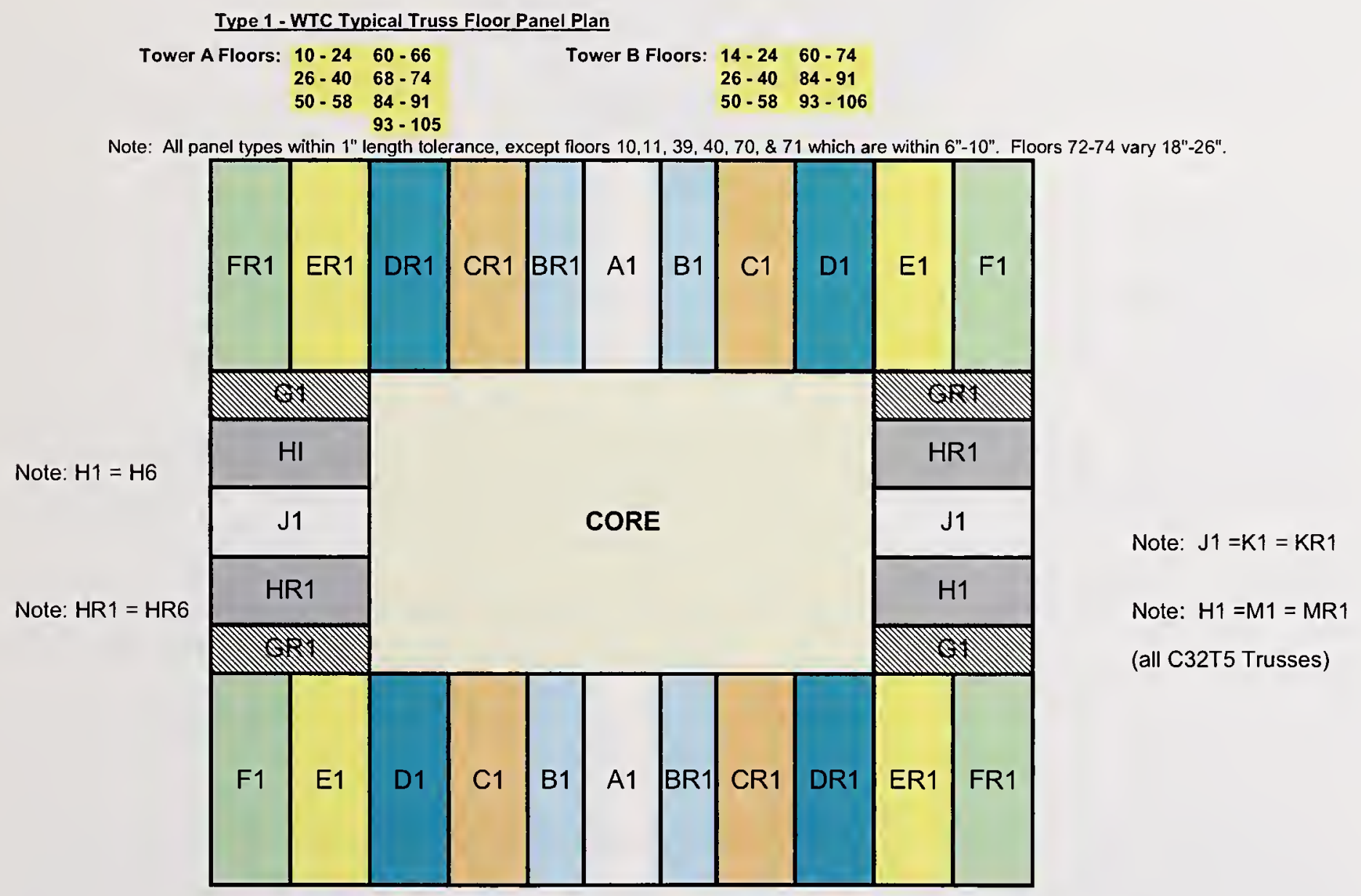

Figure B-25. Typical truss-framed floor panels arrangement. 


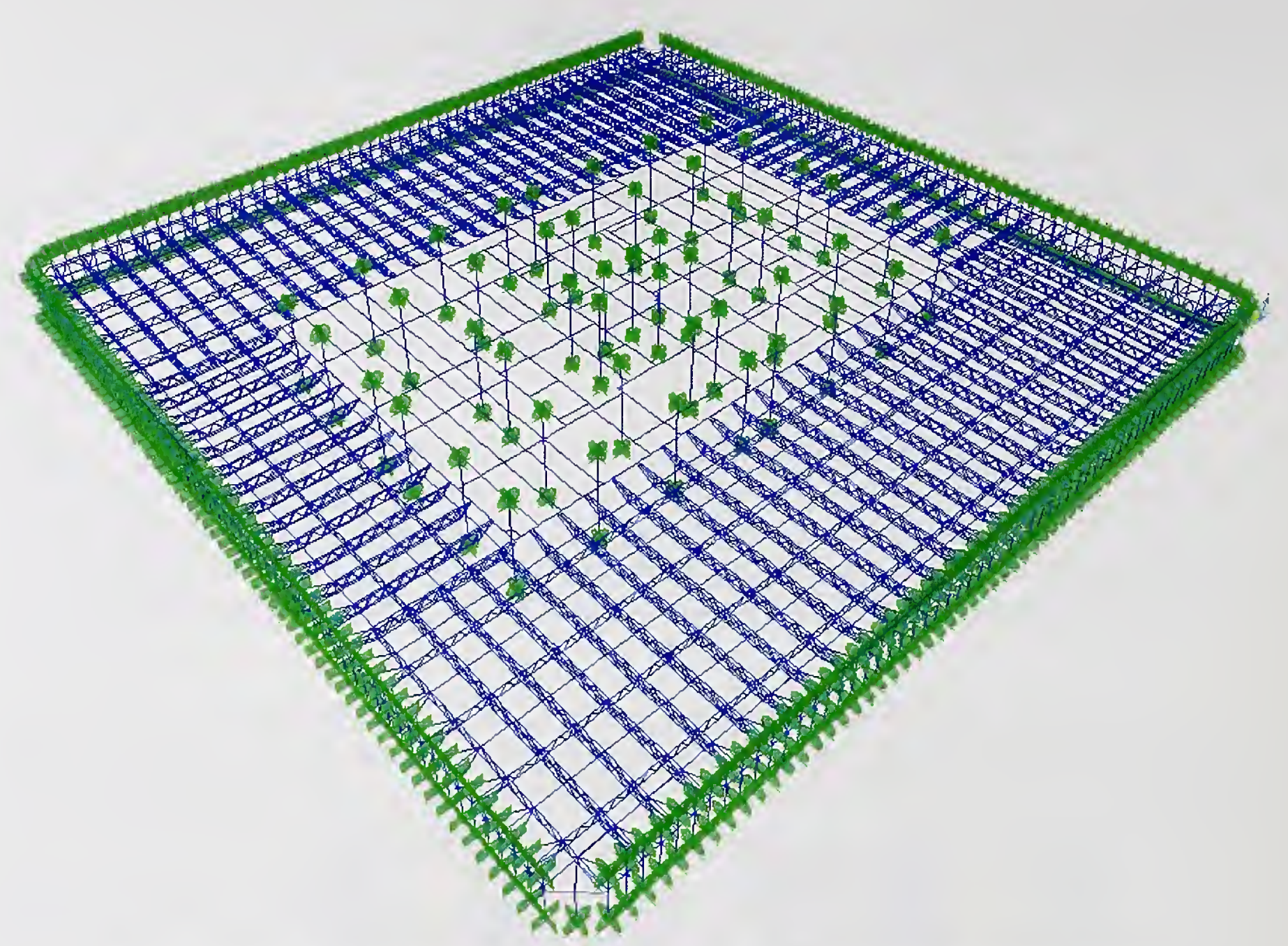

Figure B-26. Typical truss-framed floor model (floor 96A), slab not shown.

\section{Primary Trusses}

The primary trusses consisted of double angle top and bottom chords which were 29 in. out-to-out of the chords. The trusses acted compositely with a 4 in. concrete slab on 1 1/2 in. metal deck. For a typical long-span truss, $\mathrm{C} 32 \mathrm{~T} 1$, the top chord consisted of two angles 2 by 1.5 by 0.25 in., short legs back-toback (SLB), and the bottom chord consisted of two angles 3 by 2 by $0.37 \mathrm{in}$., SLB. The distance between the centroid of the two chords was calculated to be 28.05 in. The distance from the centroid of the top chord to the neutral axis of the transformed composite slab with top chord was calculated to be 1.93 in. The sum of $(28.05+1.93)$ is $29.98 \mathrm{in}$. (Fig. B-27). In the model, therefore, $30.0 \mathrm{in}$. was taken as the typical distance between the top and bottom chords for both short- and long-span primary trusses.

In the long-span truss zone, the two individual primary trusses, which were part of the same floor panel and attached to the same column, were separated (typically) by a distance of $71 / 8 \mathrm{in}$. At the joint between panels, the distance between the abutting long-span trusses was $71 / 2 \mathrm{in}$. Therefore in the model, $71 / 2$ in. was used as the spacing between all long span primary trusses. In the short-span truss zone, two individual trusses which attached to the same column were separated by a distance that varied between 4 7/8 in., 5 in., and 5 1/4 in. In the model, the typical spacing between all short-span double trusses was $5 \mathrm{in}$. The long span trusses in the two-way zone had an as-modeled length of $58 \mathrm{ft} 10 \mathrm{in}$. while the long span trusses in the one-way zone had an as-modeled length of $59 \mathrm{ft} 8 \mathrm{in}$. 


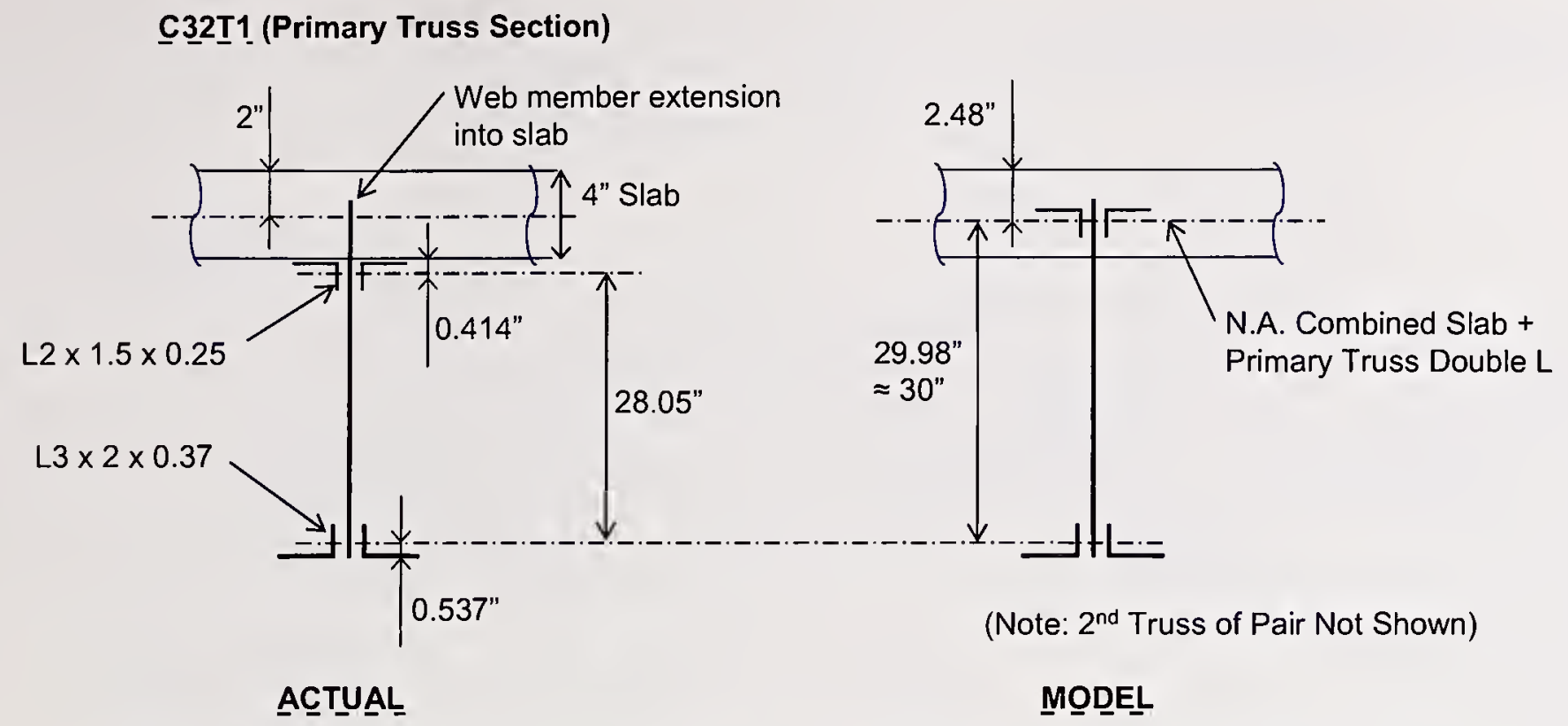

\section{Figure B-27. Typical primary truss cross-section, as-built and as-modeled transformed truss work points.}

The diagonal web bars for the primary trusses were most often 1.09 in. diameter bars. Therefore, for double angle shapes in the primary trusses, $1.09 \mathrm{in}$. is taken as the distance between the two angles. This holds true for primary trusses where bar diameters varied between $0.92 \mathrm{in}$. and $1.14 \mathrm{in}$.

The as-built truss diagonals had end fixity, but were considered pinned for the analysis. Pinning the diagonals is conservative and provides an upper bound of the gravity load stresses. To mitigate the effect of the pinned member approach, end length offsets were used for the truss diagonals to compensate for the difference in the as-built diagonal unbraced length and the model unbraced length. The as-built unbraced length for a typical diagonal in a primary truss was 32.4 in., while the modeled member length was 36.05 in., and therefore, an end offset of 1.8 in. was used at both ends. Similarly, for the bridging trusses, the actual unbraced length for a typical diagonal of a bridging truss was 29 in., while the modeled length was 30.66 in. Therefore, an end offset of 0.83 in. was used at both ends. A rigid zone factor of 100 percent is used for all offset zones.

In the model, the deck support angles, typically 3 by 2 by 0.75 in. were located in the same plane as the combined truss top chord and composite slab centroid.

\section{Bridging Trusses}

The bridging trusses were 24 in. deep, edge-to-edge, with double angle chords. For a typical bridging truss, $24 \mathrm{~T} 11$, the top and bottom chords consisted of two angles 1.5 by 1.25 by 0.23 in., SLB. The distance between the centroid of the two chords was $23.26 \mathrm{in}$. The distance used as the offset between the top and bottom chords for all bridging trusses was taken as 23.25 in. (Fig. B-28). The distance between the work points of the top chord of the bridging truss and the top chord of the primary trusses and equivalent slab plate for $24 \mathrm{~T} 11$ was calculated to be $3.39 \mathrm{in}$. This distance was selected for all bridging trusses to be $3.375 \mathrm{in}$. As in the as-built structure, the bridging truss was not connected along its length to the slab shell elements in the model. At the intersection of the top chords of the primary and the bridging 
trusses, the intersection was modeled using vertical rigid links, connected in turn to the slab shell elements representing the concrete slab.

$\underline{24 T 11}$ (Bridging Truss Section)

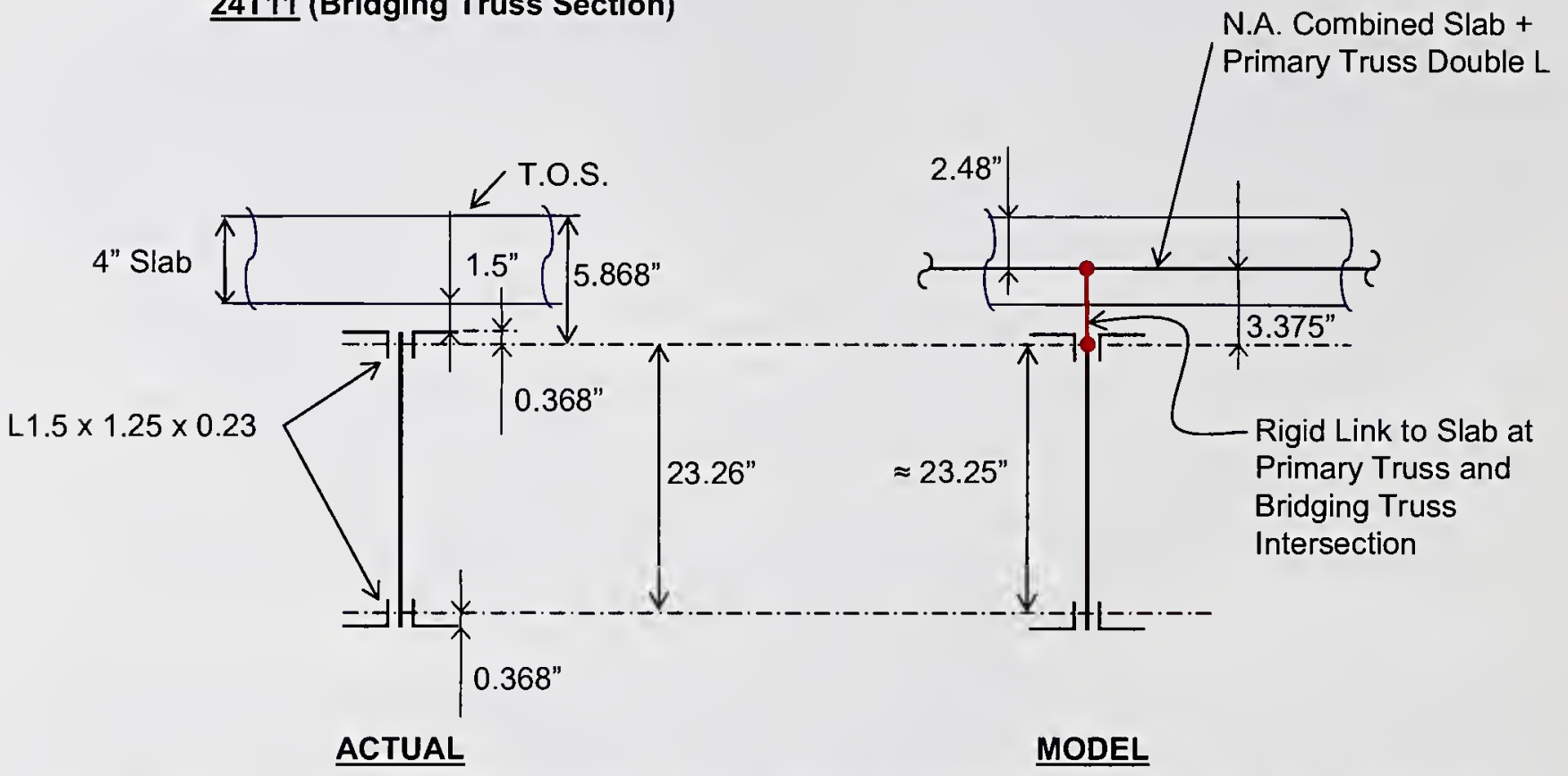

Figure B-28. Typical bridging truss cross-section, as-built and as-modeled transformed truss work points.

The bottom chord of the primary trusses was connected to the bottom chord of the bridging trusses along the length of the primary trusses only on column lines $111,149,311$, and 349 . The connection consisted of double angles 2 by $11 / 2$ by 0.25 in. These connection angles were included within the model.

For bridging trusses in the model, a 0.75 in. angle gap was used for trusses with web bar diameters that varied between $0.75 \mathrm{in}$. and $0.98 \mathrm{in}$.

\section{Truss Member Cover Plates}

In 30 percent of the floor area, truss members were supplemented with cover plates. The members with additional plates included top chords, web members, and most typically bottom chords. Section properties were calculated with SAP Section Designer. The primary truss top chords were reinforced with an additional set of double angles at truss end connections. At these locations, the work points for the section were located at the centroid of the composite double angle and concrete slab.

The Laclede shop drawings indicated plates $3 / 8$ in. by 3 in. connecting the bottom chord of the primary truss pairs together at each end and where intersected by a bridging truss. These plates were included in the model.

\section{Viscoelastic Dampers}

Viscoelastic dampers were located where the bottom chords of the long span, short span, and bridging trusses intersected the exterior columns. The dampers were defined in Drawing Book D. The dampers 
resisted static and quasi-static loads (such as gravity loads) at the time of load application. Immediately following load application, the dampers shed load until the stress in the dampers was dissipated. A placeholder element was located in the model at the damper location.

\section{Strap Anchors}

Exterior columns not supporting a truss or truss pair were anchored to the floor diaphragm by strap anchors. These strap anchors were connected to the columns by complete penetration welds. The strap anchors were then connected to the slab with shear stud connectors and to the top chords of the trusses by fillet welds. The straps were included in the model and located in the plane of the centroid of the composite top chord. Also, in the model the work points intersected with the centerline of the column and used a rigid link to attach back to the spandrel (see Fig. B-29).

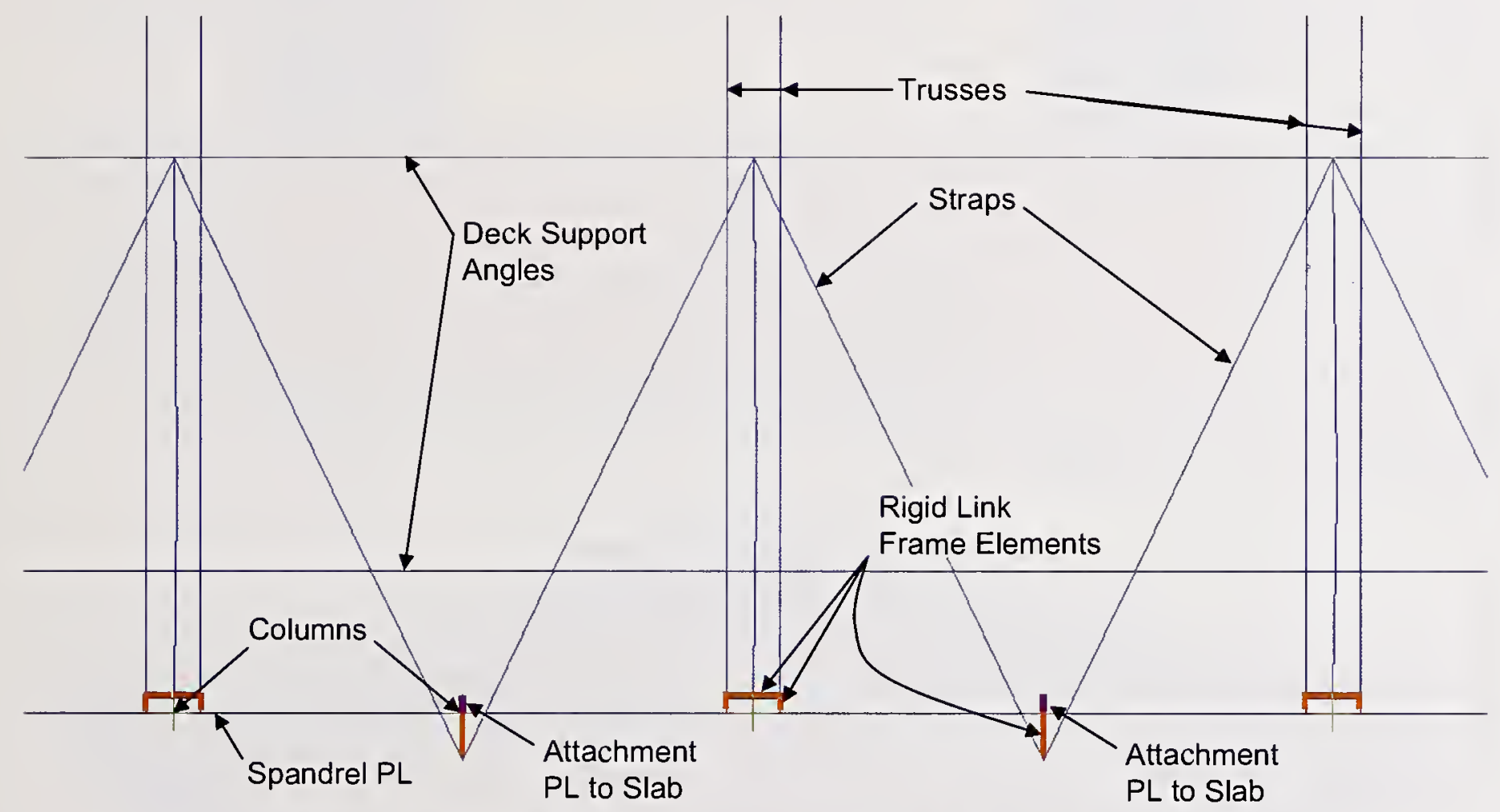

Figure B-29. Strap anchors modeling, slab not shown.

\section{Concrete Slab and Metal Deck}

Outside the core, the primary trusses acted compositely with the 4 in. concrete slab on $11 / 2 \mathrm{in}$. metal deck. In the model, the average depth of the slab plus deck was modeled as $4.35 \mathrm{in}$. The concrete slab consisted of lightweight concrete with a self-weight of $100 \mathrm{pcf}$ and a design compressive strength, $f^{\prime}{ }_{c}^{\prime}=3,000$ psi. The concrete modulus of elasticity, $E_{c}$, used for modeling is $1,810 \mathrm{ksi}$, and the calculated modular ratio, $n=E_{s} / E_{c}$, is taken as 16 , where $E_{s}$ is the steel modulus of elasticity. These values are consistent with those included within the WTC Structural Design Criteria Book.

Typically, inside the core, the beams acted compositely with a $41 / 2$ in. formed concrete slab. The concrete slab consisted of normal weight concrete with a self-weight of $150 \mathrm{pcf}$ and a design compressive 
strength, $f_{c}^{\prime}=3000 \mathrm{psi}$. The concrete modulus of elasticity, $E_{c}$, used for modeling was $3,320 \mathrm{ksi}$ and the calculated $n$ ratio, $E_{s} / E_{c}$, was taken as 8.7 .

The floors of the WTC towers had an in-floor electrical distribution system of electrified metal deck and trench headers. The effects of the in-slab trench headers were accommodated by reducing the slab shell element thickness. A $1 \mathrm{ft} 8$ in. wide shell panel (the typical truss-floor shell mesh size) was reduced in thickness from 4.35 in. to 2.35 in. or 1.35 in. at the trench header locations per drawing SCA-109 (Floor 96A Structural Concrete Floor Plan).

\section{Initial Verification of the 96th Floor Model}

Several steps were taken to verify the model input. SAP2000 Version 8 offers a 'shading' option once a model has been built with frame section assignments. This allows the user to view the members as the program has interpreted their input. The shading option was helpful for using section designed shapes, and for verifying the orientation (i.e., local axes) of members. The work was independently reviewed by engineers not associated with the initial model development.

Once the model was completed, checks were performed for gravity loads. All superimposed dead loads and live loads included in the model were based on WTC Design Criteria; self weight is accounted for by SAP2000. To justify the modeling assumptions, several studies were performed to compare stress results to hand calculations for representative composite sections. Hand calculations estimate deflections and member stresses for a simply supported composite truss under gravity loading. For the composite truss sections, the steel stress results were within 4 percent of those calculated by SAP2000 for the long-span truss and 3 percent for the short-span truss. Deflections for the beams and trusses matched hand calculations within 5 to 15 percent.

\section{B.3.3 Typical Beam-Framed Floor Model-Floor 75B}

As described in Section B.3.2 for truss-framed floors, the structural drawings were reviewed to identify structural similarities between the beam-framed floors within the expanded impact and fire zones of both towers. It was found that floor 75 of WTC 2 (75B) represents the typical beam-framed floor in the expanded impact zone for WTC 2 (floors 74B to 88B). There were no beam-framed floors within the expanded impact zone of WTC 1.

Floors 75 and 76 of WTC 2, lower and upper mechanical equipment (MER) floors, respectively, were typical of the lower three mechanical equipment floor pairs in both towers (floors 7 and 8, 41 and 42, and 75 and 76 for both WTC 1 and WTC 2). Floor 77 of WTC 2, a lower escalator floor, was a beam-framed floor similar to the lower floor of the mechanical equipment floor pairs, i.e., floor 75B.

Based on the above discussion, floor 75 of WTC 2 was selected as the overall representative beam-framed floor for the expanded impact and zone in both towers and is described in the following sections (see Fig. B-30). An isometric view of the typical beam-framed floor model is illustrated in Fig. B-31. Table B-2 includes a summary of the size of the 75B floor model. The following presents the major structural systems and components of the beam-framed floor model. 
Iype 12 - WTC Beam Framed Floor Floor Plan

Towers A \& B MER Floors: $7,41,75,108$

Towers A \& B Near MER Floors: $9,43,77,107,110$,Roof

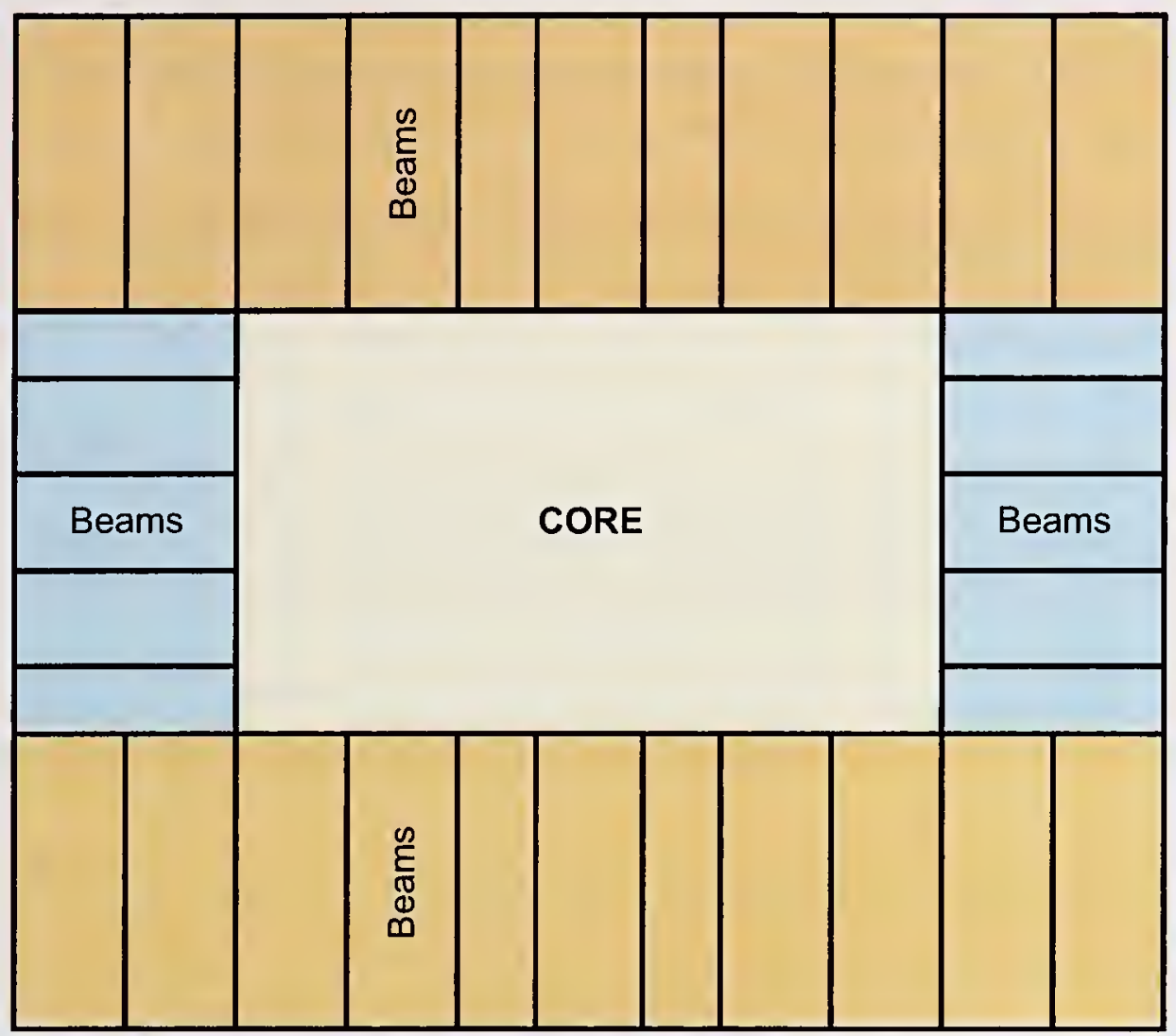

Figure B-30. Typical beam-framed floor arrangement.

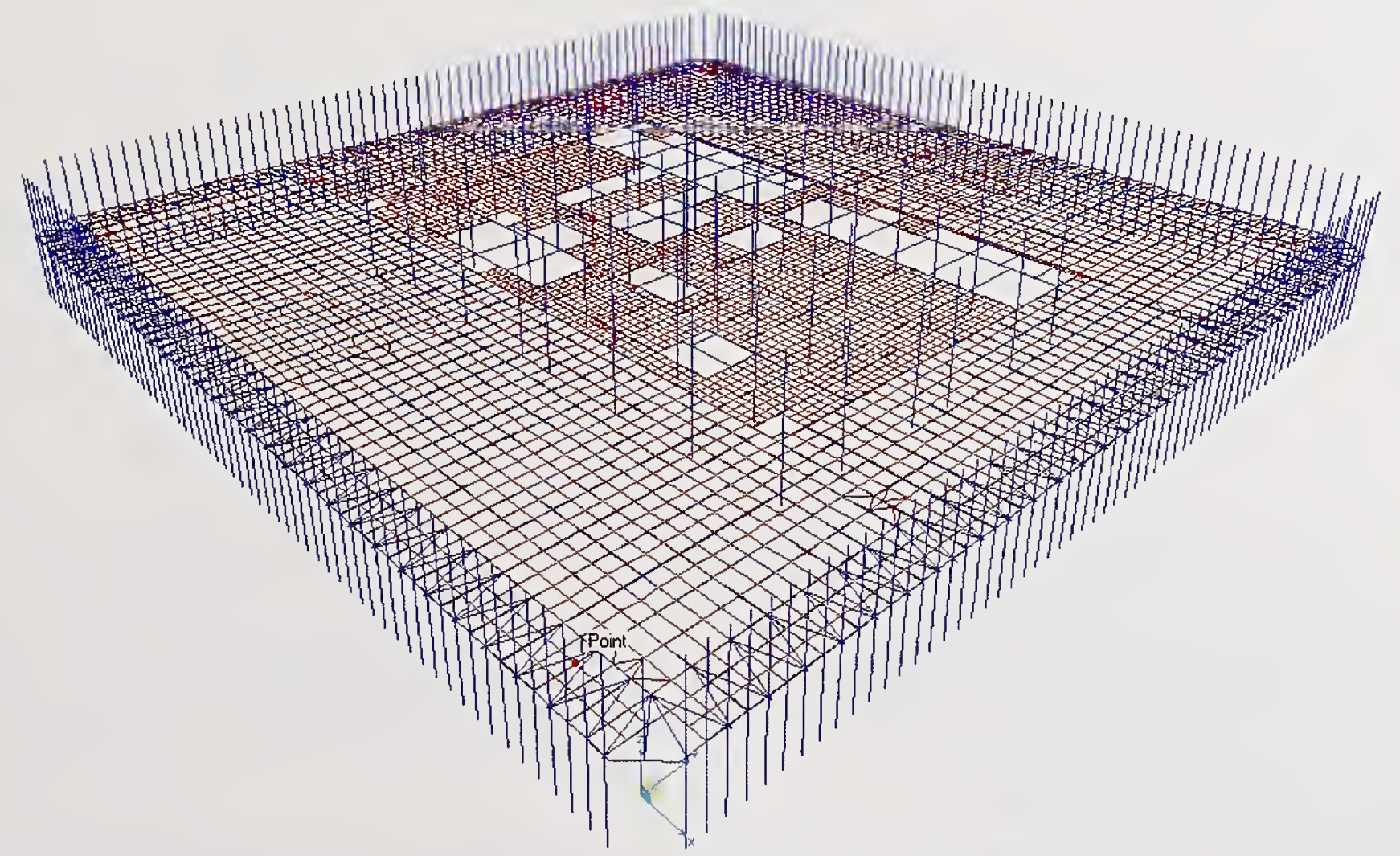

Figure B-31. Typical beam-framed floor model (floor 75B). 


\section{Composite Beams}

The beams in the model were located at the elevation of the centerline of the concrete slab. The insertion point for the beams was set at the beam top flange, and then the beam was offset down by one-half the thickness of the slab. The beam was rigidly linked with the slab to simulate the composite action. This option provided for accurate estimation of the composite stiffness of the floor.

For beams with cover plates, the properties were calculated by SAP Section Designer, and the slab, beam, and reinforcing plates were rigidly linked.

\section{Horizontal Trusses}

Exterior columns which did not support a beam were connected to the floor for bracing purposes by horizontal trusses. These exterior horizontal trusses were anchored to the columns with complete joint penetration welds. The horizontal trusses were then connected with shear stud connectors to the slab. The truss angles (typically 4 by 4 by $5 / 16$ in.) were then connected to the top flange of the beams. In the model, the work points intersected with the centerline of the column and used a rigid link to attach back to the spandrel. The truss members were located in the plane of the centroid of the composite top chord (see Fig. B-32).

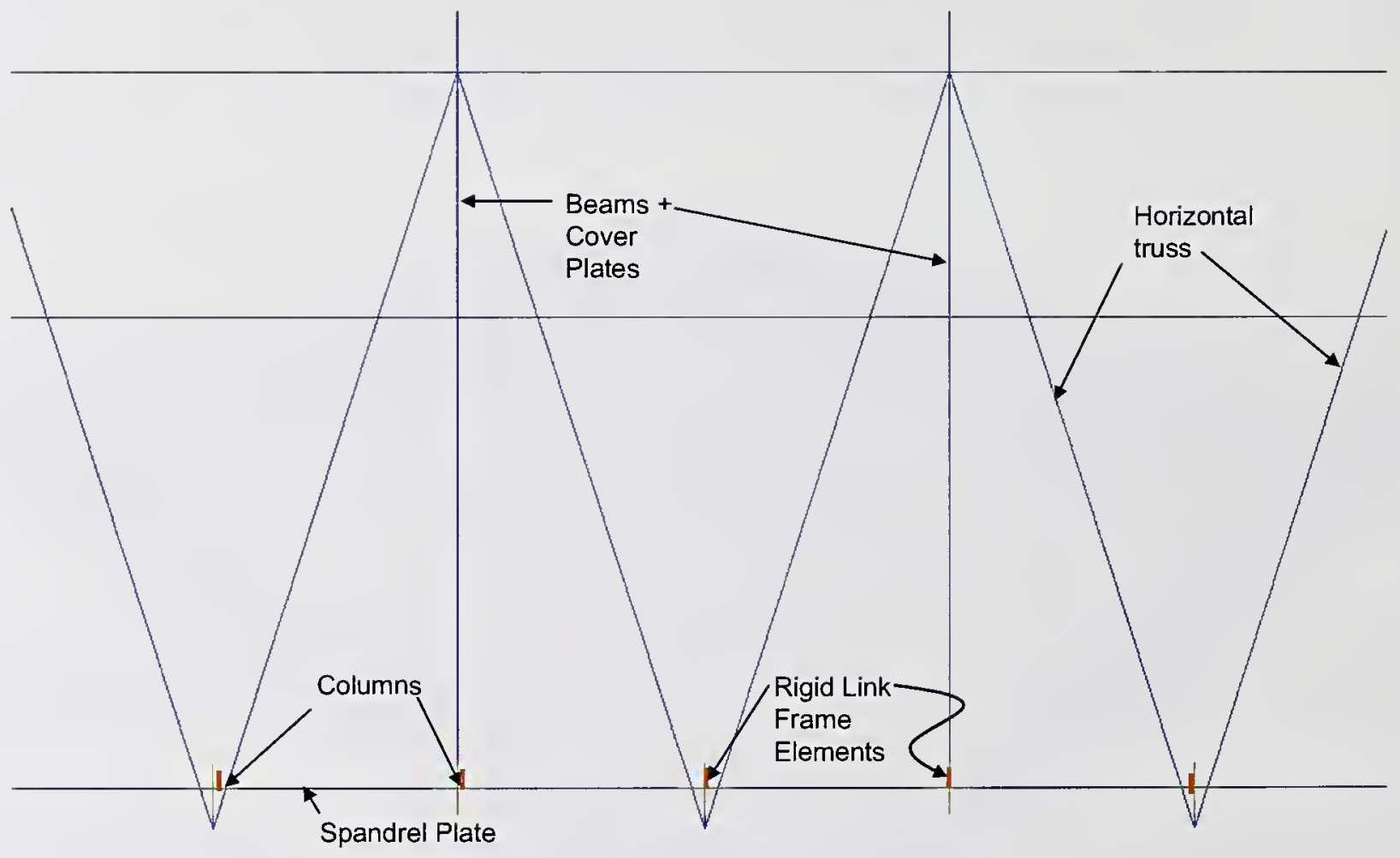

Figure B-32. Horizontal truss modeling, slab not shown.

\section{Concrete Slab and Metal Deck}

Outside the core on the mechanical floors, the beams acted compositely with a $53 / 4$ in. concrete slab on $11 / 2$ in. metal deck. The average cross-sectional depth of the slab in the model was taken as $6.1 \mathrm{in}$. The 
concrete slab consisted of normal weight concrete with a self-weight of $150 \mathrm{pcf}$ and a design compressive strength of typically ${f_{c}^{\prime}}_{c}=3,000 \mathrm{psi}$. The concrete modulus of elasticity, $E_{c}$, used for modeling is $3,320 \mathrm{ksi}$ and the calculated modular ratio, $n$, is taken as 8.7 .

Typically, inside the core, the beams acted compositely with a 6 in. formed concrete slab. The concrete slab consisted of normal weight concrete with the same properties as concrete outside the core.

The mechanical floors had a 2 in. maximum depth topping slab both inside and outside the core. The topping slab stiffness was not included in the models, but the weight will be accounted for in the baseline analysis.

\section{Viscoelastic Dampers}

Viscoelastic dampers were located below the bottom flange of the beams where the beams intersected the exterior columns. Similar to the 96 floor model, a placeholder element was located in the model at the damper location.

\section{Initial Verification of the 75 Floor Model}

Similar to the 96 floor model, the 'shading' option in SAP2000 was used to view the members as the program has interpreted their input. The shading option was helpful for using section designed shapes, and for verifying the orientation (i.e., local axes) of members. The work was independently reviewed by engineers not associated with the initial model development.

Once the model was completed, checks were performed for gravity loads. All superimposed dead loads and live loads included in the model are based on WTC Design Criteria; self weight is accounted for by SAP2000. To justify the modeling assumptions, several studies were performed to compare stress results to hand calculations for representative composite sections. Hand calculations estimate deflections and member stresses for a simply supported composite beam under gravity loading. The model yielded accurate steel stress results compared to hand calculations - around 1 percent for both short and long span beams. Where the beams were built-up with reinforcing plates, it was found that SAP Section Designer shapes were not calculating the stresses correctly, so instead, separate beam and plate elements drawn over each other were inserted. This method yielded very accurate steel stress results - between 1 percent and 2 percent for both short and long span beams.

\section{B.3.4 Parametric Studies}

Modeling techniques employed in the development of the global models of WTC 1 and WTC 2 are consistent with, but often more advanced than, the techniques typically employed in the analysis and design of high-rise buildings. As such, building components were idealized so that overall performance was replicated while appropriately reducing the computational requirements. The following describes the studies undertaken to establish the idealizations used in the models including typical exterior wall panels, exterior corner panels, and flexible floor diaphragms. 


\section{Exterior Wall Columns/Spandrel Typical Panels (Floors 9 to 106)}

A parametric study of typical three-column, three-spandrel exterior wall panels from the face of the towers (floors 9 to 106) was performed using two modeling methods (see Fig. B-33). The first model was a detailed shell model where each plate of each column or spandrel was specifically modeled, and the second was a simplified frame model. The parametric study assumes that the shell model best represents the as-built panel performance, and therefore, it was used to tune the performance of the frame model which was used throughout the global model (see Section B.3.1). The objectives of the study were to (1) match the axial stiffness of the frame model with the detailed shell model under gravity load and (2) match the inter-story drift of the two models by modifying the rigidity of the column/spandrel intersections in the frame model.
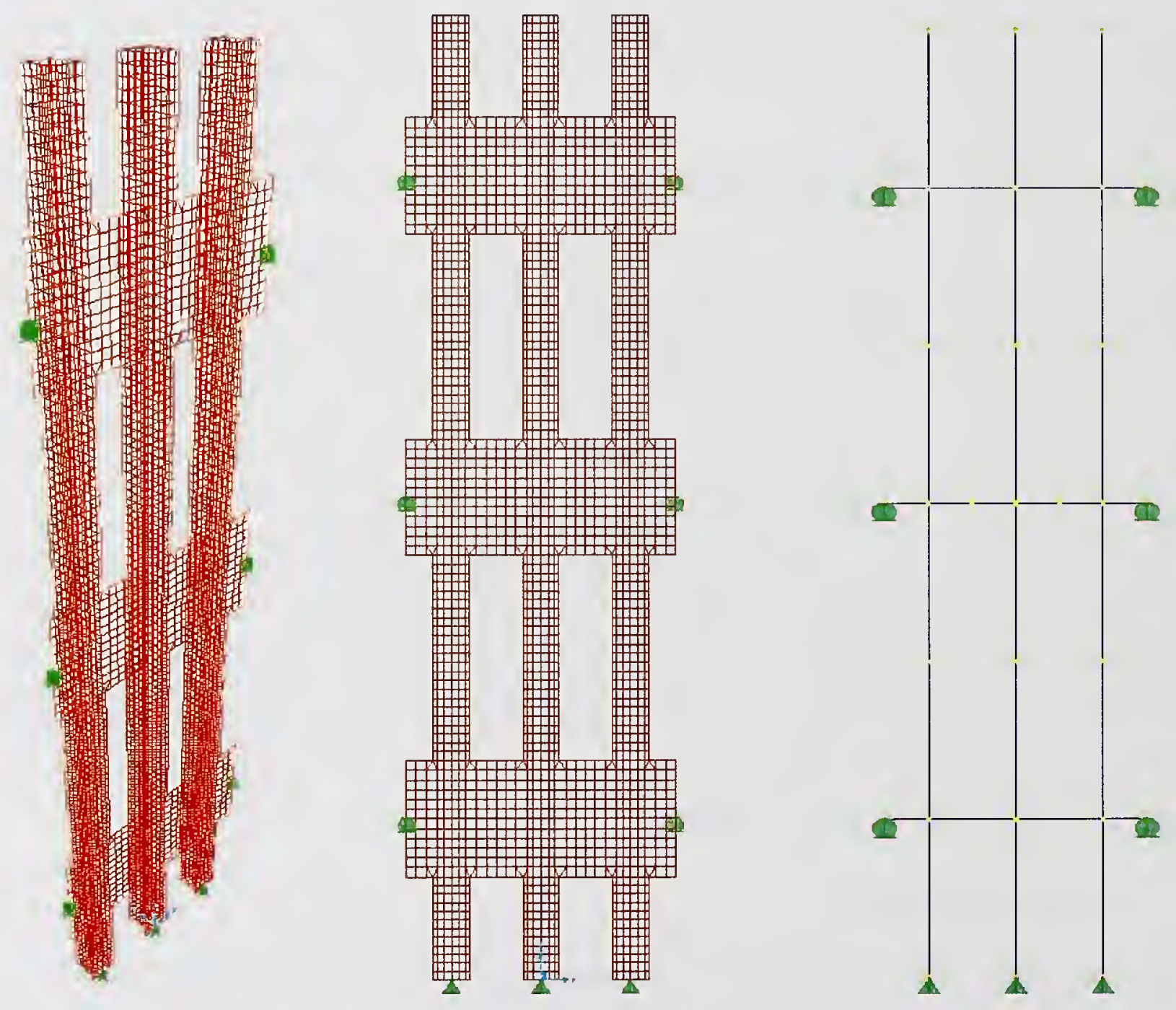

Figure B-33. Shell element and frame models of typical exterior wall panel. 
For the axial stiffness of the simplified frame model of the panel versus the detailed shell model, results of loading both models vertically indicated that the shell model was stiffer than the equivalent beam model due to the contribution of the spandrel beams to the columns' axial stiffness. This is due to the rigidity of the spandrel beams and the proximity between the columns. The parametric study on a wide range of panels over the height of the towers showed that the vertical stiffness of the columns in the bottom third of the towers should be increased by a factor in the range of 25 percent to 28 percent, and the columns in the middle and upper thirds of towers should be increased by a factor in the range of 20 percent to 28 percent. Based on these figures, 25 percent increase of axial stiffness of exterior columns was selected as a reasonable representation for the panel vertical stiffness over the height of the towers between floors 9 and 106 (see Section B.3.1).

For studying the lateral deformation of the exterior panels, panel properties were taken from three different areas of the building. These include floors 79 to 82,53 to 56 , and 23 to 26 . Internal column stiffeners were included in the shell model. The deformations at points A, B, I, and II (see Fig. B-34) were studied for three different panel locations and their respective spandrel and column thickness. The top most columns were connected via a rigid link and loaded in the plane of the panel and perpendicular to the column with a 100 kip load.

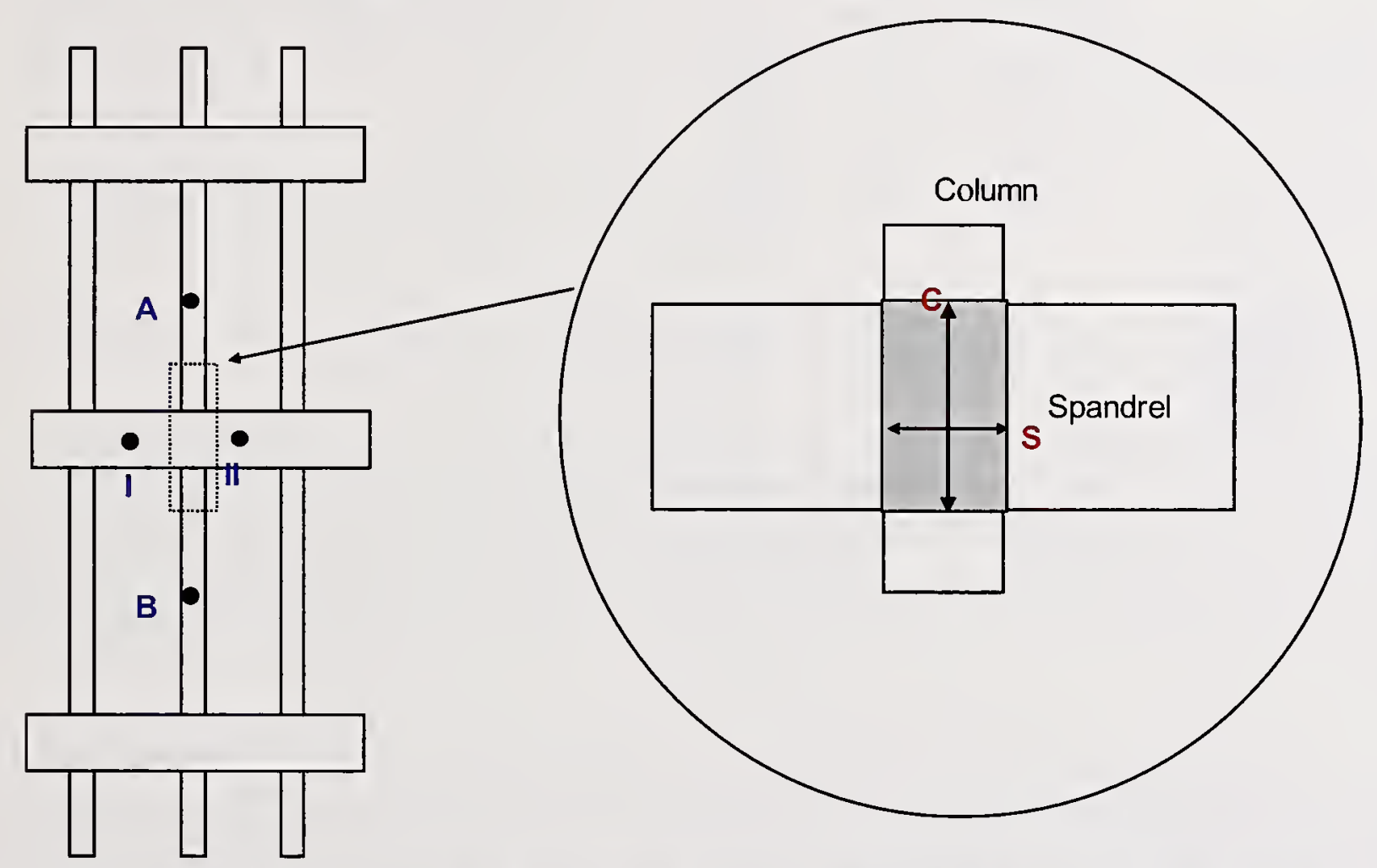

Figure B-34. Column and spandrel rigidity of typical exterior wall panel.

The lateral displacements found for the shell and frame models of typical exterior wall panels with varied column and spandrel intersection rigidities are reported in Table B-3. The study found that 50 percent column rigidity and 100 percent spandrel rigidity in the frame model produced deflection results consistent with the shell model. 
Table B-3. Lateral displacement (in.) for the shell and frame models of typical exterior wall panel with varied column and spandrel rigidities.

\begin{tabular}{|c|c|c|c|c|}
\hline & \multicolumn{4}{|c|}{ Lateral displacement (in) } \\
\hline & \multicolumn{4}{|c|}{ Floor 79-82 } \\
\hline & \multirow{2}{*}{ Shell model } & \multicolumn{3}{|c|}{ Frame model (Rigidity) } \\
\hline & & No rigidity & $\mathrm{C}: 50 \%, \mathrm{~S}: 100 \%$ & $\mathrm{C}: 100 \%, \mathrm{~S}: 100 \%$ \\
\hline$A$ & 0.60 & 1.04 & 0.59 & 0.35 \\
\hline B & 0.28 & 0.52 & 0.29 & 0.18 \\
\hline 1 & 0.45 & 0.78 & 0.44 & 0.26 \\
\hline \multirow[t]{4}{*}{ II } & 0.45 & 0.78 & 0.44 & 0.26 \\
\hline & \multicolumn{4}{|c|}{ Floor 53-56 } \\
\hline & \multirow{2}{*}{ Shell model } & \multicolumn{3}{|c|}{ Frame model (Rigidity) } \\
\hline & & No rigidity & $\mathrm{C}: 50 \%, \mathrm{~S}: 100 \%$ & $\mathrm{C}: 100 \%, \mathrm{~S}: 100 \%$ \\
\hline A & 0.26 & 0.43 & 0.27 & 0.18 \\
\hline $\mathrm{B}$ & 0.12 & 0.22 & 0.14 & 0.11 \\
\hline 1 & 0.19 & 0.32 & 0.2 & 0.15 \\
\hline \multirow[t]{4}{*}{ II } & 0.19 & 0.32 & 0.2 & 0.15 \\
\hline & \multicolumn{4}{|c|}{ Floor 23-26 } \\
\hline & \multirow{2}{*}{ Shell model } & \multicolumn{3}{|c|}{ Frame model (Rigidity) } \\
\hline & & No rigidity & C:50\%, S: $100 \%$ & C:100\%, S: $100 \%$ \\
\hline A & 0.21 & 0.37 & 0.21 & 0.12 \\
\hline $\mathrm{B}$ & 0.1 & 0.18 & 0.1 & 0.06 \\
\hline 1 & 0.16 & 0.28 & 0.16 & 0.09 \\
\hline II & 0.16 & 0.28 & 0.16 & 0.09 \\
\hline
\end{tabular}

\section{Exterior Wall Columns/Spandrel Corner Panels (Floors 9 to 106)}

A parametric study was performed of an exterior wall corner panel typical over each corner of the towers from floors 9 to 106. Similar to the exterior typical panels, to account for the contribution of the spandrels into the axial stiffness of the columns, it was found that an area modifier to provide a 25 percent increase in the axial stiffness of the two continuous columns of the corner panels is suitable for modeling the columns' axial stiffness. No modifiers were needed for the $100,200,300$, and 400 series intermittent columns.

The panel from floor 53 to 56 was selected to be representative with two additional columns attached on either side. The objective of the study was to match the inter-story drift of a detailed shell model and a simplified frame model of the corner panel by modifying the rigidity of the column/spandrel intersections in the frame model. For this parametric study, the panel was straightened to simplify the study and to isolate the behavior of interest (see Fig. B-35). The deformations at points T1, T2, B1, B2, and M2 (Fig. B-36) were studied for representative column and spandrel plate dimensions. The top most columns were connected via a rigid link and loaded in the plane of the panel and perpendicular to the column with a 100 kip load.

The lateral displacements calculated for the shell and frame models of the typical exterior wall corner panel with varied column and spandrel rigidities are reported in Table B-4. The study indicated that 25 percent column rigidity and 50 percent spandrel rigidity in the frame model produced deflection results consistent with the shell model. 


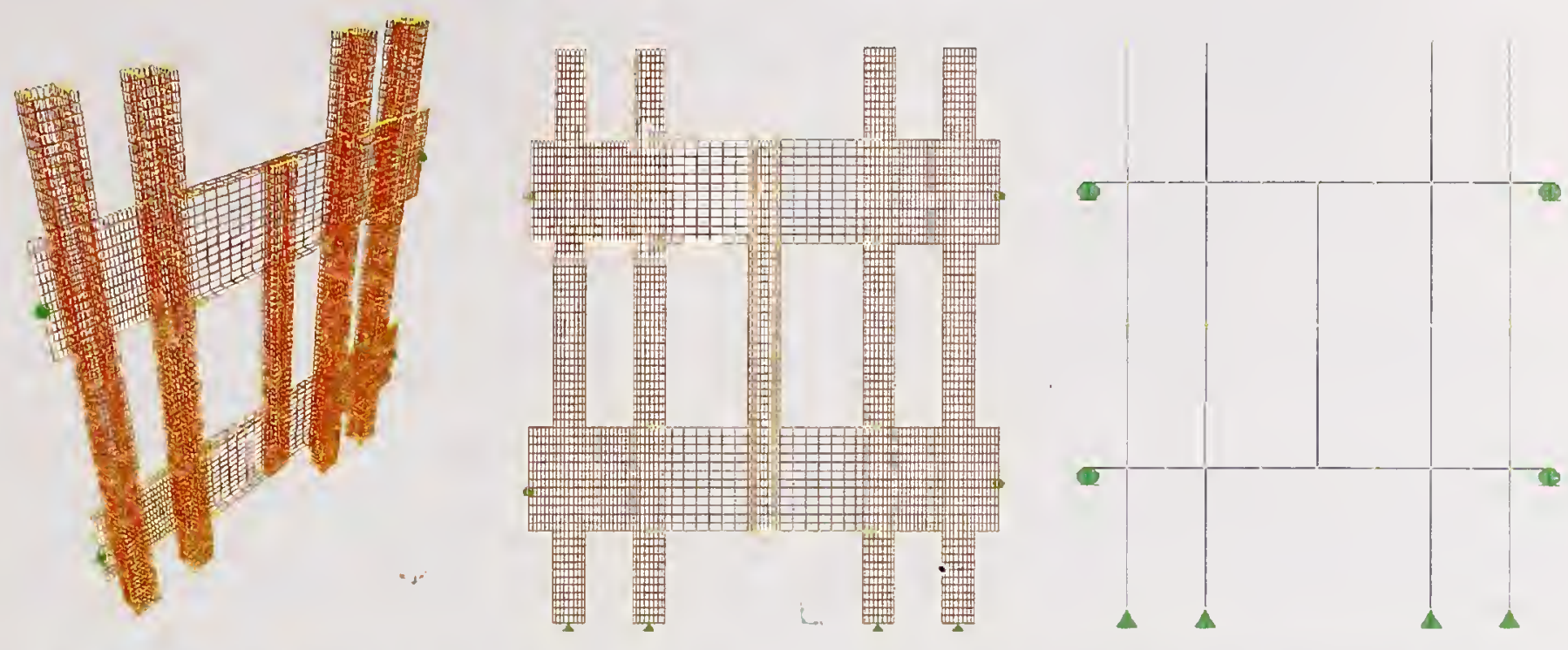

Figure B-35. Shell element and frame models of typical exterior wall corner panel.

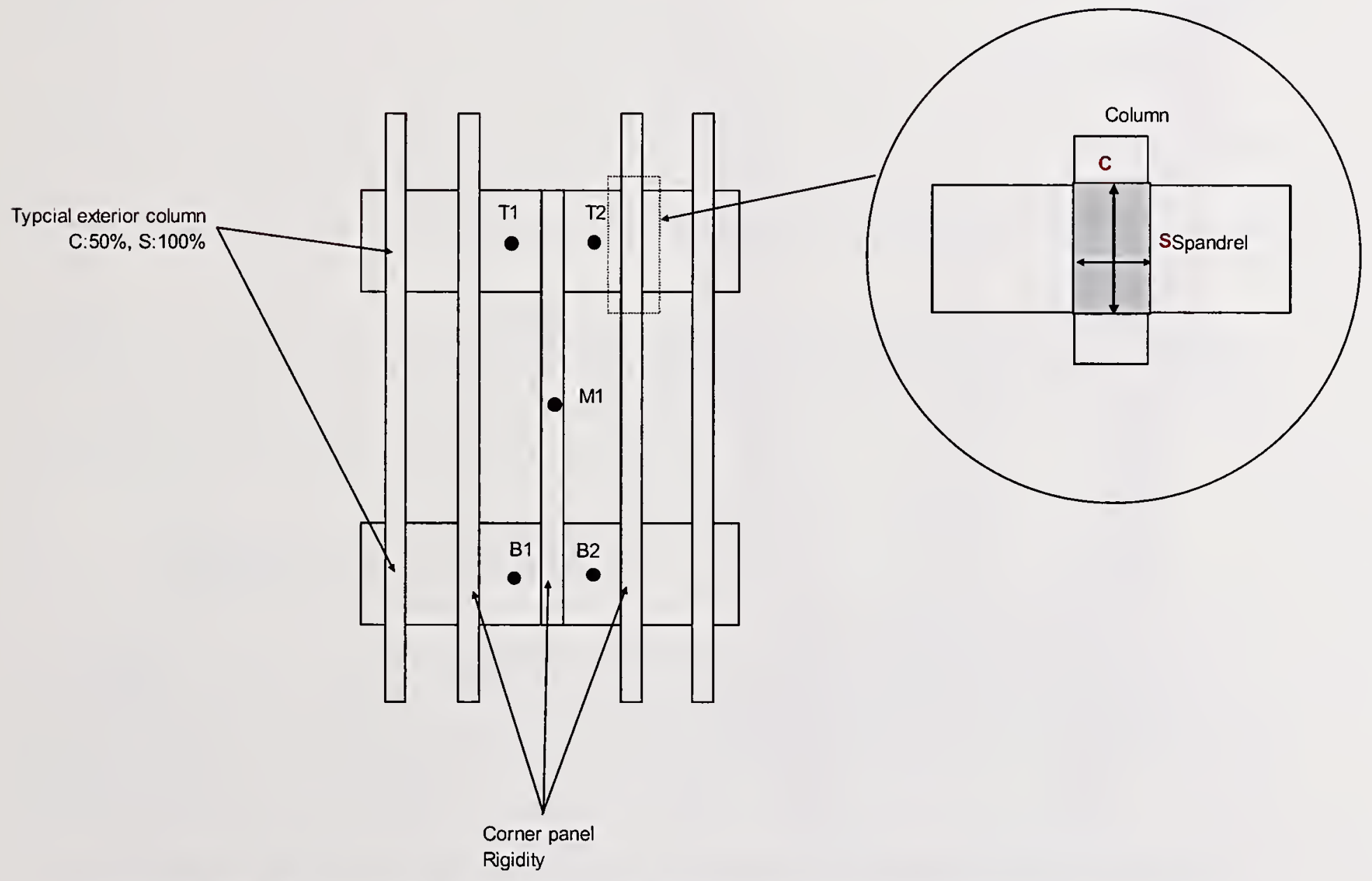

Figure B-36. Column and spandrel rigidity of typical exterior wall corner panel. 
Table B-4. Lateral displacement (in.) for the shell and frame models of typical exterior wall corner panel with varied column and spandrel rigidities.

\begin{tabular}{|c|c|c|c|c|}
\hline \multirow{2}{*}{} & \multirow{4}{*}{ Shell model } & \multicolumn{3}{|c|}{ Corner panel rigidity } \\
\cline { 3 - 5 } & & No rigidity & $\mathrm{C}: 25 \%, \mathrm{~S}: 50 \%$ & $\mathrm{C}: 100 \%, \mathrm{~S}: 100 \%$ \\
\hline T1 & 0.227 & 0.236 & 0.222 & 0.152 \\
\hline T2 & 0.227 & 0.236 & 0.222 & 0.152 \\
\hline M1 & 0.149 & 0.154 & 0.149 & 0.102 \\
\hline B1 & 0.084 & 0.072 & 0.077 & 0.053 \\
\hline B2 & 0.084 & 0.072 & 0.077 & 0.053 \\
\hline
\end{tabular}

As part of the in-house NIST review of the reference structural models (see Section B.4), a detailed shell element model of original corner panel (not straightened) was analyzed under lateral loads to test the accuracy of the simplified frame model with 25 percent column rigidity and 50 percent spandrel rigidity calculated above. Both the detailed and simplified models were loaded as shown in Fig. B-37. The deflections calculated from the frame model were consistent with those estimated from the shell model, indicating that the rigidities estimated using the straight model (Fig. B-35) accurately represent the actual corner panel behavior.
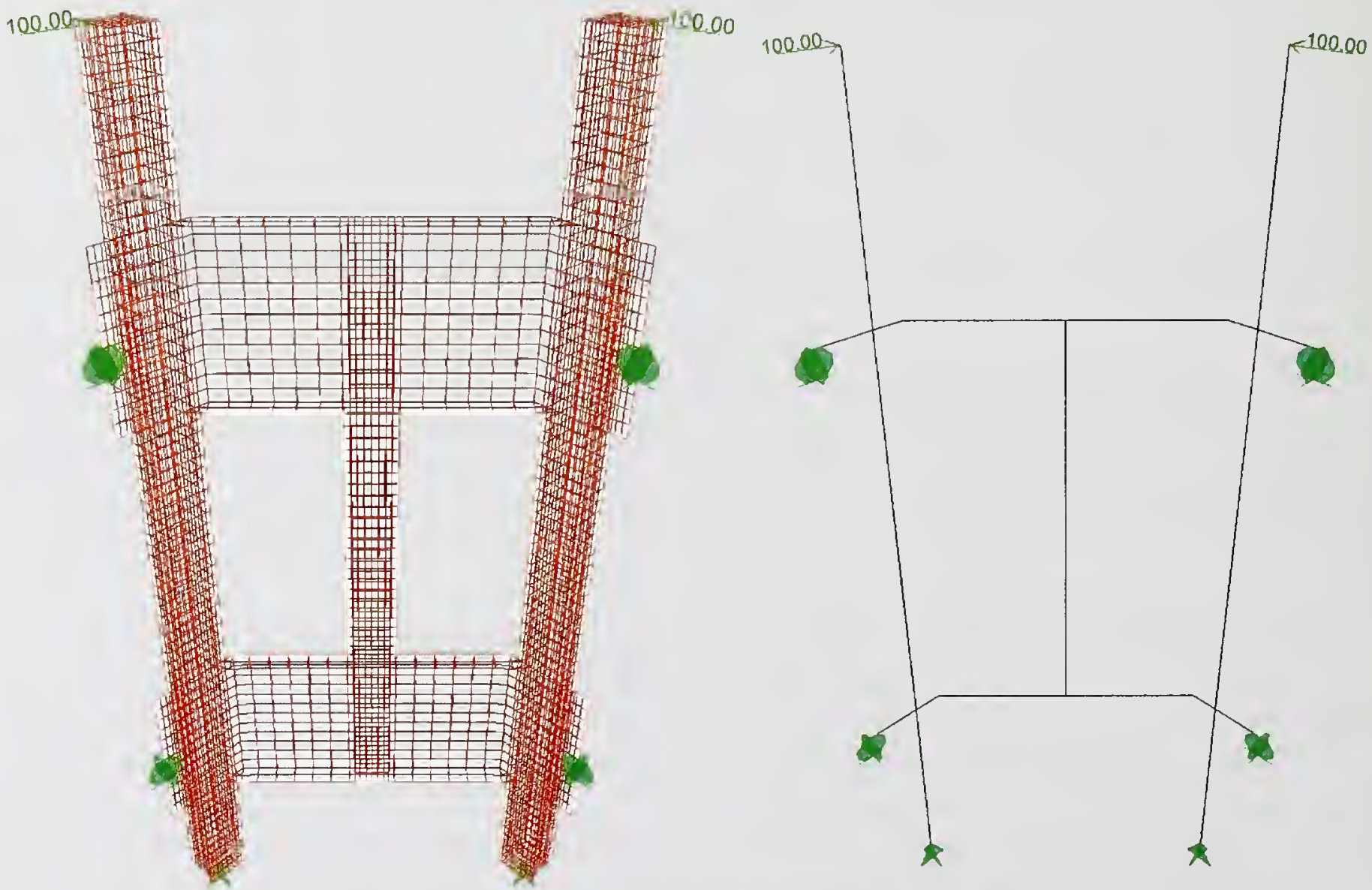

Figure B-37. Detailed and simplified model of the exterior wall corner panel.

\section{Flexible Floor Diaphragm}

The floor models developed in Sections B.3.2 and B.3.3 were used to develop the flexible diaphragm stiffness used within the WTC 1 and WTC 2 global models. The in-plane diaphragm stiffness of the 
detailed floor models was determined and used to arrive at an equivalent shell element floor model. This flexible shell element floor model is then inserted in the global models at specific floors to capture the inplane flow of forces and deformations. These flexible diaphragms were not used throughout, as the rigid diaphragms in the majority of floors provided for a sufficiently accurate representation of the flow of forces and deformations while keeping manageable the model's computational requirements. In the global models, flexible diaphragms were used at the beam-framed floors $3,4,5,6,7,9,41,42,43,75,76$, $77,107,108,109,110$, and roof of both towers.

Parametric studies were performed to compare the diaphragm stiffness of two different floor models for both the typical truss-framed floor and the beam-framed floor. The typical floor models were compared with the simplified equivalent models that duplicate the representation of the exterior wall columns, exterior wall spandrels, core columns, and their boundary conditions. The floor framing, both inside and outside the core was replaced by shell elements. The material properties of the shell model matched the properties of the concrete floor outside the core in the respective floor model.

The comparative floor models were loaded in the plane of the floors with a lateral load of $180 \mathrm{lb} / \mathrm{ft}$. (equivalent to $15 \mathrm{psf}$ over the $12 \mathrm{ft}$ story height) on both the windward and leeward faces. The column base supports were released for the exterior wall columns along the loaded faces and for all core columns to allow lateral translation only in the direction of loading.

The comparative models were executed to assess the horizontal deflection of the floor on both the windward and leeward sides of the model and for the case where the lateral loads were applied nonconcurrently along the 100 face and 200 face of the tower. Both the total horizontal deflection of the slab and the relative displacement between the windward and leeward sides were compared between the models. The shell thickness was modified to match the in-plane stiffness determined by the detailed floor models.

The deformations from the lateral load case using the 96 floor model of WTC 1 are illustrated in Fig. B-38, while Fig. B-39 shows the deformations of the simplified floor model. Fig. B-40 shows the lateral deflection of the north and south sides of the floor model under lateral load applied in the north direction using the detailed and equivalent floor models.

\section{B.4 REVIEW OF THE STRUCTURAL DATABASES AND REFERENCE MODELS OF THE TOWERS}

NIST has implemented a rigorous and comprehensive review procedure to mitigate potential conflicts of interest and to ensure the integrity and objectivity of the deliverables of this project, including the structural databases and reference models. The review procedure includes an in-house NIST review as well as a third-party review by the firm of SOM. The following summarizes the results of these reviews for the developed structural databases and reference models. 


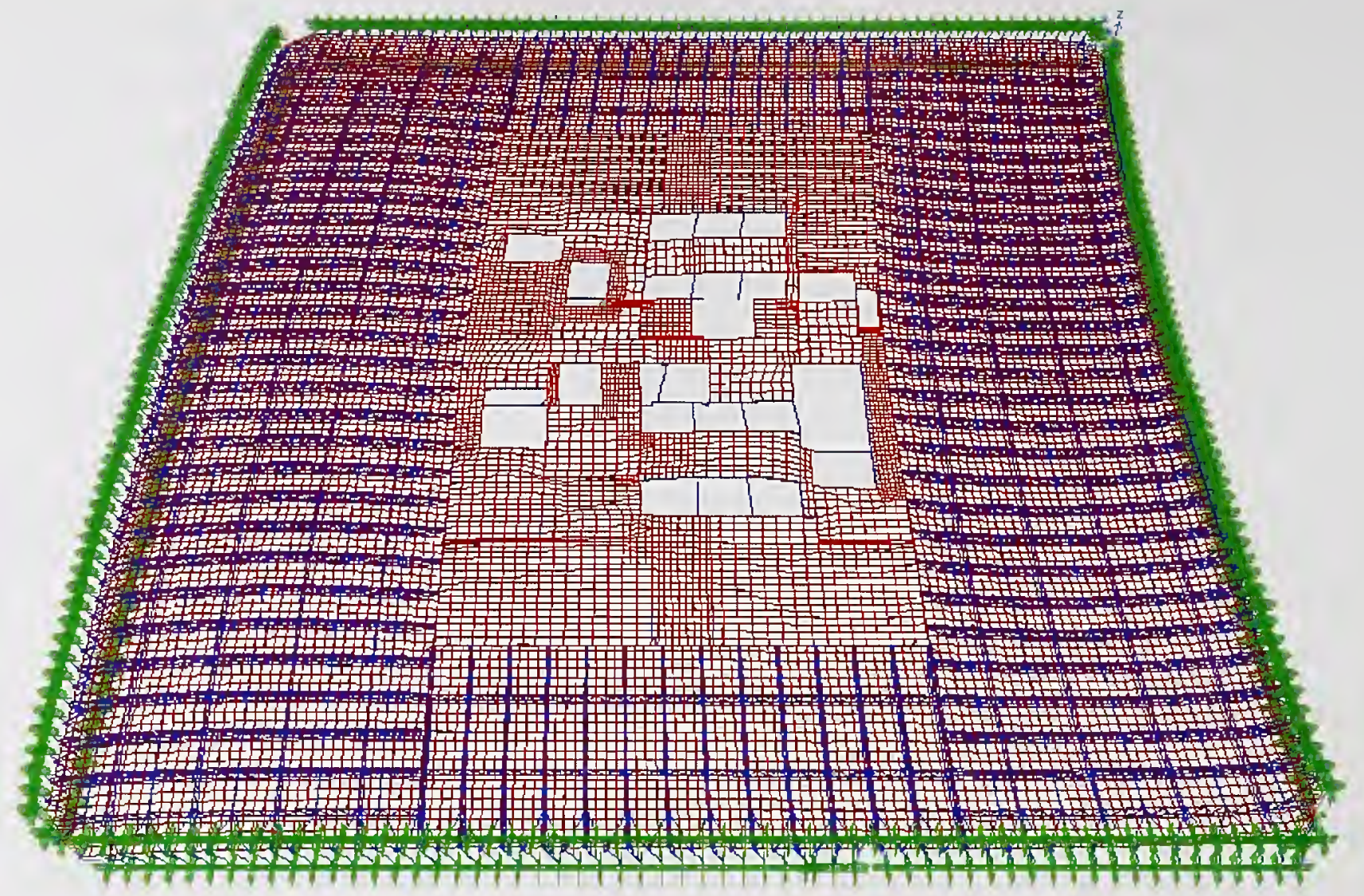

Figure B-38. Deflection of typical truss-framed floor model due to lateral loading (exaggerated scale).

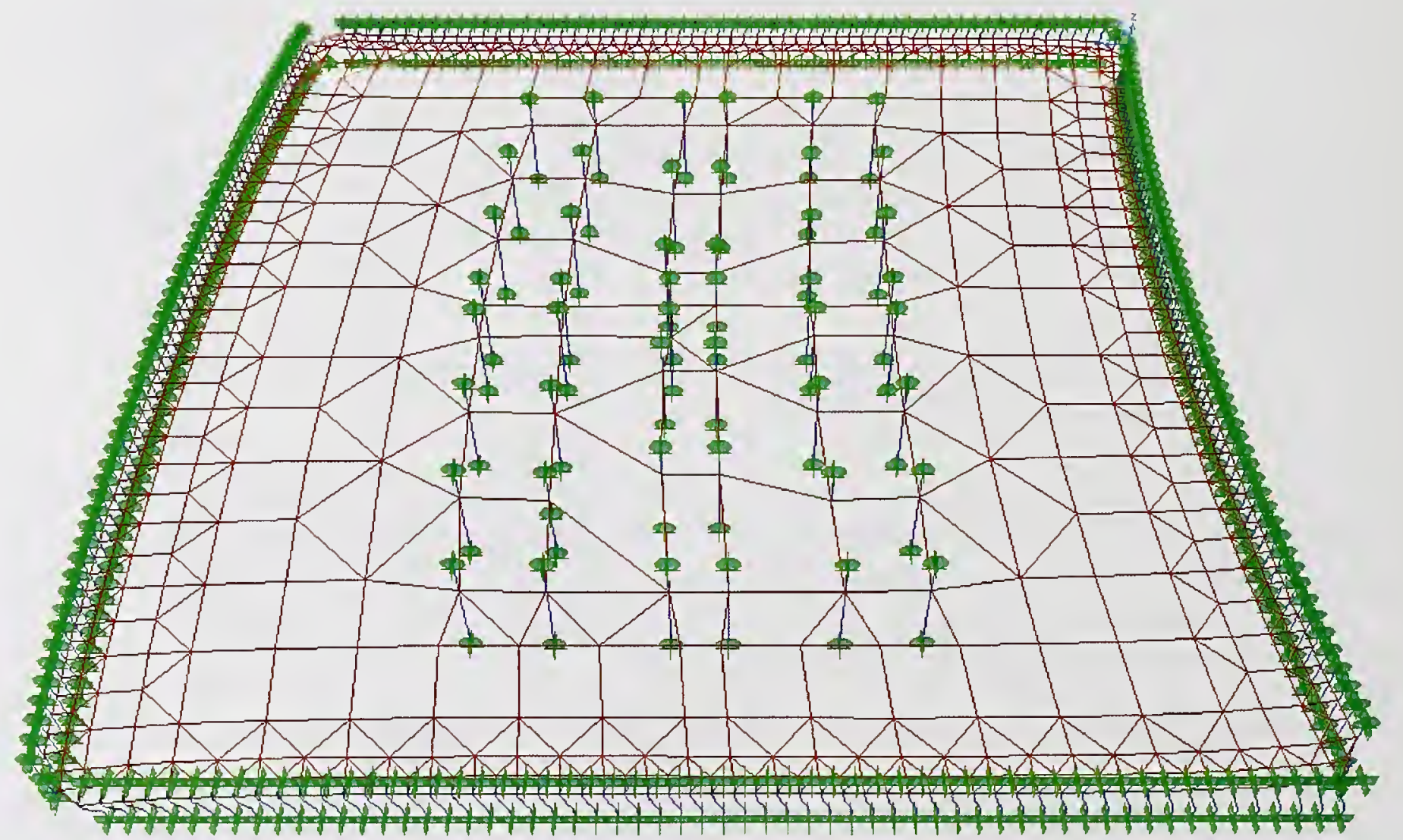

Figure B-39. Deflection of equivalent floor model due to lateral loading (exaggerated scale). 


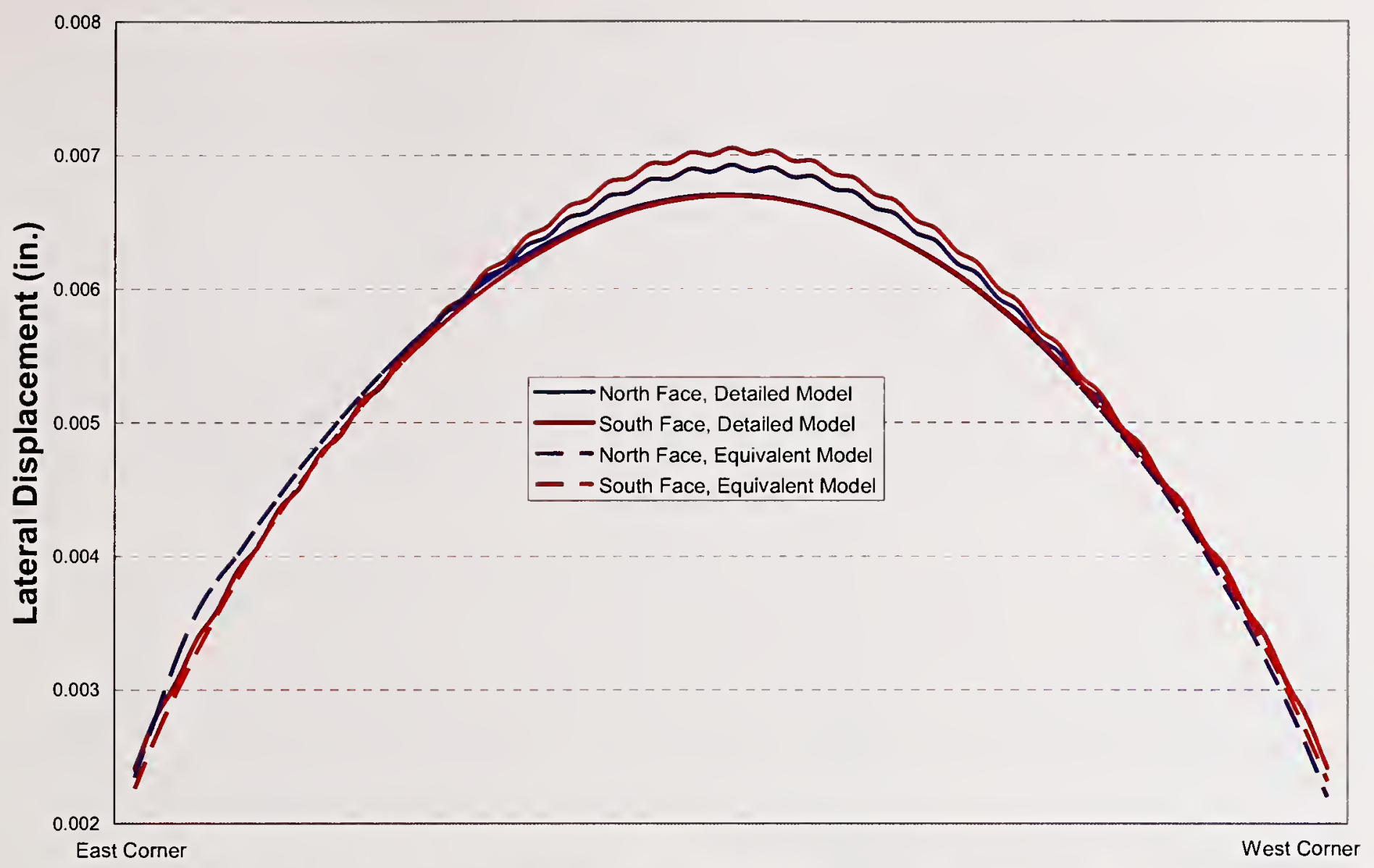

\section{Figure B-40. Deflections of the north and south faces of the floor for the detailed and equivalent floor models.}

\section{B.4.1 Review of the Structural Databases}

The third-party review by SOM included random checks of the digitized structural databases and cross section property calculations. The review indicated no discrepancies between the developed databases and the original drawing books. Also for cross section property calculations, the review indicated a good agreement (within 1 percent) between the properties in the developed databases and those estimated by SOM. Special attention was given to the calculation of the torsional constant, $J$ (see Section B.2.5). It was found that using the software ShapeBuilder, version 3.0 which uses a finite element approach for the calculation of $J$ a good agreement was obtained between the $J$ values in the developed databases and those estimated by SOM.

The in-house NIST review included the following steps: (1) line-by-line review of all database files, (2) random checks on the developed databases by the project leader, and (3) calculation of all cross section properties and comparison with those in the developed databases. The review indicated minor discrepancies between the developed databases and the original drawing books. For cross section property calculations, good agreement was obtained between the properties in the developed databases and those estimated by NIST. The discrepancies between the developed databases and the original drawing books were reported to LERA, who implemented the changes and modified the databases accordingly. Consequently, the structural databases have been approved by NIST and are being made available for other phases of the NIST investigation. 


\section{B.4.2 Review of the Reference Structural Models}

The third-party review by SOM included: (1) random checks of the consistency of the developed reference models with the original structural drawings and drawing books, and (2) verification and validation of the models, including reviewing assumptions and level of detail and performing analyses using various loading conditions to test the accuracy of the models. The review indicated that the developed models are consistent with the original design documents. The review indicated that, in general, the modeling assumptions and level of detail in the models are accurate and suitable for the purpose of the project. The SOM review identified two areas where the models need to be modified. The first is the effect of additional vertical stiffness of the exterior wall panels due to the presence of the spandrel beams (see Sections B.3.1 and B.3.4). The second area is the modeling of the connections of the floor slab to the exterior columns of the 75B floor model (Section B.3.3), where this connection appeared to be fixed while the connection should be modeled as pinned.

The in-house NIST review included: (1) checks on the consistency of the developed reference models with the original structural drawings and drawing books, and (2) verification and validation of the models, including reviewing assumptions and level of detail and performing analyses using various loading conditions to test the accuracy of the models. The review indicated minor discrepancies between the developed reference models and the original design documents. Similar to the third-party review, the inhouse NIST review identified the proper modeling of the vertical stiffness of the exterior wall panels and the accurate modeling of the floor slab connections to the exterior columns in the $75 \mathrm{~B}$ floor model as areas that need to be modified in the models.

In addition, NIST conducted a workshop for NIST investigators and contractors to review the reference structural models developed by LERA. The workshop attendees included experts from LERA (two experts); SOM (two experts); Teng and Associates (one expert, outside experts on probable structural collapse); Professor Kasper Willam (outside expert on thermal-structural analysis); Professor David M. Parks (outside expert on computational mechanics for aircraft impact analysis); Applied Research Associates (two experts, contractor on analysis of aircraft impact into the WTC towers) as well as all key investigators from NIST (17 experts). The purpose of the workshop was to discuss the methodology, assumptions, and details of the developed reference models. The minutes of the workshop are being prepared and will be made public. The feedback from the workshop was included in the final review of the models.

The discrepancies between the developed models and the original design documents, as well as the areas identified by both the third-party and in-house review for modification, were reported to LERA, who implemented the changes and modified the models accordingly. Consequently, the reference structural models have been approved by NIST and are being made available for other phases of the NIST investigation. 


\section{TABLE OF CONTENTS}

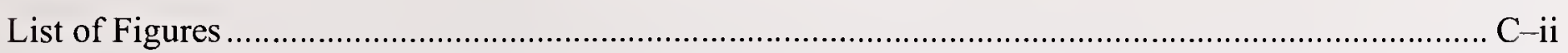

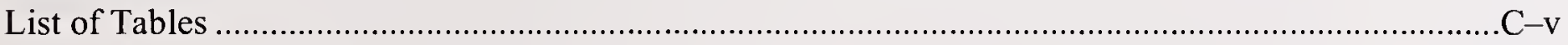

\section{Appendix C}

Interim Report on Analysis of Aircraft Impact into the WTC Towers ............................... C-1

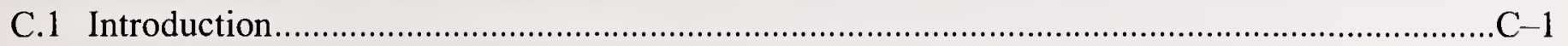

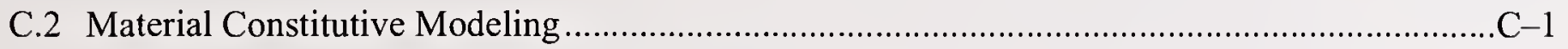

C.2.1 WTC Tower Steel Constitutive Models ....................................................................... -2

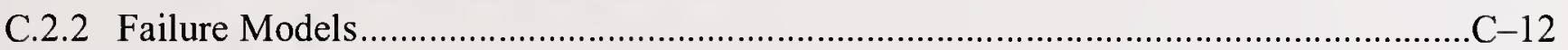

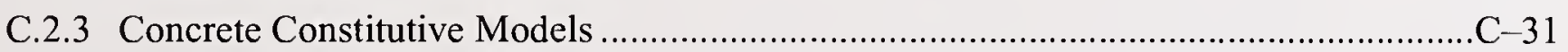

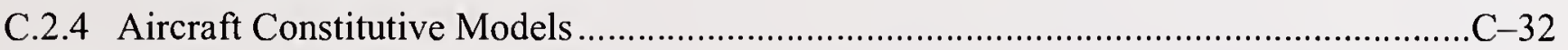

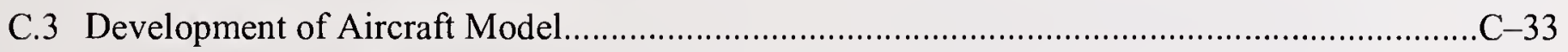

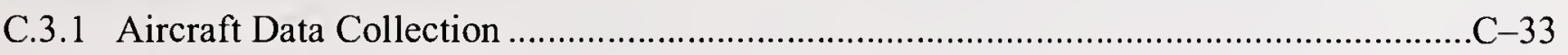

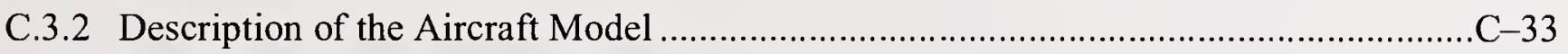

C.3.3 Analysis of Fuel Distribution at Impact ........................................................... -40

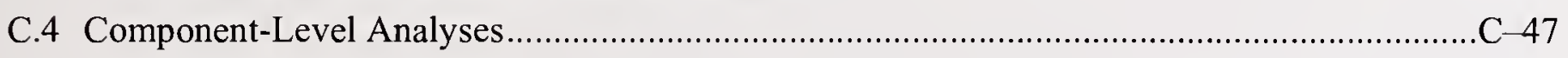

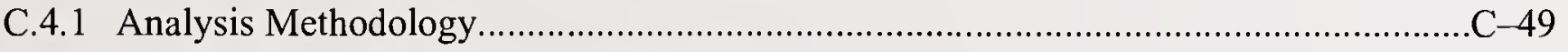

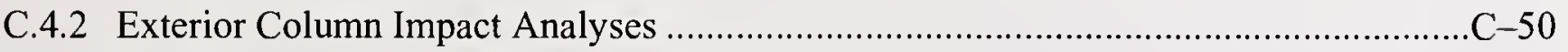

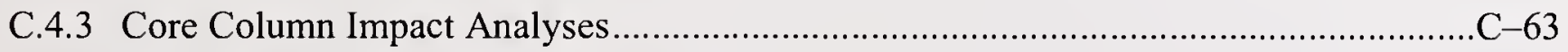

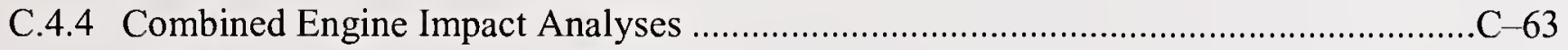

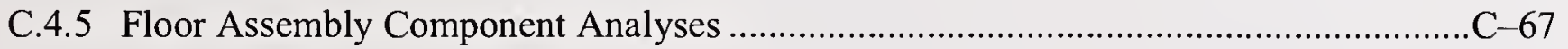

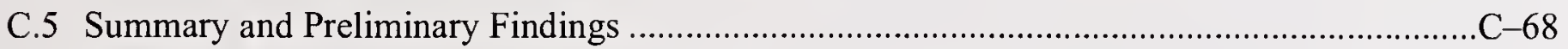

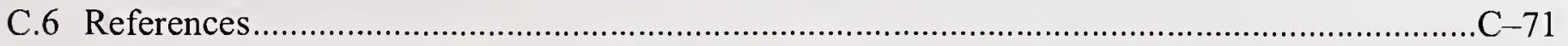




\section{LIST OF FIGURES}

Figure C-1. Example finite element models of the ASTM 370 rectangular tensile specimen. ......... C-3

Figure C-2. Example finite element models of the ASTM 370 round bar tensile specimen............. C-4

Figure C-3. Test data and true stres-strain conversion for the $75 \mathrm{ksi}$ steel................................... C-6

Figure C-4. Tabular true stress-strain constitutive model curve for the $75 \mathrm{ksi}$ steel. ....................... C-6

Figure C-5. Calculated tensile test response with necking for the $75 \mathrm{ksi}$ steel............................. C-7

Figure C-6. Comparison of measured and calculated engineering stress-strain curves for the

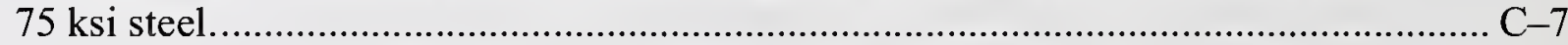

Figure C-7. Comparison of the constitutive model and synthetic steel behaviors for the $75 \mathrm{ksi}$

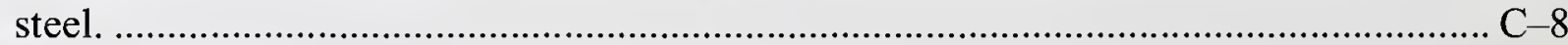

Figure $\mathrm{C}-8 . \quad$ Tabular true stress-strain constitutive model curves. ................................................. -9

Figure C-9. Comparison of the constitutive model and synthetic steel behaviors for the higher

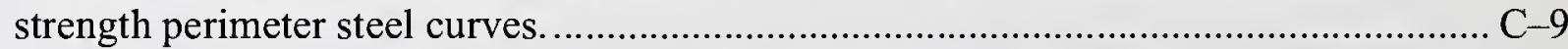

Figure $\mathrm{C}-10$. Comparison of the constitutive model and synthetic steel behaviors for the lower

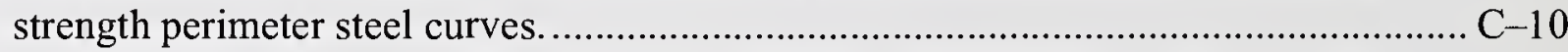

Figure $\mathrm{C}-11$. Comparison of the constitutive model and synthetic steel behaviors for the core

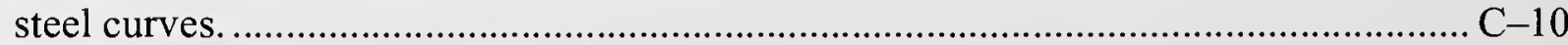

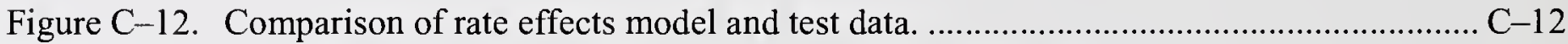

Figure $\mathrm{C}-13$. Calculated necking response in the $75 \mathrm{ksi}$ tensile specimen..................................... $\mathrm{C}-14$

Figure C-14. Coarse shell element mesh for the 75 ksi tensile specimen..........................................14

Figure $\mathrm{C}-15$. Mesh refinement effects in the calculated $75 \mathrm{ksi}$ tensile test. .................................. C-15

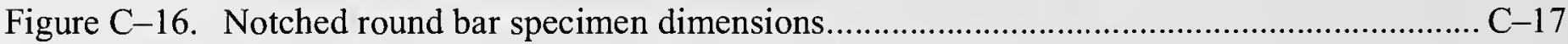

Figure $\mathrm{C}-17$. Notched round bar tensile specimen models........................................................... $\mathrm{C}-18$

Figure $\mathrm{C}-18$. Calculated notched round bar stress triaxiality. .......................................................

Figure $\mathrm{C}-1$ 9. Calculated critical plastic strain as a function of notched stress triaxiality................... C-19

Figure $\mathrm{C}-20$. Simulation of the notched and smooth round bar tests. ................................................ -20

Figure $\mathrm{C}-21$. Photograph of an exterior column with weld zone fractures....................................... C-21

Figure $\mathrm{C}-22$. Micrograph of an exterior column weld geometry ................................................. C-21

Figure $\mathrm{C}-23$. Microhardness characterization of the weld and $\mathrm{HAZ}$ materials............................. C-22

Figure $\mathrm{C}-24 . \quad 2-\mathrm{D}$ weldment model developed for analysis of failure behavior. ................................. C-23

Figure $\mathrm{C}-25$. Simulation of the $55 \mathrm{ksi}$ steel tensile test. .....................................................................24

Figure $\mathrm{C}-26$. Mesh resolutions used in the 2-D weldment failure model........................................ C-24

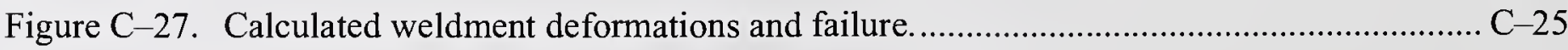

Figure $\mathrm{C}-28$. Detail of the calculated weldment failure behavior.................................................... C -25 
Figure C-29. Mesh refinement effects on calculated weldment failure behavior............................ C-26

Figure $\mathrm{C}-30$. Calculated energy balance for the 2-D weldment models......................................... C-27

Figure $\mathrm{C}-31$. Drop test model for column weld fracture analysis. ................................................ -27

Figure $\mathrm{C}-32$. Models developed for column weld fracture analysis............................................ C-28

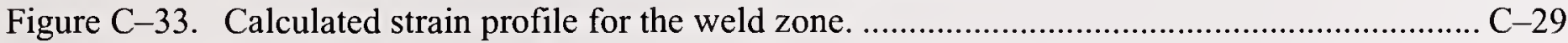

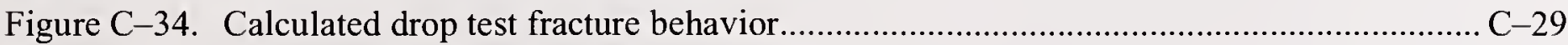

Figure C-35. Measured bolt load-displacement behavior............................................................. C-30

Figure $\mathrm{C}-36$. Comparison of the measured and calculated bolt behavior....................................... C-31

Figure $\mathrm{C}-37$. Finite element analysis of the unconfined compression test. ...................................... C-32

Figure $\mathrm{C}-38$. Comparison of the calculated unconfined compression behavior with concrete

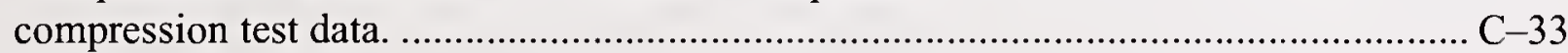

Figure $\mathrm{C}-39$. Digitized engineering stress-strain curves for various 2024 aluminum alloys............. C-34

Figure $\mathrm{C}-40$. Digitized engineering stress-strain curves for various 7075 aluminum alloys............. C-34

Figure $\mathrm{C}-41$. True stress-strain curves developed for various aircraft aluminum alloys.................. C-35

Figure $\mathrm{C}-42$. Tabular true stress-strain curves developed for various aircraft aluminum alloys........ $\mathrm{C}-35$

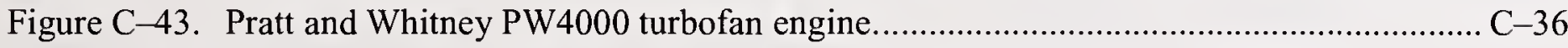

Figure $\mathrm{C}-44$. PW4000 engine cross sectional geometry and simplification.................................. C-37

Figure C-45. Pratt and Whitney PW4000 turbofan engine model............................................... C-37

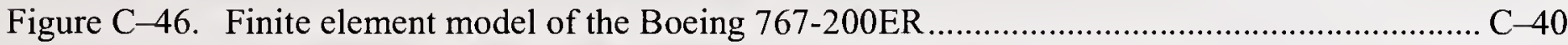

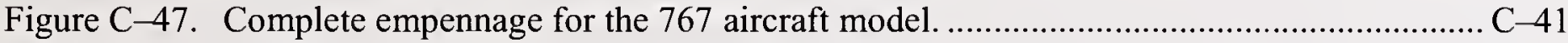

Figure C-48. Retracted landing gear components for the 767 aircraft model. .............................. C -41

Figure $\mathrm{C}-49$. Underside of the 767 airframe model (skin removed) showing the position of

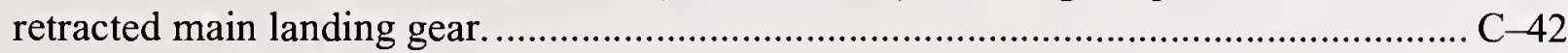

Figure $\mathrm{C}-50$. Complete wing structures for the 767 aircraft model........................................... C -42

Figure C-51. Small wing section model for component-level analyses. ....................................... C-43

Figure $\mathrm{C}-52$. Wing section model developed for the subassembly impact simulations. .................. C -43

Figure $\mathrm{C}-53$. Flammable material locations in a Boeing 767 aircraft........................................... C -44

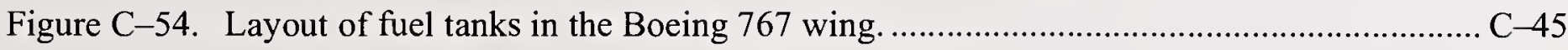

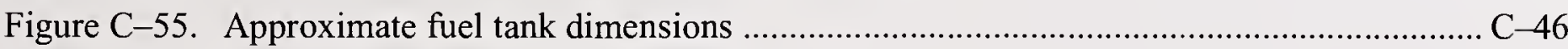

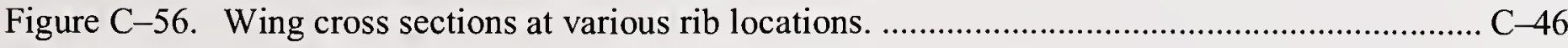

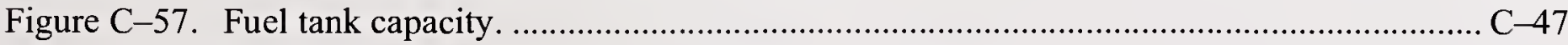

Figure C-58. Approximate fuel locations for smooth and level flight.......................................... C -48

Figure C-59. Exterior column response comparison, showing contours of the displacement

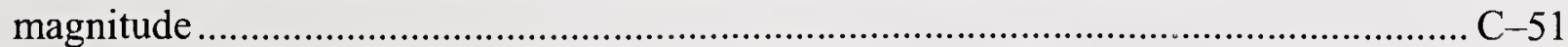

Figure $\mathrm{C}-60$. Calculated impact damage with the empty short wing section component model........ C-52 Figure $\mathrm{C}-61$. Damage produced by the empty wing section impact.............................................. C-52 


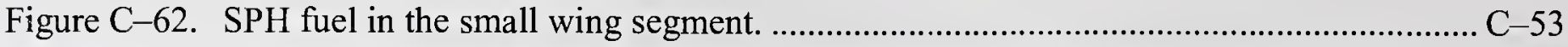

Figure C-63. Exterior panels impact behavior for a wing segment with fuel (SPH fuel model)....... C-54

Figure C-64. SPH Analysis of structural damage and fuel dispersion (top view)............................ C-55

Figure $\mathrm{C}-65$. ALE analysis of structural damage and fuel dispersion (top view).............................. C-55

Figure C-66. SPH analysis of structural damage and fuel dispersion (side view) ............................. C-56

Figure C-67. ALE analysis of structural damage and fuel dispersion (side view). .......................... C-56

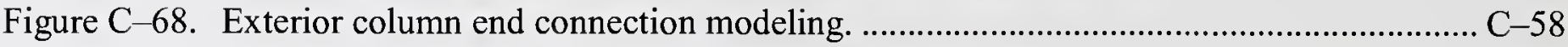

Figure C-69. Typical bolt bearing shear failures of spandrel connections. ..................................... C-58

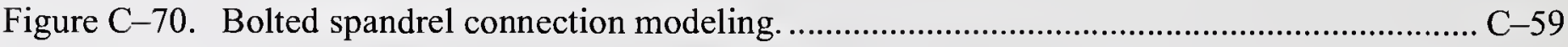

Figure $\mathrm{C}-71$. Example engine impact analysis with exterior columns. ........................................ C-60

Figure $\mathrm{C}-72$. Engine velocity history for the exterior wall impact............................................. C-61

Figure $\mathrm{C}-73$. Example engine impact analysis with different impact locations. ............................ C-61

Figure $\mathrm{C}-74$. Example engine impact analysis with different spandrel connection treatments.......... C-62

Figure $\mathrm{C}-75$. Engine velocity history for the exterior wall impact................................................. -62

Figure $\mathrm{C}-76$. Wide flange core column response comparison, showing contours of the

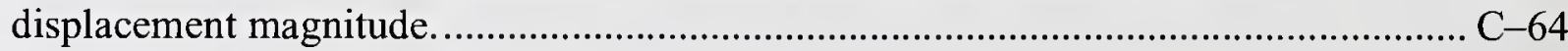

Figure $\mathrm{C}-77$. Displacement and kinetic energy comparison for wide flange core column wing

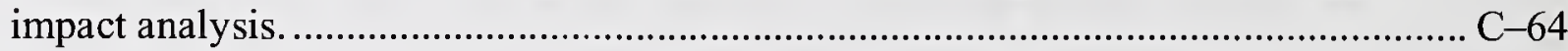

Figure $\mathrm{C}-78$. Box core column response comparison, showing contours of the displacement

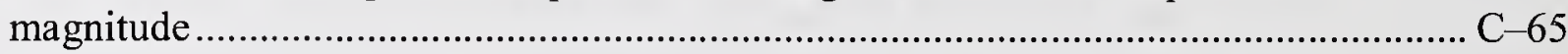

Figure C-79. Displacement and kinetic energy comparison for box core column wing impact

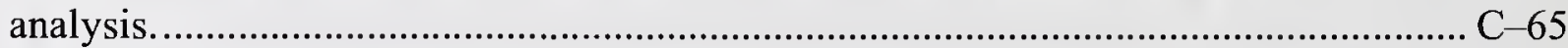

Figure $\mathrm{C}-80$. Example engine impact analysis with interior and exterior columns......................... C-66

Figure $\mathrm{C}-81$. Example engine impact analysis with interior and exterior columns.......................... C-67

Figure C-82. Floor assembly impact analysis with brick element concrete slab............................... C-69

Figure $\mathrm{C}-83$. Floor assembly impact analysis with shell element concrete slab. ............................ C-70 


\section{LIST OF TABLES}

Table C-1. Material constitutive parameter table-WTC tower steels......................................... C-11

Table C-2. Summary of notched round bar tensile tests. ...................................................... C-17

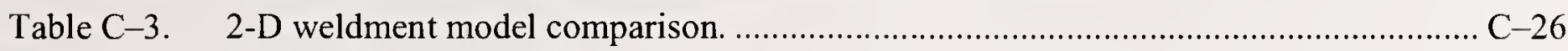

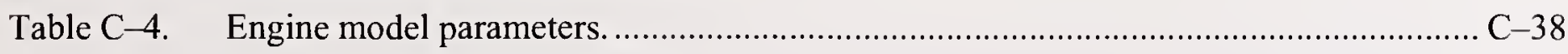

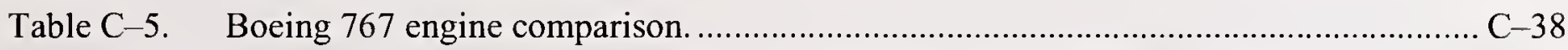

Table C-6. Summary of Boeing 767-200 aircraft model size (under construction)..................... C-42

Table C-7. Truss floor assembly component analyses comparison. ........................................ C-68 
This page intentionally left blank.

C-vi 


\section{Appendix C \\ INTERIM REPORT ON ANALYSIS OF AIRCRAFT IMPACT INTO THE WTC TOWERS}

\section{C.1 INTRODUCTION}

One of the objectives of Project 2, Baseline Structural Performance and Aircraft Impact Damage Analysis, of the National Institute of Standards and Technology (NIST)-led investigation into the collapse of the World Trade Center (WTC) towers is to analyze the aircraft impact into each of the two towers. The purpose of this analysis is to provide the following: (1) estimates of the damage to structural systems due to aircraft impact - including exterior walls, floor systems, and interior core columns; (2) estimates of the aircraft fuel dispersal during impact; (3) estimates of accelerations and deformations as a function of time in each of the two towers due to aircraft impact to be used for estimating damage to fire proofing; and (4) a database of the major fragments of the aircraft and destroyed structural components of the towers to be used for estimating damage to the mechanical and architectural systems inside the towers. The analyses, thus, establish the initial conditions for the fire dynamics modeling in Project 5 , Reconstruction of Thermal and Tenability Environment, and the thermal-structural response and collapse initiation analysis in Project 6, Structural Fire Response and Collapse Analysis.

The impact analyses are conducted at various levels including: (1) the component level, (2) the subassembly level, and (3) the global level to estimate the probable damage to the towers due to aircraft impact. The analyses also include simplified and approximate methods. Analysis of uncertainties using the component, subassembly, global, and simplified analyses will also be conducted to assess the effect of variability associated with various parameters on the damage estimates. NIST is working with experts from Applied Research Associates (ARA), Inc., to conduct the impact analyses. This appendix summarizes the progress made to date on this project. Emphasis is on the models development and component level analyses.

Section C. 2 outlines the development of constitutive models describing the actual behavior of the various materials included in the aircraft impact analysis. The materials in this section include WTC steels, reinforced concrete, and aircraft materials. Special emphasis is also placed on the modeling of weldments and bolts. Section C.3 presents the status of the development of the aircraft model, including the engine and airframe. This section also provides an analysis of the fuel distribution at the time of aircraft impact. Section C. 4 provides details on the component level analyses performed to date, including exterior and core columns, column and spandrel connections, and floor segments under the impact of an aircraft engine or a segment of a wing. A summary and preliminary findings are provided in Section C.5.

\section{C.2 MATERIAL CONSTITUTIVE MODELING}

An important requirement for high fidelity simulation of the aircraft impact damage is the development of constitutive models to represent the actual behavior of the structure under the dynamic impact conditions of the aircraft. The primary materials that need to be considered for the component analyses are the several grades of steel used in the columns, spandrels, and floor trusses and beams of the WTC towers, 
the concrete floor slabs, and the aluminum airframe structure of the Boeing 767 aircraft. All of these materials play a significant role in the aircraft impact damage analyses. These materials also display significant nonlinear rate-dependent deformation and failure behavior.

The analysis of the aircraft impact damage is being performed with the LS-DYNA finite element code (LS-DYNA 2003). LS-DYNA has an extensive library of more that 130 different constitutive models and is capable of accurately reproducing the important material behaviors required in this analysis. Material models currently available in LS-DYNA have been utilized for the analyses using material data from tests conducted by NIST or available in the public domain.

Secondary materials of interest include the nonstructural aircraft components and masses such as fuel, seats, interior trim, cargo, and luggage. Furthermore, a significant part of the mass of the WTC towers is material not included in the primary structural steel frame that includes windows, nonstructural walls, partitions, furniture and other building contents, flooring, mechanical equipment, and insulation. Selection of the constitutive modeling for these secondary material behaviors has not yet been performed. However, the strength of these materials is relatively small compared to the structural materials and simple description of their constitutive behavior will be adequate.

\section{C.2.1 WTC Tower Steel Constitutive Models}

Various constitutive models are available in LS-DYNA that can capture the nonlinear behavior of the steel under impact conditions including strain rates effects and failure. The primary constitutive model applied to date is the Piecewise Linear Plasticity model. This model is sufficient to model the nonlinear dynamic deformation and failure of the steel structures. A tabular effective stress versus effective strain curve can be used in this model with various definitions of strain rate dependency.

The constitutive model parameters were developed for each grade of steel used in the construction of the WTC towers based on engineering stress-strain data provided by Project 3 of the NIST-led investigation on Mechanical and Metallurgical Analysis of Structural Steel. The approach to developing the constitutive parameters for each grade of steel was:

- Convert the engineering stress-strain curve to a true stress versus true strain curve. The conversion process is described below and is valid up to the onset of necking in the specimen.

- Extrapolate the true-stress-strain curve beyond the point of necking onset.

- Perform iterative finite element analyses of the tensile test and adjust the true stress-strain curve extrapolation and failure strain until the necking behavior and failure point are accurately captured. The primary criterion is the quantitative agreement of the measured and calculated engineering stress-strain behavior in the softening region beyond maximum stress. These analyses require a fine mesh resolution in the specimen to accurately model the large strain deformation response during necking.

- Perform a final finite element analysis of the material test using a coarser mesh resolution (medium mesh corresponding to the mesh resolution applied in the component analyses). Adjust the failure criteria (strain at failure) to obtain failure at the same engineering strain level. 
The advantage of this approach is that the measured nonlinear material behavior up to failure is accurately captured in the constitutive model. In addition, the simulation of the material testing provides a validation that the constitutive model parameters are defined accurately and that the model can reproduce the measured response for the test conditions.

The tensile tests performed by NIST applied the ASTM 370 test standard (ASTM Designation A 370-03a 2003). Example finite element models of a rectangular test specimen with the fine and medium mesh resolutions are shown in Fig. $\mathrm{C}-1$. This specimen type was used for all of the tests on WTC exterior column materials. A similar figure of the round bar specimen models used for testing of the WTC core column steels is shown in Fig. C-2. The typical element length used in the gage section for the fine meshes is approximately $0.015 \mathrm{in}$. and for the medium meshes is approximately $0.10 \mathrm{in}$. The use of the specimen models to develop the constitutive model parameters is described in the following subsections.

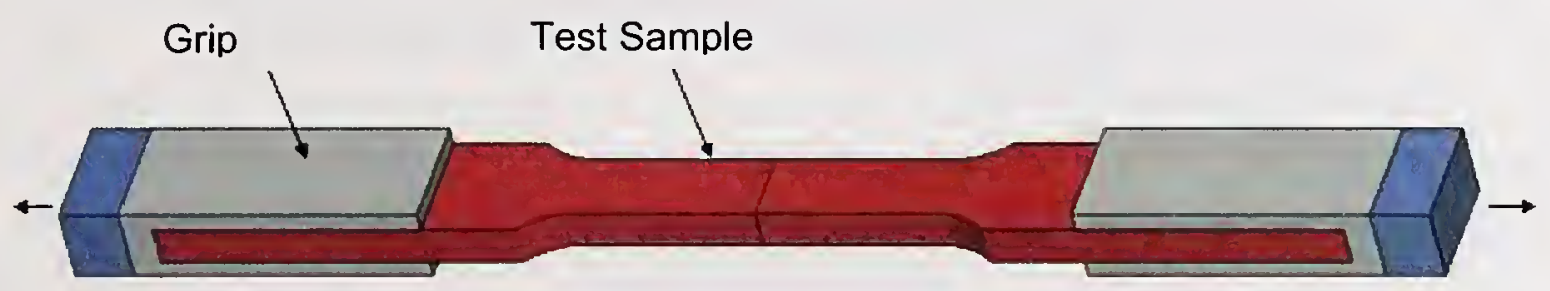

Fine Mesh
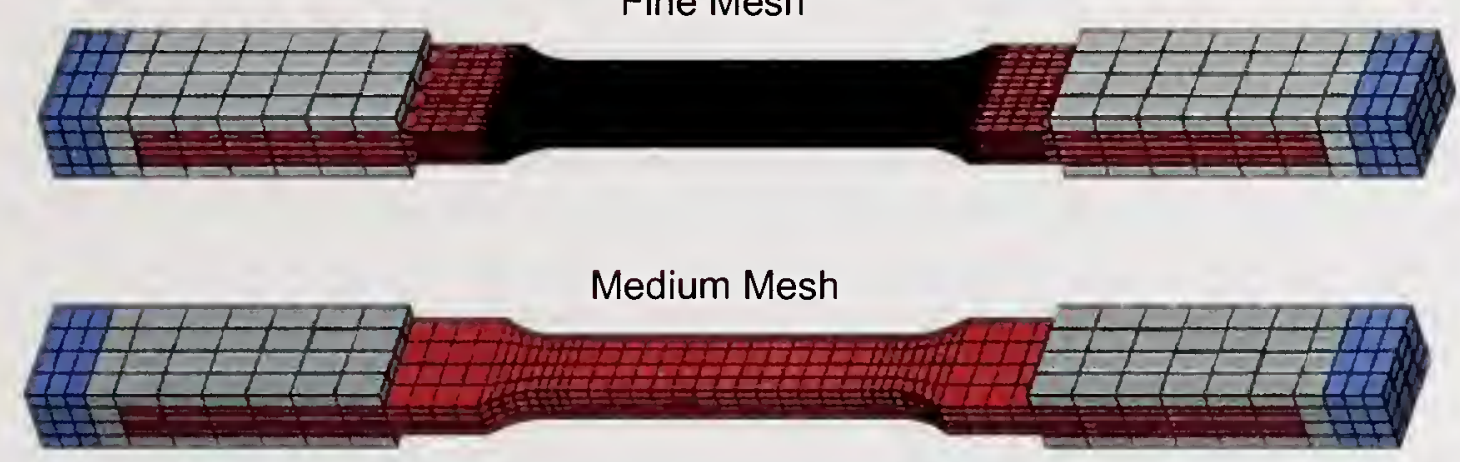

\section{Figure C-1. Example finite element models of the ASTM 370 rectangular tensile specimen.}

\section{True Stress and True Strain Corrections}

In most tensile tests, a plot is generated of the load measured at the cross head of the testing machine against the displacement of the specimen. A plot of engineering stress versus strain can be generated from this plot by dividing the load by the original cross sectional area of the specimen and the displacement by the original length of the specimen. If the changes in area and length are small during the test, these measures give a good indication of material behavior. However, in reality, the cross section changes (shrinks) significantly during the test and the engineering stress does not yield the "true" stress in the cross section. Similarly, the engineering strain is not representative of the material behavior, especially when a general 3-D state of strain exists. As a result, the engineering stress decreases as some materials approach failure, implying a weakening of the material. In reality, the stress in the cross section is increasing due to the reduction in the cross sectional area (i.e., necking). 

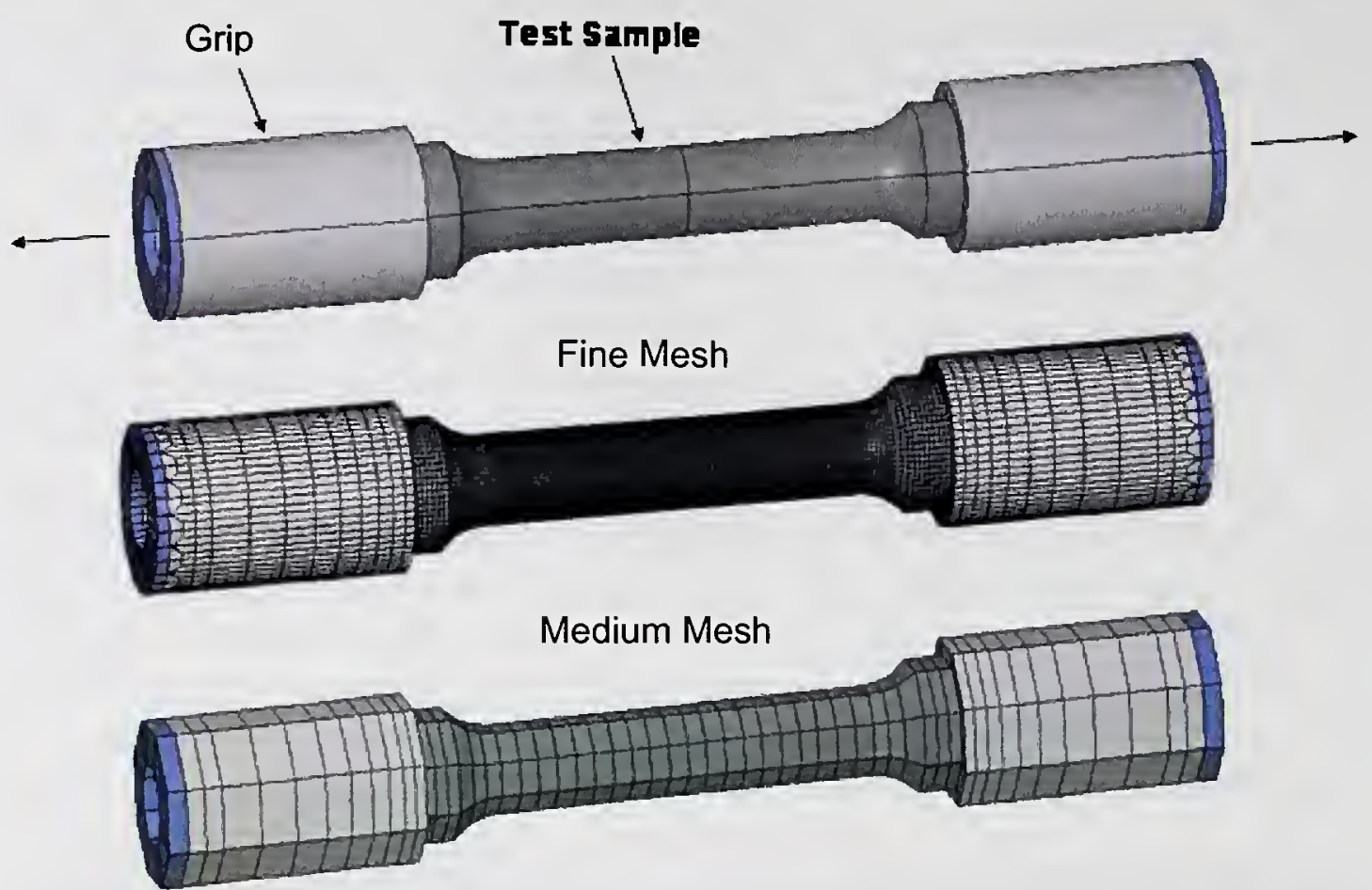

Figure C-2. Example finite element models of the ASTM 370 round bar tensile specimen.

There are several different ways to measure stress and strain based on the coordinate system used. Some are based on material (Lagrangian) coordinates and some on spatial (Eulerian) coordinates. These give rise to terms such as "Green" and "Almansi" strain tensors. These are important in writing a computer code to solve large strain problems. An alternate approach is to define a "true" or "natural" stress and strain. The true stress is based on the load divided by the actual cross sectional area of the specimen and is equal to the engineering stress multiplied by a term to correct for the change in cross section.

$$
\sigma_{T}=\sigma_{\text {eng }}(1+e)
$$

where:

$$
\begin{aligned}
& \sigma_{T}=\text { true stress } \\
& \sigma_{\text {eng }}=\text { engineering stress } \\
& e=\text { engineering strain }
\end{aligned}
$$

The natural or true strain is defined as

$$
\varepsilon_{T}=\ln \left(\frac{l}{l_{o}}\right)=\ln (1+e)
$$

where:

$$
\varepsilon_{T}=\text { true strain }
$$


This definition comes about from defining the incremental true or "natural" strain as the current "change in length" divided by the current length, or

$$
d \varepsilon_{T}=\frac{d l}{l}
$$

This is in contrast with the definition of engineering strain that references the change in length, $\Delta l$, divided by the original length, $l_{0}$, or

$$
e=\frac{\Delta l}{l_{0}}
$$

\section{Development of Steel Constitutive Properties}

In this section, examples are provided to illustrate the methodology for the development of the steel constitutive models and typical results. Figure $\mathrm{C}-3$ shows an example of the measured engineering stress-strain behavior for the $75 \mathrm{ksi}$ perimeter column steel. Four tests were performed by Project 3 , and the data clearly indicates anisotropy in the behavior introduced by the roll forming process (longitudinal tests $\mathrm{L} 1$ and $\mathrm{L} 2$ versus transverse tests $\mathrm{T} 1$ and $\mathrm{T} 2$ in the figure). This particular grade of steel had a larger anisotropy than seen in most of the other steel grades. Whenever anisotropy was observed, the material had greater ductility for specimens aligned with the rolling direction. In addition, the largest effects of the anisotropy were seen in the behavior after the onset of necking.

The first step in the constitutive model development process is to obtain a true stress-true strain curve. The typical approach is to select a representative test and perform the data conversion process described earlier. In this example, the data from test L1 was used to create the true stress-strain curve shown in Fig. C-3. This true stress-strain curve is then approximated by a piecewise linear curve in tabular form as shown in Fig. C-4. This tabular curve is the input used to specify the mechanical behavior in the constitutive model.

The final step is to apply the tabular true stress-strain behavior in the constitutive model to simulate the tensile test as shown in Fig. C-5. If necessary, the extrapolation of the true stress-strain behavior is adjusted until the simulation matches the measured engineering stress-strain response including necking and failure (the portion of the stress-strain curve beyond the maximum engineering stress). A comparison of the calculated and measured tensile behavior for the $75 \mathrm{ksi}$ perimeter steel is shown in Fig. C-6. In this example, the constitutive model was developed as an average between the longitudinal and transverse properties. Test results conducted by Project 3 on the tower steels indicated that the stress-strain behavior is very similar in the longitudinal and transverse directions up to the onset of necking. The difference between the longitudinal and transverse properties is in the ductility, where the average ratio of the longitudinal to transverse strain to failure in the exterior column steels is about 1.22:1. The approach used in the constitutive modeling is to use an average between the longitudinal and transverse properties and ignore the orthotropic characteristics of the material in the impact analyses. The effects produced by the variation of ductility between the longitudinal and transverse directions will be assessed as part of the uncertainty analyses. 


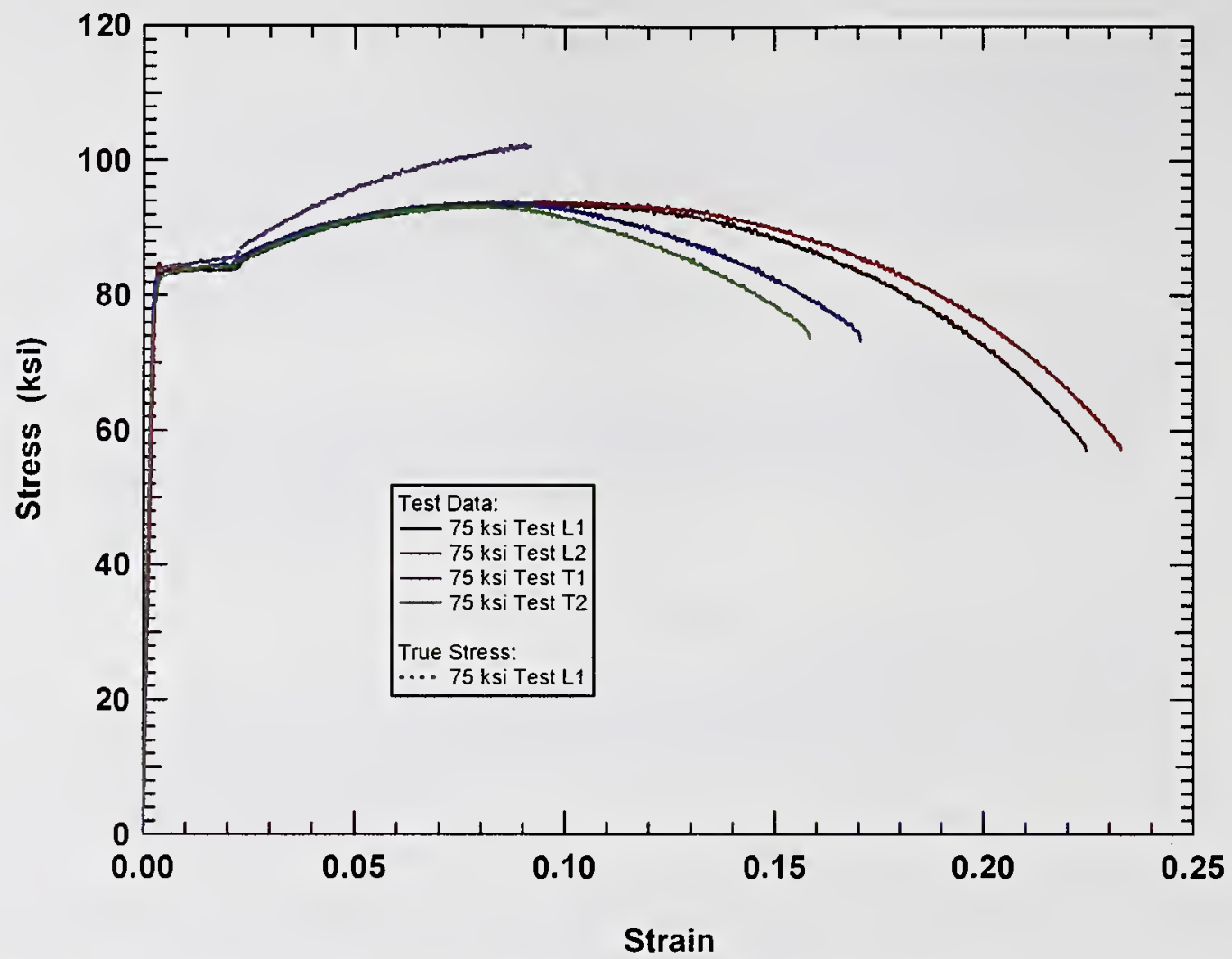

Figure $\mathrm{C}-3$. Test data and true stress-strain conversion for the $\mathbf{7 5} \mathrm{ksi}$ steel.

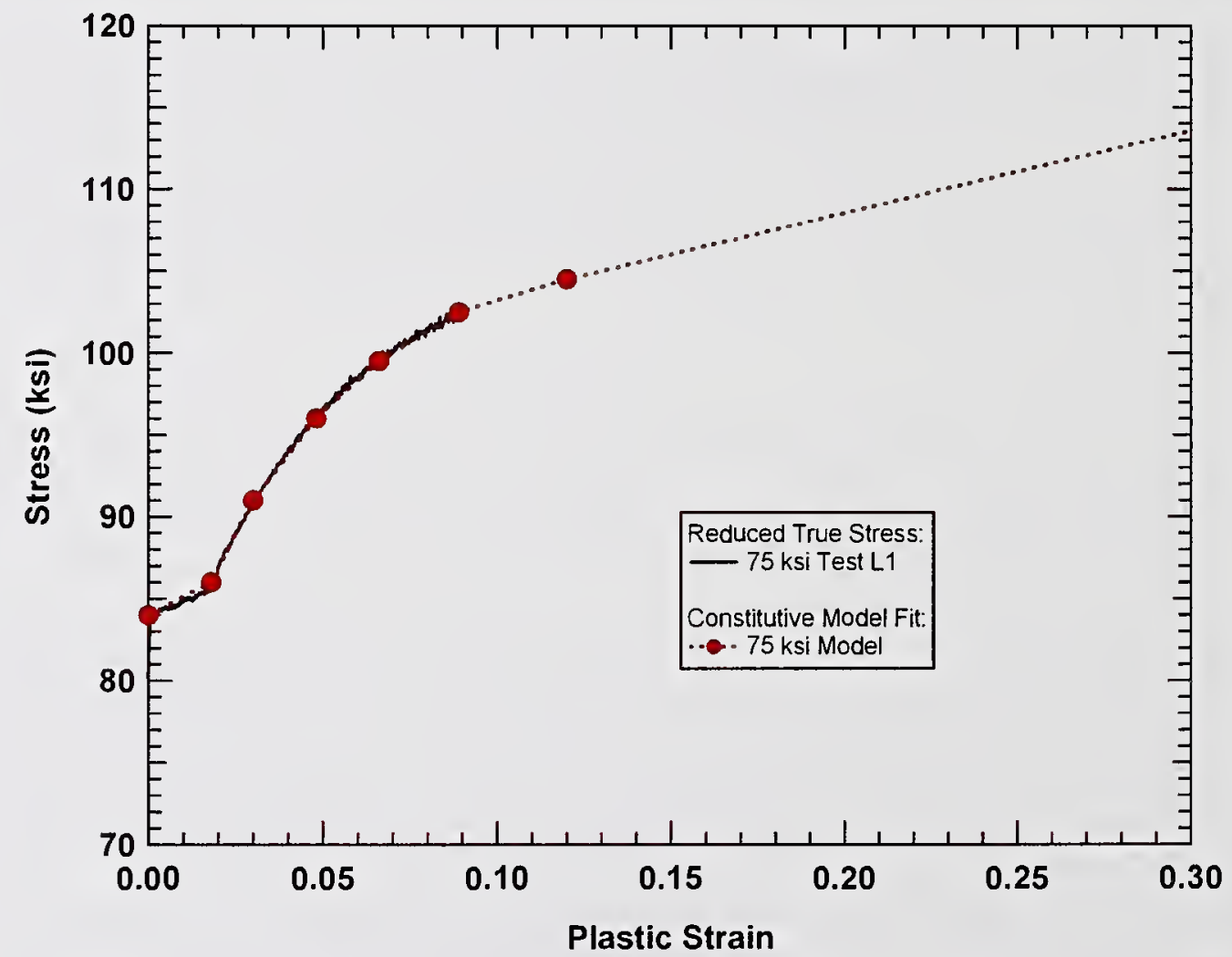

Figure C-4. Tabular true stress-strain constitutive model curve for the $\mathbf{7 5} \mathrm{ksi}$ steel. 

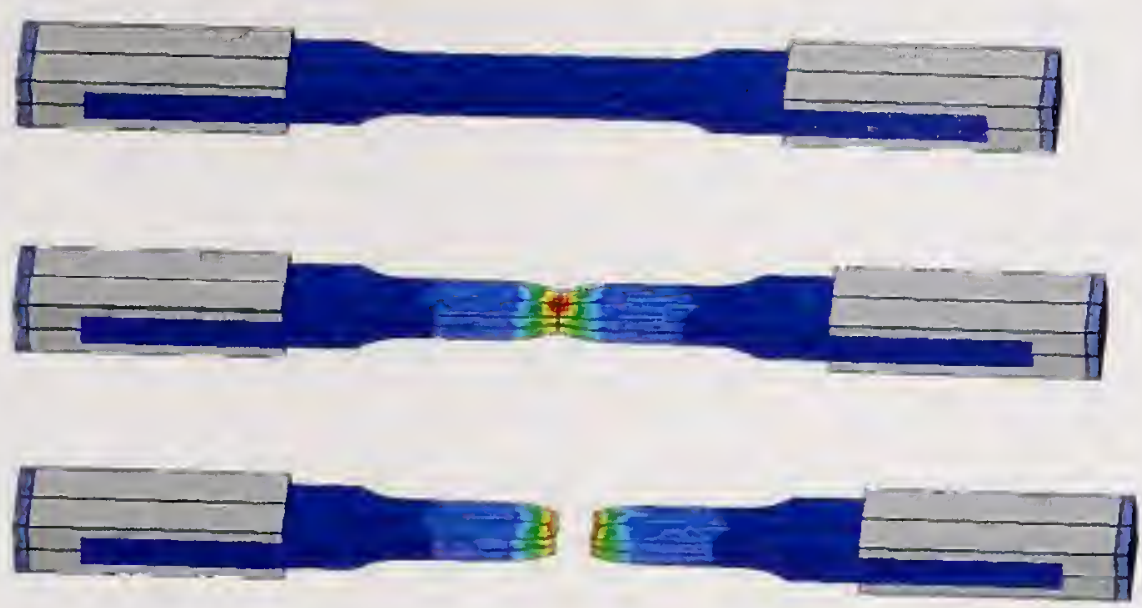

Plastic Strain

Fringe Levels

8.000e-01

7.200e-01

6.400e-01

$5.600 \mathrm{e}-01$

4.800e-01

4.000e-01

$3.200 e-01$

2.400e-01

$1.600 \mathrm{e}-01$

$8.000 e-02$

$0.000 e+00$

Figure $\mathrm{C}-5$. Calculated tensile test response with necking for the $75 \mathrm{ksi}$ steel.

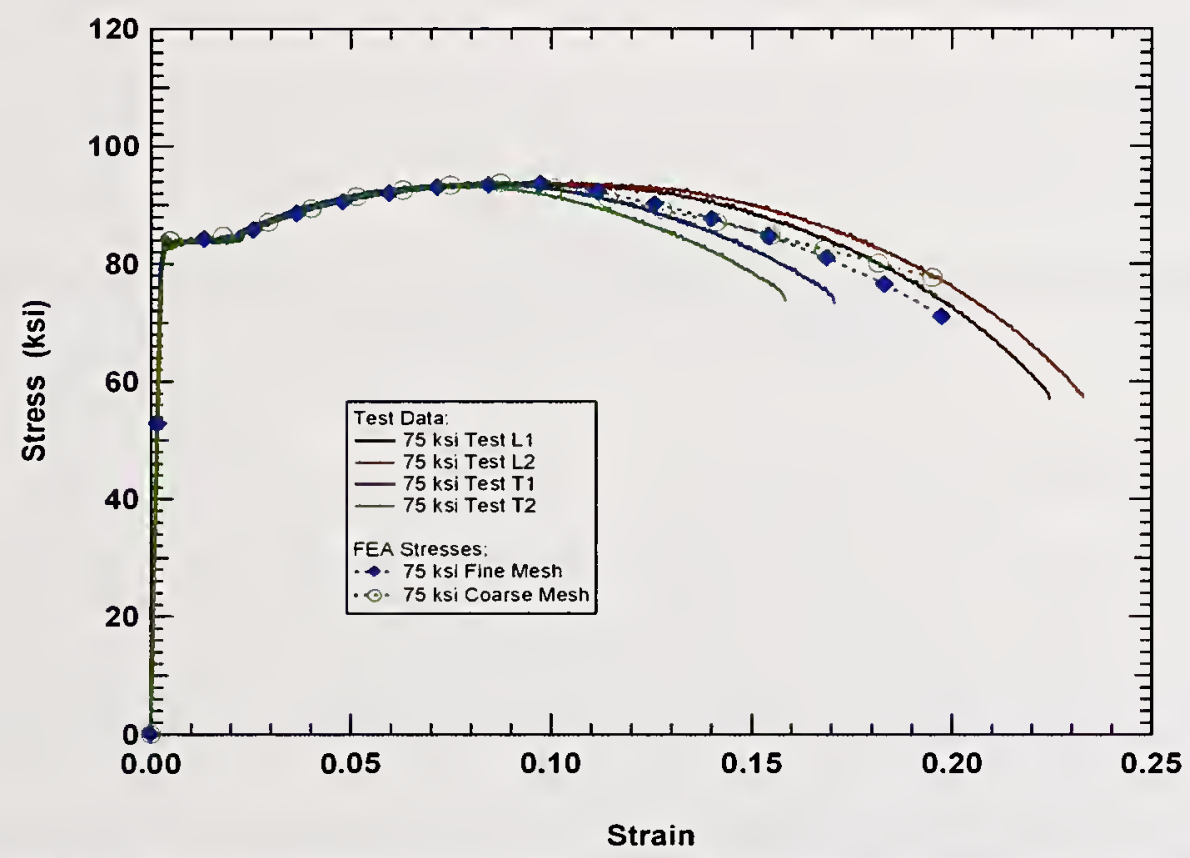

Figure C-6. Comparison of measured and calculated engineering stress-strain curves for the $75 \mathrm{ksi}$ steel.

The resulting true stress-true strain behavior incorporated into the constitutive model is representative of the steels tested in this project. However, there were multiple sources (suppliers) of steel used in the construction of the WTC towers. Project 3 developed synthetic stress-strain curves for each grade of steel based on several data sources. A comparison of this synthetic curve with the constitutive model behavior is shown in Fig. C-7. There are observable differences in the curves such as the representation of a yield point behavior in the constitutive model. However, the differences are not sufficiently large to produce a large variation in the calculated structural impact behavior. In addition, the effect of material strength variation on impact damage will be assessed in the uncertainty analyses.

The above procedure was applied to develop constitutive models for all of the WTC tower steels for which test data was provided by Project 3. 


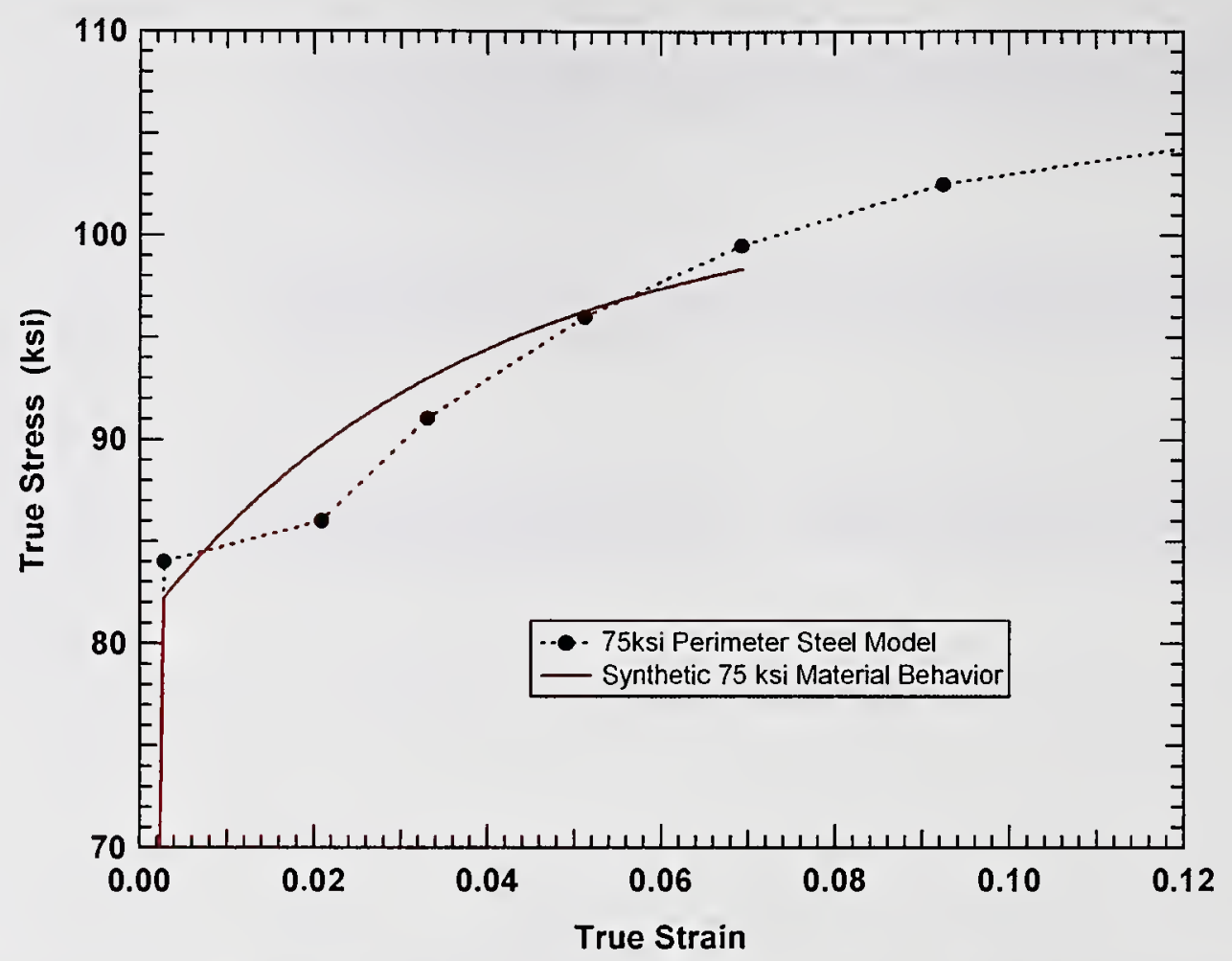

Figure C-7. Comparison of the constitutive model and synthetic steel behaviors for the $75 \mathrm{ksi}$ steel.

\section{Summary of Steel Constitutive Properties}

A summary of the true stress-strain curves used in the constitutive models for the various WTC tower steels are summarized in Fig. C-8. Similarly a comparison of the true stress-strain constitutive curves with the synthetic stress-strain curves developed by Project 3 for the various exterior column steels is shown in Figures $\mathrm{C}-9$ and $\mathrm{C}-10$, and for core column steels in Fig. C-11. In general, the true stressstrain curves developed from the test data and the synthetic curves developed from multiple sources agree to within approximately 10 percent. This variation in measured and expected material strengths will be used as part of the future uncertainty analyses.

\section{Strain Rate Effects in Steel Constitutive Models}

Strain rate effects on the steel yield strength are included in the constitutive model for tower steels with the Cowper and Symonds rate effect model. The functional form for the rate effects on strength is governed by the equation:

$$
\sigma_{y}(\dot{\varepsilon})=\sigma_{y}\left[1+\left(\frac{\dot{\varepsilon}}{C}\right)^{1 / p}\right]
$$

Where $\sigma_{y}$ is the yield strength, \& is the strain rate, and $C$ and $p$ are the Cowper and Symonds parameters. 


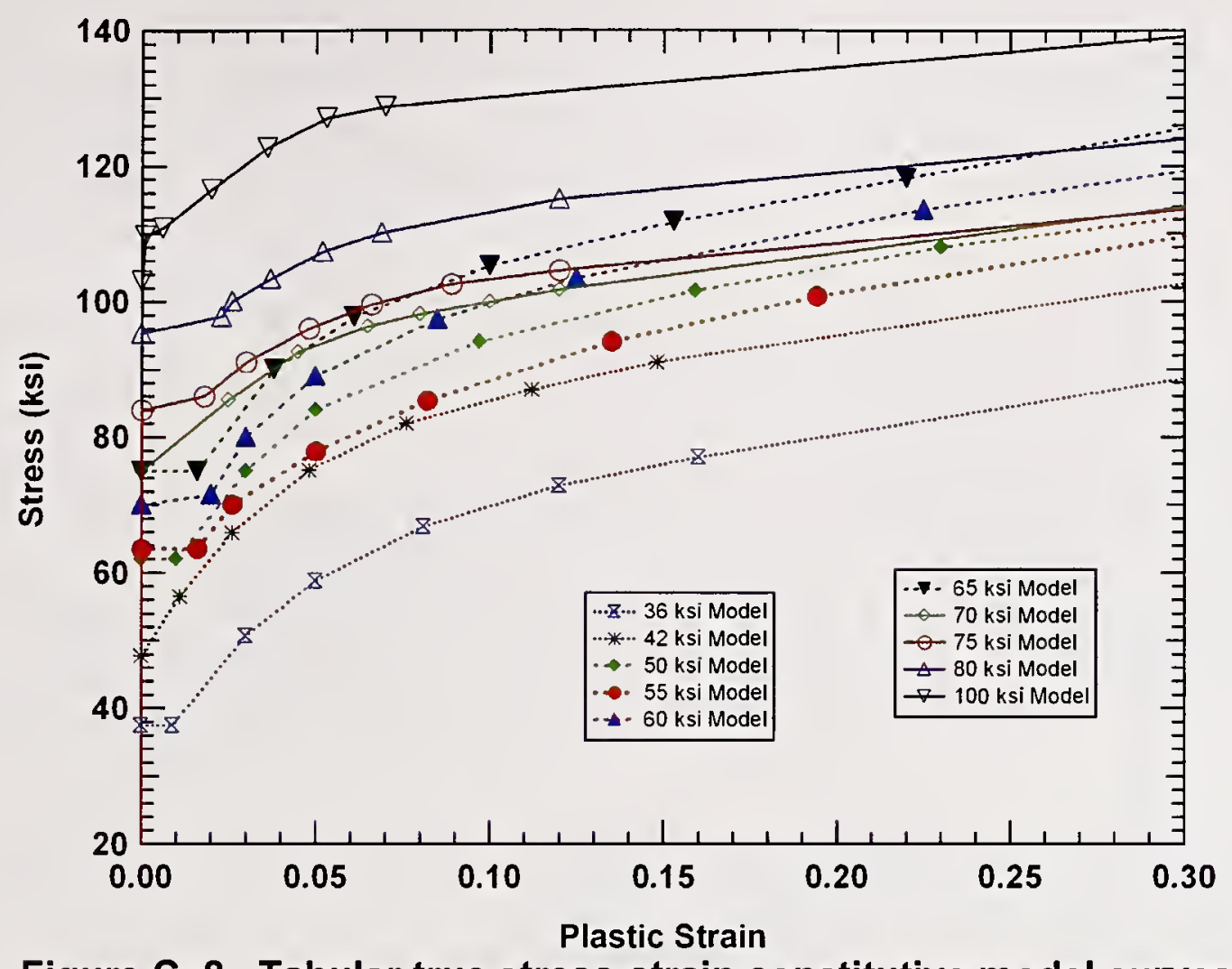

Figure C-8. Tabular true stress-strain constitutive model curves.

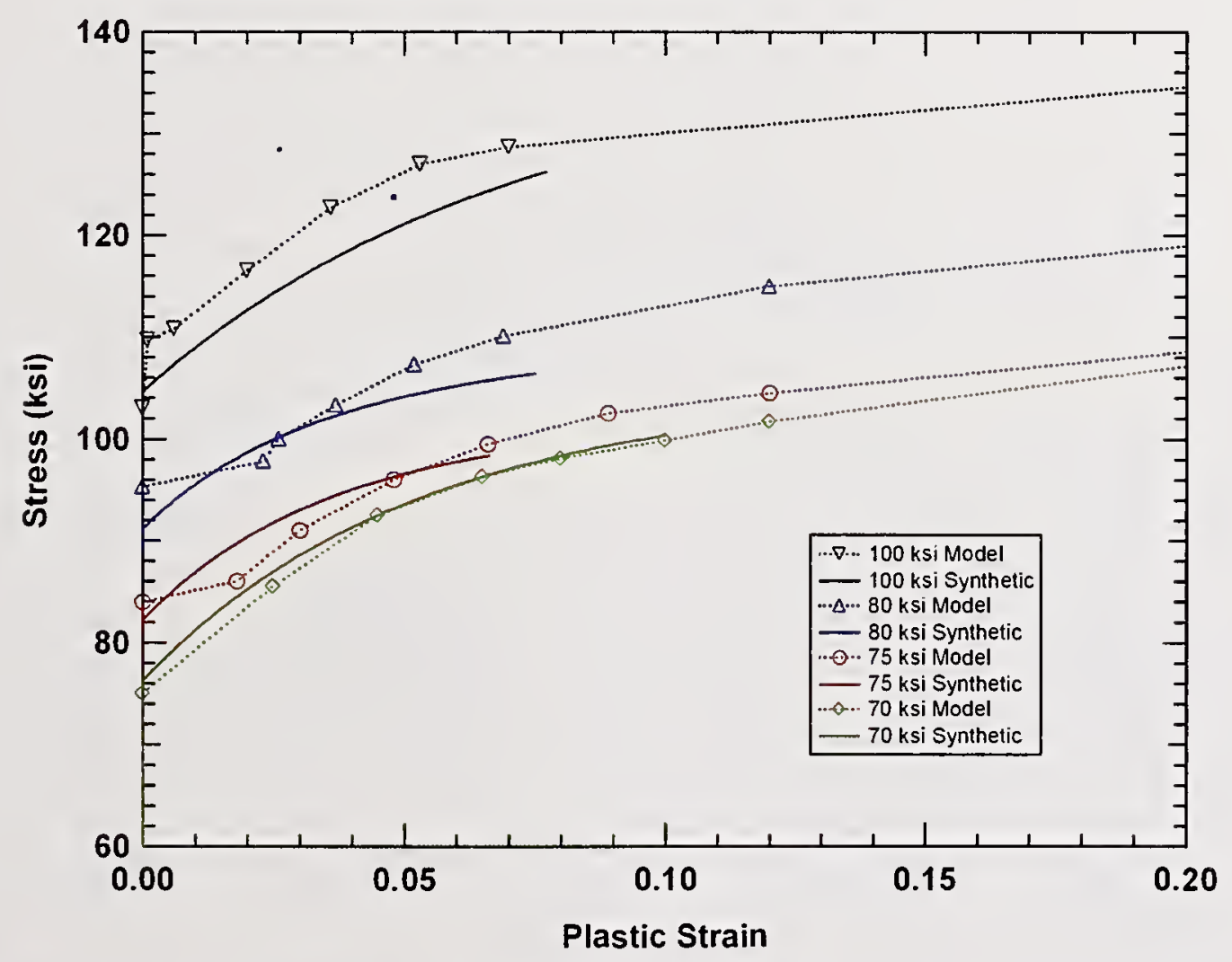

Figure C-9. Comparison of the constitutive model and synthetic steel behaviors for the higher strength perimeter steel curves. 


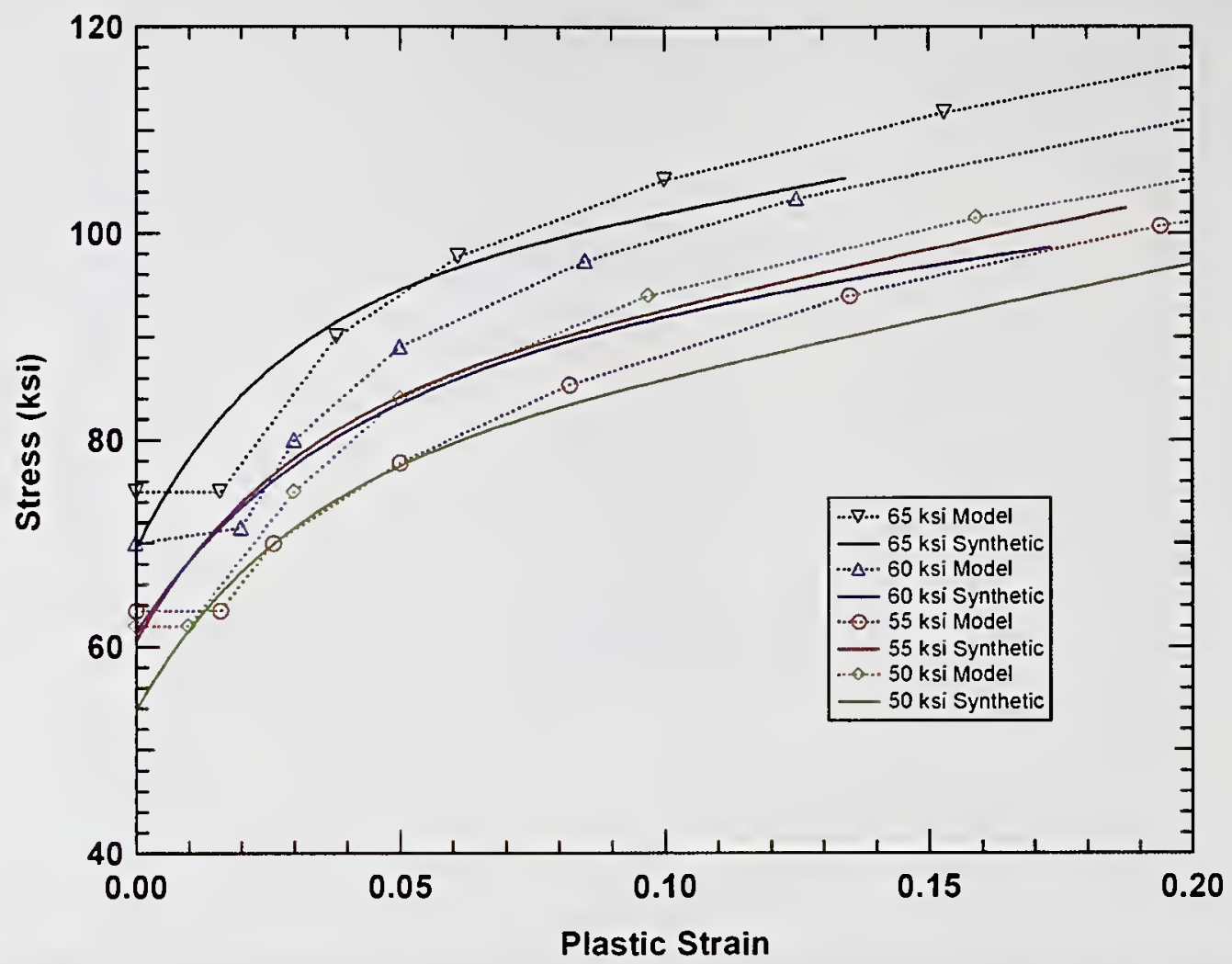

Figure $\mathbf{C}-10$. Comparison of the constitutive model and synthetic steel behaviors for the lower strength perimeter steel curves.

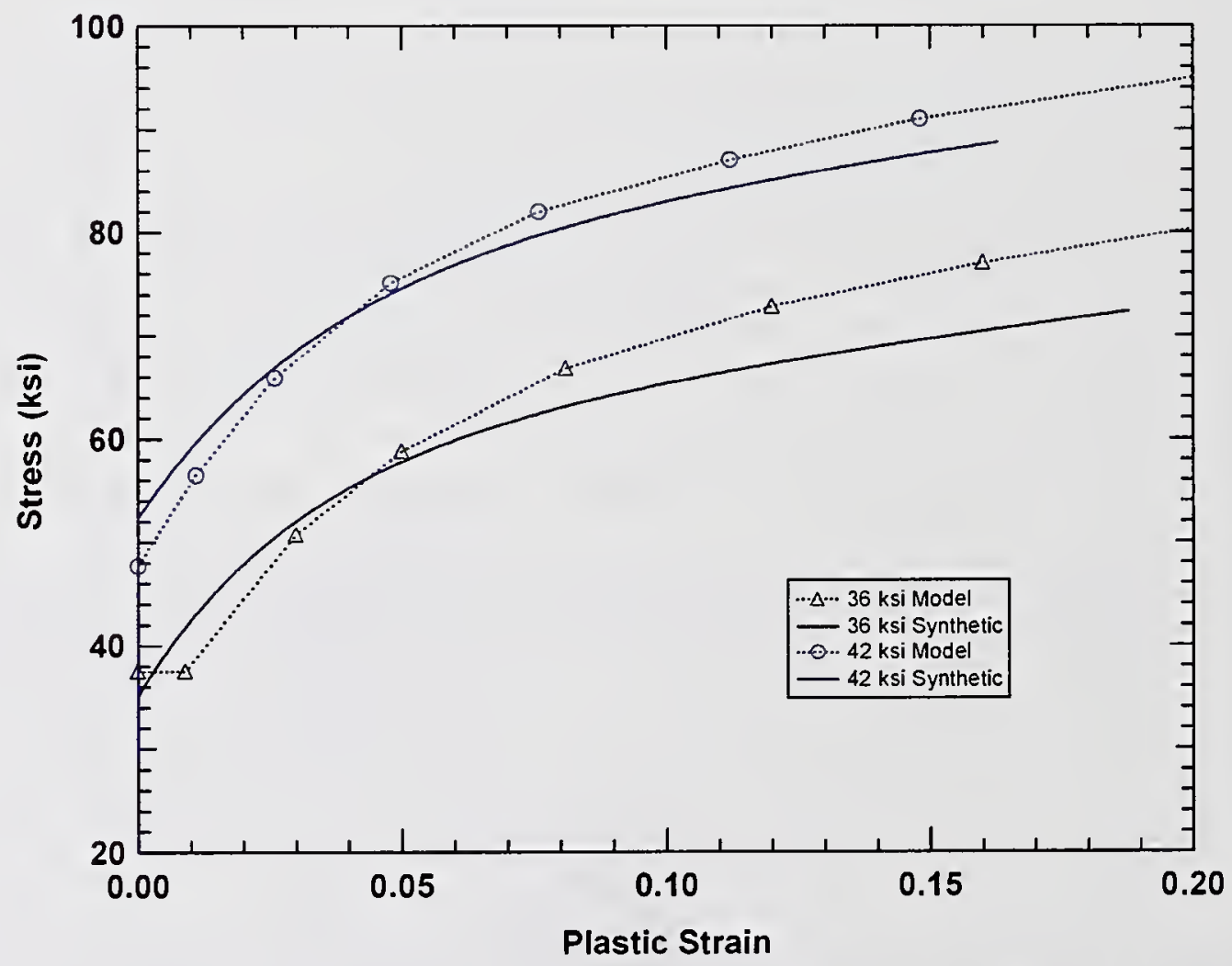

Figure C-11. Comparison of the constitutive model and synthetic steel behaviors for the core steel curves. 
A series of high-rate characterization tests was performed on tower steels by Project 3. In addition to quasi-static tests (performed at a rate below $0.001 \mathrm{~s}^{-1}$ ), a series of high rate tests was performed primarily at strain rates between $100 \mathrm{~s}^{-1}$ and $1000 \mathrm{~s}^{-1}$. The Cowper and Symonds model parameters $C$ and $p$ were then fit to the test data and provided in the following functional form for a strain rate in $\mathrm{s}^{-1}$ and a yield strength in ksi:

- $\log (C)=-7.55+0.324 \sigma_{y}-0.00153\left(\sigma_{y}\right)^{2}$

- $\mathrm{p}=6.7824$

The specific values used for each of the different tower steels are summarized in Table $\mathrm{C}-1$. The $36 \mathrm{ksi}$ and $42 \mathrm{ksi}$ steels are materials used in the core columns and the remaining steels are used in the exterior columns. The resulting rate effects used in the constitutive modeling of tower steel based on Equation (5) are compared to the measured high-rate test data for the $50 \mathrm{ksi}, 75 \mathrm{ksi}$, and $100 \mathrm{ksi}$ tower steels in Fig. $\mathrm{C}-12$. The comparison shows that the Cowper and Symonds model is capable of reproducing the rate effects for the range of data available.

Table C-1. Material constitutive parameter table-WTC tower steels.

\begin{tabular}{|c|c|c|c|c|c|}
\hline $\begin{array}{c}\text { Material } \\
\text { Yield } \\
\text { Specification }\end{array}$ & $\begin{array}{c}\text { Young's } \\
\text { Modulus }\end{array}$ & Poisson's Ratio & $\begin{array}{c}\text { Strain-Rate } \\
\text { Coefficient (C) }\end{array}$ & $\begin{array}{c}\text { Strain-Rate } \\
\text { Exponent (p) }\end{array}$ & $\begin{array}{c}\text { Brick Element } \\
\text { Failure Strain }\end{array}$ \\
\hline $36 \mathrm{ksi}$ & $29,700 \mathrm{ksi}$ & 0.288 & $7.900 \mathrm{e}+01$ & 6.782 & 0.32 \\
\hline $42 \mathrm{ksi}$ & $29,700 \mathrm{ksi}$ & 0.288 & $1.360 \mathrm{e}+05$ & 6.782 & 0.32 \\
\hline $50 \mathrm{ksi}$ & $29,700 \mathrm{ksi}$ & 0.288 & $4.220 \mathrm{e}+06$ & 6.782 & 0.50 \\
\hline $55 \mathrm{ksi}$ & $29,700 \mathrm{ksi}$ & 0.288 & $6.700 \mathrm{e}+06$ & 6.782 & 0.64 \\
\hline $60 \mathrm{ksi}$ & $29,700 \mathrm{ksi}$ & 0.288 & $3.950 \mathrm{e}+07$ & 6.782 & 0.56 \\
\hline $65 \mathrm{ksi}$ & $29,700 \mathrm{ksi}$ & 0.288 & $1.270 \mathrm{e}+08$ & 6.782 & 0.51 \\
\hline $70 \mathrm{ksi}$ & $29,700 \mathrm{ksi}$ & 0.288 & $1.270 \mathrm{e}+08$ & 6.782 & 0.62 \\
\hline $75 \mathrm{ksi}$ & $29,700 \mathrm{ksi}$ & 0.288 & $6.710 \mathrm{e}+08$ & 6.782 & 0.56 \\
\hline $80 \mathrm{ksi}$ & $29,700 \mathrm{ksi}$ & 0.288 & $2.440 \mathrm{e}+09$ & 6.782 & 0.49 \\
\hline $100 \mathrm{ksi}$ & $29,700 \mathrm{ksi}$ & 0.288 & $3.430 \mathrm{e}+09$ & 6.782 & 0.53 \\
\hline
\end{tabular}

Test results indicated that the influence of strain rate on the ductility of the tower steels did not follow a consistent trend. Several grades of steel had an increased ductility at high rates (more common for low strength steels), some had a reduced ductility at high rates (more common for high strength steels), and some showed no significant effect of strain rate on ductility. The approach used in the constitutive modeling is to ignore the changes in ductility produced by elevated strain rates. The effects of the variation of ductility over the expected range of strain rates will be assessed as part of the uncertainty analyses. 


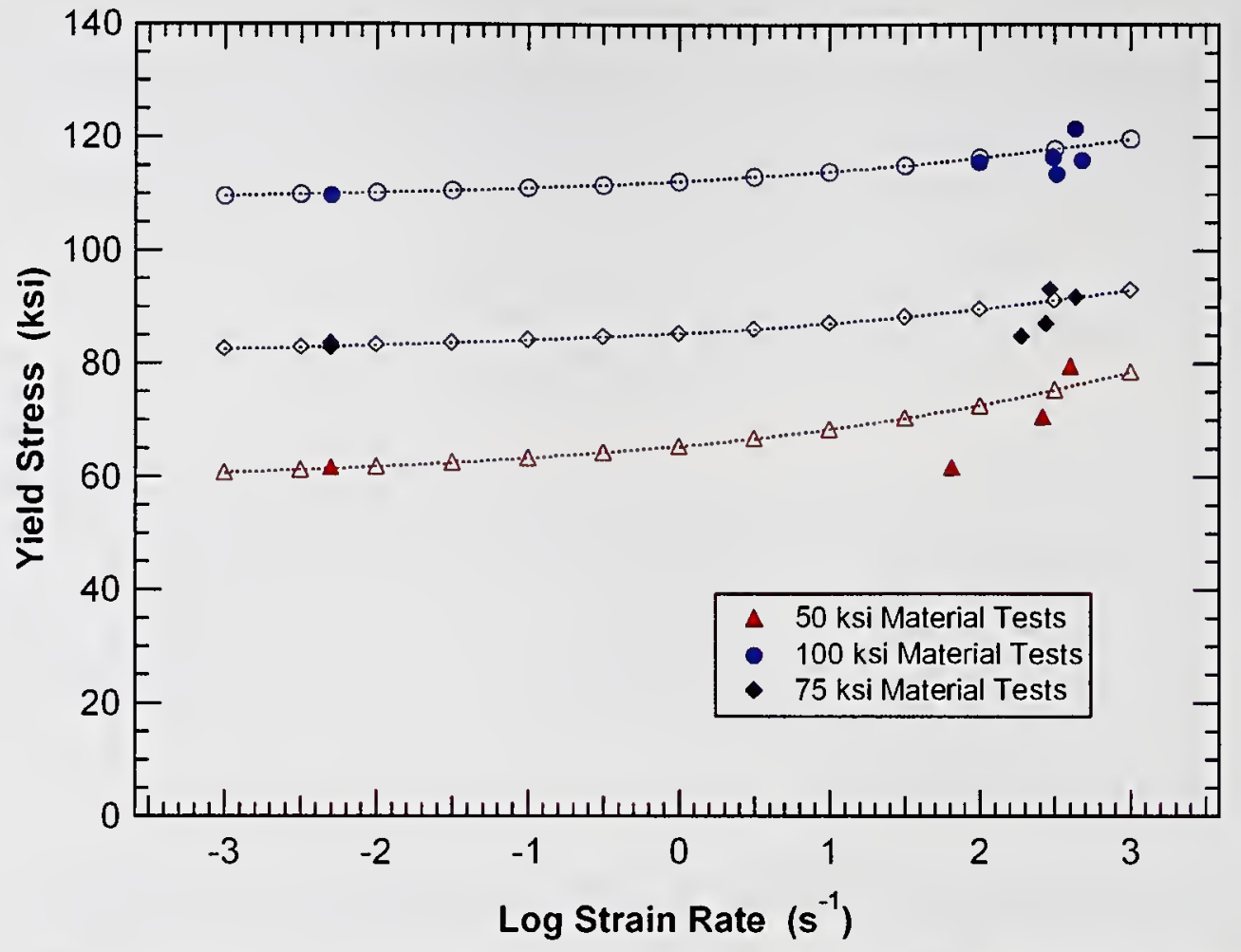

Figure C-12. Comparison of rate effects model and test data.

\section{C.2.2 Failure Models}

A challenge for calculating the aircraft impact response and damage to the WTC towers is the wide range of failure mechanisms that occur in both the aircraft and tower structures. These failures result from large scale deformations of the materials as well as from exceeding the strength of bolted, welded, and riveted connections. At the connection locations, complex behaviors are influenced by variations in material cross sectional geometry and material properties that produce large stress and strain concentrations.

The overall approach applied to modeling the impact damage and failure of the structures is to use engineering damage mechanics within the framework of the LS-DYNA finite element analyses. This analysis methodology is also referred to as local damage modeling and has been applied successfully in a wide variety of applications (e.g., Mudry 1985; Beremin 1983; Simons et al., 1999). Detailed fracture mechanics analysis of all the failures that occurred is beyond the scope of this project. The damage is calculated within each element in the impact simulations and damage development is based on local (element) quantities including plastic strain and stress state. When the specified failure criterion in an element is exceeded, the element is eroded (deleted) from the calculation. The erosion of elements allows for the propagation of failure through a structure.

Calculation of the failure of structural components is further complicated by the scale of the global impact analyses. Local damage modeling is often applied to the analysis of smaller components and failure initiation. In these applications, a relatively fine mesh can be applied, and damage regions around a local fracture can be resolved on a fine scale. For the global impact of an aircraft into a WTC tower, element sizes will have to be on average a few in. to maintain a model size at approximately 2 million to 3 million elements. At this resolution, the gradients around a fracture cannot be accurately resolved, and the damage criteria need to be adjusted to obtain the appropriate strength and ductility of the structures. In 
the following subsections, various local damage modeling techniques applied to estimate failure of the aircraft and tower structures are described.

\section{Mesh Refinement Effects}

One of the significant modeling issues for the analysis of aircraft impact damage and failure is the effect of mesh refinement. The global impact analyses of the aircraft impacts into the WTC towers are very large analyses of complex structures and will require the refinement of the model to be reduced significantly from the detailed component analyses. As the mesh refinement is reduced, it is important to ensure that the damage mechanisms and extent of impact damage are properly captured.

A preliminary example of the effects of mesh refinement on the response was introduced earlier in the analysis of the material tests on the WTC tower steels. Figure $\mathrm{C}-1$ showed both a fine mesh and a coarser mesh (referred to as medium mesh) version of the ASTM 370 rectangular tensile specimen for plate material. A comparison of the calculated necking behavior for two $75 \mathrm{ksi}$ specimens immediately preceding failure is shown in Fig. $\mathrm{C}-13$. The fine mesh is able to better resolve the strain gradients in the necking region and as a result has higher peak strain values at the same level of specimen displacement.

The effects of further reductions in mesh refinement required for global impact analyses can be demonstrated with the ASTM 370 tensile test example used in this section. The extreme limit for a coarse model of the tensile specimen would use a single shell element to model the entire specimen gage section. An example of coarse shell element model of the tensile specimen is shown in Fig. C-14. This coarse tensile specimen model would have a single stress and a single strain value for the gage section and does not have sufficient independent degrees of freedom to model the localization that occurs during necking. As a result, the critical plastic strain criterion for this single shell element model would be approximately equal to the engineering failure strain of 0.20 (see Fig. C-6).

The calculated engineering stress-strain behavior obtained with the three different mesh resolutions is shown in Fig. $\mathrm{C}-15$. In these calculations, a maximum plastic strain criterion was used and the critical failure strain was shifted until each calculation failed at a value matching the average measured engineering failure strain. The corresponding critical plastic strains were 1.00 for the fine mesh resolution, 0.56 for the medium mesh resolution, and 0.18 for the coarse mesh resolution (shell element model).

The medium mesh resolution used in the above analysis of the tensile test corresponds to the mesh resolution applied in the exterior column component impact analyses described in Section C.4. Therefore, the critical failure strain of 0.56 would be carried forward to the detailed component analyses. The coarser shell element subassembly and global impact models are typically developed with shell elements and a resolution that might correspond to the coarse model shown in Fig. C-14. Therefore, the measured engineering elongation of the specimens is used for the critical strain. Additional modifications for regions with stress concentrations, such as along welds, is described later in this section. 


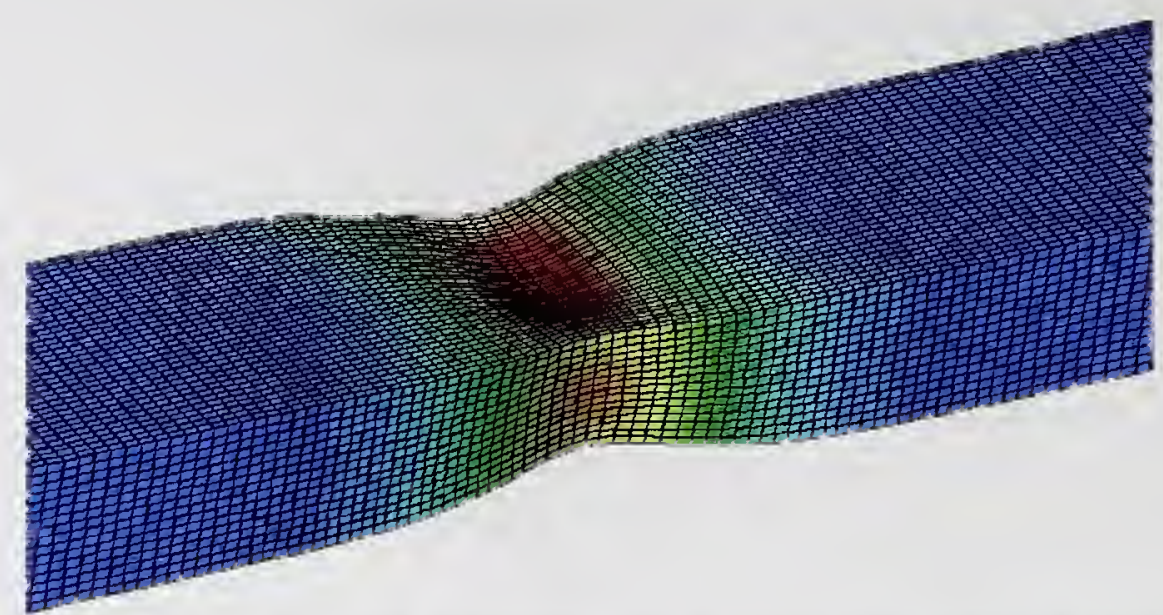

(a) Fine mesh necking behavior (red $=75$ percent plastic strain)

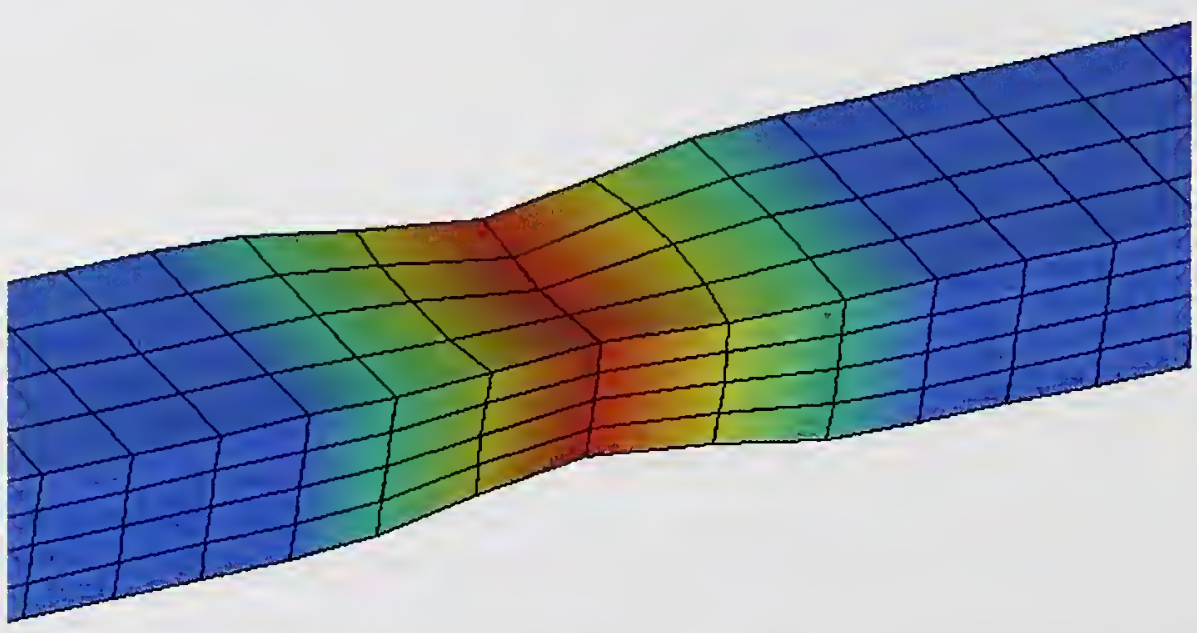

(b) Medium mesh necking behavior ( $\mathrm{red}=\mathbf{5 0}$ percent plastic strain)

Figure $\mathrm{C}-13$. Calculated necking response in the $75 \mathrm{ksi}$ tensile specimen.

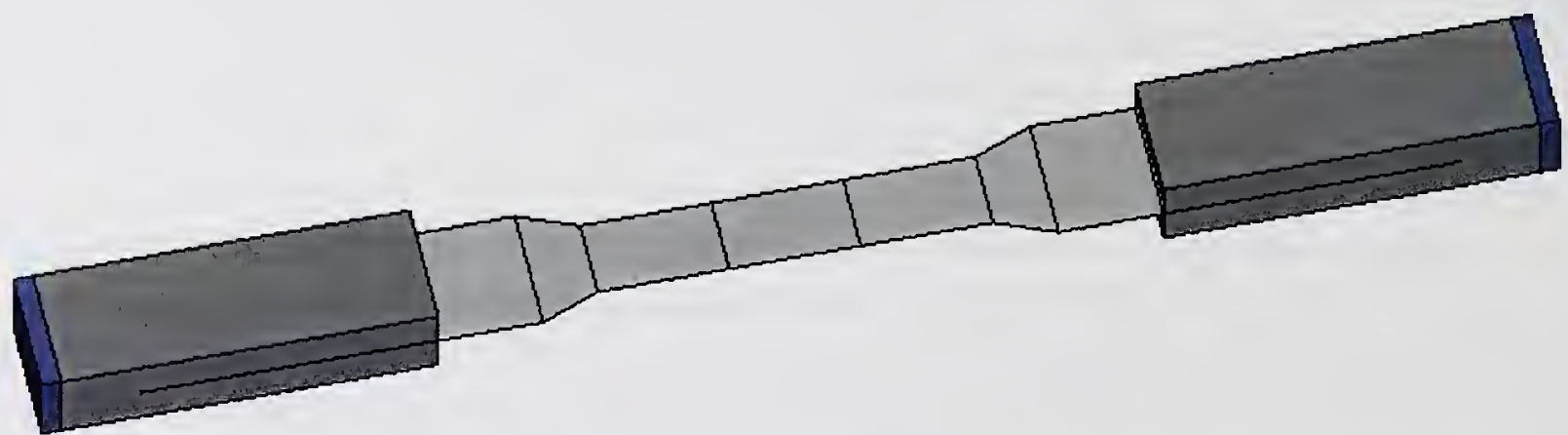

Figure C-14. Coarse shell element mesh for the $75 \mathrm{ksi}$ tensile specimen. 


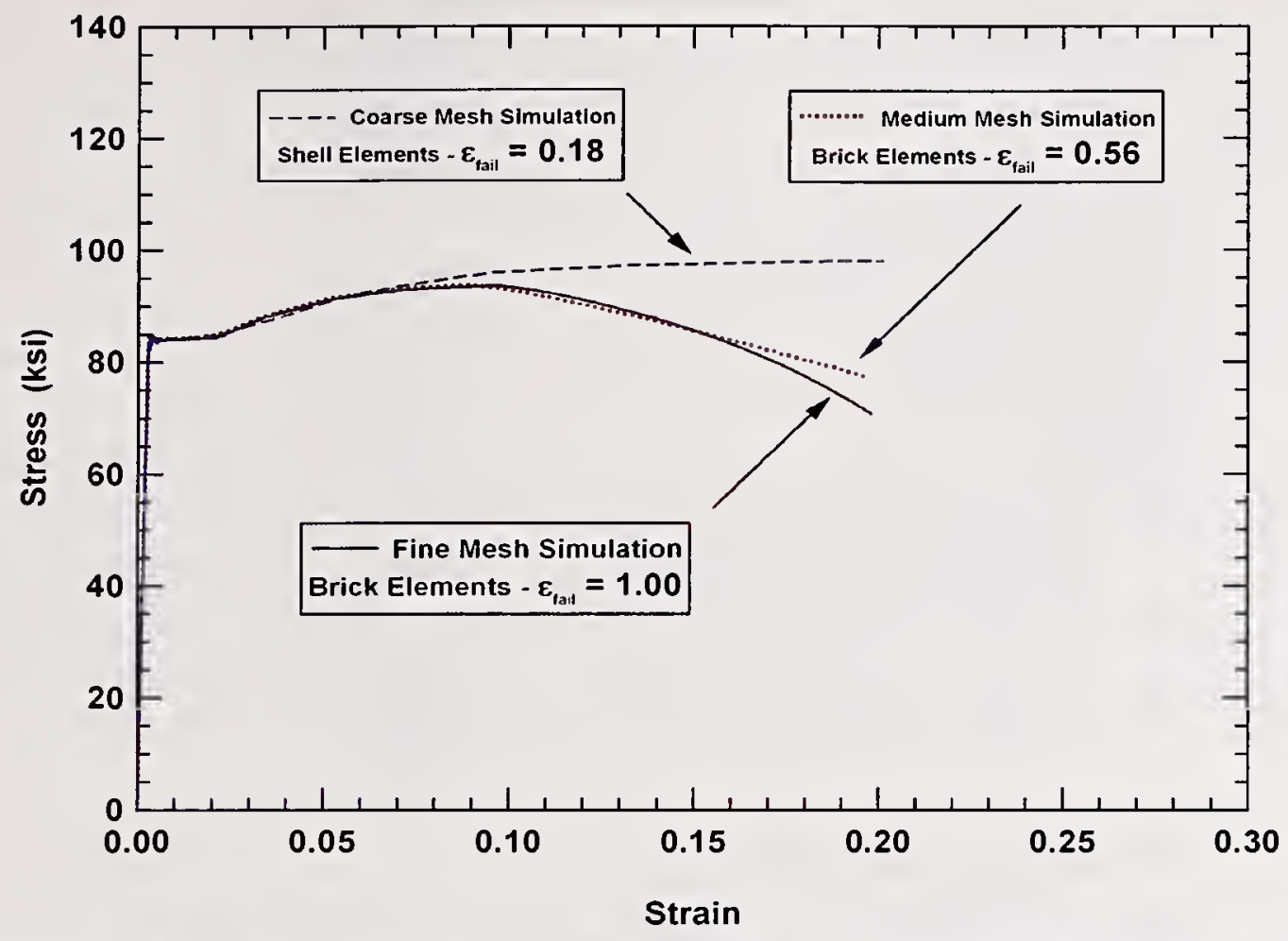

Figure $\mathrm{C}-15$. Mesh refinement effects in the calculated $75 \mathrm{ksi}$ tensile test.

\section{Stress Triaxiality Effects}

Using a local damage approach to model fracture with a damage model incorporating stress triaxiality effects has been successful in predicting the response and failure of welded steel structures to dynamic loads (Kirkpatrick, Giovanola, and Simons 1996). The strength of welded steel structures subjected to dynamic loads can be strongly influenced by the weld strengths and connection details. The following describes this approach to modeling fracture for impact damage to the WTC towers.

The damage analyses use a local damage approach within a finite element code to simulate the development of damage as the structure deforms. The fracture model is a simple form of a ductile fracture criterion (Mudry 1985). It assumes that failure of a material location occurs when the damage within a surrounding microstructural characteristic volume, $\mathrm{V}_{\mathrm{MIC}}$, exceeds a critical value. Mathematically, the damage function in the failure criterion can be written in the form:

$$
\mathrm{D}=\int \frac{\mathrm{d} \varepsilon_{\mathrm{eq}}^{\mathrm{p}}}{\varepsilon_{\mathrm{c}}\left(\sigma_{\text {mean }} / \sigma_{\mathrm{eq}}\right)}=1 \quad \text { over } \mathrm{V}_{\mathrm{MIC}} \approx\left(\mathrm{R}_{\mathrm{MIC}}\right)^{3}
$$

where:

$$
\begin{aligned}
& \mathrm{D}=\text { normalized damage parameter } \\
& \mathrm{d} \varepsilon_{\mathrm{eq}}^{\mathrm{p}}=\text { increment in plastic strain } \\
& \varepsilon_{\mathrm{c}}\left(\sigma_{\text {mean }} / \sigma_{\mathrm{eq}}\right)=\text { critical failure strain as a function of the stress triaxiality }
\end{aligned}
$$

The stress triaxiality is defined as the ratio of the mean stress to the equivalent stress. 
This critical strain function can be determined by a series of notched tensile tests with specimens of varying notch radii (e.g., Mackenzie, Hancock, and Brown 1977). $\mathrm{V}_{\mathrm{MIC}}$ is a characteristic volume of the material, which can be interpreted as the critical microstructural process zone. In turn, $\mathrm{R}_{\mathrm{MIC}}$, the representative linear dimension of the volume $\mathrm{V}_{\mathrm{MIC}}$, can be associated with microstructural dimensions such as grain size or spacing of the microvoid nucleating inclusions. $\mathrm{R}_{\mathrm{MIC}}$ is therefore a constant length dimension that can be used to introduce a scaling effect in the fracture simulations. In its present form, the model does not account for a possible strain rate sensitivity of the damage growth and has been calibrated using static data for the failure strain as a function of stress triaxiality.

The damage function in Equation (6) provides the failure criterion based on the accumulation of damage over the history of the material. However, this damage law requires an appropriate definition of a critical failure strain function. In this type of model, the performance of the damage law is typically better if the form of the damage law has a physical basis from observations of the microstructural failure processes. Previous studies have shown that the rate of void growth in the ductile fracture process is an exponential function of the stress triaxiality (Rice and Tracey 1969) in the form:

$$
\frac{\mathrm{dR}}{\mathrm{R}_{\mathrm{o}}}=0.28 \mathrm{~d} \varepsilon_{\text {eq }} \exp \left[1.5\left(\sigma_{\text {mean }} / \sigma_{\mathrm{eq}}\right)\right]
$$

This type of void growth law can be used to develop a critical strain function of the form:

$$
\varepsilon_{\mathrm{c}}\left(\sigma_{\text {mean }} / \sigma_{\mathrm{eq}}\right)=\alpha\left\{\frac{1.0}{\exp \left[1.5\left(\sigma_{\text {mean }} / \sigma_{\mathrm{eq}}\right)\right]}\right\}-\varepsilon_{\text {shift }}
$$

where $\alpha$ and $\varepsilon_{\text {shift }}$ are constants. The critical strain function in Equation (8), combined with the damage law in Equation (6), form the basis of the local fracture model.

The effect of stress triaxiality on damage development was measured by Project 3 for the core column steel materials using the specimen geometry shown in Fig. C-16. Only the core column materials were selected since the thickness of the components was sufficiently large to fabricate the notched round bar specimens. A series of 12 tests were performed using two different steel strengths and three different notch radii with a repeat test for each configuration. A summary of the notched round bar tests is given in Table C-2.

To determine the triaxiality in the three different notched round bar specimen geometries, models were developed of the specimens and the tests were analyzed. The models for the three different specimen geometries are shown in Fig. C-17. The models had a fine mesh (average element size of approximately 0.008 in.) capable of resolving the gradients in stress and strain across the specimen. It was found that the triaxiality and damage across the gage section is relatively uniform with a maximum along the axis of the specimen (failure is expected to initiate at the center of the specimen and propagate to the edges). 


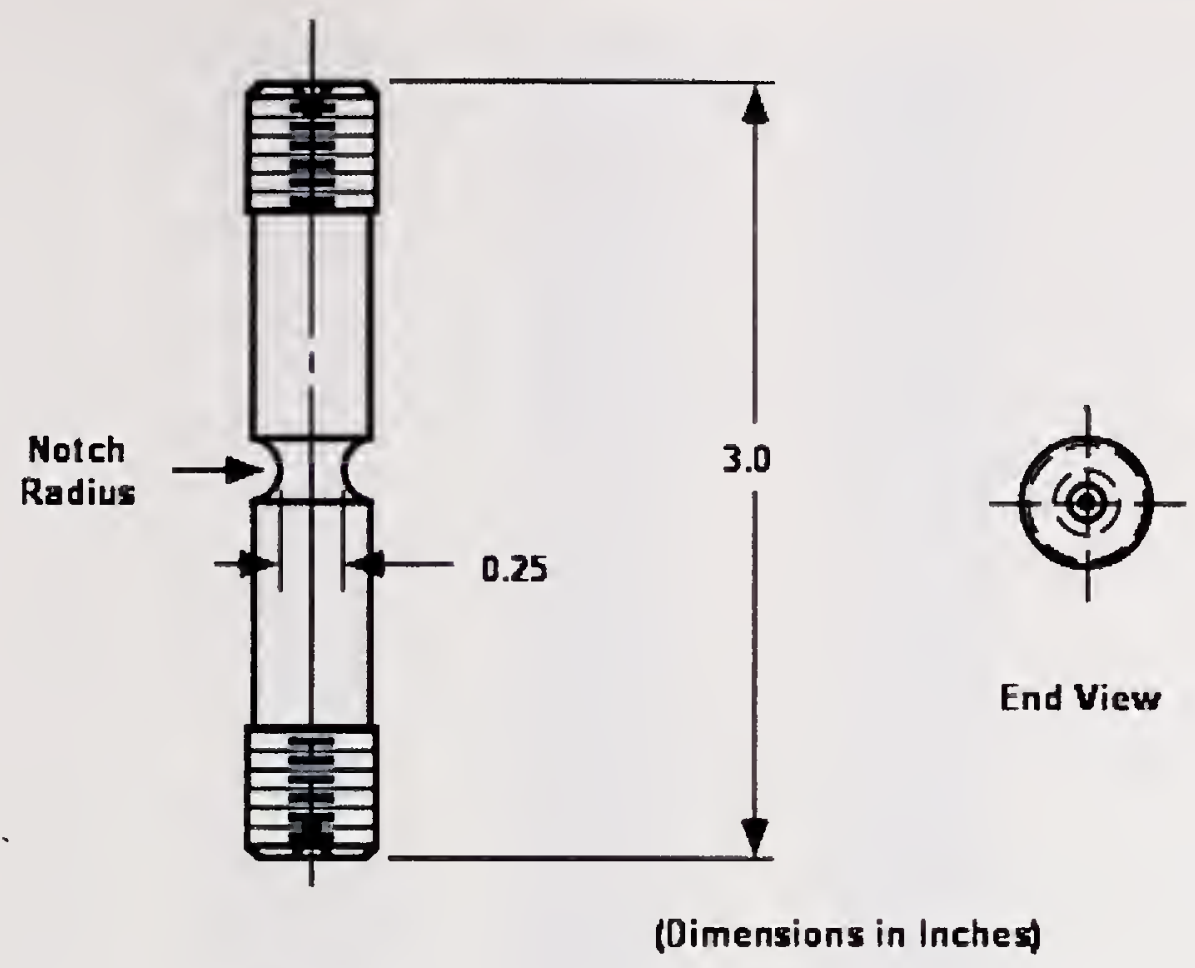

Figure $\mathrm{C}-16$. Notched round bar specimen dimensions.

Table C-2. Summary of notched round bar tensile tests.

\begin{tabular}{|c|c|c|c|c|c|c|}
\hline Specimen Number & $\begin{array}{c}\text { Gage Dia. } \\
\text { (in.) }\end{array}$ & $\begin{array}{c}\text { Specimen } \\
\text { Length (in.) }\end{array}$ & $\begin{array}{c}\text { Notch } \\
\text { Radius (in.) }\end{array}$ & $\begin{array}{c}\text { Failure Dia. } \\
\text { (in.) }\end{array}$ & $\begin{array}{c}\text { Failure } \\
\text { Strain }\end{array}$ & $\begin{array}{c}\text { Stress } \\
\text { Triaxiality }\end{array}$ \\
\hline B6152-1-F1-1-1-05 & 0.2519 & 3.005 & 0.245 & 0.18646 & 0.2598 & 0.7 \\
\hline B6152-1-F1-1-1-06 & 0.2488 & 3.008 & 0.25 & 0.19223 & 0.2274 & 0.7 \\
\hline B6152-1-F1-1-2-01 & 0.2526 & 3.007 & 0.065 & 0.21466 & 0.1502 & 1.2 \\
\hline B6152-1-F1-1-2-02 & 0.2518 & 3.003 & 0.065 & 0.20518 & 0.1851 & 1.2 \\
\hline B6152-1-F1-1-2-03 & 0.2513 & 3.005 & 0.148 & 0.18571 & 0.2610 & 0.9 \\
\hline B6152-1-F1-1-2-04 & 0.2507 & 3.006 & 0.125 & 0.19837 & 0.2087 & 0.9 \\
\hline C71-1-F1-07 & 0.2506 & 3.005 & 0.245 & 0.19835 & 0.2085 & 0.7 \\
\hline C71-1-F1-08 & 0.2519 & 3.004 & 0.249 & 0.20325 & 0.1931 & 0.7 \\
\hline C71-1-F1-09 & 0.2487 & 3.005 & 0.125 & 0.21888 & 0.1199 & 0.9 \\
\hline C71-1-F1-10 & 0.2519 & 3.01 & 0.13 & 0.21818 & 0.1339 & 0.9 \\
\hline C71-1-F1-11 & 0.2514 & 3.005 & 0.064 & 0.23301 & 0.0732 & 1.2 \\
\hline C71-1-F1-12 & 0.2525 & 3.005 & 0.063 & 0.23919 & 0.0527 & 1.2 \\
\hline
\end{tabular}



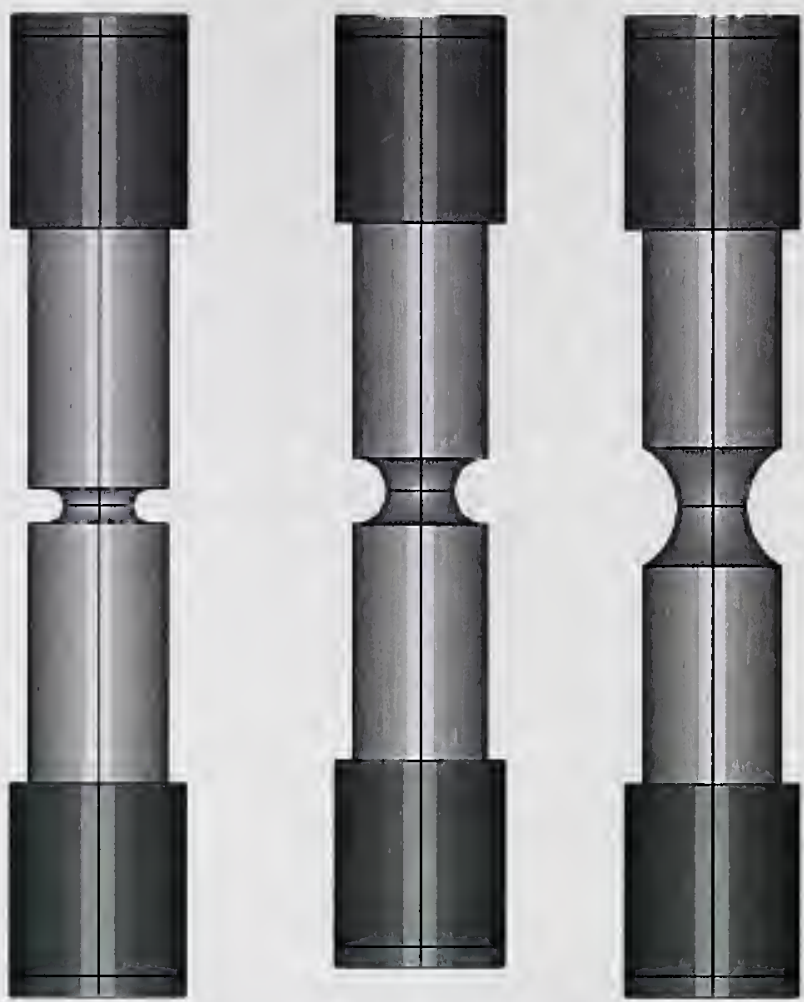

Figure $\mathbf{C}-17$. Notched round bar tensile specimen models.

The calculated triaxiality at the specimen center as a function of damage, parameter D in Equation (6), for the three different notched round bar specimens is shown in Fig. $\mathrm{C}-18$. The calculated responses for all three specimens show an initial spike in triaxiality and then settle to a constant stress triaxiality over a wide range of specimen deformation. The average value of triaxiality from these calculations is summarized in the last column of Table $\mathrm{C}-2$.

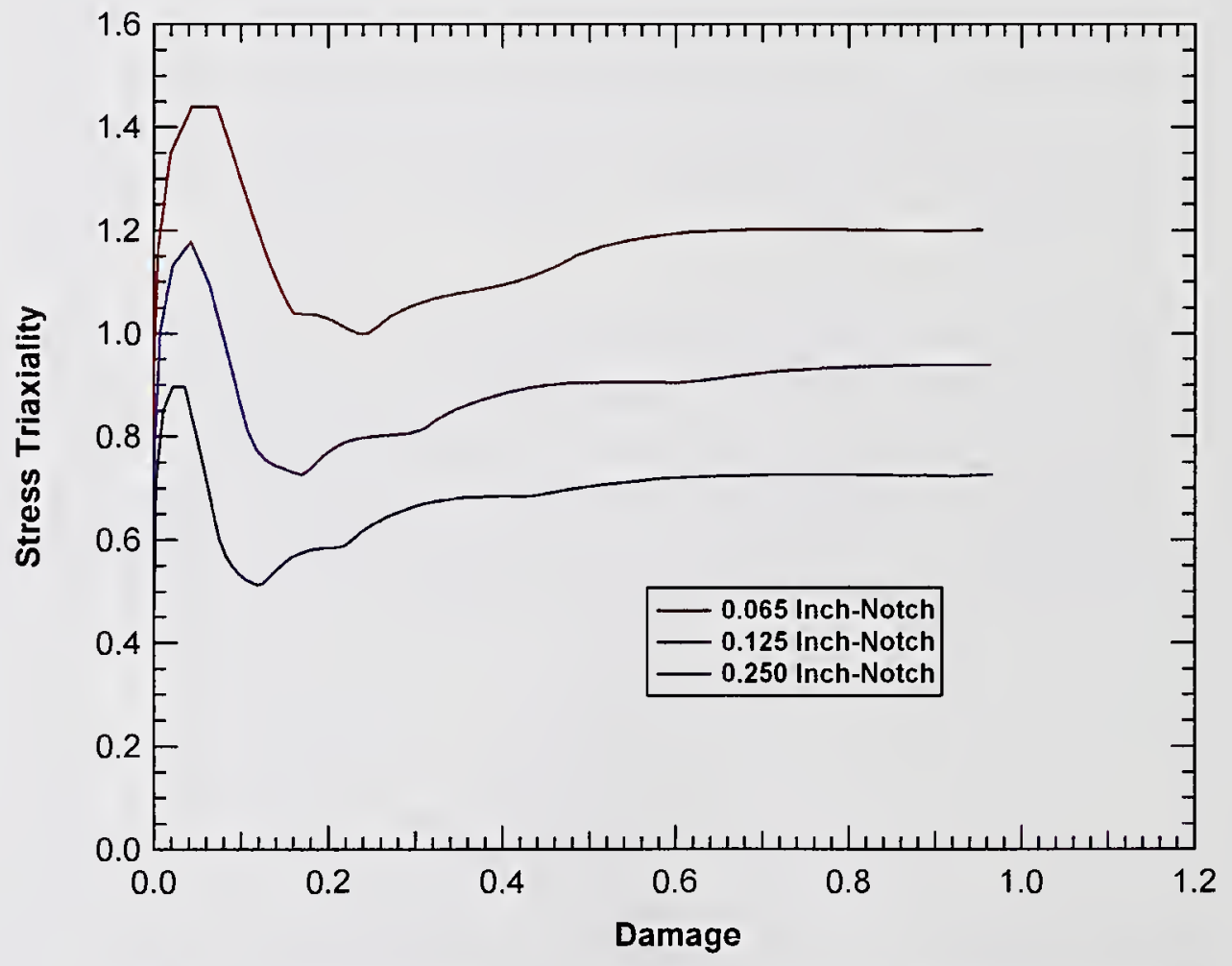

Figure $\mathrm{C}-18$. Calculated notched round bar stress triaxiality. 
A summary of the WTC steel notched round bar tests is shown in Fig. C-19. In addition, the figure shows failure criteria fit to the notched round bar data using Equation (8). For the WTC steels of interest, the presence of sulfide inclusions can be used to justify that the nucleation of voids occurs nearly instantaneously and $\varepsilon_{\text {shift }}$ can be set to zero. The figure compares the C71-1-F1 tests with the failure criterion using a coefficient value $\alpha=0.5$. Similarly the tests with the B6152-1-F1-1 steel (36 ksi yield) are compared to the failure criterion using a coefficient value $\alpha=0.90$. Although neither set of material test is in perfect agreement with the failure criteria, the overall trends of the aggregate data set match and suggest that the form of the failure criteria is appropriate for the steels.

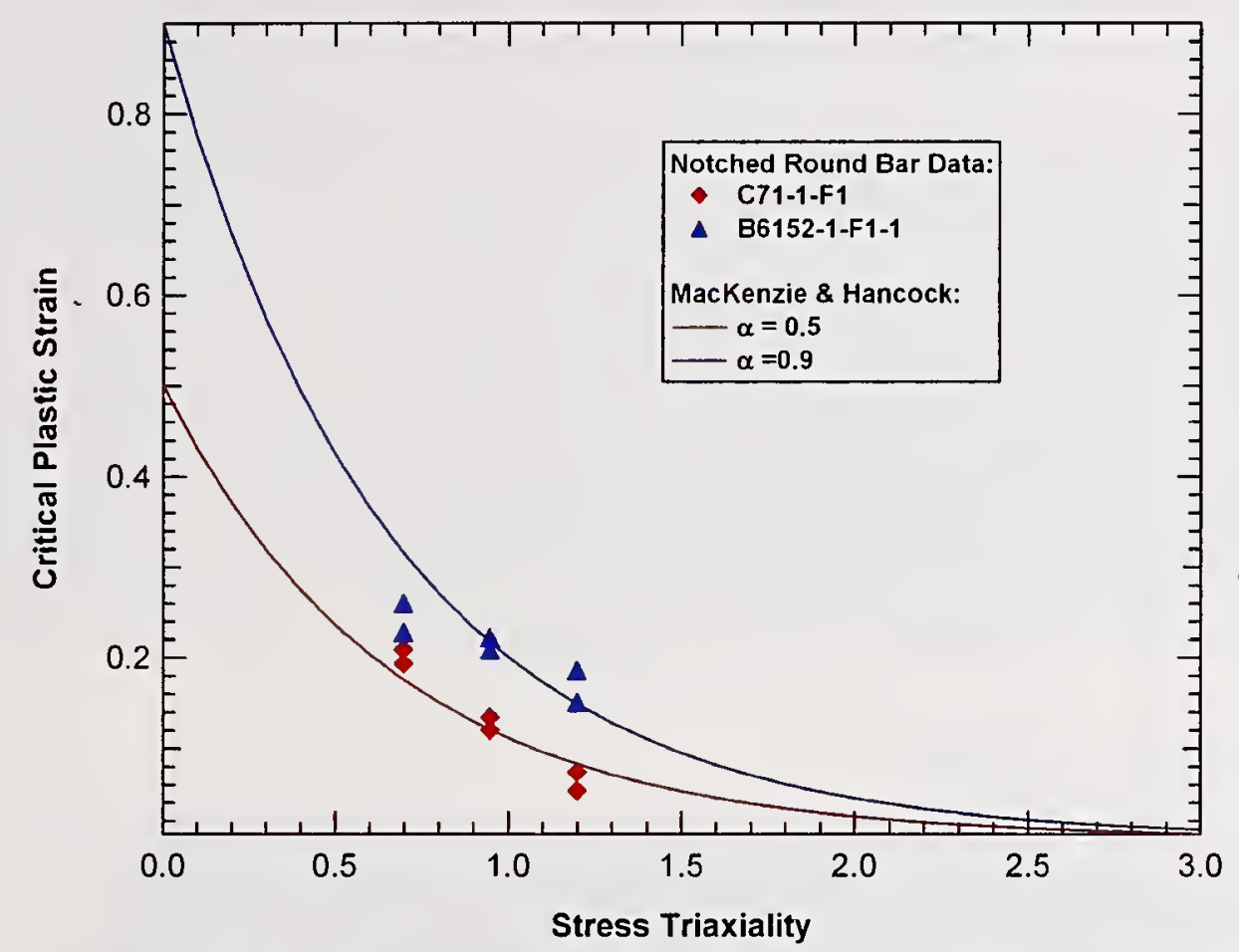

Figure C-19. Calculated critical plastic strain as a function of notched stress triaxiality.

A user-defined constitutive and failure model was developed and incorporated into LS-DYNA in this project. The model is identical to the piecewise linear constitutive model applied previously for the analysis of the WTC tower steels with the addition of the above stress triaxiality damage function incorporated. The simulations of the B6152 steel tensile and notched round bar tests were repeated with the user-defined constitutive model. The load-displacement relationships were compared to the previous analyses to validate the stress-strain relationships in the user-defined constitutive model. The calculated failure of the specimens is compared to the corresponding failure criteria in Fig. C-20. The agreement of the failure strains is a validation of the damage algorithm within the user-defined constitutive model.

In the following subsection, the user defined constitutive and damage model is applied to investigate failure of components in the WTC tower structure. A region of the WTC towers where the stress triaxiality is expected to be relatively high and play a role in the failure strength is the welded joints in the exterior column flanges and webs. This welded connection is analyzed below. 


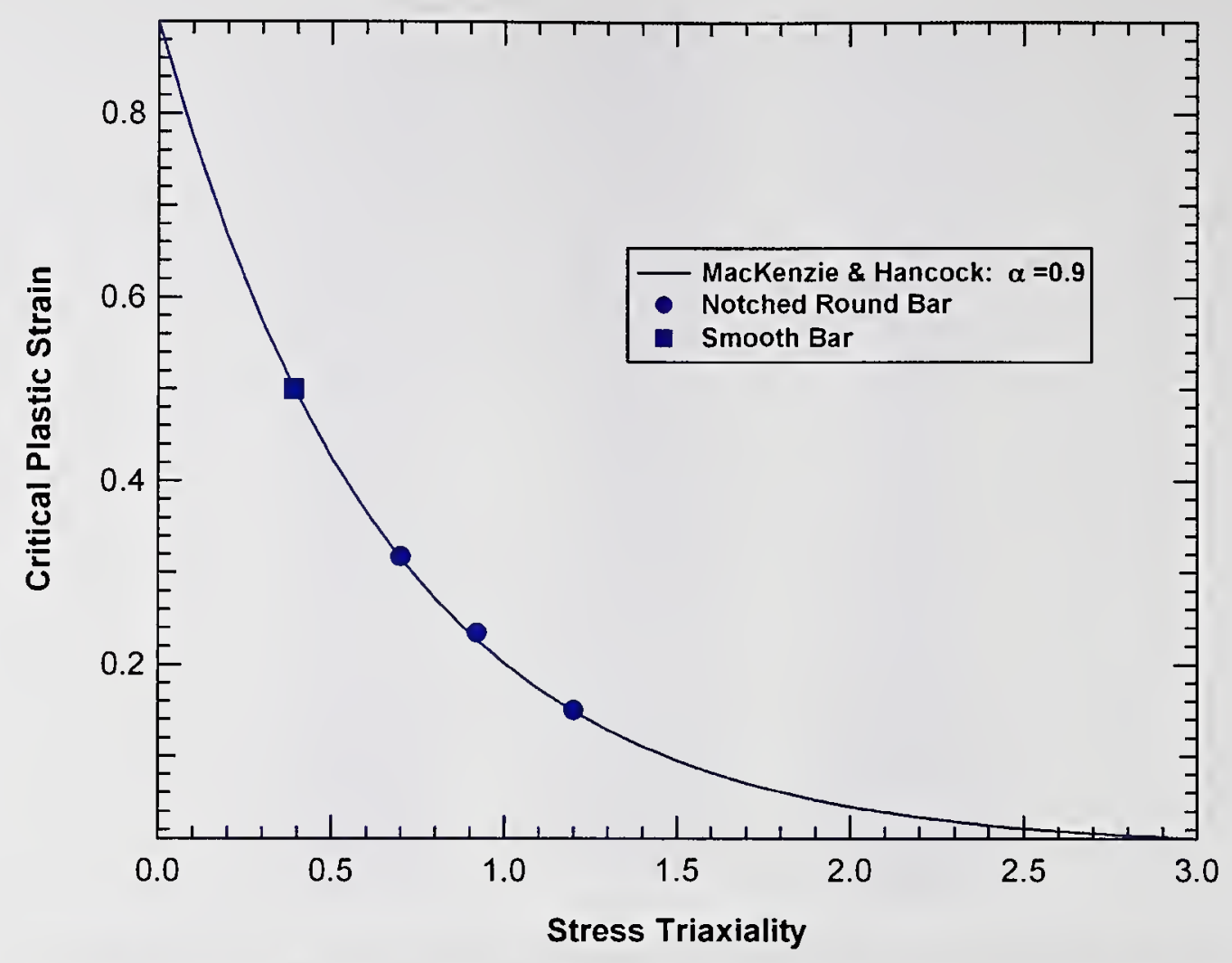

Figure $\mathrm{C}-20$. Simulation of the notched and smooth round bar tests.

\section{Weld Zone Constitutive Modeling}

Photographs of the WTC towers immediately after impact, and inspection of the recovered exterior wall panels in the impact zone, have shown that failure along the weld zone was a characteristic feature of the impact damage. An example exterior column from the impact zone that has significant fractures along the weld zone for the outer web is shown in Fig. C-21. The amount of energy dissipated by these weld fractures is very small compared to the overall impact energy. As a result, the failure of the welds will have little effect on the subsequent damage to the interior structures and contents of the towers. However, to capture the damage mechanisms of the impacted exterior columns and to develop models and failure criteria for the global impact analysis, a failure model for the weld zone is required.

Modeling of the constitutive behavior for the weld and heat affected zone (HAZ) material is a challenging task due to the lack of significant material testing in these regions. To date, the data obtained on the weld properties consist of a micrographic characterization of an exterior column weld with microhardness indentation tests performed at various locations across the weld geometry. The specific weld geometry and microhardness characterization locations are shown in Fig. C-22. The corresponding hardness measurements across the base, HAZ, and weld materials are shown in Fig. C-23. 


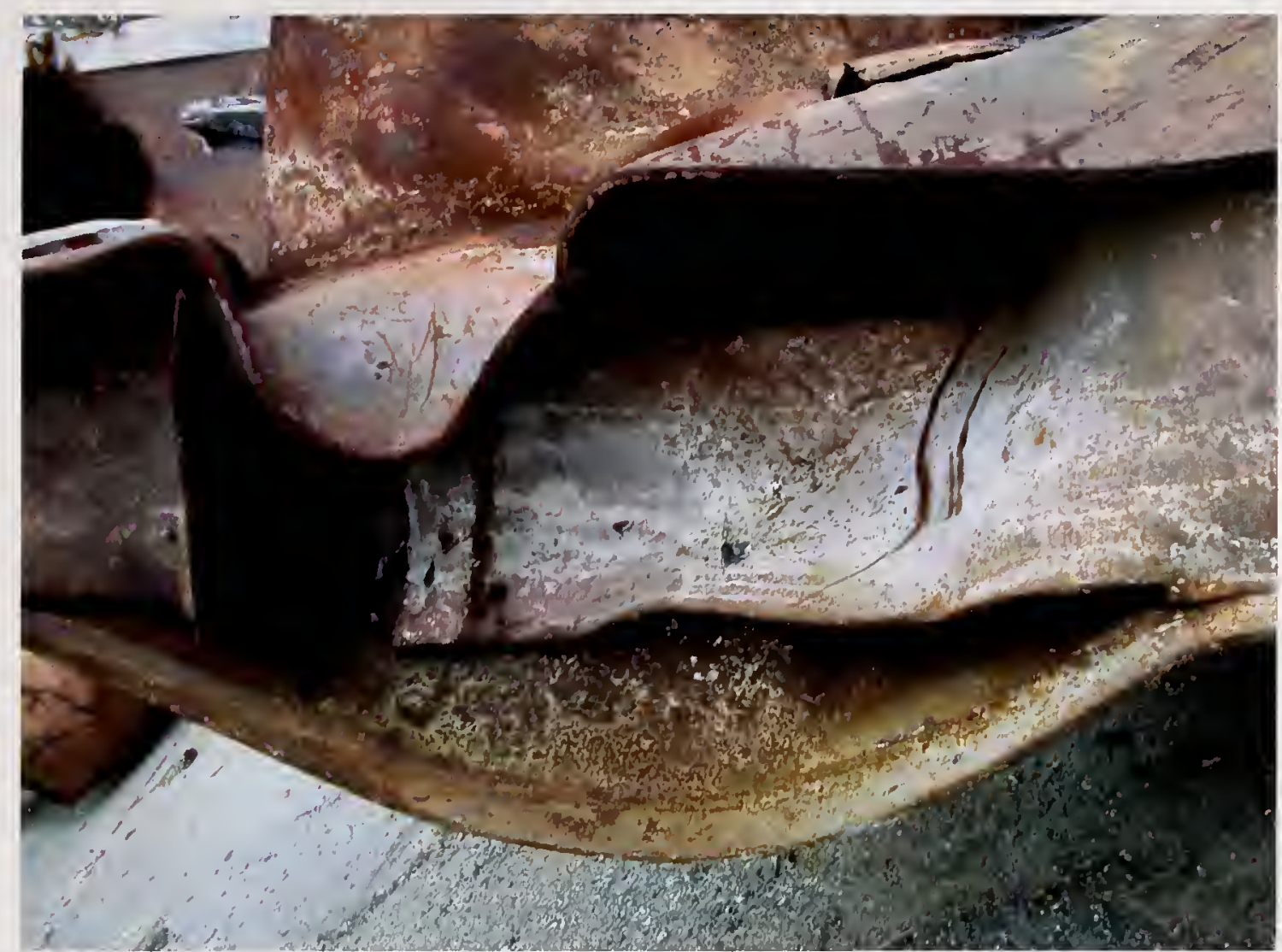

Figure C-21. Photograph of an exterior column with weld zone fractures.

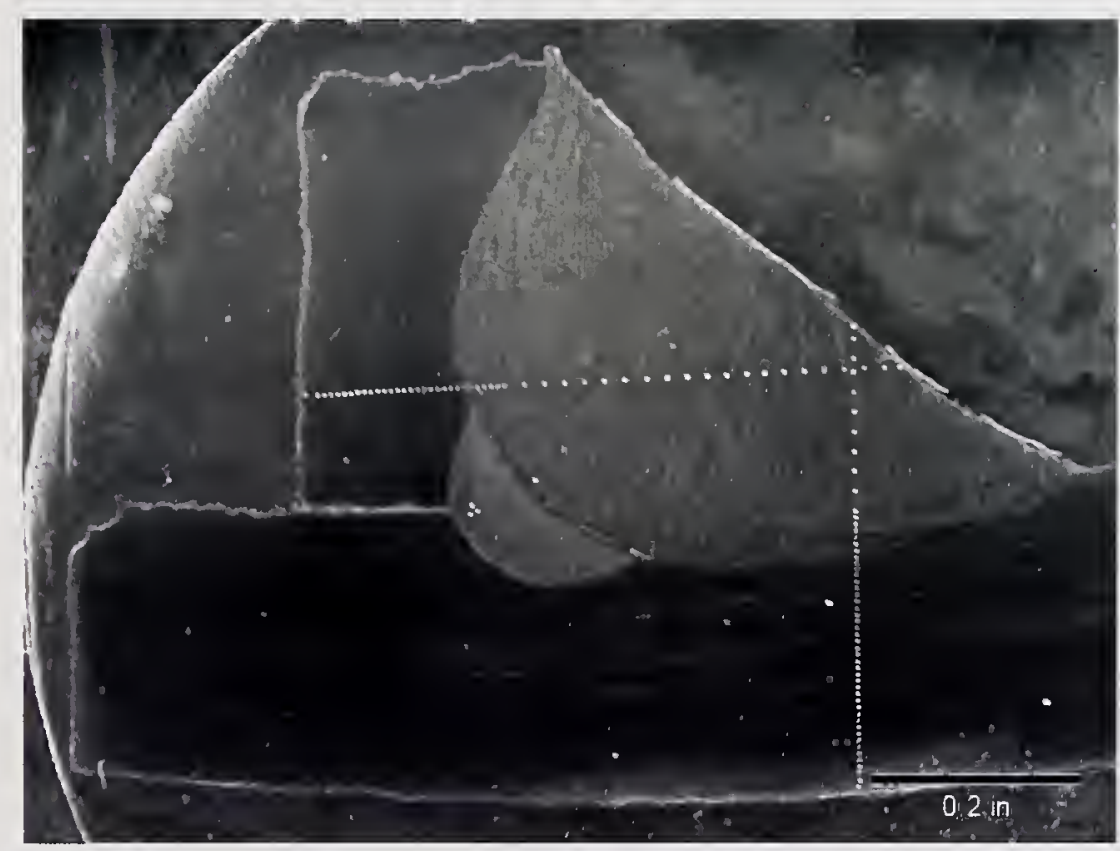

Figure C-22. Micrograph of an exterior column weld geometry. 


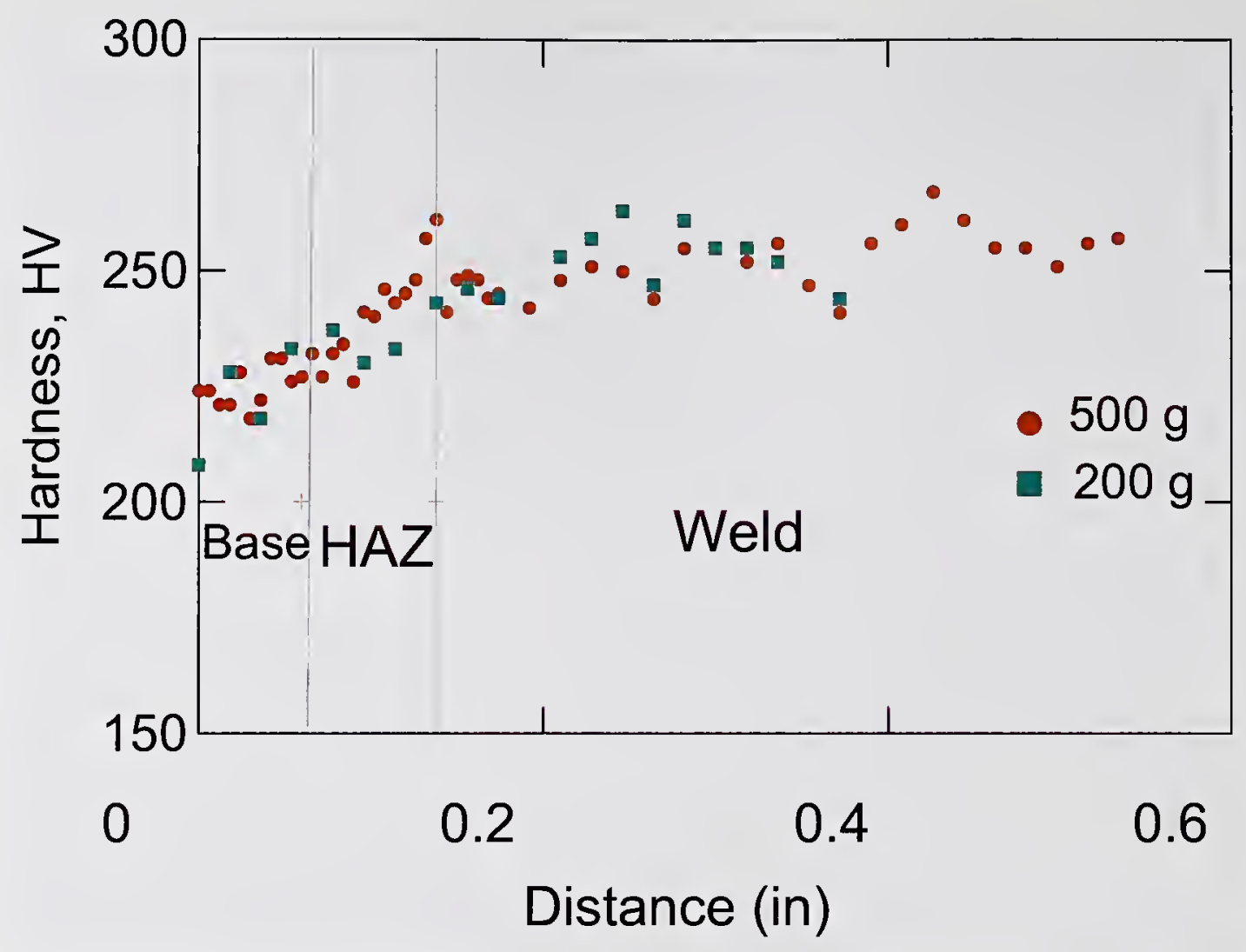

Figure C-23. Microhardness characterization of the weld and HAZ materials.

The microhardness measurements shown in Fig. C-23 were used to develop approximate plasticity behaviors for the weld and HAZ material regions. The approach used was to use the base material constitutive behavior and shift the flow stress of the HAZ and weld materials by 12 percent and 18 percent, respectively. These shifts correspond to the relative magnitude of the average measured hardness in each material region.

Analyses were performed to investigate the weld failure behavior using a detailed model of a simplified two-dimensional (2-D) weldment geometry representative of an exterior column side flanges and welded outer web as shown in Fig. C-24. A short duration pressure load is applied across the front web to introduce a dynamic loadcondition on the welded connection. The boundary conditions were approximated by fixing the displacements at the top and bottom of the side plates, seen in Fig. C-24 (b). The entire model is constrained to a plane strain condition. The weldment model includes weld and HAZ regions as shown in Fig. $\mathrm{C}-24$ (c).

The base metal for the weldment is the $55 \mathrm{ksi}$ steel. An approximate damage criterion was developed for the steel based on the results of the tensile tests on the material. The criterion is that of Equation (8) with a coefficient value $\alpha=0.92$. This value was obtained by using an approximate value for the average triaxiality of the tensile specimen and the failure strain obtained from the previous analyses of the tensile tests described earlier in Section C.2.1. The estimate of the average triaxiality is approximate since the triaxiality is changing in the region of the necking prior to failure. The user-defined constitutive model with this estimated damage model was used to simulate the tensile test. The comparison to the data and previous analyses is shown in Fig. $\mathrm{C}-25$. The approach underestimated the engineering failure strain by approximately 10 percent. 


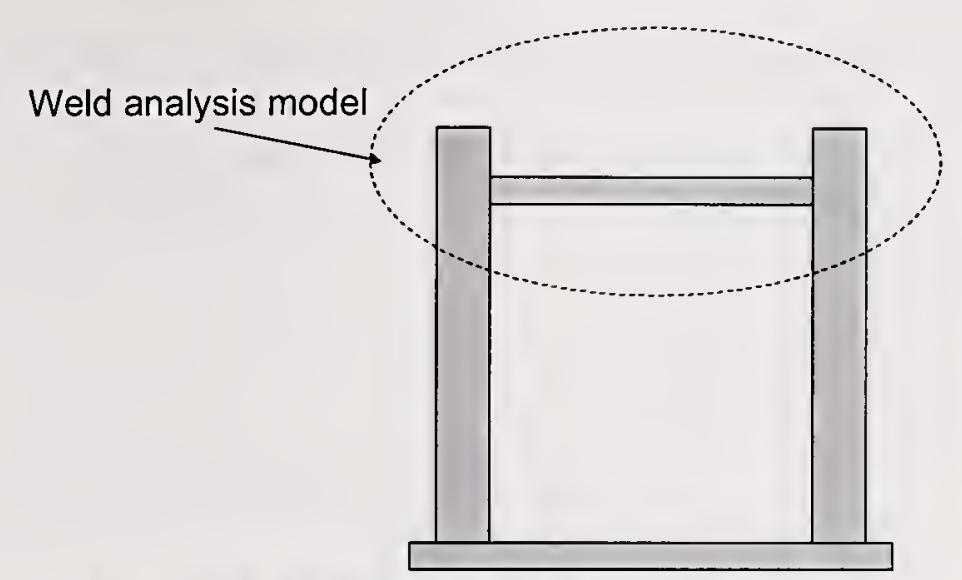

(a) Cross section of an exterior column

Fixed Boundaries

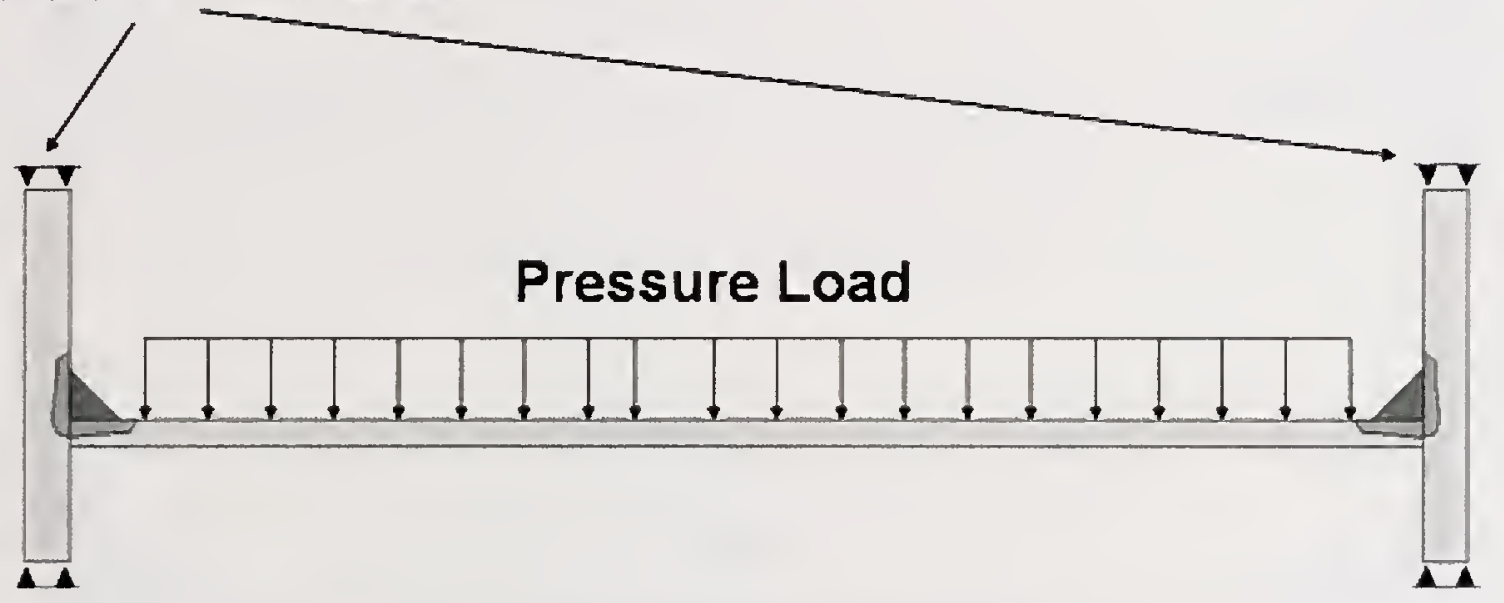

(b) Weld analysis model

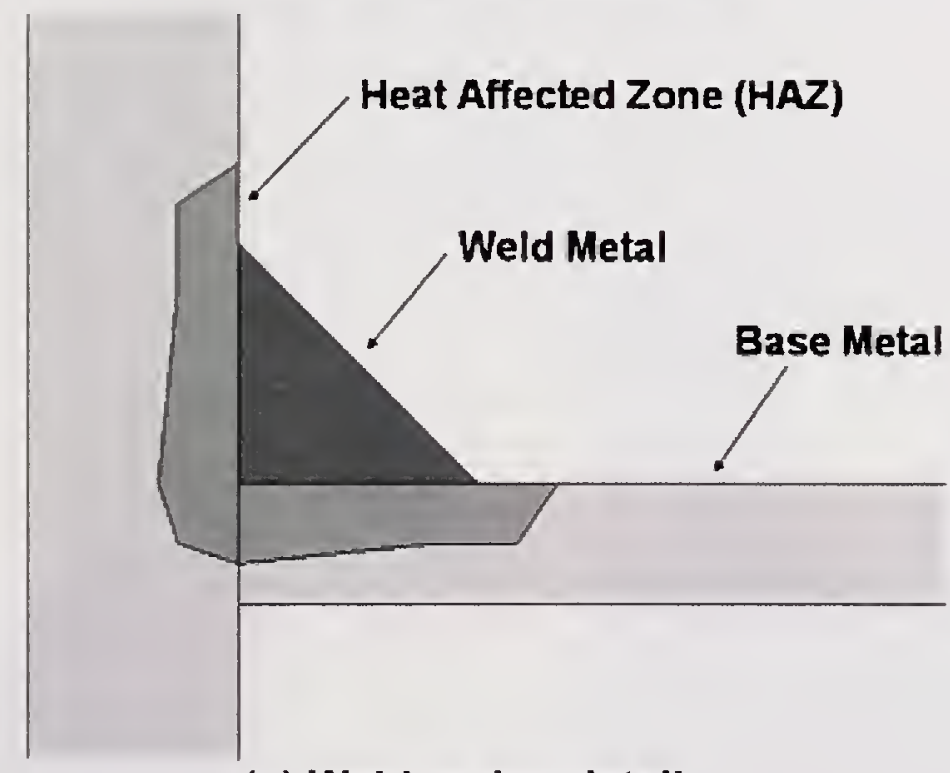

(c) Weld region detail

Figure C-24. 2-D weldment model developed for analysis of failure behavior. 


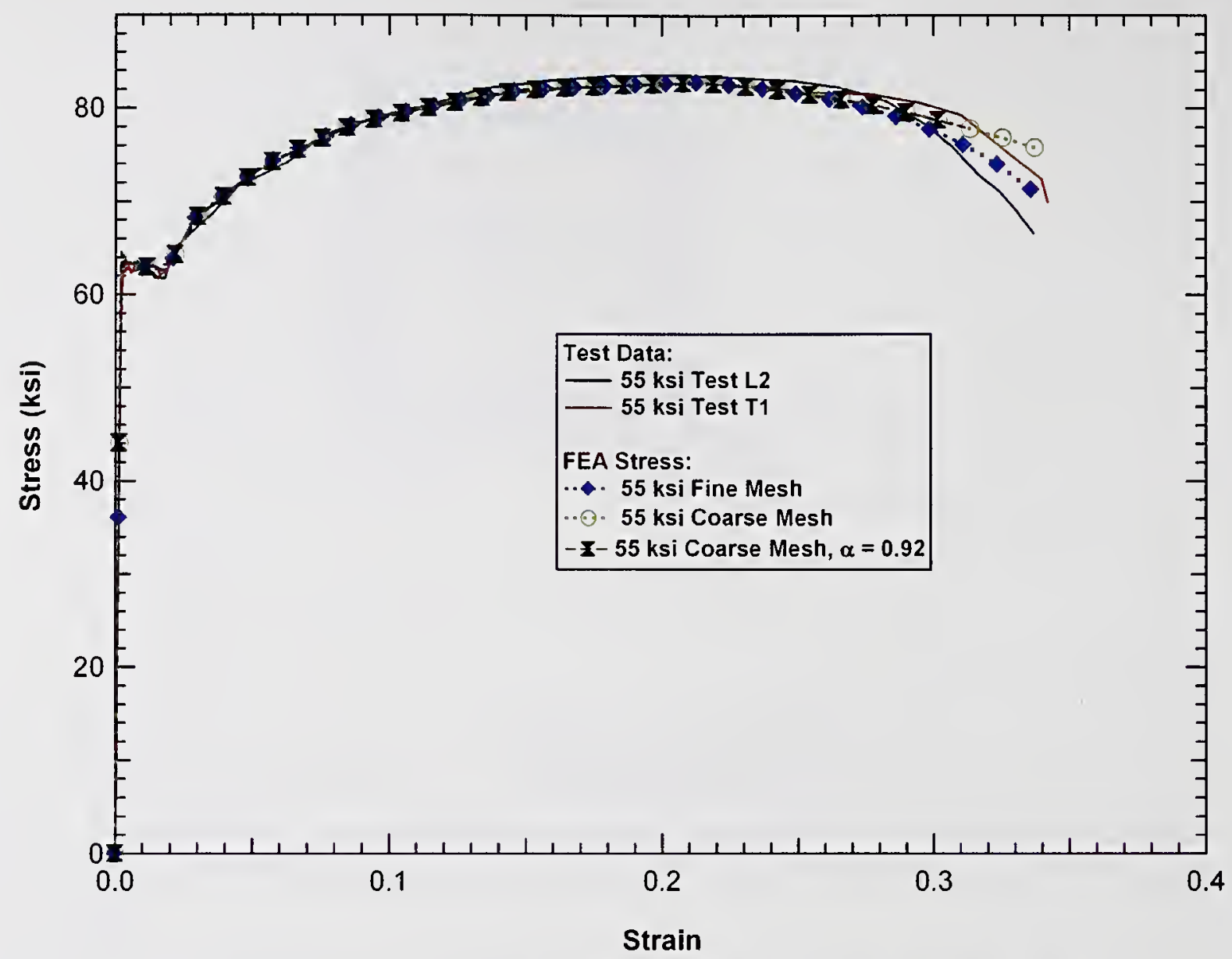

Figure C-25. Simulation of the $55 \mathrm{ksi}$ steel tensile test.

Two different mesh refinements were developed for the weldment model as shown in Fig. C-26. The model developed using the fine mesh has 10,240 solid brick elements, as shown in Fig. C-26 (a). The fine mesh model should have sufficient resolution to capture the gradients in stress and strain around the weld and HAZ. The model developed using the medium mesh has 702 solid brick elements, as shown in Fig. C-26 (b). This model was developed with a mesh refinement that could be applied to a threedimensional analysis of a column for component impact analyses.

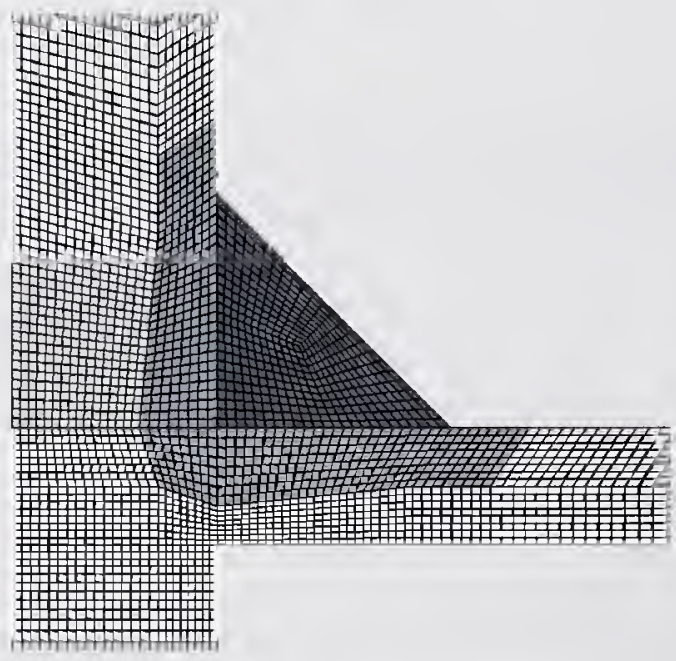

(a) Fine mesh resolution

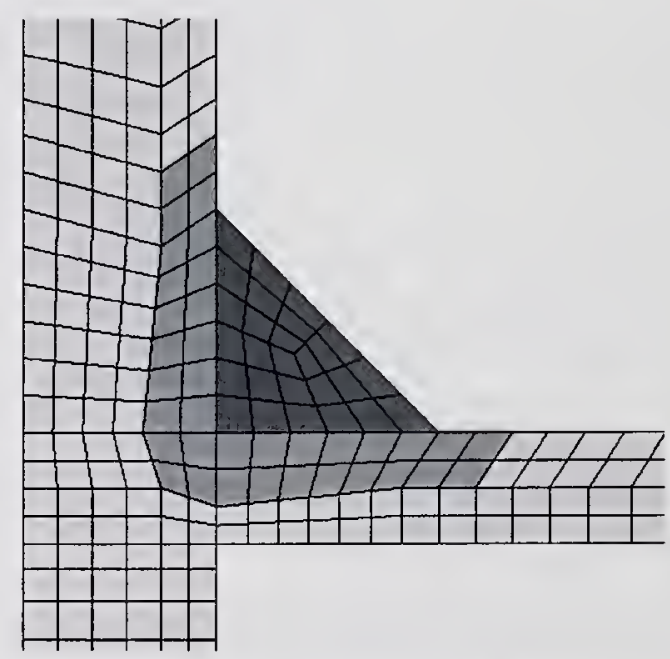

(b) Medium mesh resolution

Figure $\mathrm{C}-26$. Mesh resolutions used in the 2-D weldment failure model. 
An example fracture analysis of the weldment model using the fine mesh model is shown in Fig. C-27. The loading was provided by a rectangular pressure pulse with $0.10 \mathrm{~ms}$ duration and amplitude of $38 \mathrm{ksi}$ $(262 \mathrm{MPa})$. The failure initiates at the toe of the weld and propagates through the heat affected zone and outer web plate. This is the most common weld failure mode observed in the recovered WTC exterior columns. The pressure load results in a downward velocity of the front web. The motion at the ends of the web is restrained by the welds at the flanges and a moving plastic hinge behavior develops in the web. The deformations result in bending and tension at the weld location and eventually the local deformations initiate a fracture at the toe of the weld that propagates through the HAZ and web base metal. The details of the calculated fracture behavior are shown in Fig. C-28.

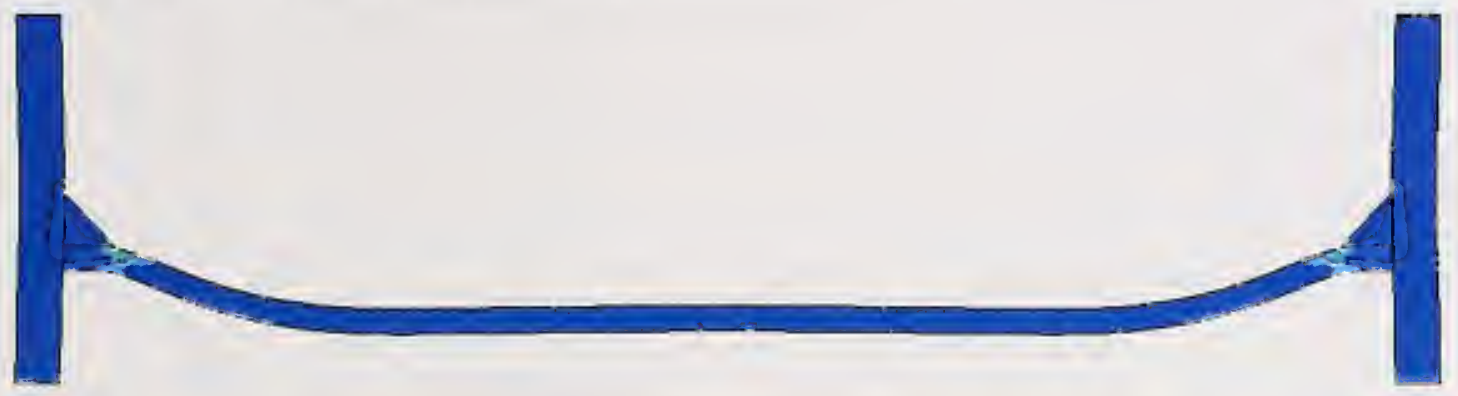

\section{(a) Initiation of fracture}

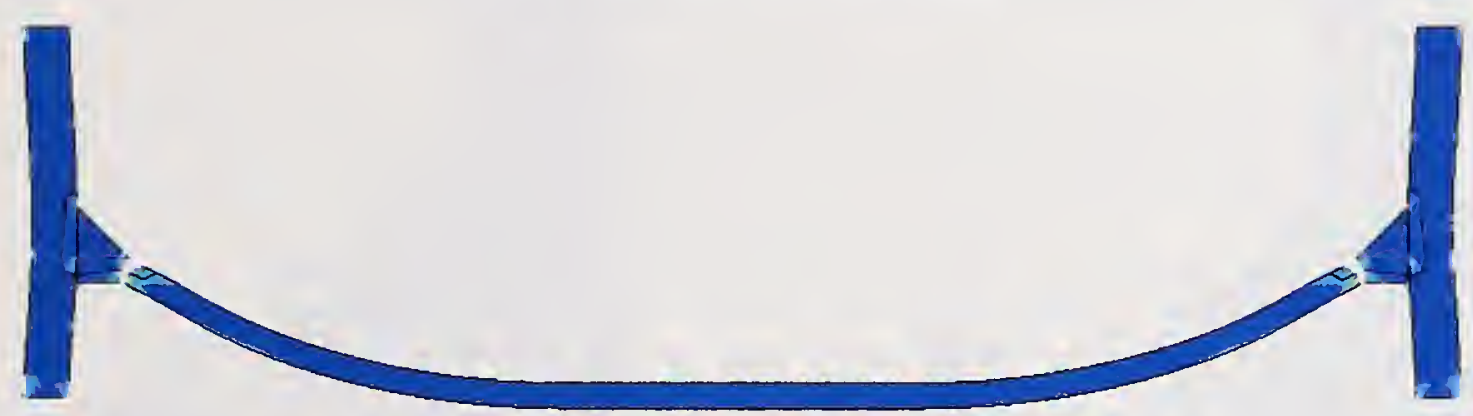

(b) Complete fracture through the web

Figure C-27. Calculated weldment deformations and failure.

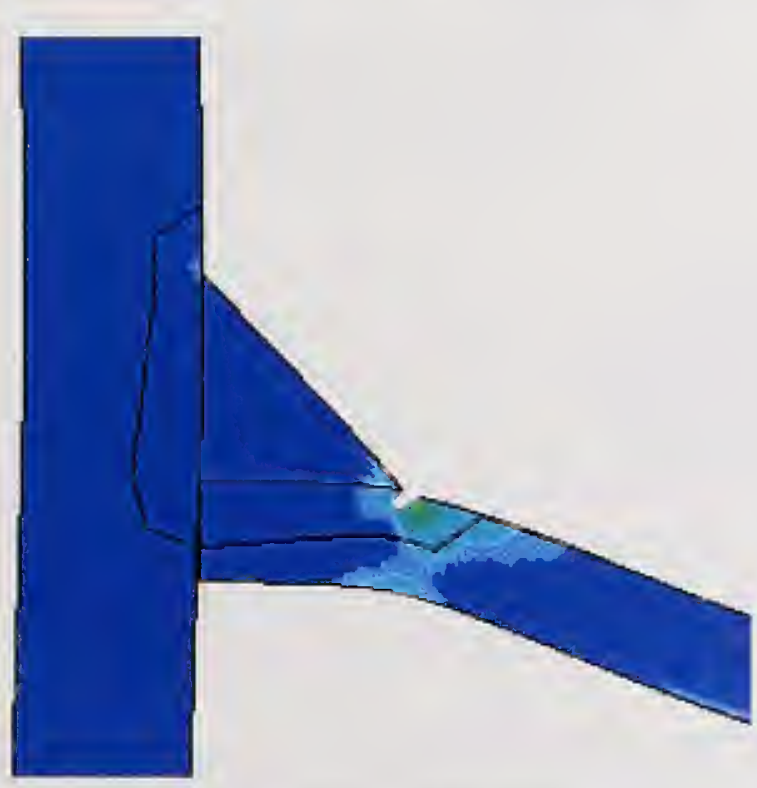

(a) Initiation of fracture

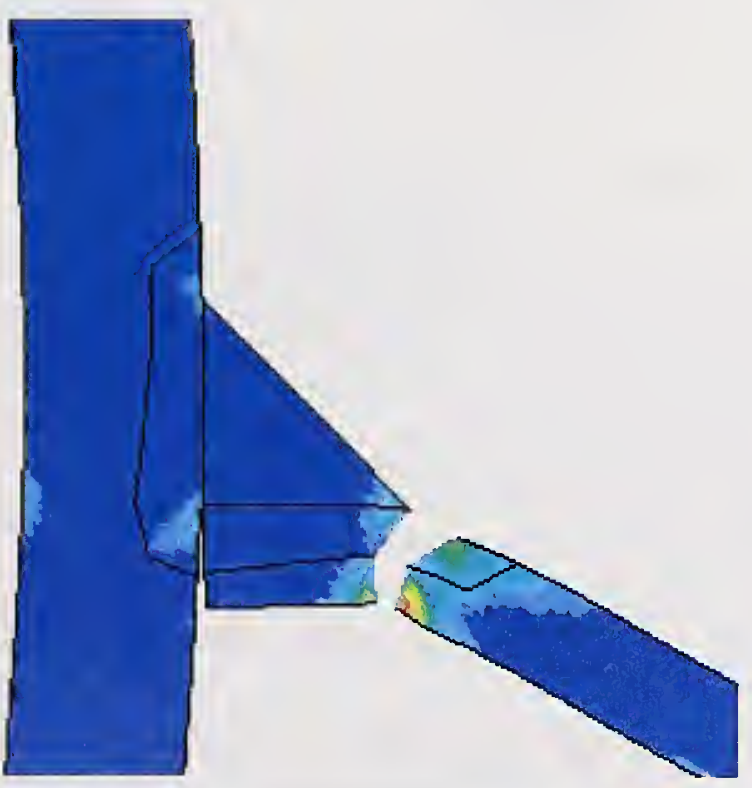

(b) Complete fracture through the web

Figure C-28. Detail of the calculated weldment failure behavior. 
As described in previous analyses, the application of a coarser mesh resolution does not resolve the same gradients in stress and strain and the failure criteria need to be adjusted. The failure criteria parameters used in the two analyses are given in Table $\mathrm{C}-3$. The comparison of the fracture behavior for the two mesh resolutions is shown in Fig. C-29. Similarly the kinetic and internal energies for the two calculations are compared in Fig. C-30. The comparisons show that both models have the same deformation and failure modes at very similar energy levels.

Table C-3. 2-D weldment model comparison.

\begin{tabular}{|l|c|c|}
\hline \multicolumn{1}{|c|}{ Mesh Refinement } & Fine & Medium \\
\hline Element class & Brick & Brick \\
\hline Base metal failure coefficient $(\alpha)$ & 1.35 & 0.76 \\
\hline HAZ metal failure coefficient $(\alpha)$ & 0.81 & 0.45 \\
\hline Weld metal failure coefficient $(\alpha)$ & 1.10 & 0.62 \\
\hline
\end{tabular}

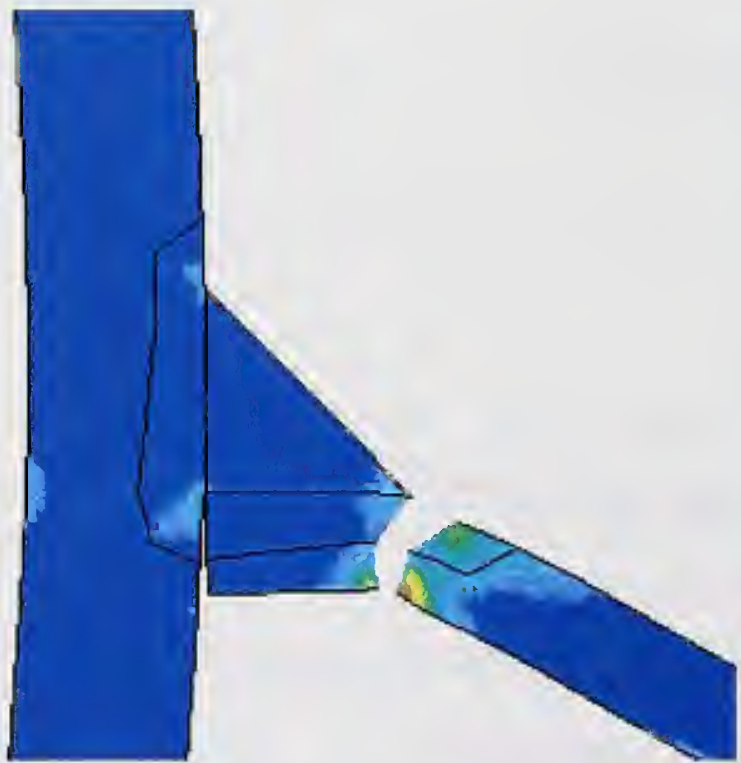

(a) Fine mesh resolution

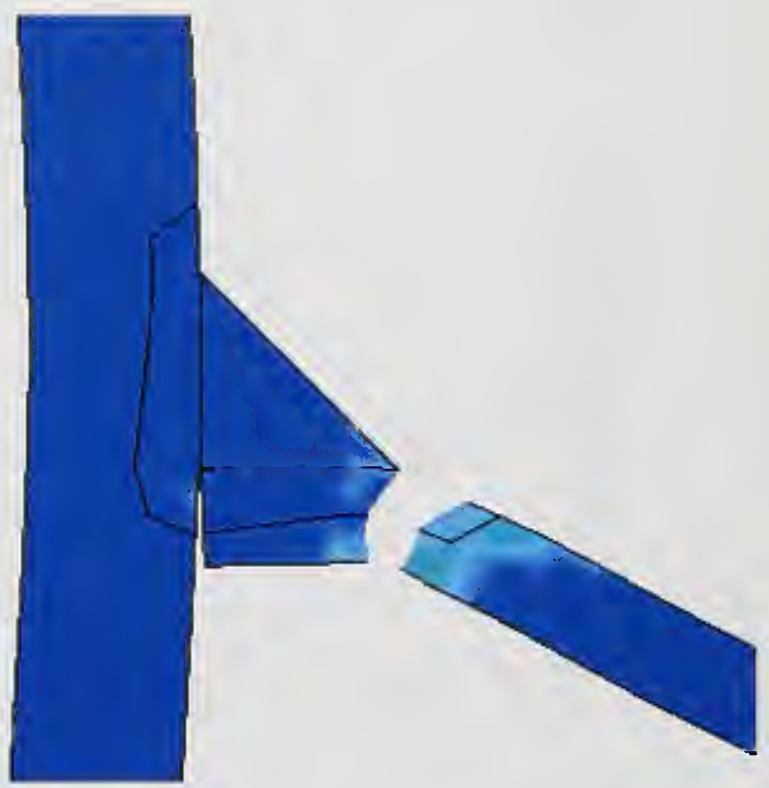

(b) Medium mesh resolution

Figure C-29. Mesh refinement effects on calculated weldment failure behavior.

The remaining stage in developing the weldment failure model is to perform three-dimensional component impact analyses of the exterior column and develop a coarser shell element description of the weld region that can be applied in the global aircraft impact analyses. The problem analyzed is the drop test configuration shown in Fig. $\mathrm{C}-31$. The drop test configuration shown has a $550 \mathrm{lb}$ steel impactor with an impact velocity of $37.4 \mathrm{mph}$. The impactor is $12 \mathrm{in}$. wide and $5 \mathrm{in}$. across. The nose of the impactor has a reduced area that is $12 \mathrm{in.} \mathrm{wide} \mathrm{and} 2 \mathrm{in}$. across with a one-half in. radius rounded edge around the impact face. The length of the column section represents a portion of an exterior column between spandrels. 


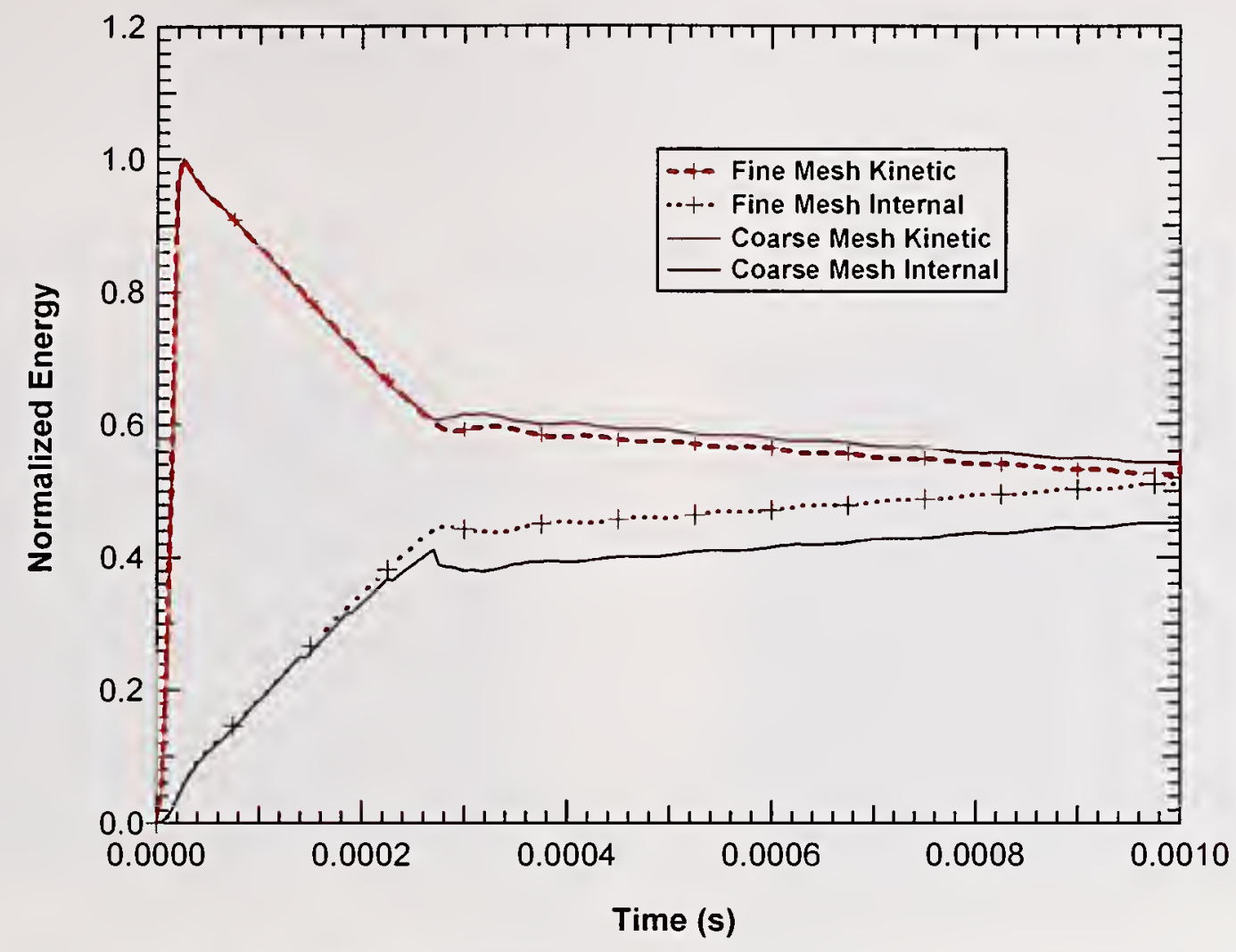

Figure C-30. Calculated energy balance for the 2-D weldment models.

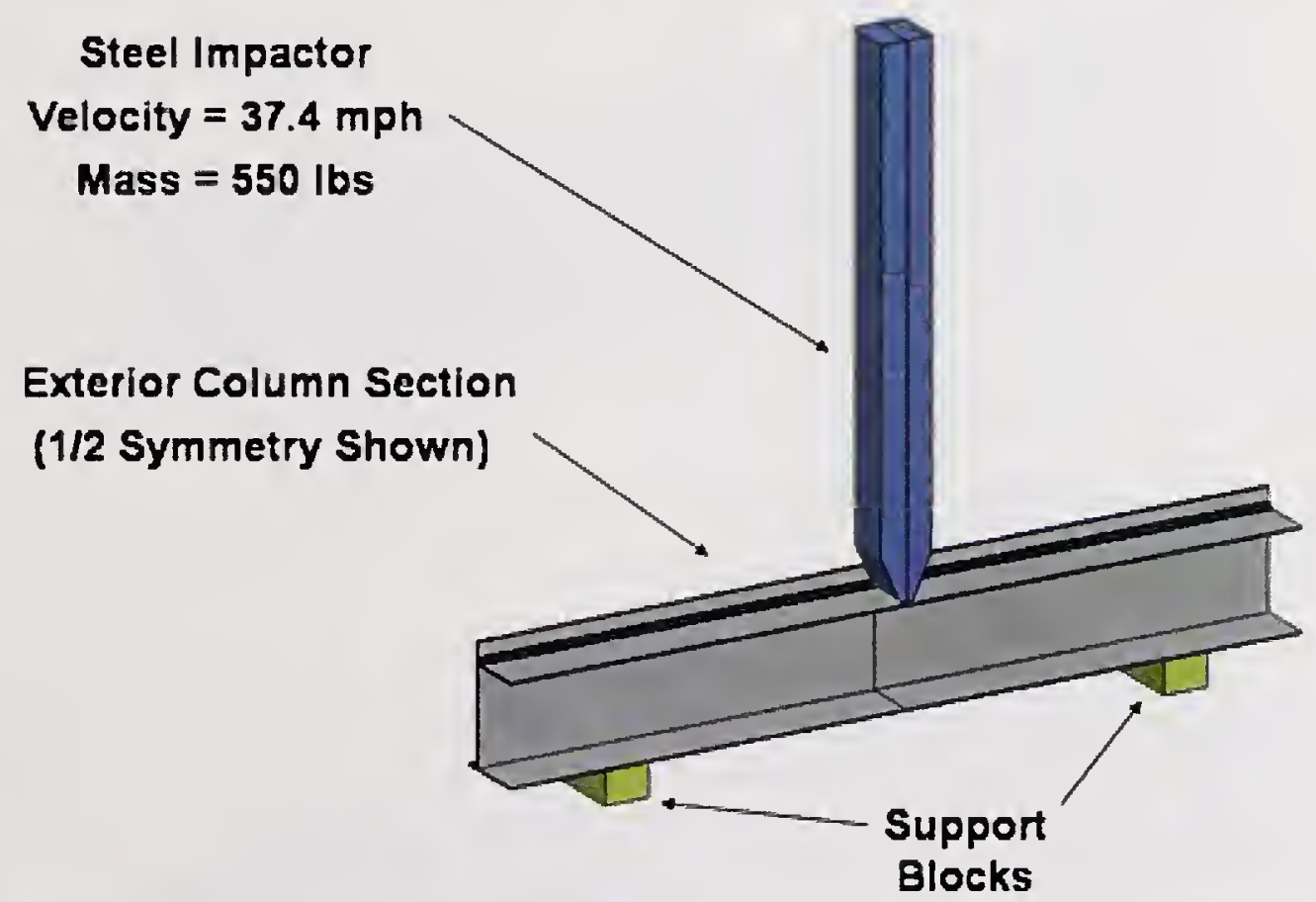

Figure C-31. Drop test model for column weld fracture analysis.

The two different column and weld models applied are shown in Fig. $\mathrm{C}-32$. The medium mesh resolution was previously applied in the $2-\mathrm{D}$ weldment fracture analyses. The half symmetry medium mesh column model contained 63,680 brick elements. The coarse shell element model has significantly fewer elements with approximately 4 in. elements to define the column and 1 in. wide elements in the weld zone. The 
half symmetry coarse shell element column model contained 144 linear shell elements. Obviously, the coarse shell element model is not capable of capturing the stress and strain gradients to the same extent as the brick element model. As a result, the shell element model applies the simpler critical plastic strain criterion available in the default piecewise linear constitutive model.

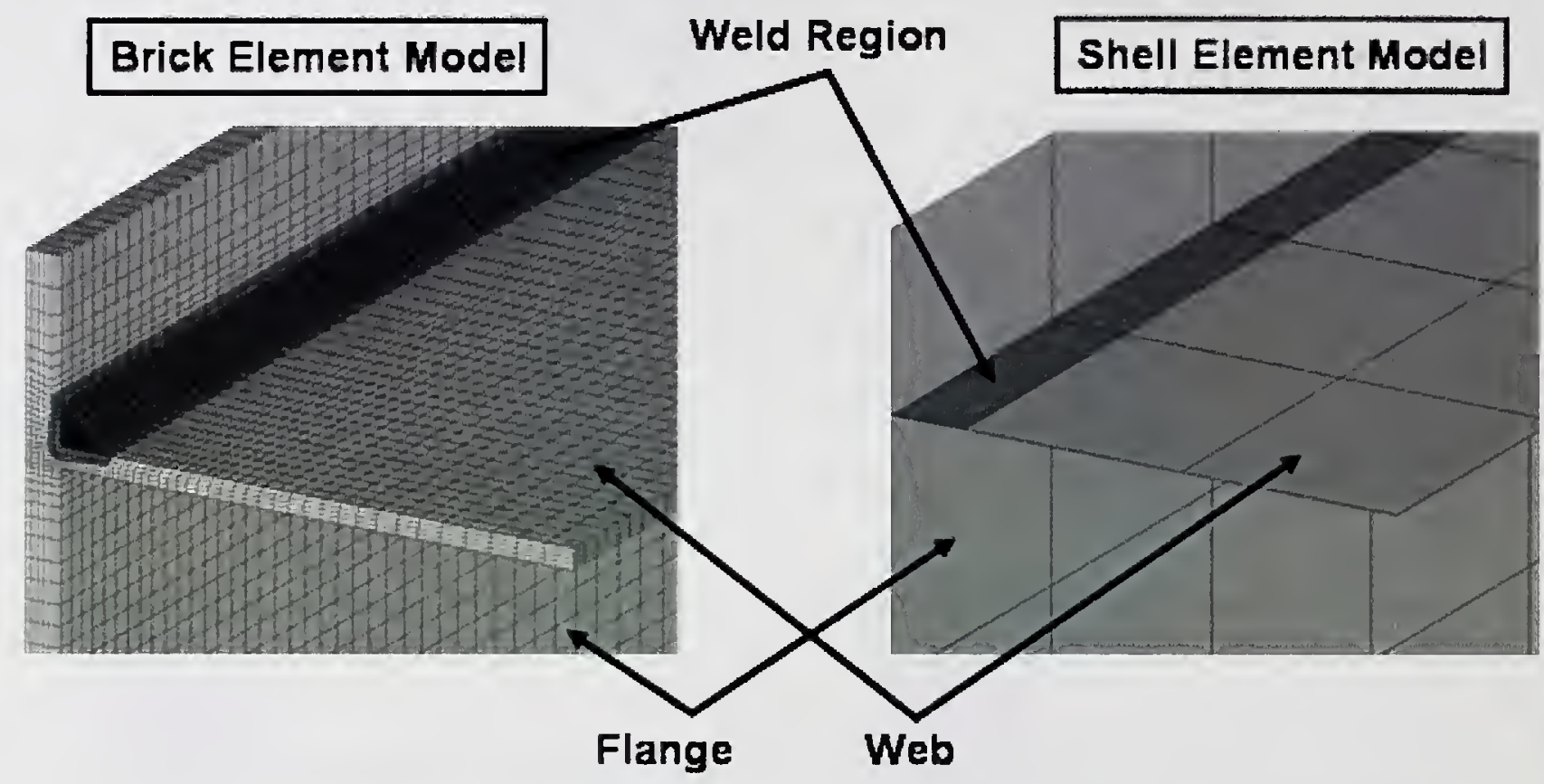

(a) Medium mesh resolution

(b) Coarse mesh resolution

Figure C-32. Models developed for column weld fracture analysis.

The drop test was simulated first using the medium resolution brick element model. The results of the calculated impact response and failure were then used to develop an appropriate failure strain for the shell element model weld zone. The strain profile calculated in elements along the upper surface of the web in the weld fracture region is plotted in Fig. $\mathrm{C}-33$. The figure shows a strong gradient in the calculated strains with the peak strains of approximately 15 percent plastic strain near the toe of the weld. A corresponding critical strain of 8 percent was selected for the corresponding one-in.-wide single shell element weld zone. This strain is indicated by the red line in Fig. C-33.

The comparison of the resulting impact behavior for the two models is shown in Fig. C-34. Both models have similar impact deformations and the lengths of the weld failures are in good agreement.

These analyses have been used to develop improved engineering fracture criteria in the weld region. There is still significant uncertainty in the details of the weld geometry and damage development in the weld region with variations in material properties and stress distributions. However, reasonable bounds on the effects of these variations will be assessed later in the uncertainty analyses. 


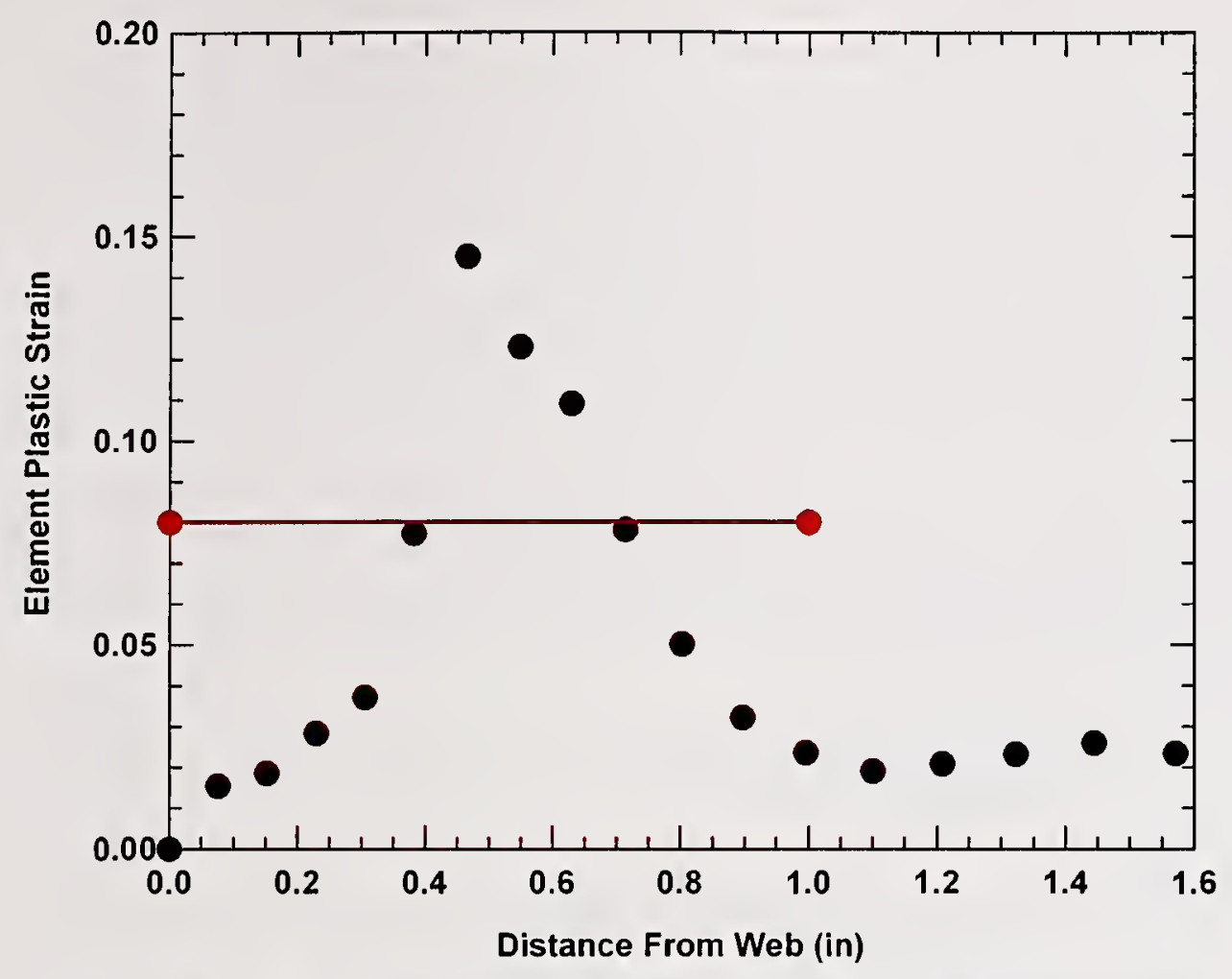

Figure C-33. Calculated strain profile for the weld zone.

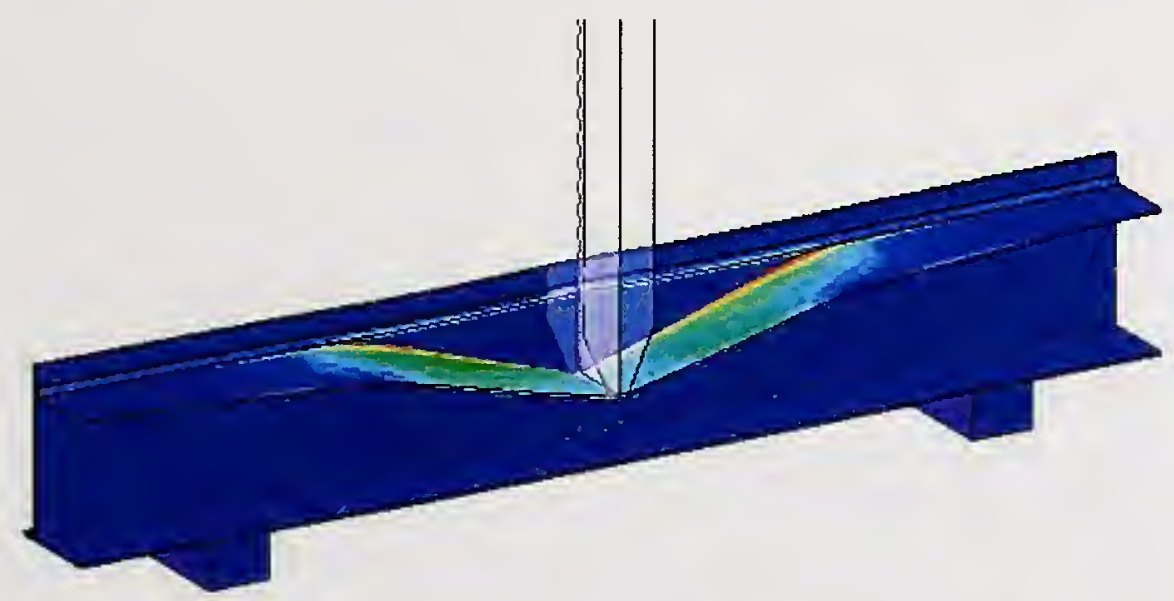

(a) Medium resolution brick element model

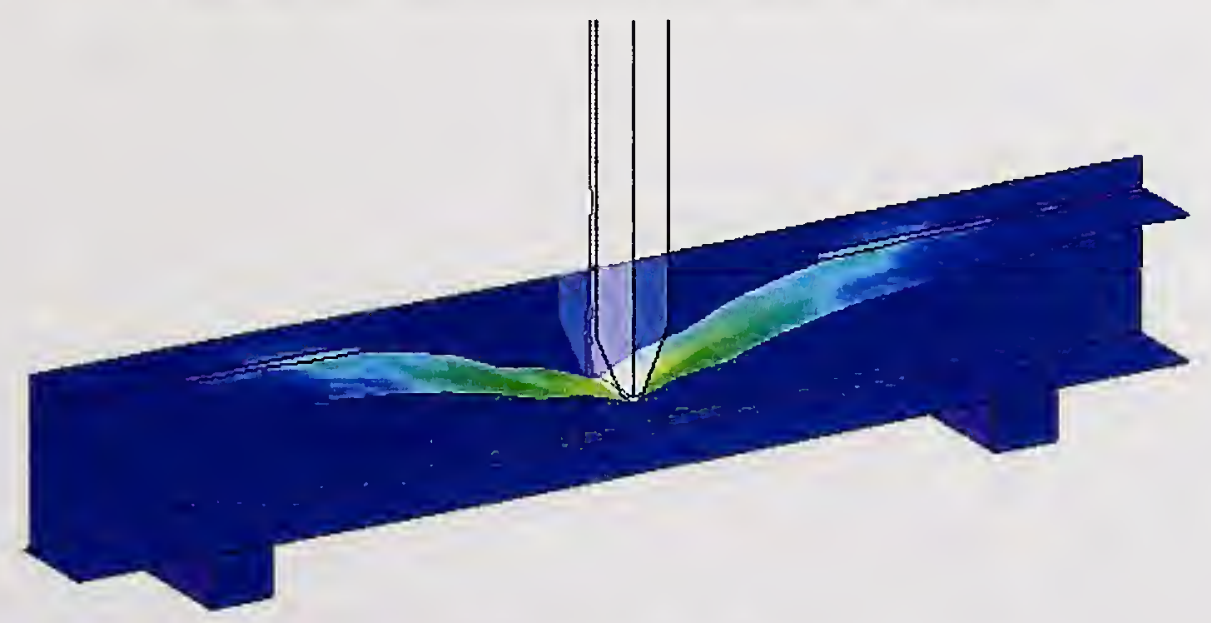

(b) Coarse resolution shell element model

Figure C-34. Calculated drop test fracture behavior. 


\section{Bolt Material Constitutive Modeling}

The primary bolts of interest for the impact analysis are those used at the connections between the exterior columns on the WTC towers. Within the impact zone, the connections are typically made using 0.875 in. in diameter steel bolts grade A325. Initially, there was no test data available that could be applied to develop a bolt model. The modeling approach was to develop a brick element bolt model and use it to develop a corresponding beam element bolt model for the majority of the impact analyses. A description of these bolt analyses are given in Section C.4.2, along with the component analyses.

Subsequently, a series of tests was performed by Project 3 on bolts recovered from the WTC towers. A summary of the bolt testing is given in Fig. C-35. The bolts were found to yield at a load of approximately $50 \mathrm{kip}$ and have an ultimate failure load of approximately $68 \mathrm{kip}$. The measured elongation at failure is approximately 0.18 in.

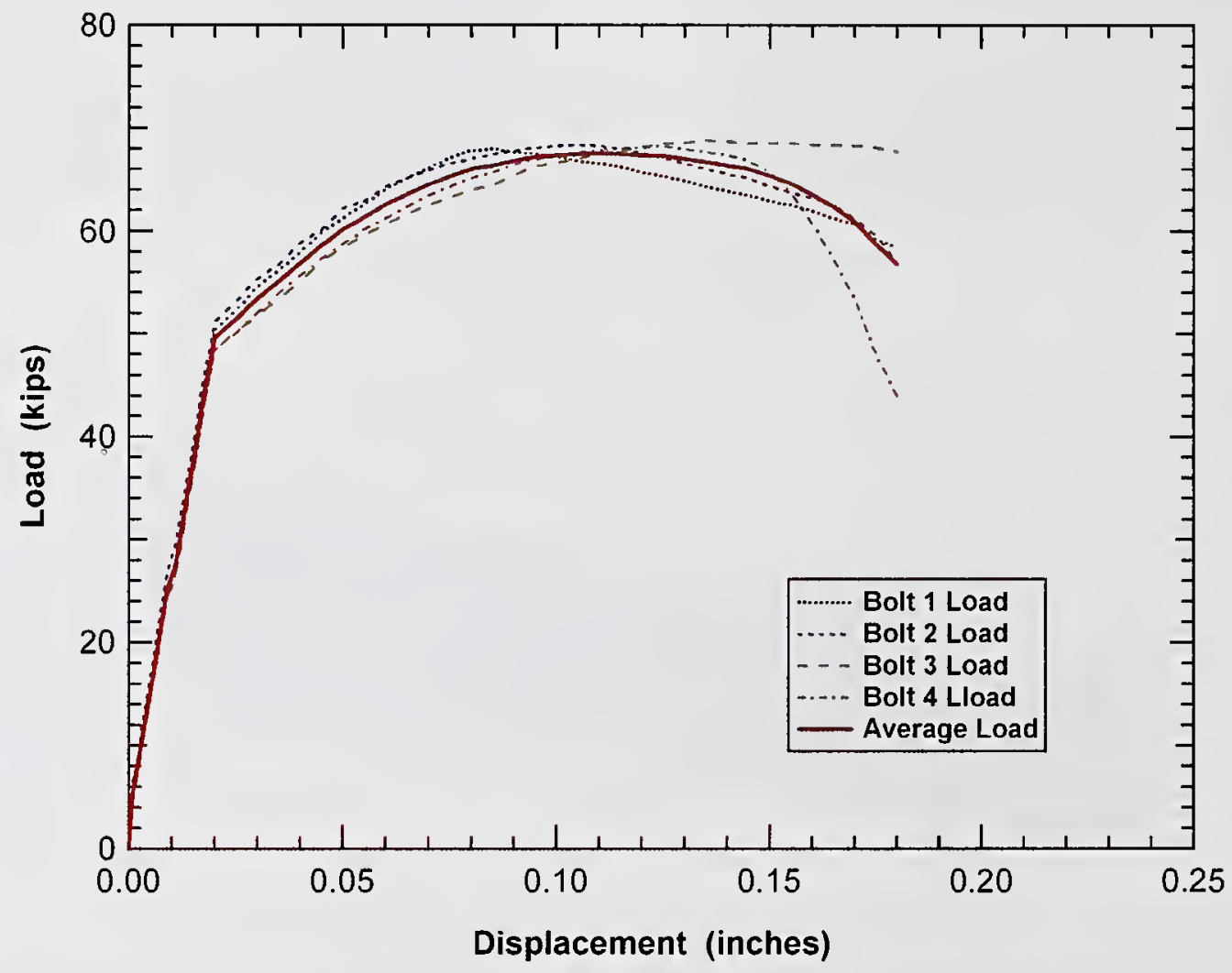

Figure C-35. Measured bolt load-displacement behavior.

The beam element model for the bolt, described in Section C.4.2, was compared to the bolt test data. The comparison showed good agreement in the strength of the bolt, but it also indicated that the beam model overestimated the ductility. This may be a result of not capturing the details of the stress concentrations in the region of the threaded connection and nut. The bolt test data was used to correct the ductility of the beam element bolt model and the resulting comparison of the model and data is shown in Fig. C-36. The bolt model shows a bilinear elastic-plastic behavior that is stiffer in the elastic region and yields at a higher stress level than the data. The inability of the simplified model to capture stress gradients in the regions of the bolt head, threads, and nut may cause this type of response. However, the overall strength and ductility of the model and test data as well as the strain energy capacity agree reasonably well that further model development was not required. 


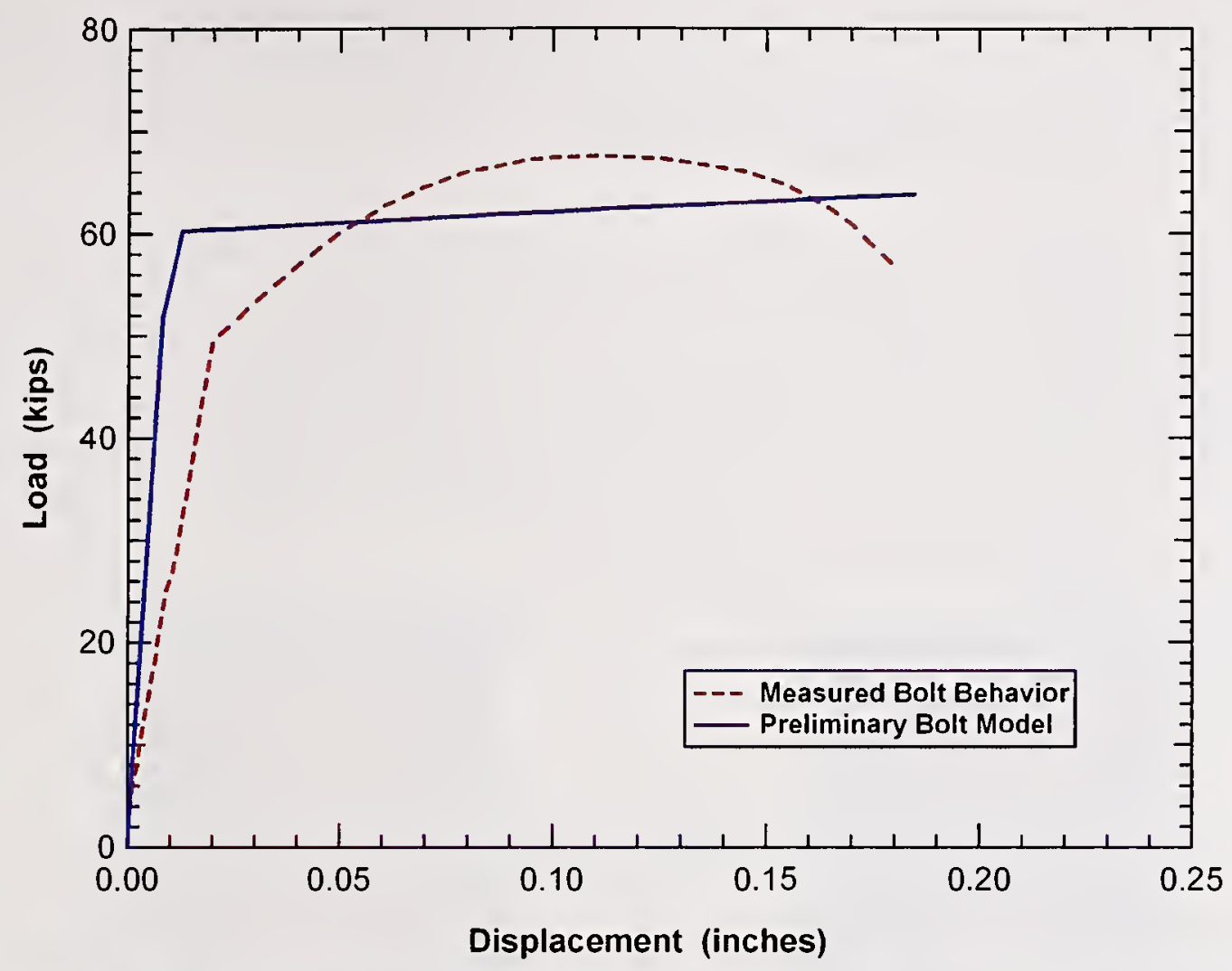

Figure C-36. Comparison of the measured and calculated bolt behavior.

\section{C.2.3 Concrete Constitutive Models}

There are several concrete models in LS-DYNA. Each has different capabilities for modeling rate effects and nonlinearity associated with damage and failure behavior. Potential concrete models in LS-DYNA are Types 5 (soil and crushable/non-crushable foam model), 16 (pseudo-tensor concrete model), 25 (kinematic hardening cap model), 78 (soil and concrete model), and 111 (Holmquist-Johnson-Cook concrete model). An important factor in determining the behavior of a concrete structure in compression or bending is its lateral confinement. The concrete floor slabs in the WTC towers were not highly confined so a material model suitable for this loading condition is needed.

In this study, the ability to accurately model the low confinement damage and softening behavior is important. Damage caused by cracking in the concrete degrades the strength in the low confinement regime. Inclusion of this damage growth provides a more accurate representation of the stress-strain response. Based on this capability, the LS-DYNA material Type 16 (pseudo-tensor concrete model) is selected for modeling the concrete floor slabs. This model also accounts for the high strain-rate sensitivity of reinforced concrete.

As implemented in LS-DYNA, the pseudo-tensor model can be operated in two major modes: (1) a simple tabular pressure-dependent yield surface, and (2) a model with two pressure-dependent yield functions and a damage-dependent function to migrate between curves. The first option is well suited for implementing standard geologic material behaviors such as a Mohr-Coulomb yield surface with a Tresca limit and has been used successfully for the analysis of ground shock and soil-structure interactions under high confinement. The second option, applied here, allows for implementation of tensile failure and damage scaling, which are more dominant material behaviors at low confinement. 
The pseudo-tensor model, as applied to the analysis of the lightweight concrete in the WTC towers, has two pressure-dependent yield functions. By defining suitable yield functions for the undamaged and fully damaged concrete and an appropriate tabular interpolation between the curves, the behavior of the damage under low confinement can be properly captured.

Material constitutive parameters for the pseudo-tensor model were developed for a $3 \mathrm{ksi}$ compressive strength lightweight concrete. A simulation was performed of a standard unconfined concrete compression test to check the constitutive model behavior. The simulated behavior of the concrete specimen is shown in Fig. C-37. The calculated compressive stress-strain response is compared to measured compression data for $2.3 \mathrm{ksi}$ and $3.8 \mathrm{ksi}$ strength concretes in Fig. C-38 (Wischers 1978). Currently, the same material parameters are being used for the concrete in both the core (normal weight concrete) and truss floor (lightweight concrete) areas.

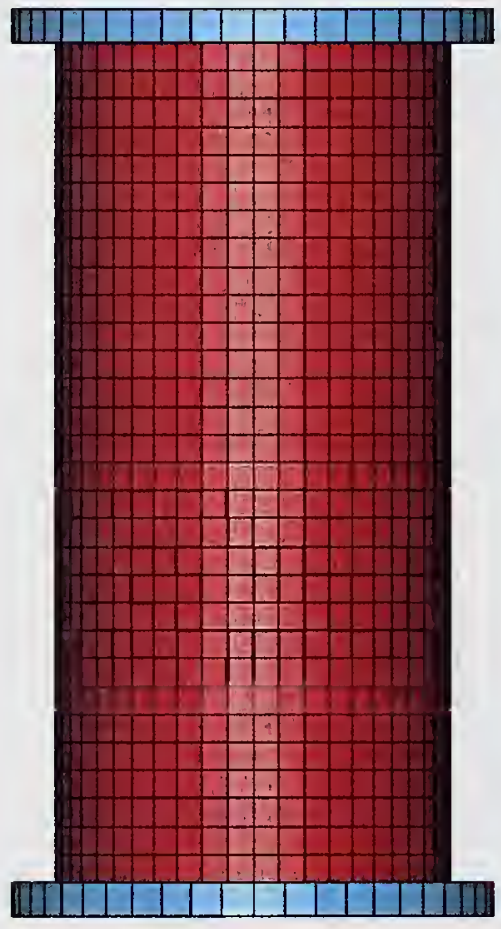

Initial Configuration

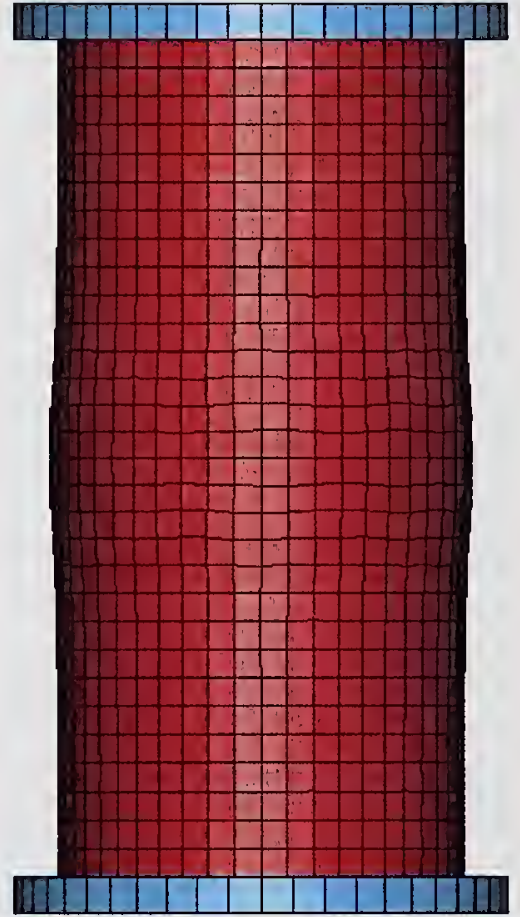

$2 \%$ Compression

Figure C-37. Finite element analysis of the unconfined compression test.

\section{C.2.4 Aircraft Constitutive Models}

No material testing was performed to characterize the structural materials in the aircraft or develop the constitutive model parameters for these materials. Therefore, the constitutive and failure properties for the aircraft materials were developed from data available in the open literature. The principal sources of data for the airframe materials are the Military Handbook (MIL-HDBK-5F), 1987 and Aerospace Structural Metals Handbook (Brown et al. 1991). Additional sources of data are used to verify and supplement the information obtained from these primary data sources.

Complete engineering stress-strain curves were provided in the MIL-HDBK-5F for various 2024 and 7075 aluminum alloys that are commonly used in the construction of the 767 airframe structures. These 


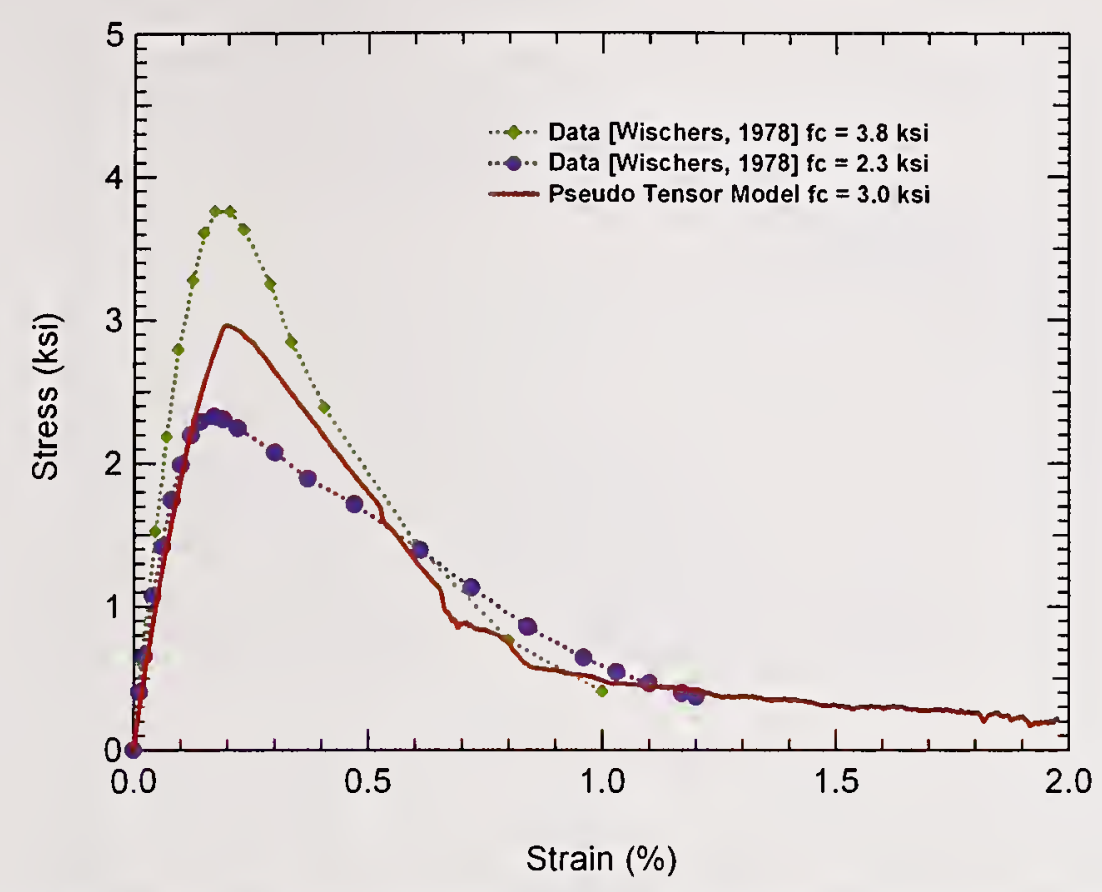

Figure $\mathbf{C}-38$. Comparison of the calculated unconfined compression behavior with concrete compression test data.

curves were digitized for the various 2024 and 7075 alloys as shown in Fig. C-39 and Fig. C-40, respectively. Representative stress-strain curves were then converted into true stress and true strain as described earlier and used to develop tabular curves for constitutive models. The calculated true stressstrain curves and tabular constitutive model fits are shown in Fig. C -41 and Fig. C -42 , respectively.

\section{C.3 DEVELOPMENT OF AIRCRAFT MODEL}

Development of the model of the Boeing 767-200ER aircraft is being accomplished through a three-step process. These are data collection, data interpretation and engineering analysis, and finally meshing of the structure. Data collection is nearing completion, and additional efforts will mainly focus on final details of non-structural contents and material properties for primary structural parts. Reviewing, organizing, and analyzing the data as well as meshing of the structure are also at the final stages.

\section{C.3.1 Aircraft Data Collection}

Data collection for the Boeing 767-200ER is nearing completion. Significant information on the aircraft structure and contents has been gathered from (1) documentary aircraft structural information, and (2) data from measurements on Boeing 767 aircraft.

\section{C.3.2 Description of the Aircraft Model}

The model for the Boeing 767-200ER is nearing completion. Certain components, such as the PW4000 engine shown in Fig. C-43, have been completed. Construction of the wings is in the final stage with only the inboard flaps and ailerons left to be modeled. Work has begun on the fuselage as well. Some details of the airframe model are shown in Fig. C-46 later. The LS-DYNA model of the aircraft is generated and meshed using the TrueGrid software (TrueGrid Manual 2001). 


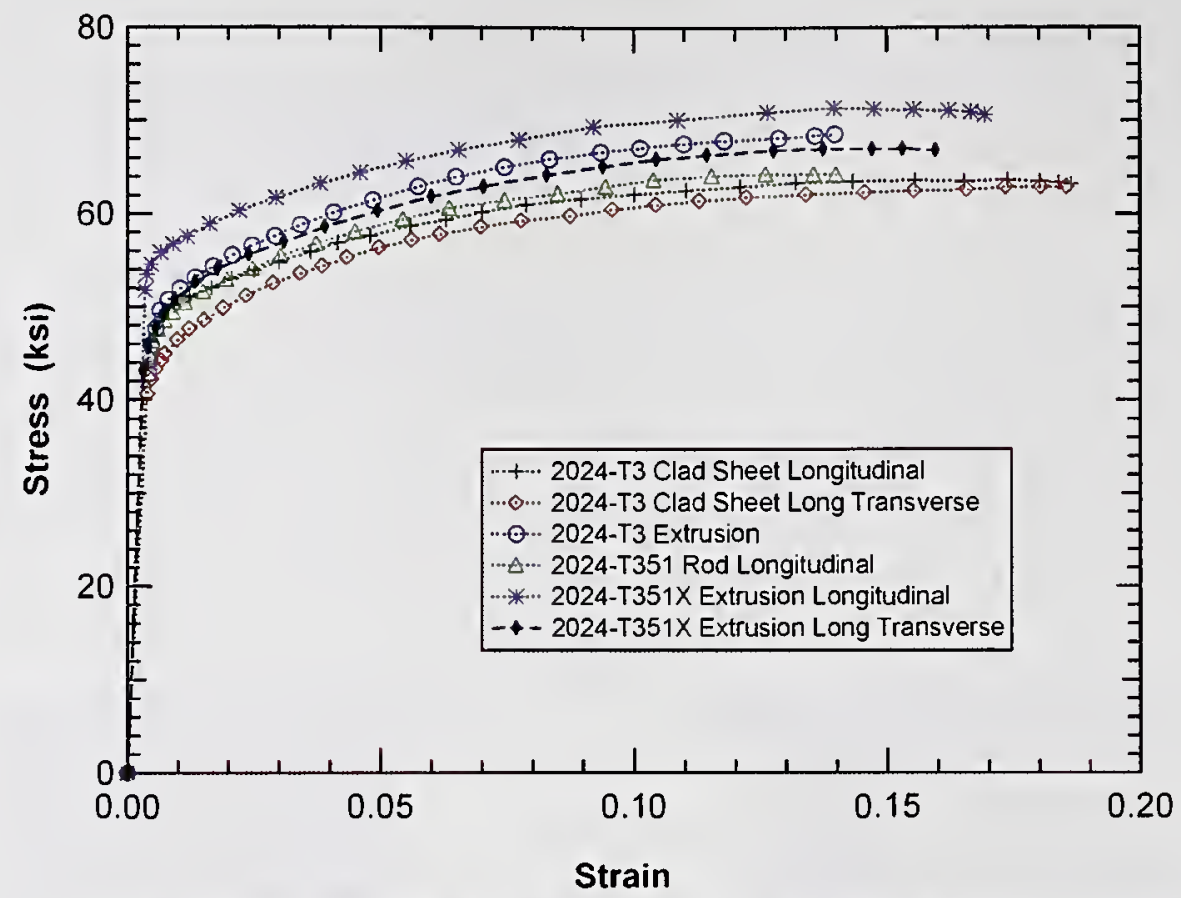

Figure C-39. Digitized engineering stress-strain curves for various 2024 aluminum alloys.

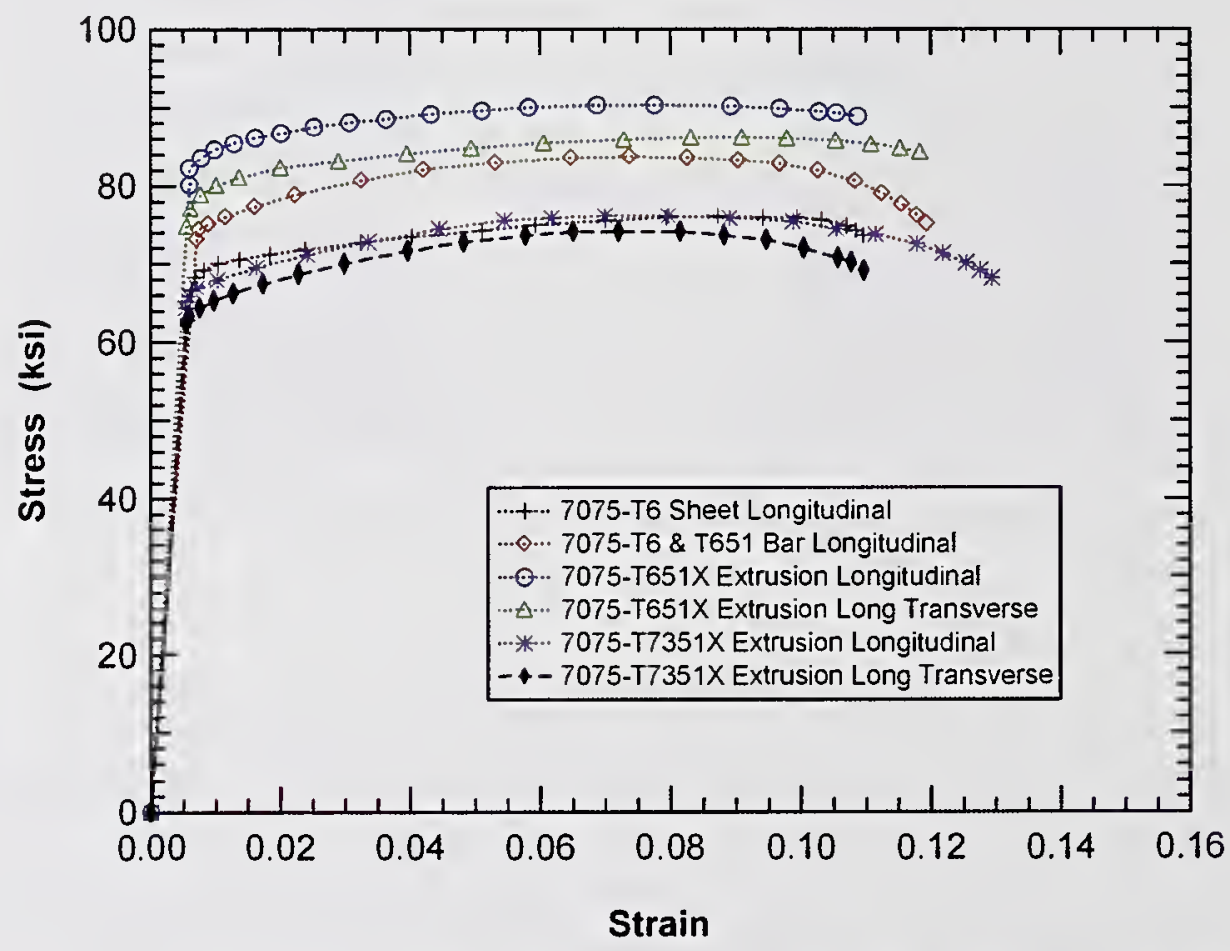

Figure C-40. Digitized engineering stress-strain curves for various $\mathbf{7 0 7 5}$ aluminum alloys. 


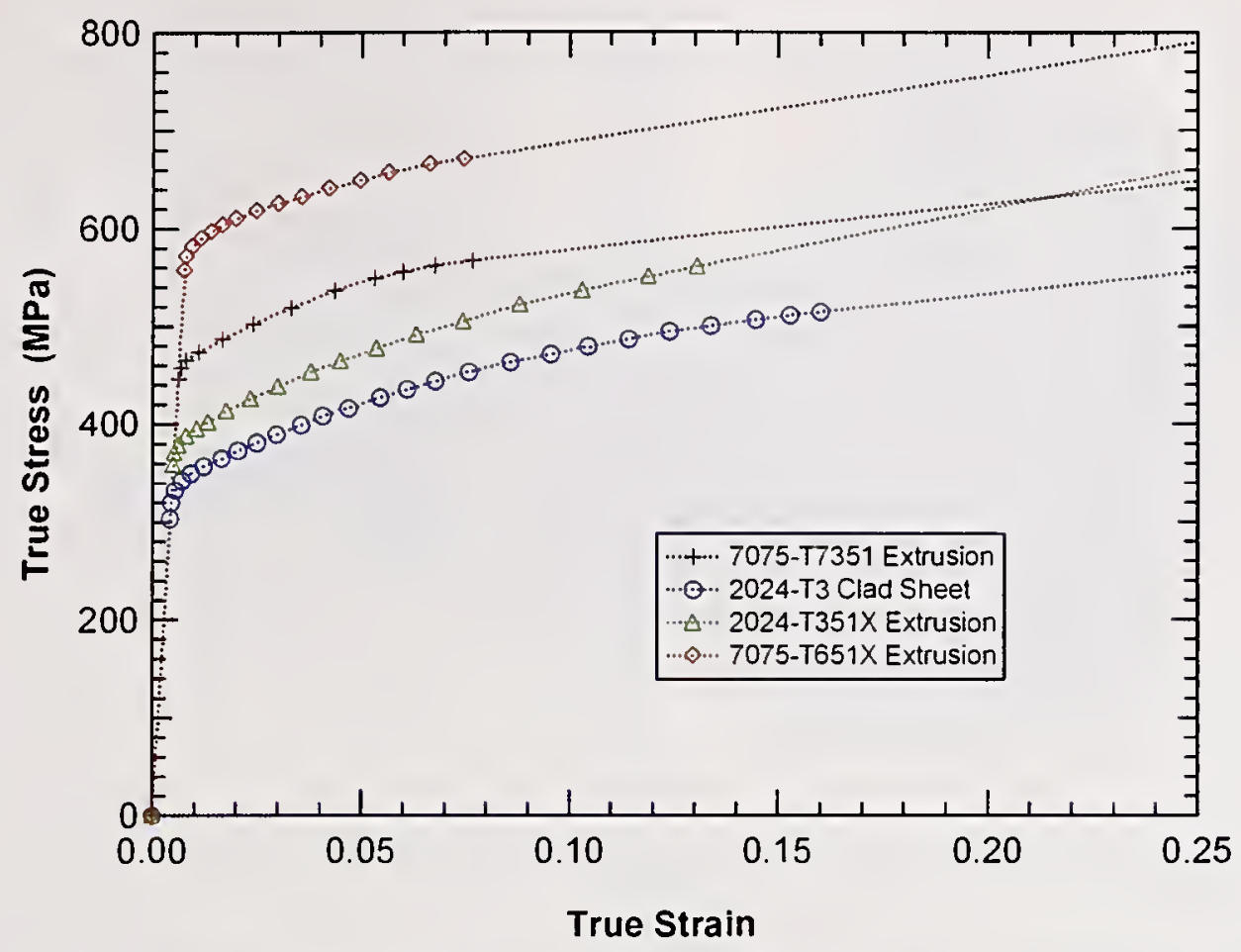

Figure C-41. True stress-strain curves developed for various aircraft aluminum alloys.

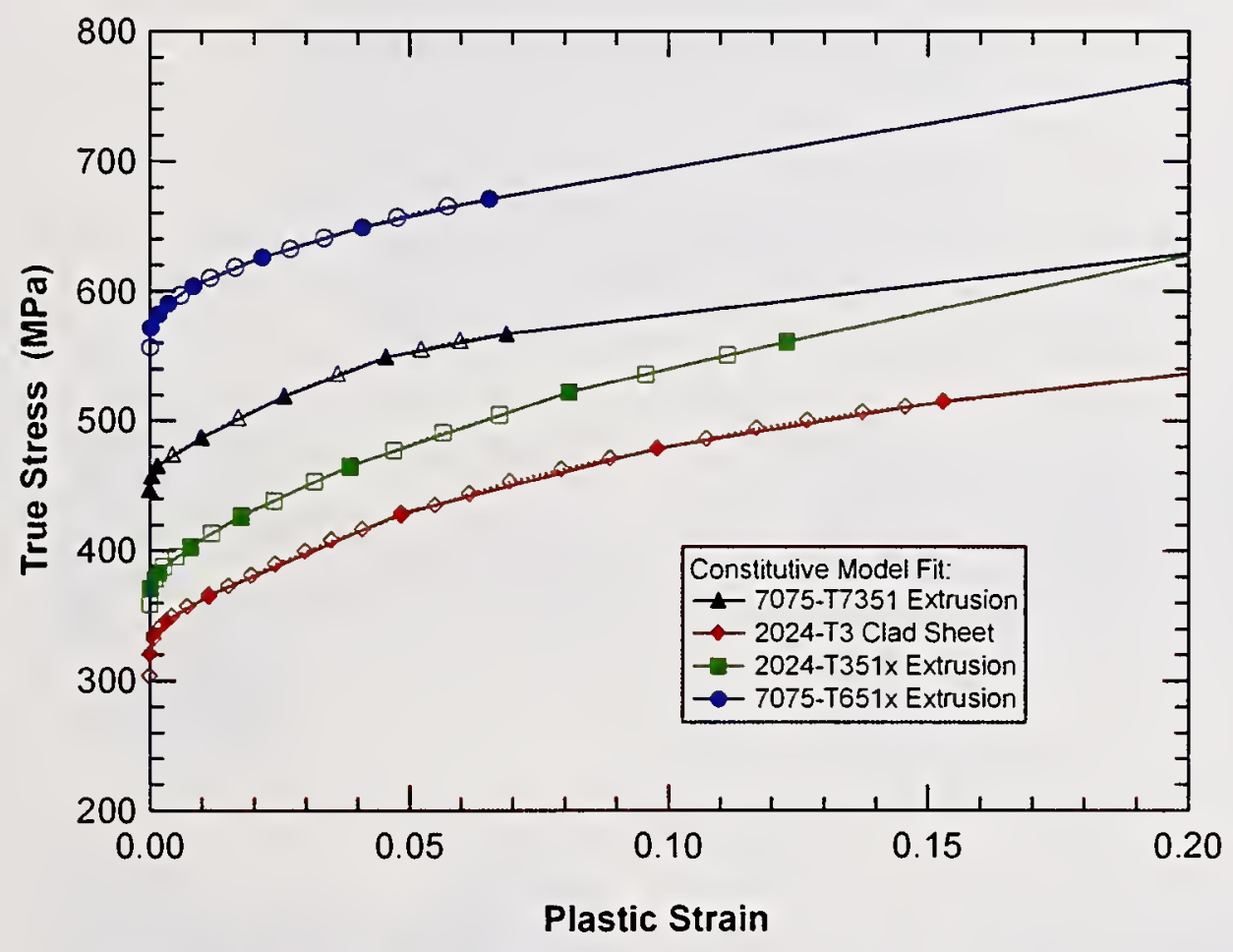

Figure C-42. Tabular true stress-strain curves developed for various aircraft aluminum alloys. 


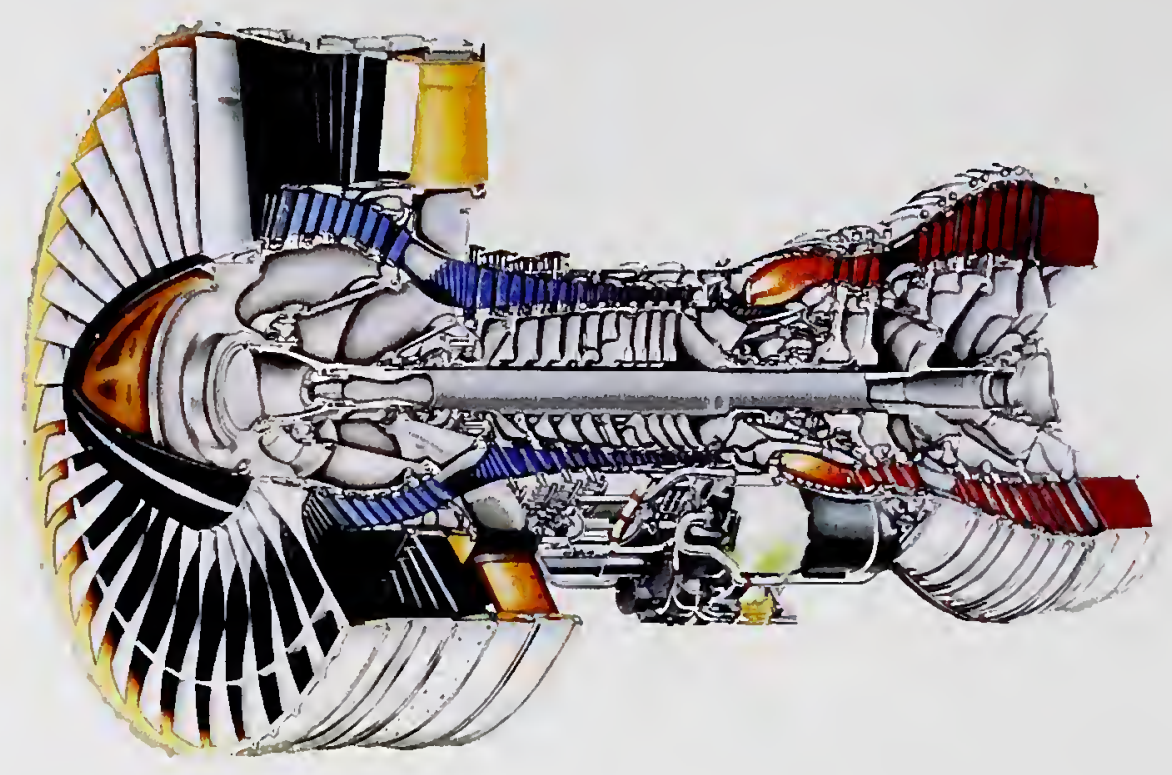

Figure C-43. Pratt and Whitney PW4000 turbofan engine.

\section{Engine Model Development}

The Pratt and Whitney PW4000 turbofan engine has a very complex structure as shown in Fig. C-43. The engine is an important component of the aircraft with the potential to produce significant impact damage to the WTC tower structures (e.g., fail core columns). As a result, special care was given to the development of the engine model to include all the details of the engine construction.

To develop a structural model of the engine, the primary structural components in the engine were identified and approximated with simplified geometry as illustrated in Fig. C-44. Known engine dimensions were used to determine the scale factor for the drawing. The simplified geometry of the engine structures could then be captured using a common digitization procedure. Once the engine's internal geometry was captured, the digitized geometry was imported into TrueGrid and used to generate surface definitions and part geometries for the engine model. The engine model was developed primarily with shell elements. The objective was to develop a mesh with typical element dimensions between one and two in. However, smaller element dimensions were required at many locations to capture details of the engine geometry. Brick elements were used for some of the thicker hubs and the roots of the compressor blades. The various components of the resulting engine model are shown in Fig. C-45. A summary of the elements used in the engine model is given in Table $\mathrm{C}-4$. 


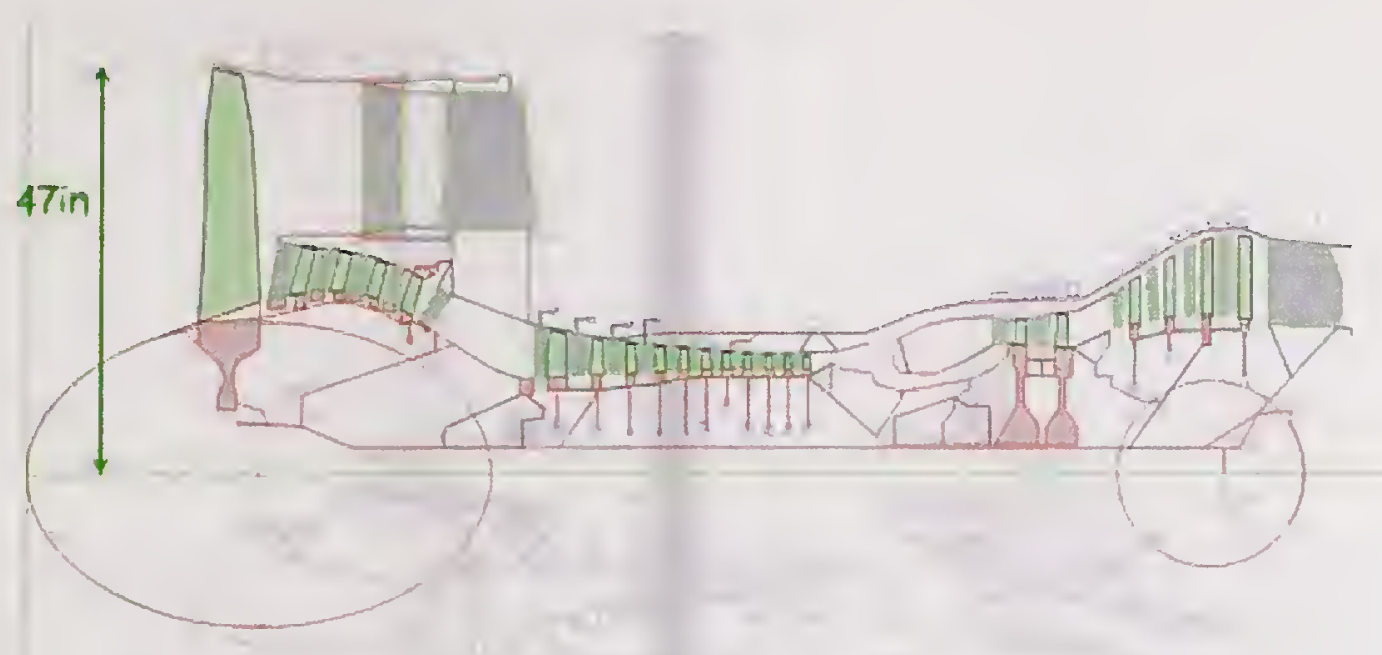

Figure C-44. PW4000 engine cross sectional geometry and simplification.
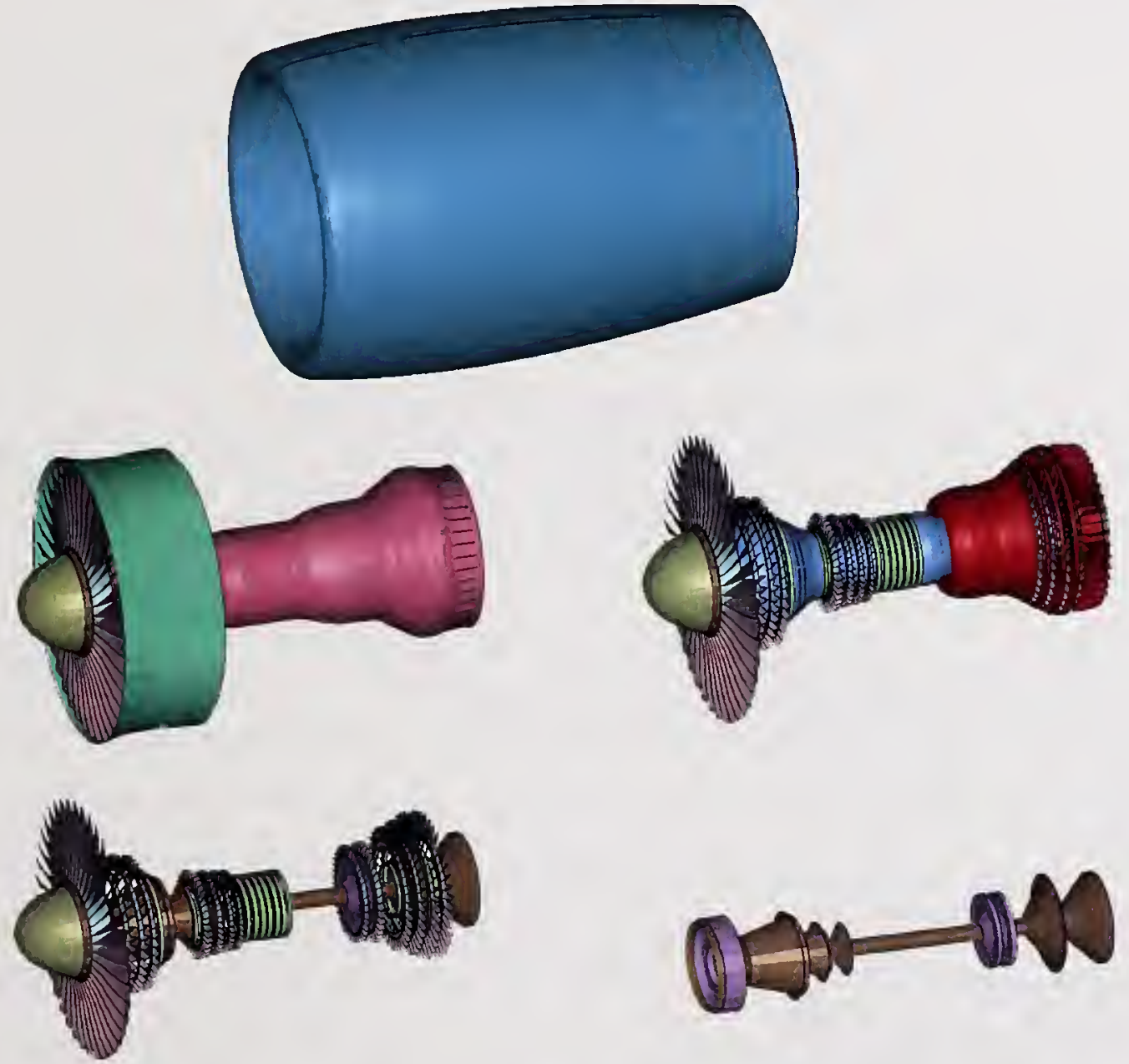

Figure C-45. Pratt and Whitney PW4000 turbofan engine model. 
Table C-4. Engine model parameters.

\begin{tabular}{|l|l|}
\hline & \multicolumn{1}{|c|}{ PW4000 Engine Model } \\
\hline Number of brick elements & 9,560 \\
\hline Number of shell elements & 54,788 \\
\hline Total nodes & 101,822 \\
\hline Preliminary engine model weight & $7,873 \mathrm{lb}(3,571 \mathrm{~kg})$ \\
\hline Adjusted engine model weight & $9,447 \mathrm{lb}(4,285 \mathrm{~kg})$ \\
\hline
\end{tabular}

After the known structural components of the engine were included in the engine model, the weight of the model was calculated at 7,873 lb $(3,571 \mathrm{~kg})$. The dry weight of the PW4000 engine is listed at 9,400 lb. The difference in weight potentially results from the nonstructural components (tubing, pumps, seals, bearings, etc) that were not captured in the model. To account for the difference, the density of all of the material models used for engine components was increased by 20 percent. This effectively smears the missing mass in proportion to the original mass distribution in the model. The resulting adjusted engine model mass is $9,447 \mathrm{lb}(4,285 \mathrm{~kg})$.

Information available from the Aviation Safety Network (http://aviation-safety.net/) indicates that American Airlines Flight 11 was powered by two General Electric CF6-80A2 engines, while United Airlines Flight 175 was powered by two Pratt and Whitney JT9D-7R4D engines. Review of these engines indicates that the PW4000 turbofan engine is very similar to the General Electric CF6-80A2 and the PW JT9D-7R4D engines. Comparisons of specific physical characteristics of the engines are given in Table C-5. In fact, the JT9D-7R4 and PW4000-94 are almost identical as they are in the same family of Pratt and Whitney aircraft engines. The PW4000 was labeled the "new technology JT9D" when it began replacing the latter engine on 767s built after 1987 where the PW4000-94 is 5.8 percent heavier than the JT9D-7R4 but produces up to 10 percent more thrust. Aside from an additional set of long stator blades and elongated exit nozzle, the CF6-80C2 is also of similar weight and dimensions to the PW4000. Due to these similarities, the PW4000 engine model will be used for all impact simulations.

Table C-5. Boeing 767 engine comparison.

\begin{tabular}{|l|l|l|l|}
\hline \multicolumn{1}{|c|}{ Engine } & \multicolumn{1}{|c|}{$\begin{array}{c}\text { Pratt and Whitney } \\
\text { PW4000-94 }\end{array}$} & \multicolumn{1}{|c|}{$\begin{array}{c}\text { Pratt and Whitney } \\
\text { JT9D-7R4, b }\end{array}$} & \multicolumn{1}{|c|}{$\begin{array}{c}\text { General Electric } \\
\text { CF6-80C2 }^{\mathrm{c}, \mathrm{d}}\end{array}$} \\
\hline Fan blade diameter & 94 (in.) & 94 (in.) & 93 (in.) $^{\mathrm{e}}$ \\
\hline Length & 153 (in.) & 153 (in.) & $161-168$ (in.) \\
\hline Dry weight & $9,400(\mathrm{lb})$ & $8,885(\mathrm{lb})$ & $9135-9860$ (lb) \\
\hline
\end{tabular}

a. Reference value of 106 in. also found-may include cowling.

b. The "tail" of the CF6-80C2 is much longer than the PW4000. This potentially accounts for the additional 15 in. in length.

c. The CF6-80C2 has an additional set of long stator blades for the excess fan air that is not present in the PW4000.

d. The second stage compressor blades in the CF6-80C2 are closer to the central shaft than the PW4000 and do not appear to have counter weights.

e. The JT9D-7R4 and PW4000-94 are almost identical: (1) They are in the same family of Pratt \& Whitney aircraft engines, and (2) the PW4000 was labeled the "new technology JT9D" when it began replacing the latter engine on 767s built after 1987.

f. The PW4000-94 is 5.8 percent heavier than the JT9D-7R4, but produces up to 10 percent more thrust. 


\section{Airframe Model Development}

All significant structural components are being included in the airframe model of the Boeing 767-200ER. Figure $\mathrm{C}-46$ shows the status of the initial version of the complete aircraft model. Detailed models of the empennage and landing gears, not shown in this figure, are shown in Figs. C-47 and C-48, respectively. Ribs, spars, rudder, and elevator have all been modeled in detail in the empennage. Tires and hubs, the main strut and truck, and support bracing have all been included in the landing gear model. The underside of the airframe in the model is shown in Fig. C-49 illustrating the position of the retracted main landing gear in the wheel well.

The models of the fuselage, empennage, and wing structures are developed using shell elements. The model is being developed in parameterized form where the mesh resolution is determined by a single element characteristic size parameter. This approach was selected early in the development to allow flexibility in the model size and resolution as the model development and impact analyses progressed. The objective was to develop a mesh with typical element dimensions between one and two in. for small components, such as spar or rib flanges, and element dimensions of 3 in. to 4 in. for large parts such as the wing or fuselage skin. A summary of the current model size is shown in Table C-6.

Figure $\mathrm{C}-50$ shows the entire wing structure modeled to-date, including the center wing which attaches the port and starboard outboard wings. The wing stringers were not explicitly modeled to help reduce the size of the model. The stringers have a z-section geometry with typical dimensions of approximately one in. flanges and a two in. web with a thickness of approximately 1/8 in. These stringers run spanwise over the top and bottom of the wing ribs. In the model, an 'effective' wing skin has been used to account for the weight and strength of the riveted skin/stringer construction.

\section{Wing Section Component Model Development}

Two wing segment models have been developed to perform the component level and subassembly level analyses. The smaller segment, for component analyses, is shown in Fig. C-51. The large wing segment for subassembly analyses is shown in Fig. C-52. The wing section components are modeled with shell elements. The main spars, wing ribs, leading edge ribs, nosebeams, leading edge slats, and outboard flaps have been included in the model. Nonstructural components, such as hydraulic lines, and mechanical components, such as slat actuators, are not included in the model geometry. The density of the spars, ribs and other structural components have been increased to account for this nonstructural mass. 


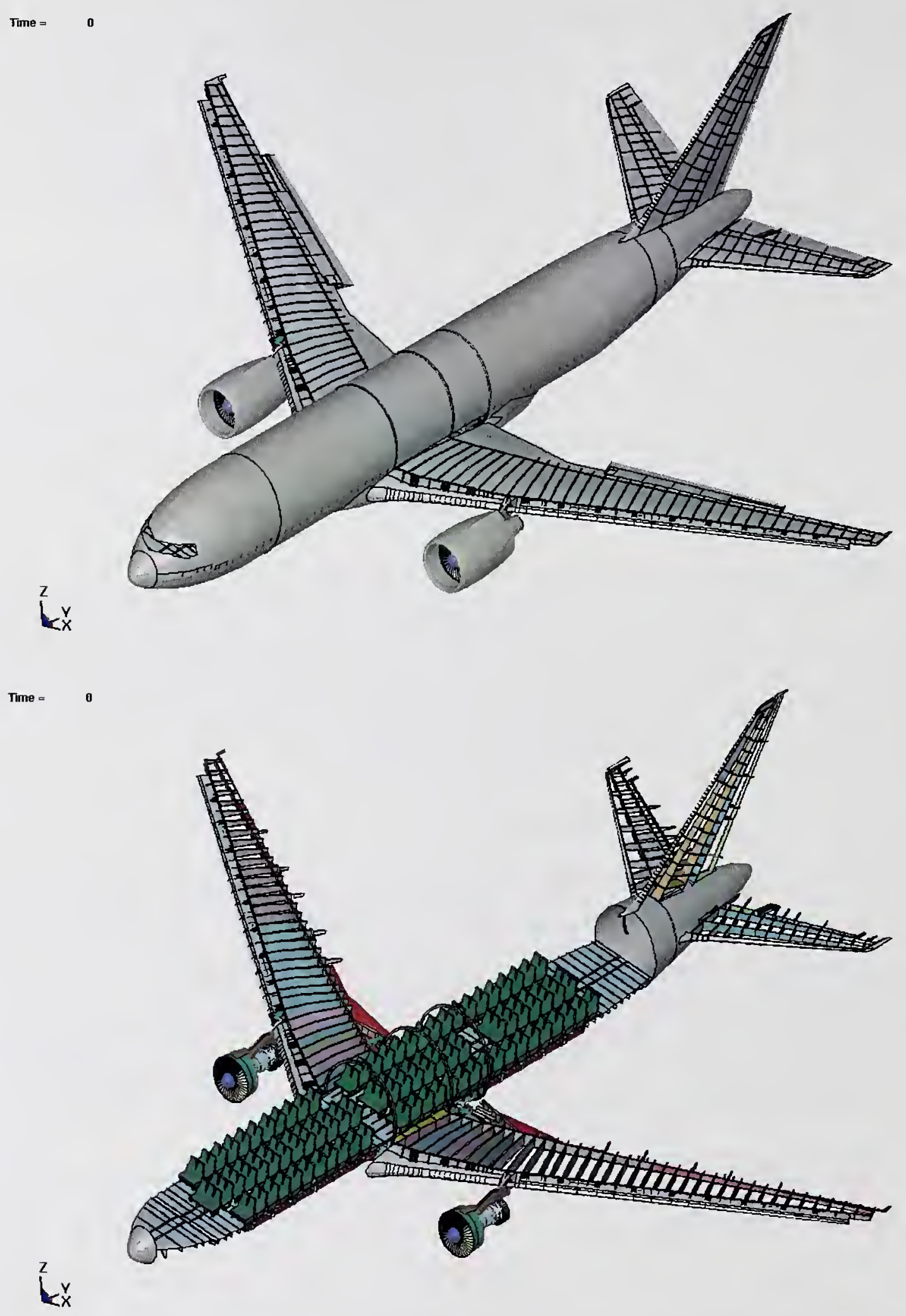

Figure C-46. Finite element model of the Boeing 767-200ER (under construction). 


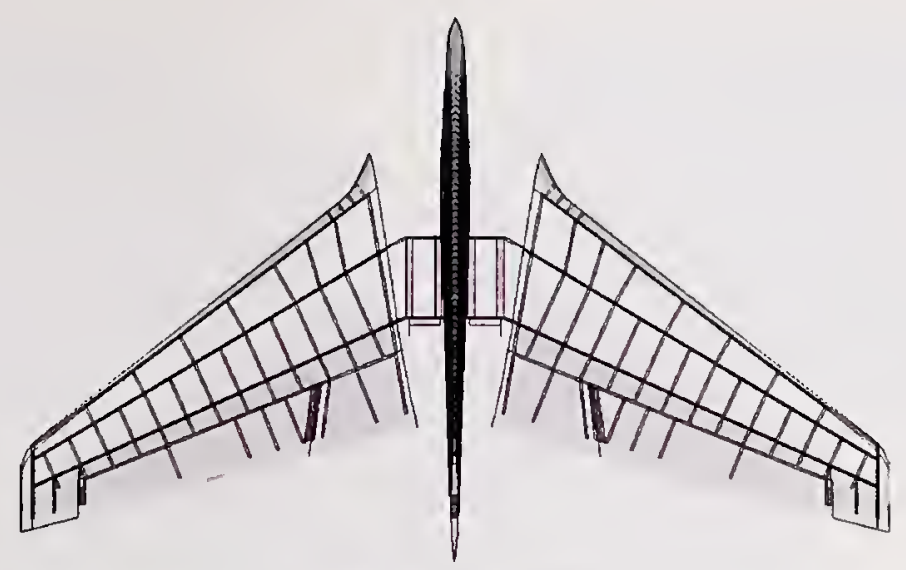

(a) Top View

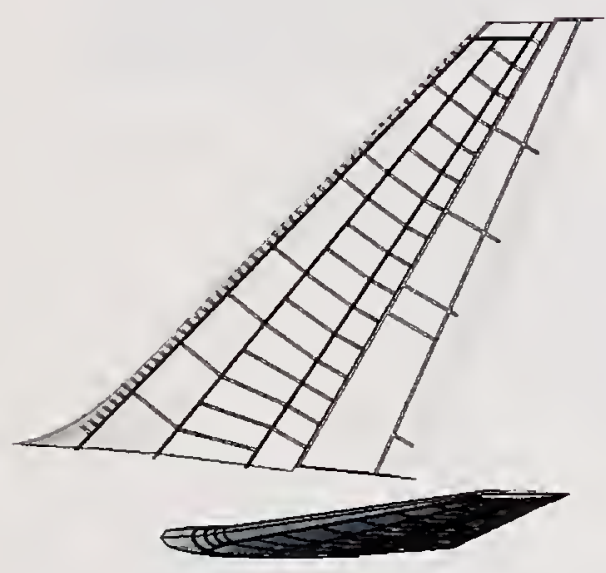

(b) Side View

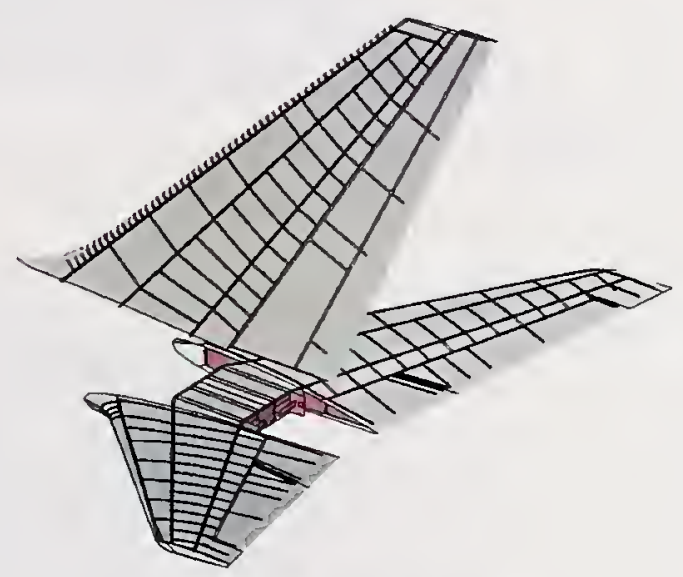

(c) Oblique View

Figure C-47. Complete empennage for the 767 aircraft model.

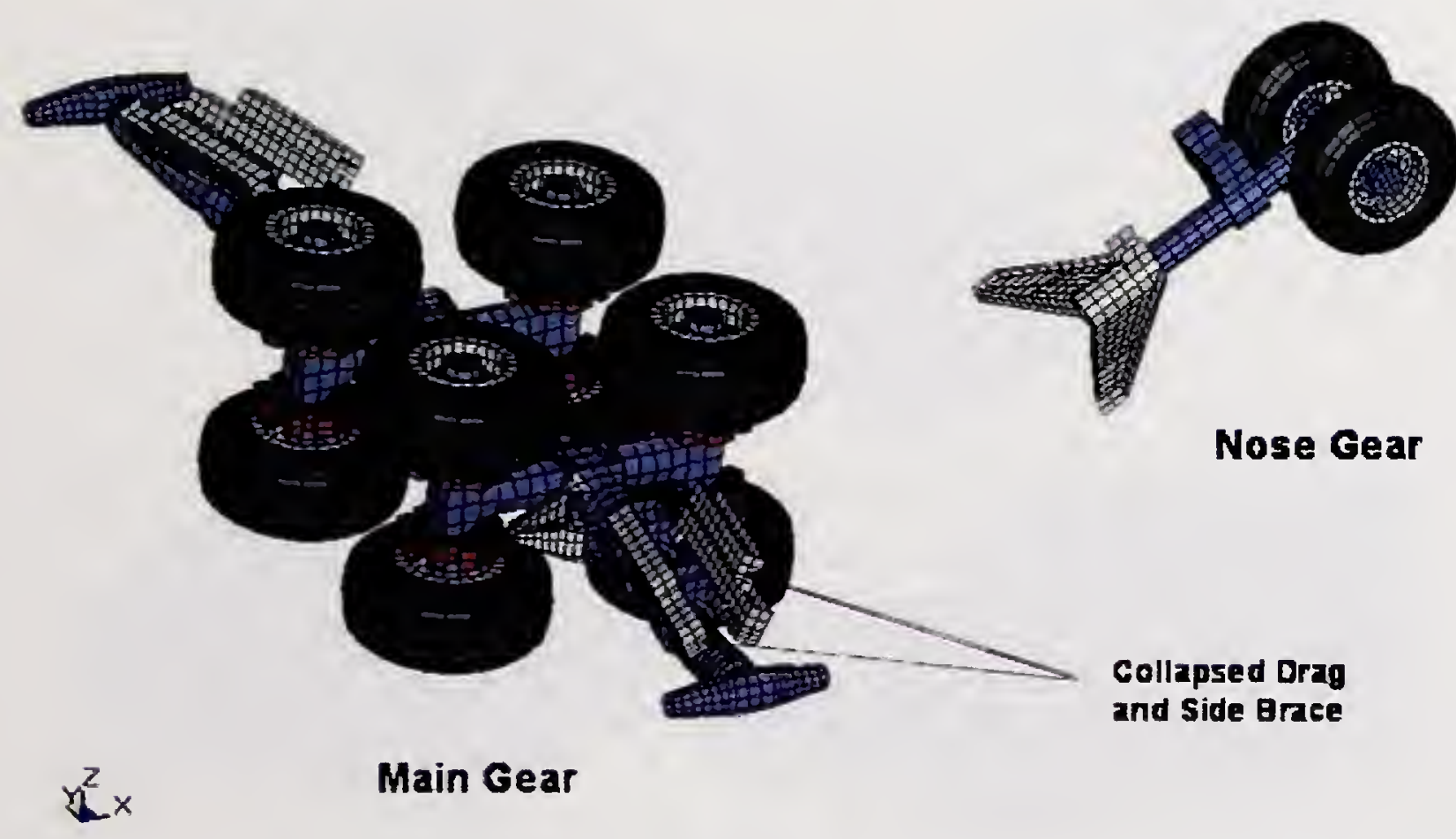

Figure C-48. Retracted landing gear components for the 767 aircraft model. 


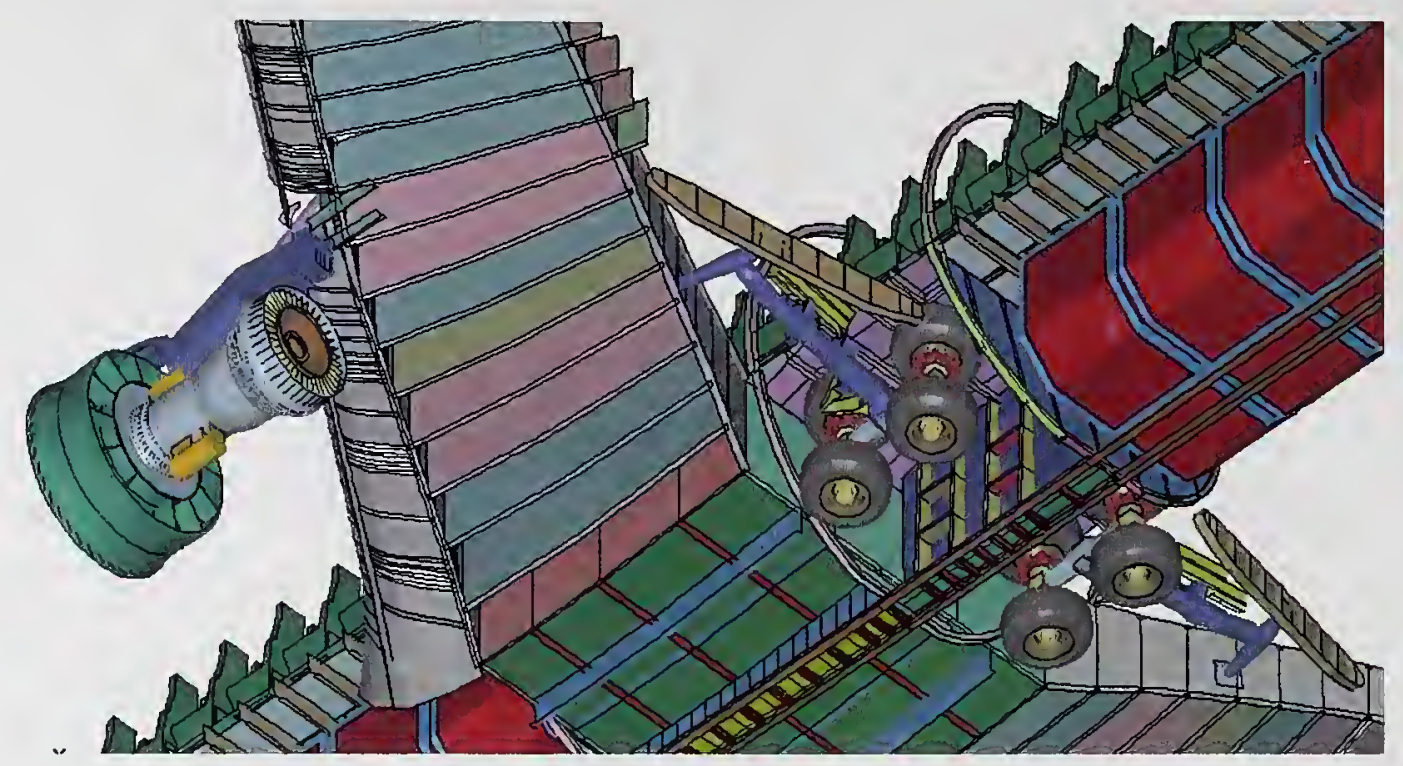

Figure C-49. Underside of the 767 airframe model (skin removed) showing the position of retracted main landing gear.

Table C-6. Summary of Boeing 767-200 aircraft model size (under construction).

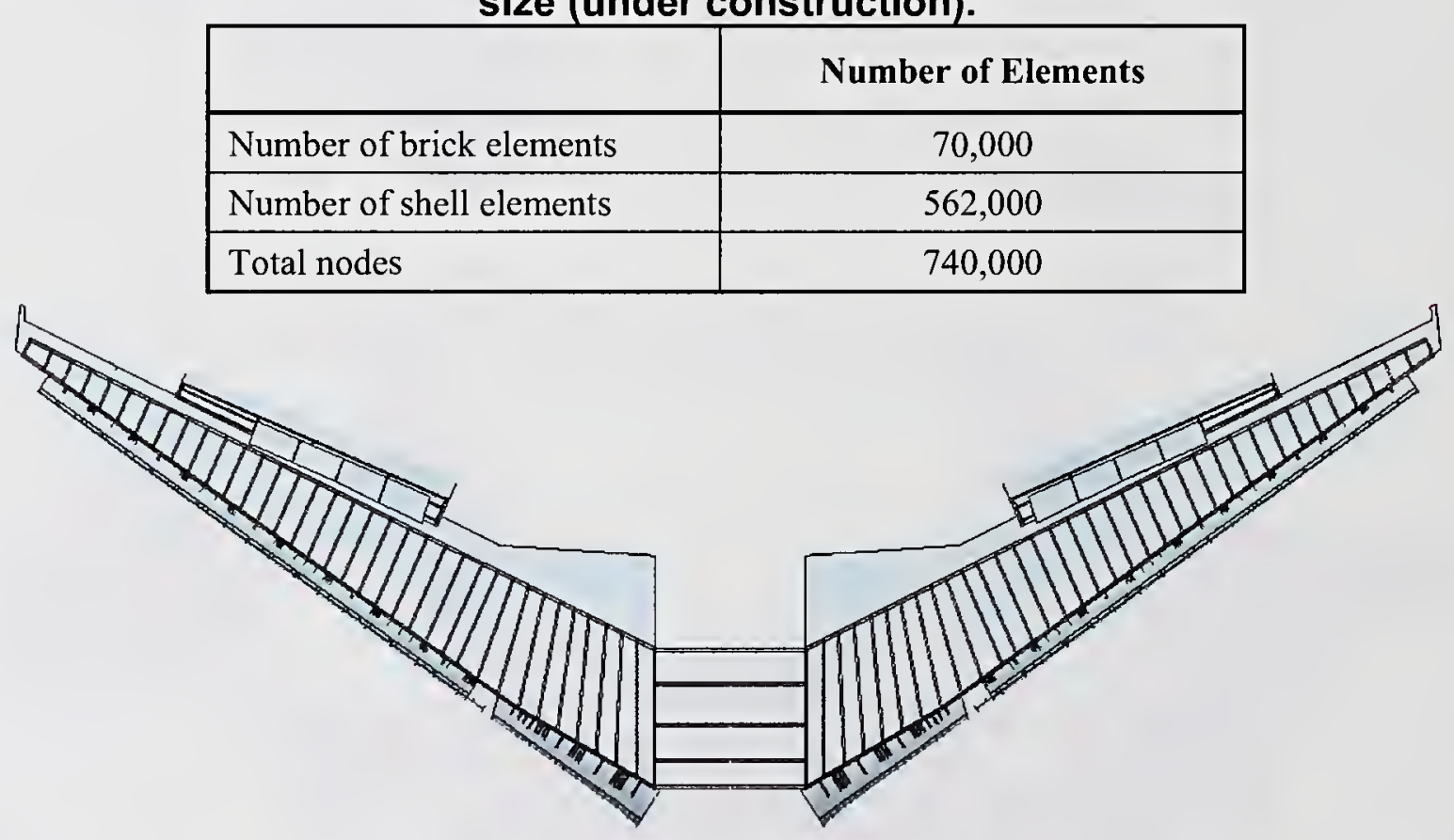

(a) Complete wing model
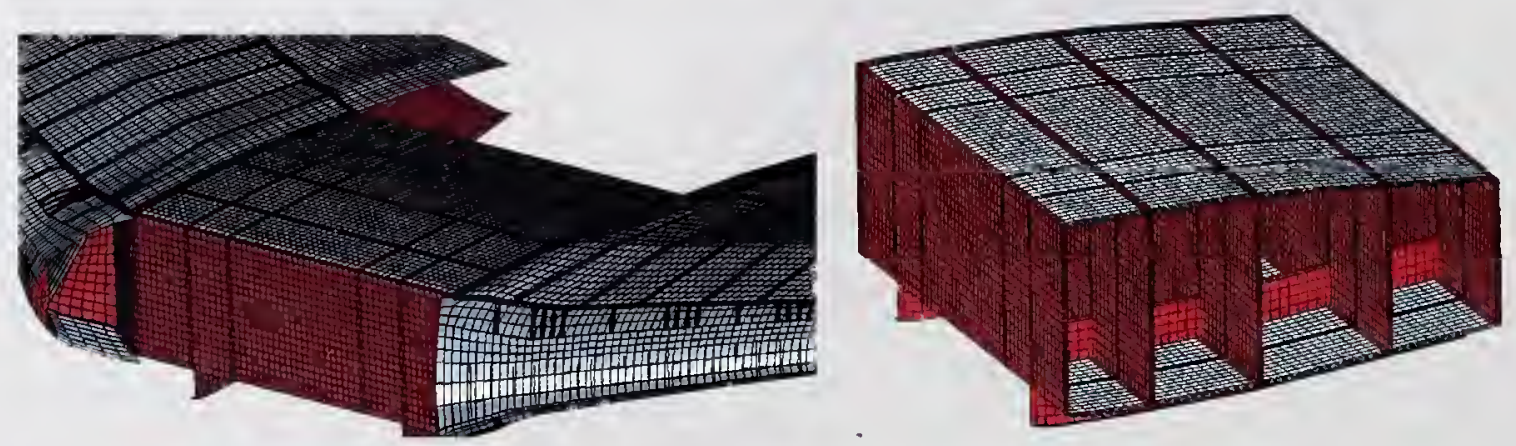

(b) Center wing structures

Figure $\mathbf{C}-50$. Complete wing structures for the 767 aircraft model. 


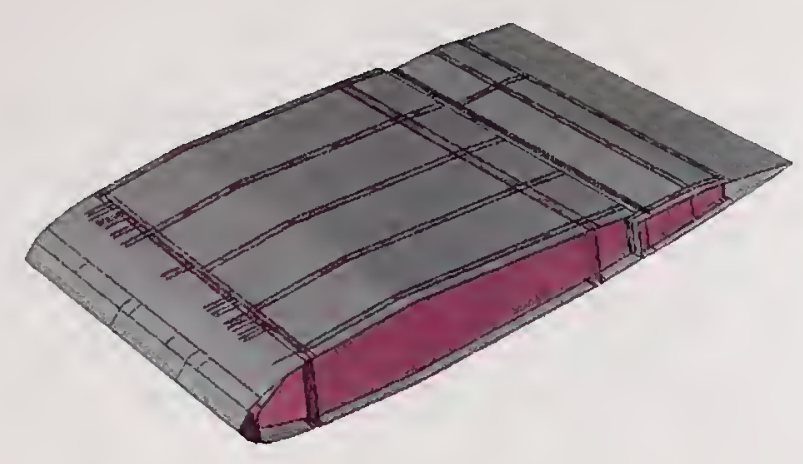

(a) Small Wing Section Model

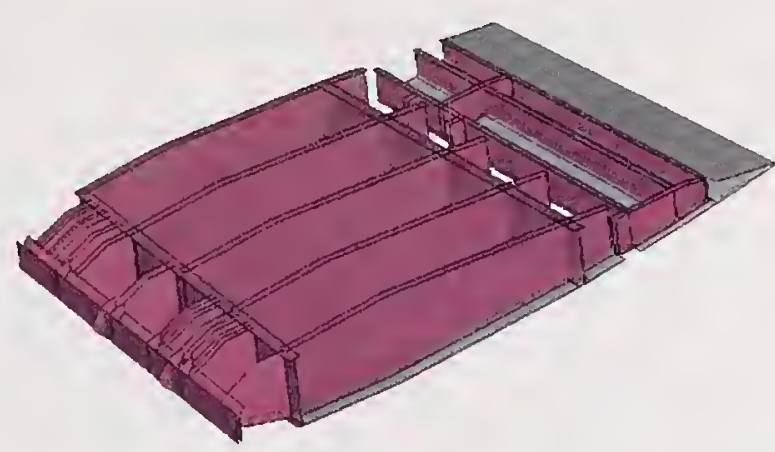

(b) Internal Structure (skin not shown)

Figure C-51. Small wing section model for component-level analyses.

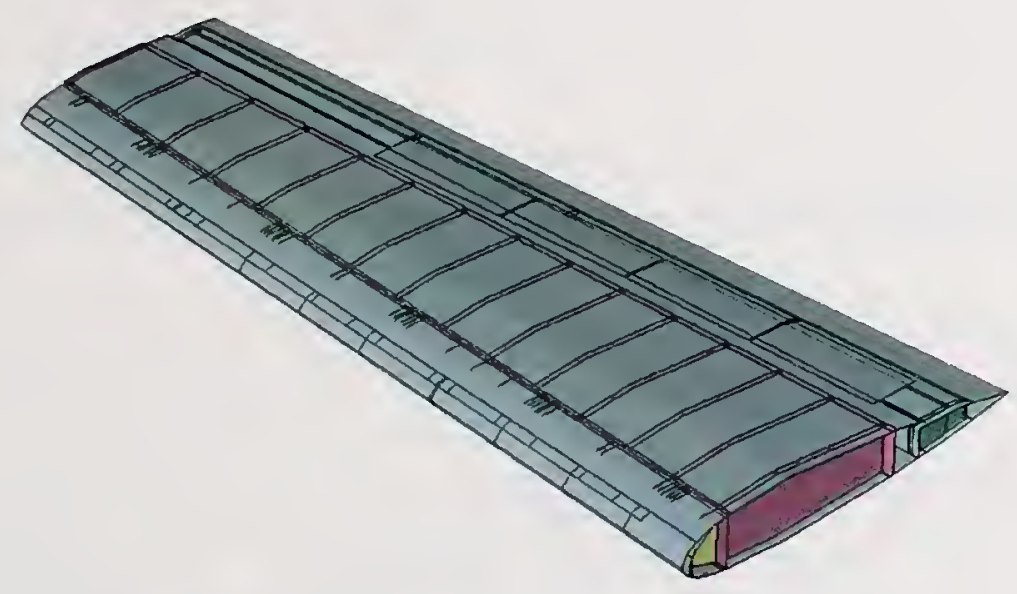

(a) Large wing section model

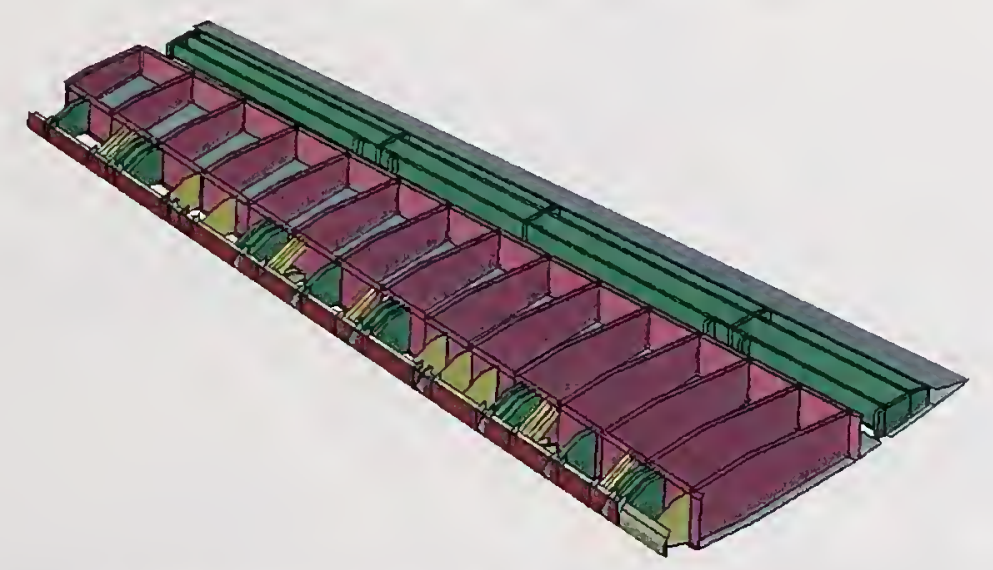

(b) Wing section internal structures (skin not shown).

Figure C-52. Wing section model developed for the subassembly impact simulations. 


\section{C.3.3 Analysis of Fuel Distribution at Impact}

An important factor for determining impact damage and subsequent fire initiation is the distribution of the fuel in the aircraft at the time of impact. Both United Airlines and American Airlines have provided estimates for the quantity and distribution of fuel for UAL Flight 175 and AA Flight 11 at the time of impact. ${ }^{1,2}$ UAL estimates that Flight 175 contained approximately $62,000 \mathrm{lb}$ or 9,118 gal of fuel at impact with the "fuel evenly distributed between both main tanks." American Airlines estimates that Flight 11 contained $66,081 \mathrm{lb}$ or $9,717 \mathrm{gal}$ of fuel at impact and "the fuel was evenly distributed between left and right wing tanks of the aircraft.",

Fuel tank locations and capacities for the Boeing 767 are shown in Fig. $\mathrm{C}-53$. The Boeing 767 uses an integral fuel tank where the wing skin, ribs, and spars serve as the fuel tank. There are three classes of fuel tanks onboard the 767-200ER, a main tank, a surge tank, and auxiliary tanks. The auxiliary tanks consist of port, starboard, and center fuel tanks. All tanks are shown for the port wing in Fig. C-54 along with the associated internal structures. The main tank is from rib 3 to rib 31 , the port and starboard auxiliary tanks are from the inboard closure rib to rib 3 . The center auxiliary tank is between the port and starboard closure ribs and the surge tank is from rib 31 to rib 34. A dry bay is located above the engine at the forward part of the main tank between ribs 6 and 9 . Baffle ribs are located at rib 5 and 18 .

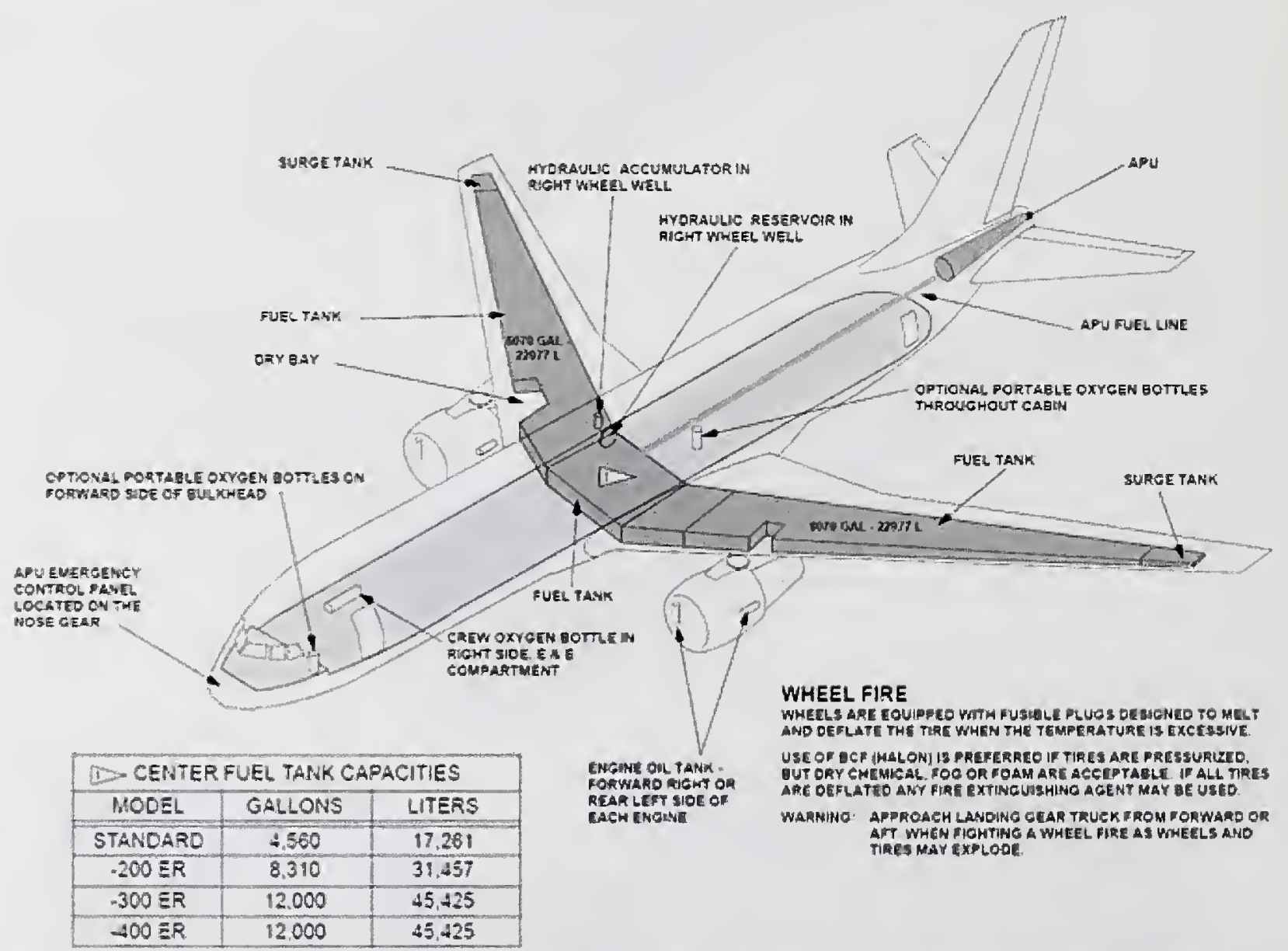

Figure C-53. Flammable material locations in a Boeing 767 aircraft (www.boeing.com).

1 Communication between United Airlines and NIST, September 5, 2003, "NIST WTC Flammable Contents Request."

2 Communication between American Airlines and NIST, August 12, 2003, "In re September 11 Litigation C\&F Ref.: DTB/MH28079." 


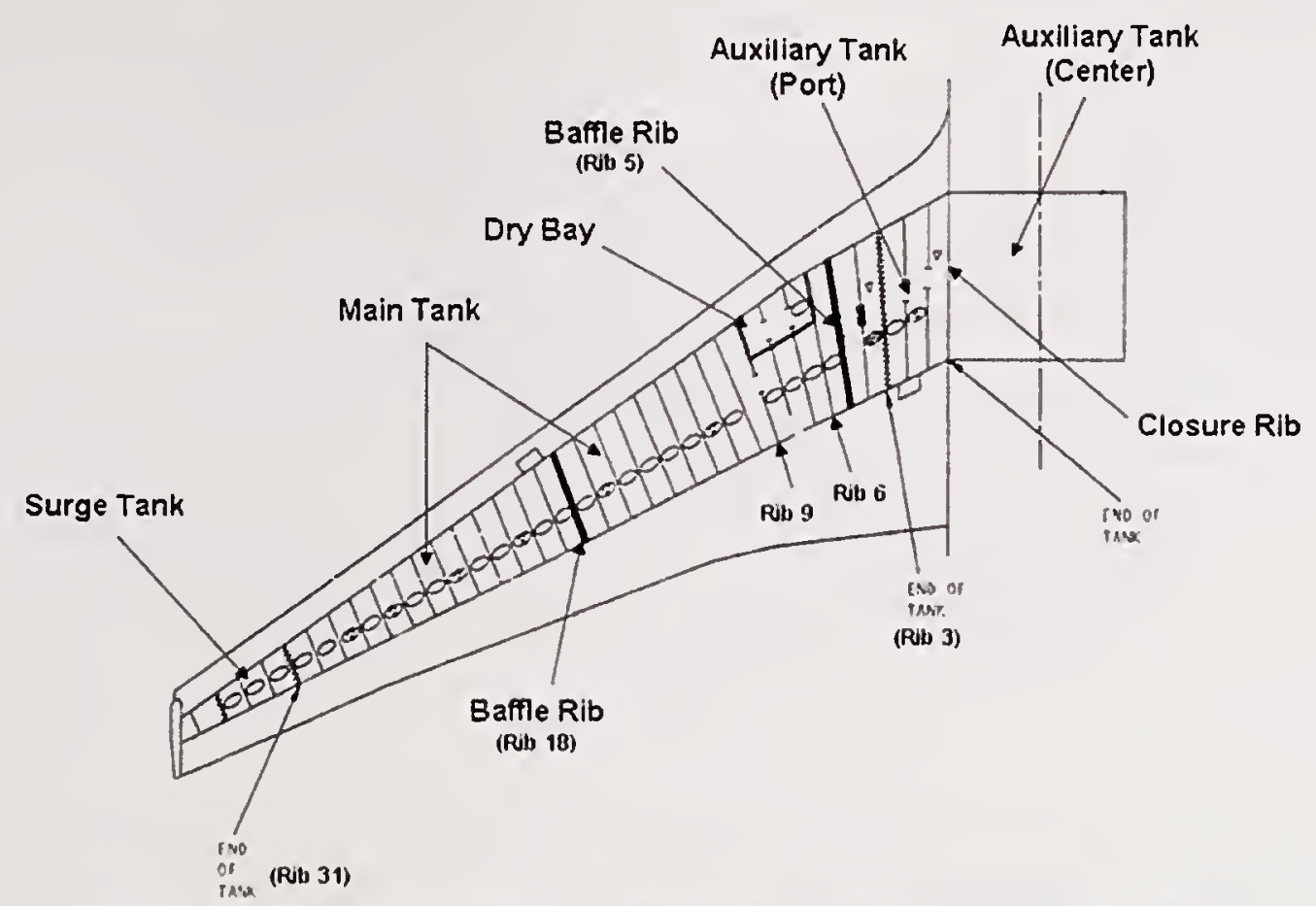

Figure C-54. Layout of fuel tanks in the Boeing 767 wing.

The functionality of the wing fuel tanks is such that a typical wing rib allows some fuel to flow along the wing but acts as a two-way fuel baffle to minimize fuel slosh. However, there are special rib designs that alter the position and flow of fuel within the tank. The ribs in the dry bay region, between ribs 6 and 9 , include a fuel barrier running parallel to the rear wing spar. In addition, baffle ribs (ribs 5 and 18) include a series of fuel dams that act as a one-way valve allowing fuel flow inboard toward the sump areas (low point of tank). According to the statements from both airlines regarding fuel distribution, it is most likely that the surge tanks and all auxiliary tanks were dry at the time of impact.

Overall tank dimensions and geometry were estimated using the dimensions and approximated geometry shown in Fig. C-55. As shown in Fig. C-56, the front spar height is a good approximation for fuel depth in a full wing section. Using these approximate dimensions, the fuel tank capacity as a function of the distance along the wing buttock line (see Fig. C-57) was calculated. The maximum capacity of each main tank was calculated to be approximately 6,500 gal. The actual main tank capacity is 6,070 gal (Fig. C-53) so the calculated fuel capacity distribution was modified to match this maximum value, as shown in Fig. C-57. Notice that the main tank capacity inboard of baffle rib 18 is approximately the same volume as the fuel onboard each aircraft at the time of impact.

The exact location and distribution of fuel at the time of impact is complicated by the flight conditions prior to and at the time of impact. The terrorist pilots likely performed extreme flight maneuvers prior to impact causing most of the fuel to flow inboard. Extreme banking maneuvers with inappropriate trim could cause the fuel to flow inboard quickly. High loads on the wings due to the extreme flight regime at the time of impact would also cause fuel to flow inboard by increasing the dihedral angle of the wing. Since the baffle ribs restrict fuel from flowing outboard, it is reasonable to assume that all fuel that could flow inboard was actually inboard at the time of impact. 

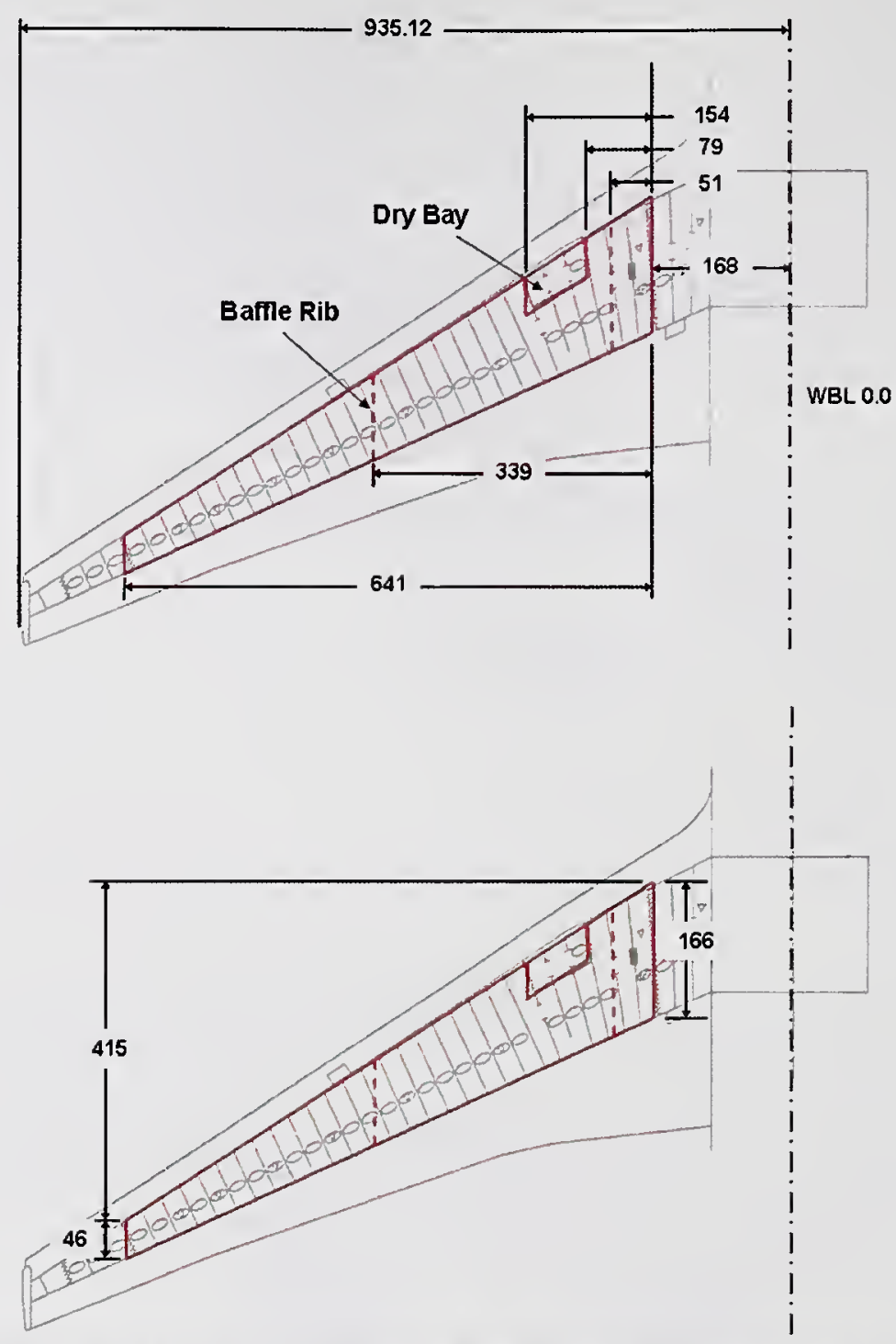

Figure C-55. Approximate fuel tank dimensions (in.).
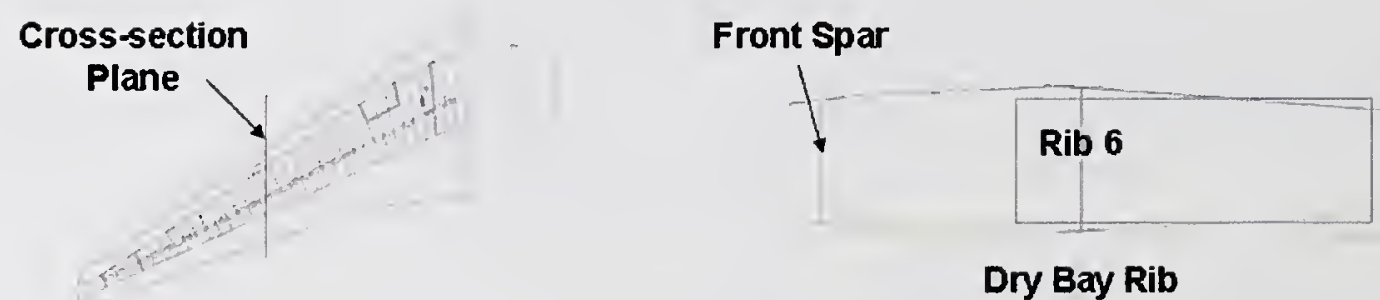

Dry Bay Rib

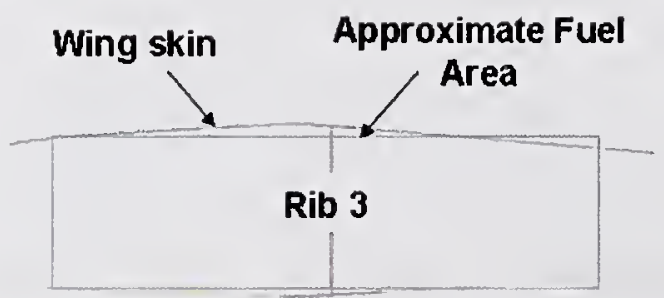

Inboard Tank Wall

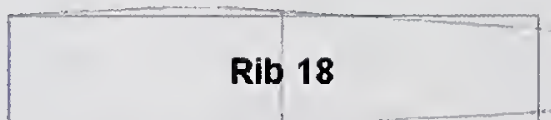

Outboard Baffle Rib

Figure $\mathbf{C}-56$. Wing cross sections at various rib locations. 


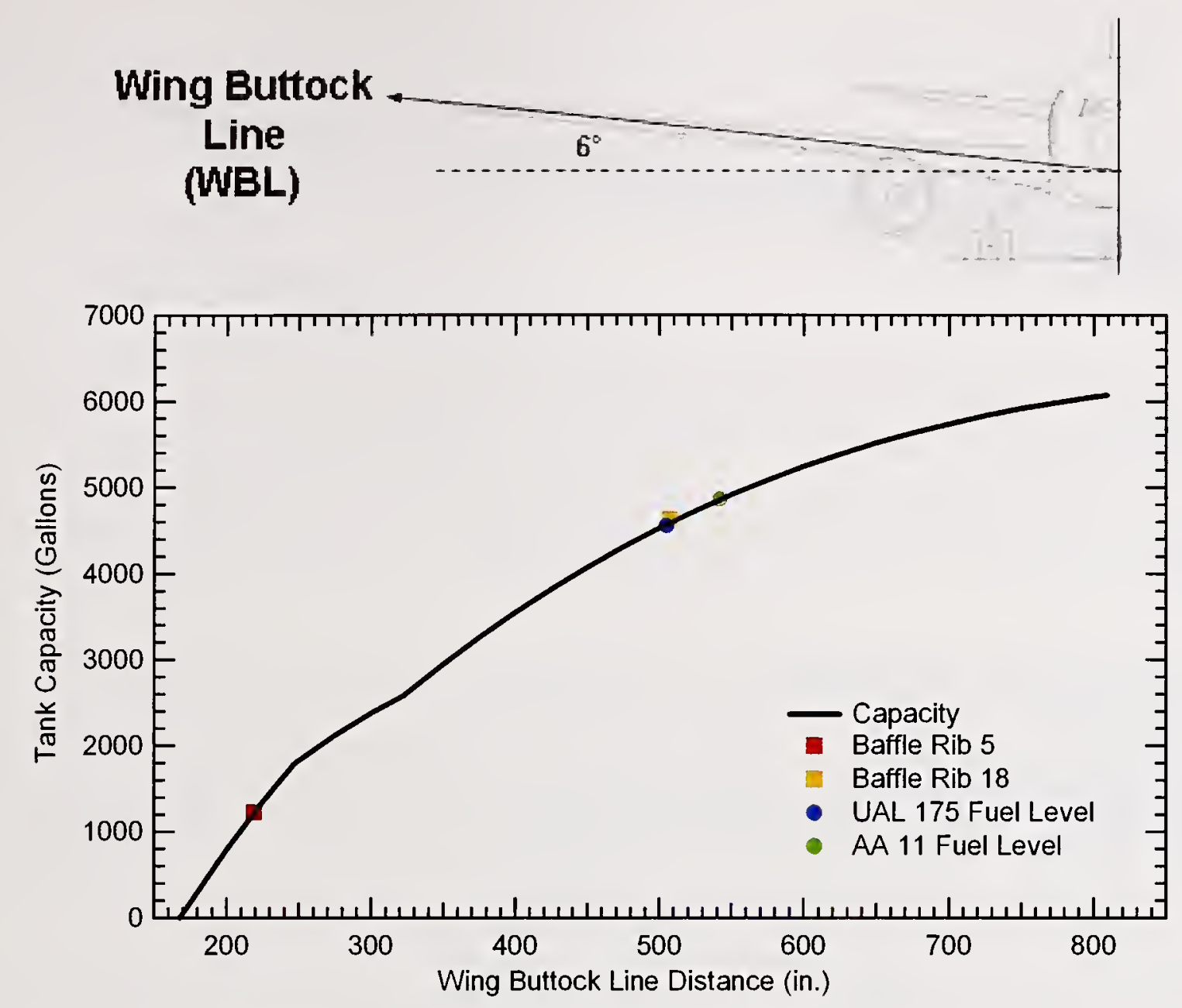

Figure C-57. Fuel tank capacity.

For simplicity, it was assumed that all fuel has moved inboard at the time of impact. Since the fuel tank capacity at the outboard baffle rib and the fuel onboard are approximately the same, a good first estimate is that the main tanks are full inboard of baffle rib 18 at the time of impact. A small amount of fuel is outboard of this rib for AA flight 11. This is shown graphically in Fig. C-58 for smooth and level flight with an undeformed wing shape. A full wing out to baffle rib 18 and dry outboard of this rib is taken as the nominal case in subsequent analyses.

\section{C.4 COMPONENT-LEVEL ANALYSES}

The primary objectives of component modeling are to (1) develop understanding of the interactive failure phenomenon of the aircraft and tower components and (2) develop the simulation techniques required for the global analysis of the aircraft impacts into the WTC towers. The approach taken for component modeling is to start with finely meshed, brick element models of key components of the tower structure and progress to relatively coarsely meshed beam and shell element representations that will be used for the subassembly and global models. This is done to develop reduced finite element models appropriate for high fidelity global impact analyses, as modeling each component with fine details would be too demanding from a computational standpoint and an inefficient use of resources. 


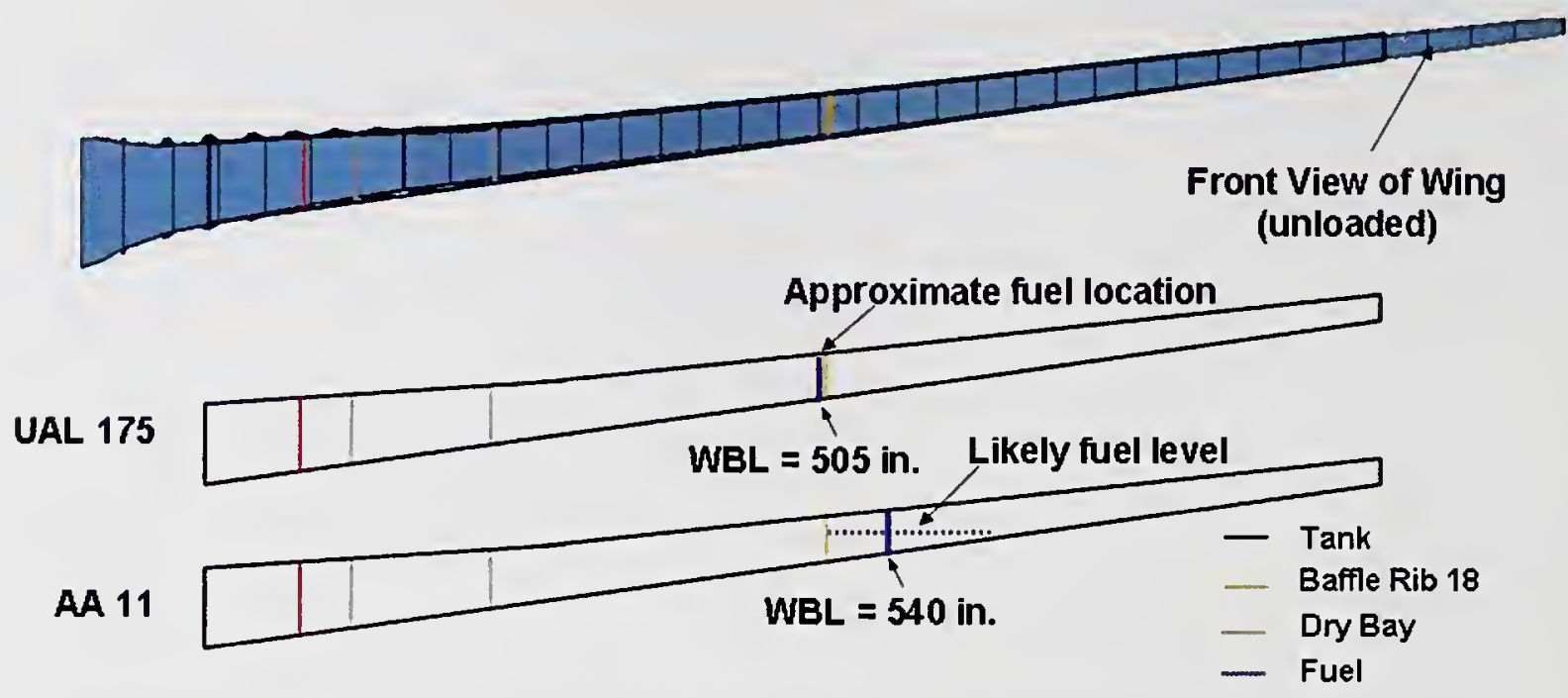

Figure C-58. Approximate fuel locations for smooth and level flight.

In addition to determining the optimal element size and type for global modeling, other key technical areas are addressed in the component modeling phase of the program. These issues include material constitutive modeling, treatment of connections, and modeling of aircraft fuel. The following component modeling scenarios were outlined at the start of the project:

- An exterior column impacted by an aircraft engine

- An interior column impacted by an aircraft engine

- An exterior column impacted by an aircraft wing segment with and without fuel

In addition to the above component impact analysis scenarios, a range of additional component analyses were identified that were considered important and helpful in developing the global impact models and analysis methods. These additional component analysis scenarios included:

- Bolted column end-plate connections with approximated dynamic loading

- Bolted spandrel connections with approximated dynamic loading

- Floor system with concrete slab impacted by an engine

The approach has deviated somewhat compared to the tasks above to maximize efficiency and to produce the most meaningful structural loading scenarios. Once preliminary calculations were performed it was found, for example, that the load generated by an impacting engine would totally overwhelm a single interior or exterior column. Simplified models based on this severe loading would match the detailed brick model but the subtle response from lesser loading might not be as accurate. To capture the more subtle response in the column components, wing sections with and without fuel were studied as impactors instead of engines. It was found that the empty wing section impact produced damage to the exterior columns that is near the failure threshold. Similarly, a fuel-filled wing section impacting both wide flange 
and box type core column resulted in damage near the failure threshold. As a result, these impact scenarios were used primarily for the exterior and core column component impact analyses.

Included in this appendix are the impact analyses for exterior columns, core columns, bolted column connections, bolted spandrel connections, and floor systems.

\section{C.4.1 Analysis Methodology}

The impact analyses were performed using the LS-DYNA finite element code (LS-DYNA 2003). LS-DYNA is a commercially available nonlinear explicit finite element code for the dynamic analysis of structures (LSTC 2003). The initial foundation of LS-DYNA was the public domain DYNA3D finite element code developed at the Lawrence Livermore National Laboratory. Since 1987, the code has been extensively developed and supported by the Livermore Software Technology Corporation (LSTC) and is used for a wide variety of crash, blast, and impact applications.

LS-DYNA has several unique capabilities for this project such as Arbitrary-Lagrangian-Eulerian (ALE) and Smooth Particle Hydrodynamics (SPH) algorithms that can be applied to the analyses of fluidstructure interaction and large-scale fracture and fragmentation of structures. These capabilities are critical for the analyses of the fuel tank breakup and dispersion of fuel inside the towers upon impact. The fuel and debris dispersion is crucial for assessing the impact loads inside the tower structures and the corresponding damage to the mechanical systems.

The impact analyses described in this report use a variety of capabilities and algorithms in LS-DYNA. A brief description of these capabilities is described in this section. A significantly greater detailed description of the analysis methods is provided in the LS-DYNA Theoretical Manual (1998).

The fine mesh detailed component analyses typically use 8-node solid hexahedron (brick) elements with single point integration. This is the most commonly used solid element type in LS-DYNA due to its computational efficiency. The biggest disadvantage of the single point integration is the potential for hourglassing or zero energy modes. There are several methodologies for controlling hourglass modes in LS-DYNA. The typical approach used in these impact analyses is to apply a viscous hourglass control where a viscous damping is introduced that suppresses the formation of hourglass modes but does not significantly influence the global modes.

The component impact analyses using solid elements typically have a fine mesh. As a result, damage and failure are included strictly through the constitutive algorithms. Damage criteria (such as maximum plastic strain) are tracked for each element within the constitutive model evaluation, and elements are eroded when the failure criteria are exceeded. This allows for a direct evaluation of damage and failure within the impact simulations.

The eroded elements allow for the initiation and extension of fracture in the model. Eroded elements no longer support any stress, and the strains in the eroded elements are no longer calculated. The associated mass of the elements remains with the nodes in the calculation. If adjacent elements have not reached the failure surface, the nodes remain attached to the structure. If all of the elements connected to a specific node have failed, the node becomes a free particle. Free nodes can either be eliminated from the calculation or remain in the calculation with associated inertial properties and potential for impacts against other structural components (free nodes remain in contact algorithms). 
As the mesh refinement and model size are reduced, the components are typically modeled using Belytschko-Lin-Tsay shell elements. This is a four node shell element with single point integration. The Belytschko-Lin-Tsay element is a computationally efficient alternative to the Hughes-Liu element in LS-DYNA and again is the most widely used shell element formulation within LS-DYNA for crash, impact, and metal forming applications. Results generated with the Belytschko-Lin-Tsay element typically agree with those using the Hughes-Liu element. As used in the solid elements, the most common approach to introducing damage and failure for the shell elements is through the constitutive models and element erosion.

In specific applications, unique algorithms are required to introduce failure modes in the analysis. An example is the interface between the skin and internal frame structures of the aircraft. Rivets are used for the primary connection between the airframe and skin. The approach used to model this connection and failure during the impact event is the tied interface with failure. In this approach, interface segments (shell elements) are constrained to move together until a failure criterion is exceeded. The failure criterion is a quadratic combination of the normal and shear failure stresses at the interface. After failure, the segments are allowed to move independently but not allowed to penetrate each other (typical contact algorithm behavior).

Overall contact in the impact analyses is modeled using the automatic single surface contact algorithm in LS-DYNA. Interacting components are defined by a material list, and contact segments are automatically generated by LS-DYNA. This greatly simplifies the specification of contact between various components in the aircraft and tower structures. The type 1 soft constraint option is used in the contact algorithm that determines the contact stiffness based on stability considerations, time step size, and nodal mass. This soft constraint option was found to be more robust than the default penalty formulation for modeling the complex contact behaviors in large impact and crash simulations.

\section{C.4.2 Exterior Column Impact Analyses}

Various exterior column component impact analyses were performed with different objectives. The preliminary exterior column component impact analyses were performed on a single column using a highly refined mesh of brick elements. These analyses were used to investigate the details of the column response and develop analysis techniques that can be applied to the subassembly and global impact analyses. These preliminary exterior column impact analyses used a simplified wing section impactor that was developed prior to gathering detailed structural information of the Boeing 767 wing design.

Subsequent exterior column impact analyses were performed using less refined models of the exterior columns in full panel configurations impacted by detailed wing section component models with and without fuel. The primary objective of these component analyses was to study the impact response of the aircraft wing structures and investigate various modeling techniques for including aircraft fuel in the analyses.

Figure $\mathrm{C}-59$ shows the calculated response of a single exterior column component, impacted by an empty wing section. The figure compares the column damage calculated with two different models of very different resolutions. The column model on the left is a fine mesh made of brick elements and the column on the right is a coarser mesh of shell elements. The failure strains of the coarse model were estimated by calibrating the response of the coarse model against the refined model (see Section C.2.2). Contours of 
resultant displacements are shown on the column components. It can be seen that the overall response, both in column and wing segment damage, is very similar. These analyses were used to develop the coarse column models used in subsequent analyses.

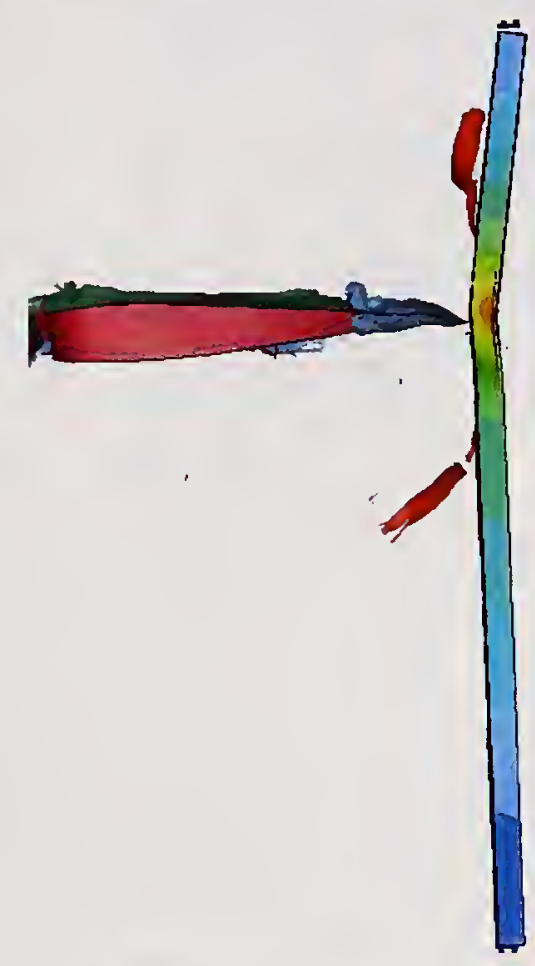

(a) Fine brick element column

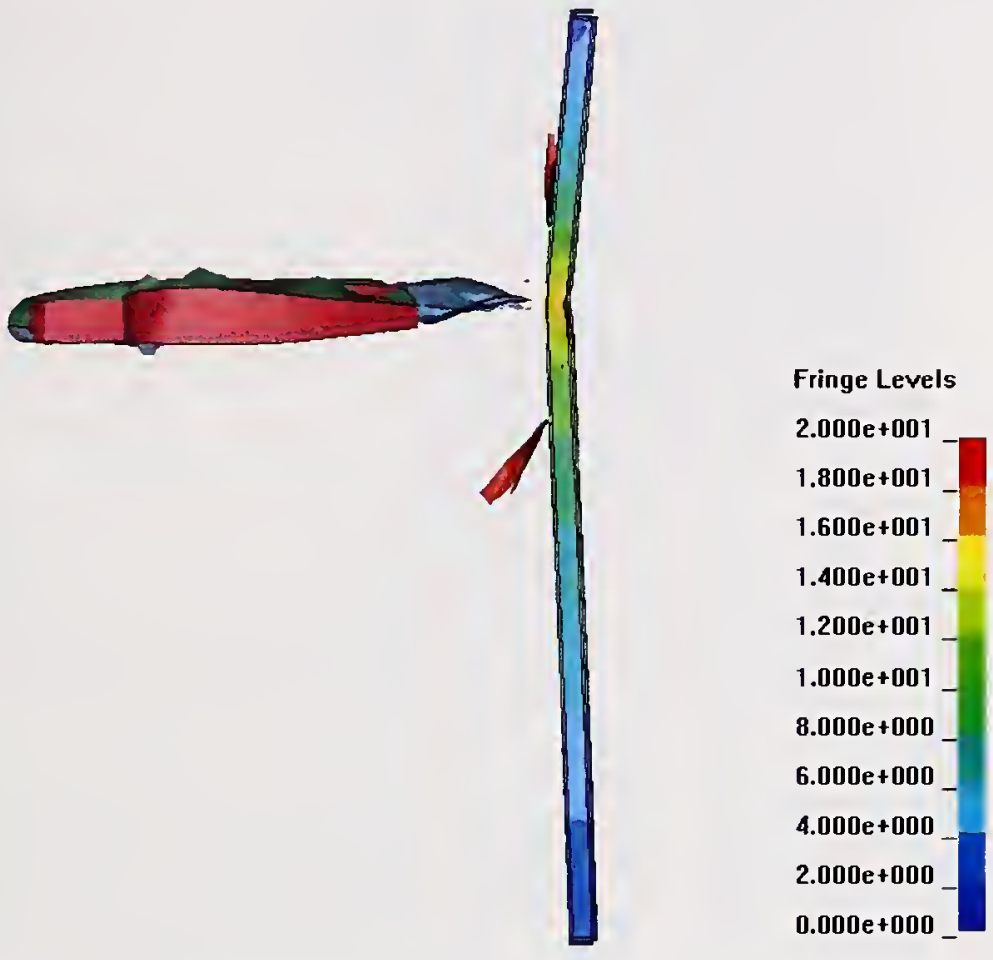

(b) Coarse shell element column

Figure $\mathbf{C}-59$. Exterior column response comparison, showing contours of the displacement magnitude (in.).

\section{Empty Wing Section Impact Analysis}

Figure C -60 shows the impact of the small empty wing section into two exterior wall panels at a speed of $500 \mathrm{mph}(223 \mathrm{~m} / \mathrm{s})$. These analyses use a wing section model with significantly improved structural fidelity over the preliminary wing segment model used in the column component impact analyses described above. The development of the wing section component model used here was described previously in Section C.3.2. The wing section model shown in Fig. C-60 consists of approximately 24,000 shell elements.

The model for the two exterior panels is made primarily of shell elements with a medium mesh resolution. The exceptions are the butt plates, which were made of solid brick elements and the bolted butt plate connections using beam element bolts, as described later. The boundary conditions at the ends of the exterior columns are a bolted connection to an adjacent butt plate with constrained displacements at the edges. In addition, the displacements in the direction of the impact were constrained on the spandrel plates at the location of the floor slab. The resulting model for the exterior panel had 54,096 shell elements (columns and spandrels), 2,112 solid brick elements ( 24 butt plates), and 48 beam elements for the bolts. 


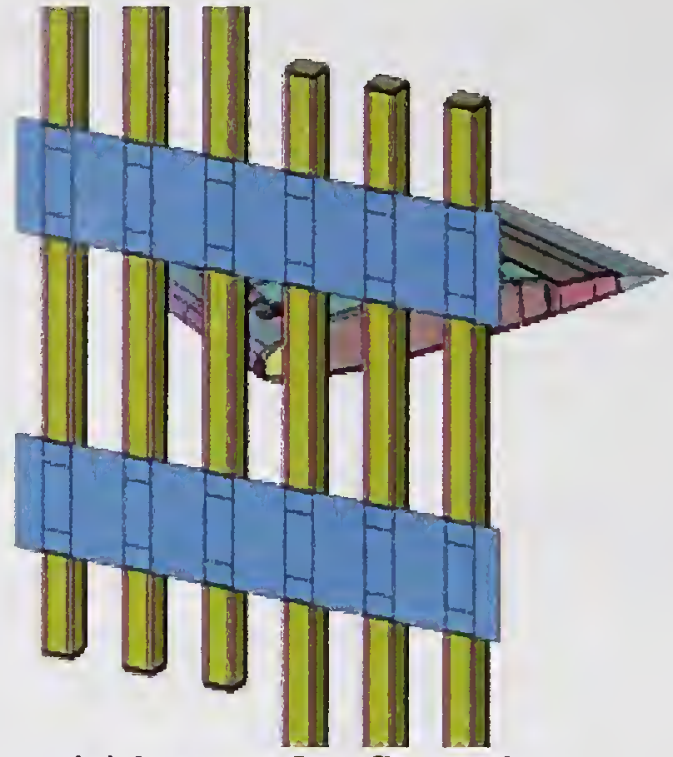

(a) Impact Configuration

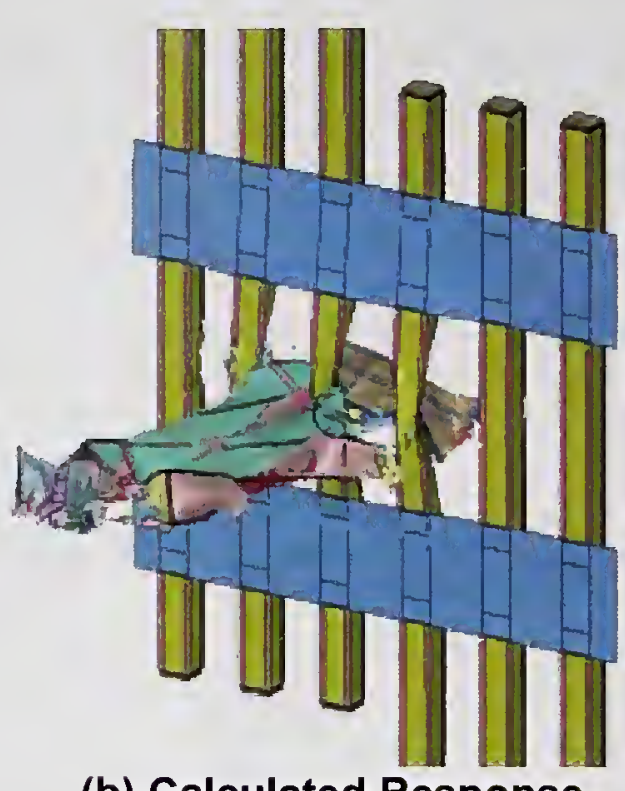

(b) Calculated Response

Figure C-60. Calculated impact damage with the empty short wing section component model.

The calculated impact response produces large scale damage and fragmentation of the empty wing section and significant damage to the exterior columns. The calculated impact damage to the exterior column panel is shown in Fig. C-61. The damage includes significant distortion of the columns, large plastic strains, and fracture of the plate connections within the columns. However, the columns are not completely severed and still maintain some load carrying capacity.

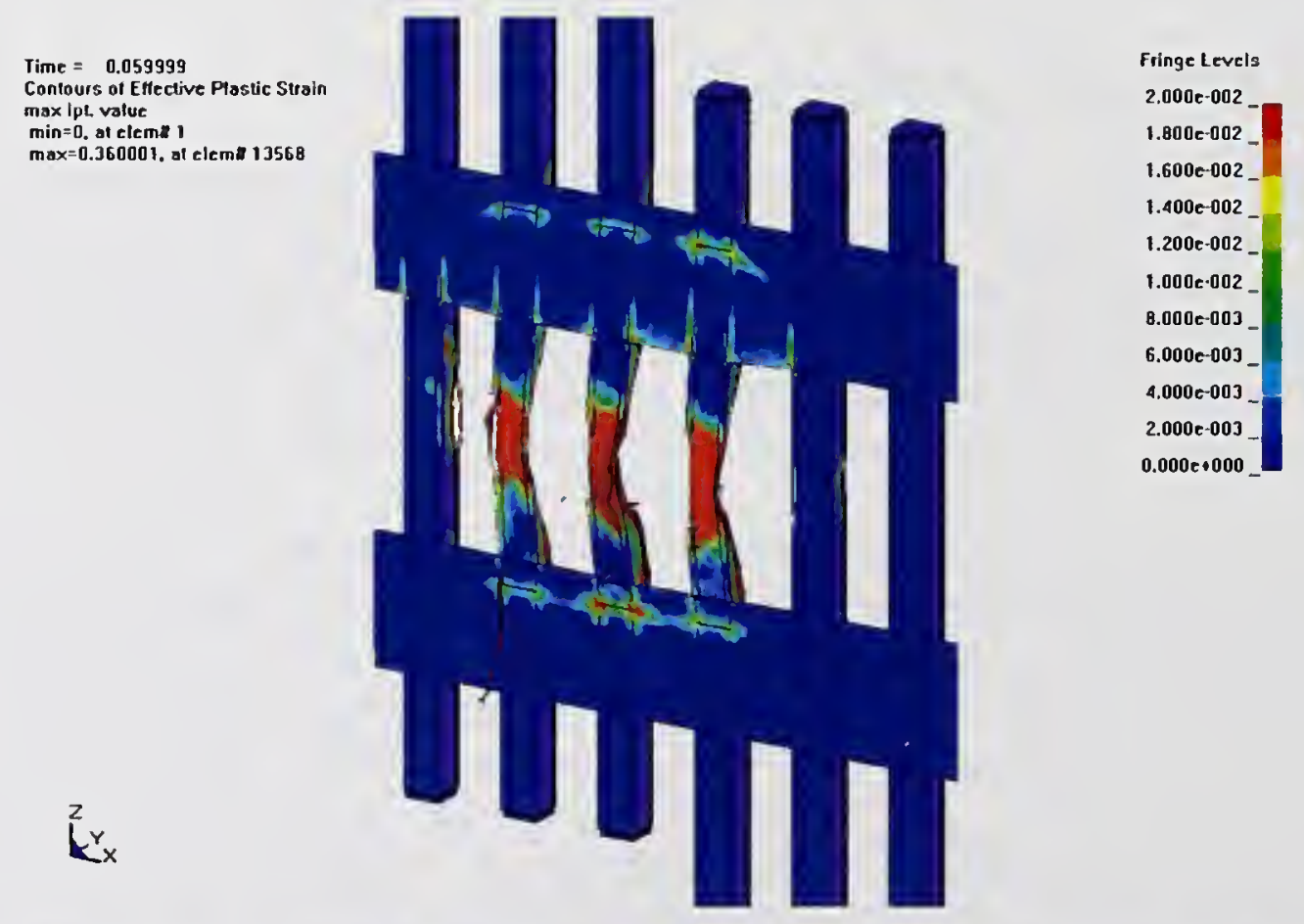

Figure C-61. Damage produced by the empty wing section impact. 


\section{Wing Section with Fuel Impact Analysis}

A significant portion of the weight of a Boeing 767 wing is from the fuel in its integral fuel tanks. At the time of impact, it is estimated that each aircraft had approximately 10,000 gal of fuel on board. Upon impact, this fuel is responsible for large distributed loads on the exterior columns of the WTC towers and subsequently on interior structures, as it flows into the building. It therefore could have a significant effect on the damage done to the building structure. Accurate modeling of the fluid-structure interaction is needed to accurately predict the extent of this damage and the fuel dispersion within the building to help establish the initial conditions for the fire dynamics modeling.

A number of approaches to solving Fluid-Structure Interaction (FSI) problems are available in LS-DYNA. One approach is the standard Lagrangian finite element analysis with erosion, where the fuel is modeled using a solid mechanics approach. This approach accounts for the inertial effects of the fuel, but does not simulate the fuel flow during impact. The ALE method has been developed as one good approach to solve fluid and solid material interaction. With this methodology, fluids are modeled with a fixed Eulerian mesh, which allows for materials to flow between mesh elements. Solid materials are modeled with a moving Lagrangian mesh. With ALE, both mesh types can interact. An alternative approach is to use mesh-free methods such as SPH. SPH modeling for fuel effects has the advantage of a smaller mesh size and potentially much faster run times than ALE analyses. Both methods will be applied to the analysis of fuel impact and dispersion.

The small wing segment was used for performing component level analyses of the wing with fuel. The small wing segment is from rib 14 to rib 18 , the outboard baffle rib. For this location, the segment was considered to be completely full of fuel. Figure $\mathrm{C}-62$ shows the fuel-filled wing section model with an SPH mesh for the fuel, shown in blue. The wing section model is identical to that used in Fig. C-60, but with the addition of 4,400 SPH fuel particles.

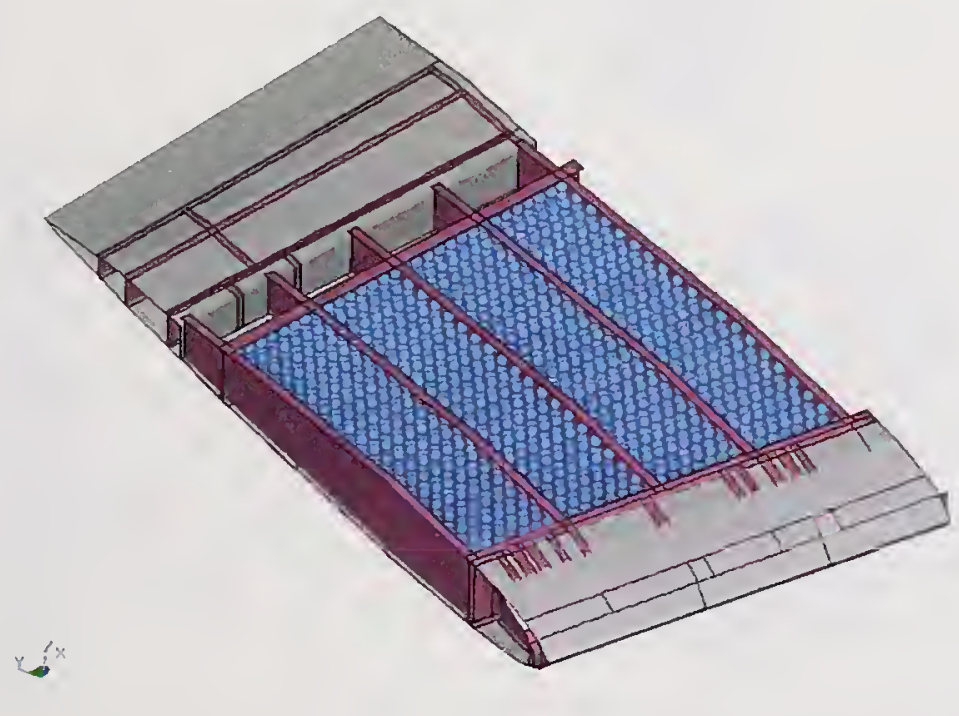

Figure C-62. SPH fuel in the small wing segment. 
For the wing section with fuel component analyses, the impacted structures are the same two exterior panels as used in the empty wing section analysis above. As shown in Fig. C-63, the columns of the exterior panels are completely destroyed due to impact. Both the SPH and ALE methods simulate this extensive damage. This was not the case for the empty wing section model, as discussed in the previous section.

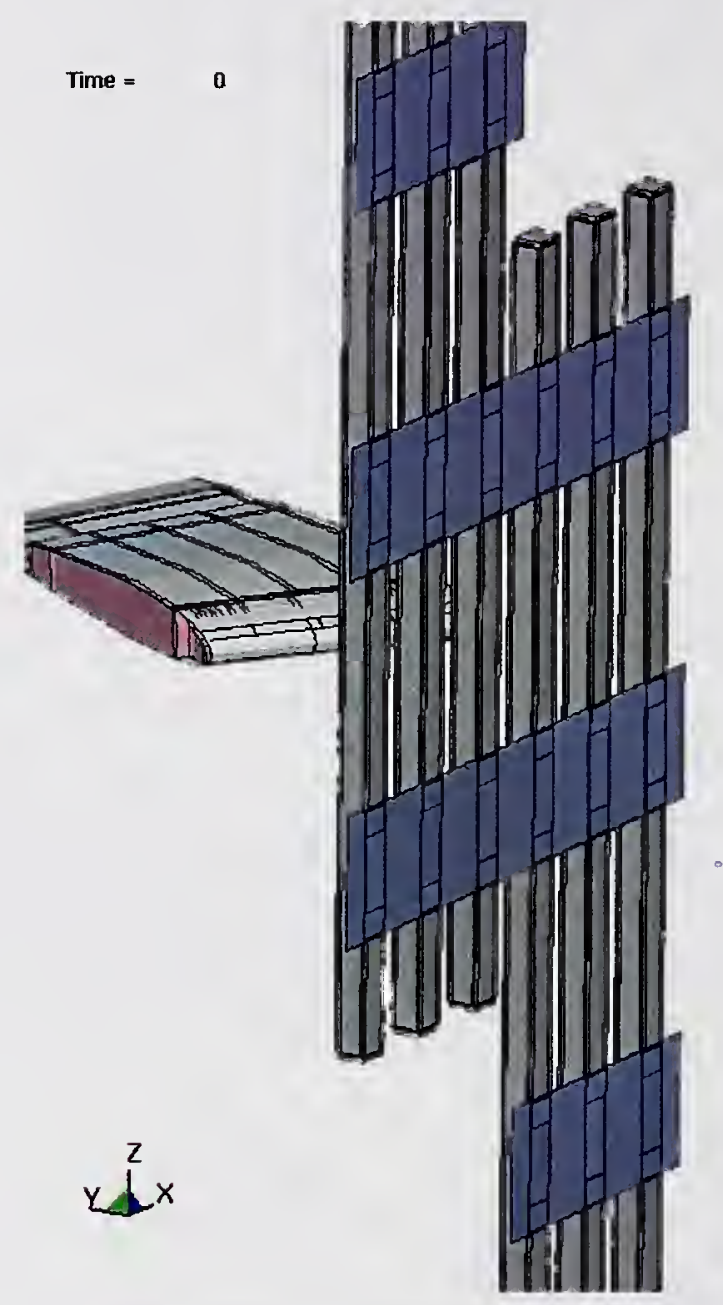

(a) Prior to impact

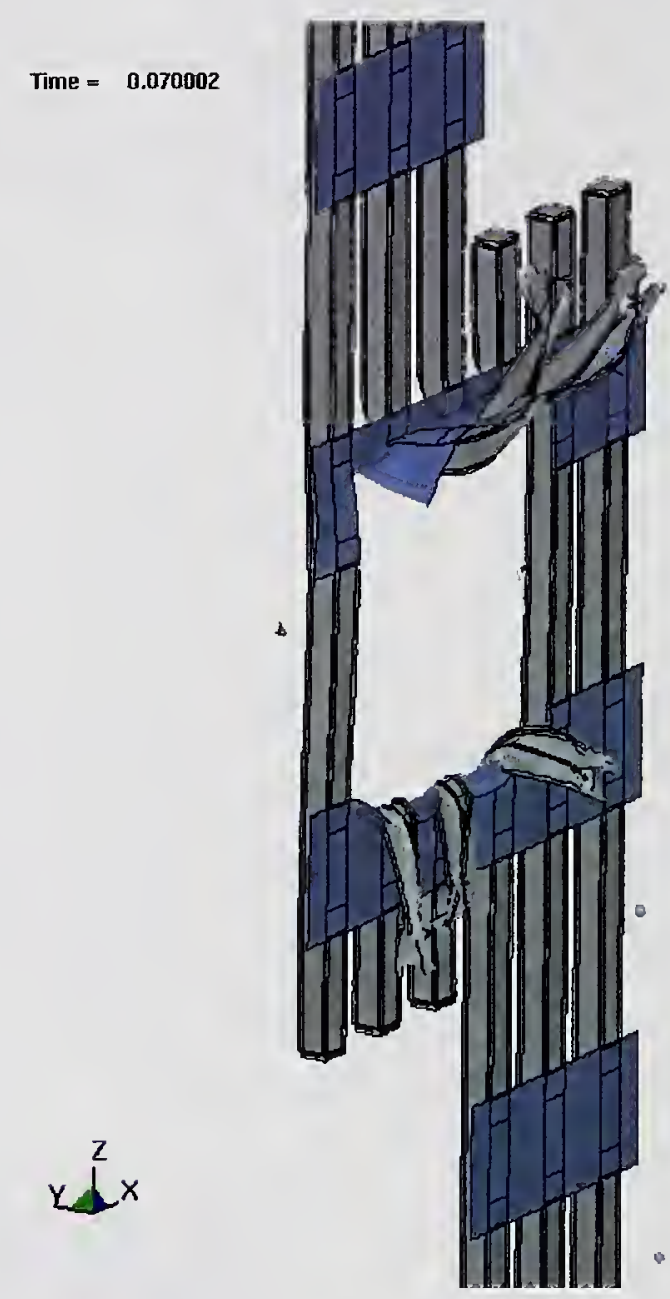

(b) After impact

\section{Figure C-63. Exterior panels impact behavior for a wing segment with fuel (SPH fuel model).}

Figures C-64 through C-67 show the fuel dispersion and wing break up predicted by the two fuel modeling methods (ALE and SPH). As most clearly shown in the side view, the current SPH modeling method predicts greater fuel dispersion and wing break up than from using ALE. Current efforts are underway to study the effect of mesh density on these results. Both analysis methods calculate an impact load sufficiently large to easily rupture the exterior columns.

Run-times from these component analyses clearly indicate that the SPH method will be more practical for the global impact analyses. The current SPH model runs significantly faster than the ALE method as it requires a smaller mesh and does not need to rezone after each time step, as is done in the ALE method. In addition, the ALE method requires a mesh for both the fuel region and the void zone into which the fuel can flow. In the example shown, this required the addition of approximately 110,000 solid elements for the ALE analysis. These preliminary calculations indicate that the ALE analysis run-times are as much as 10 times longer than those for the SPH analyses. However, additional work is underway to 
determine the mesh refinement in each approach required to calculate the fuel impact load effects and dispersion with sufficient fidelity.

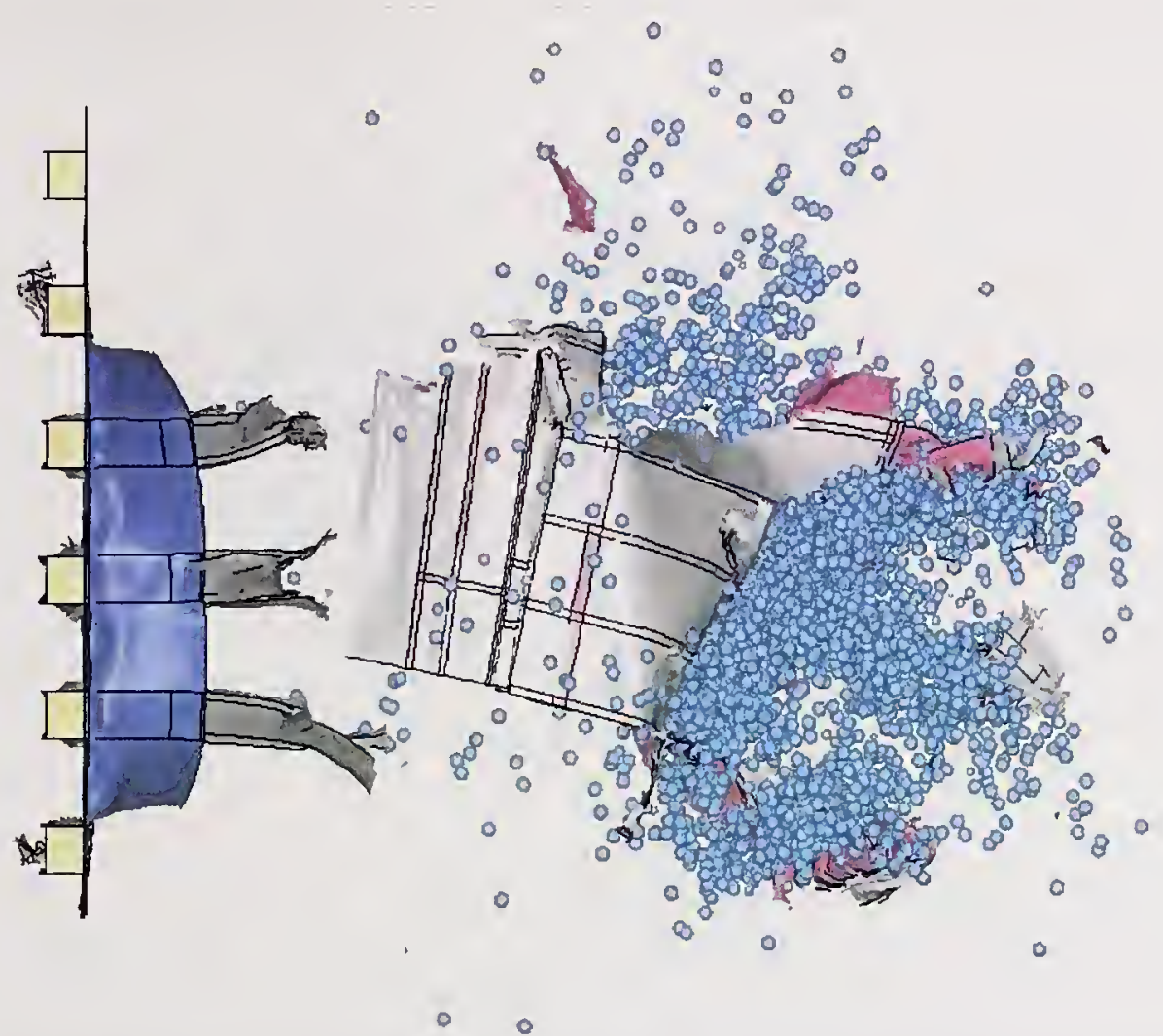

Figure C-64. SPH Analysis of structural damage and fuel dispersion (top view).

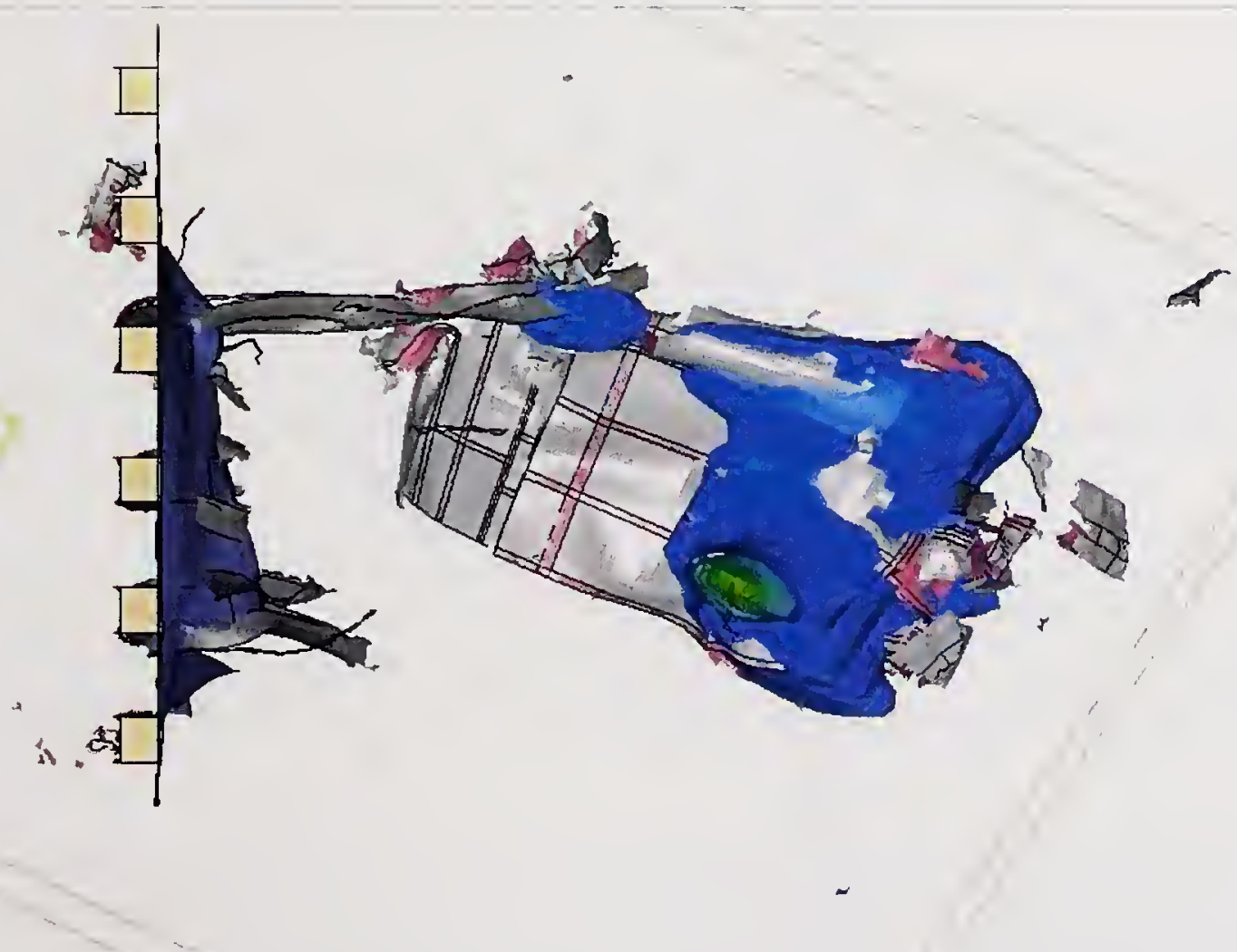

Figure C-65. ALE analysis of structural damage and fuel dispersion (top view). 


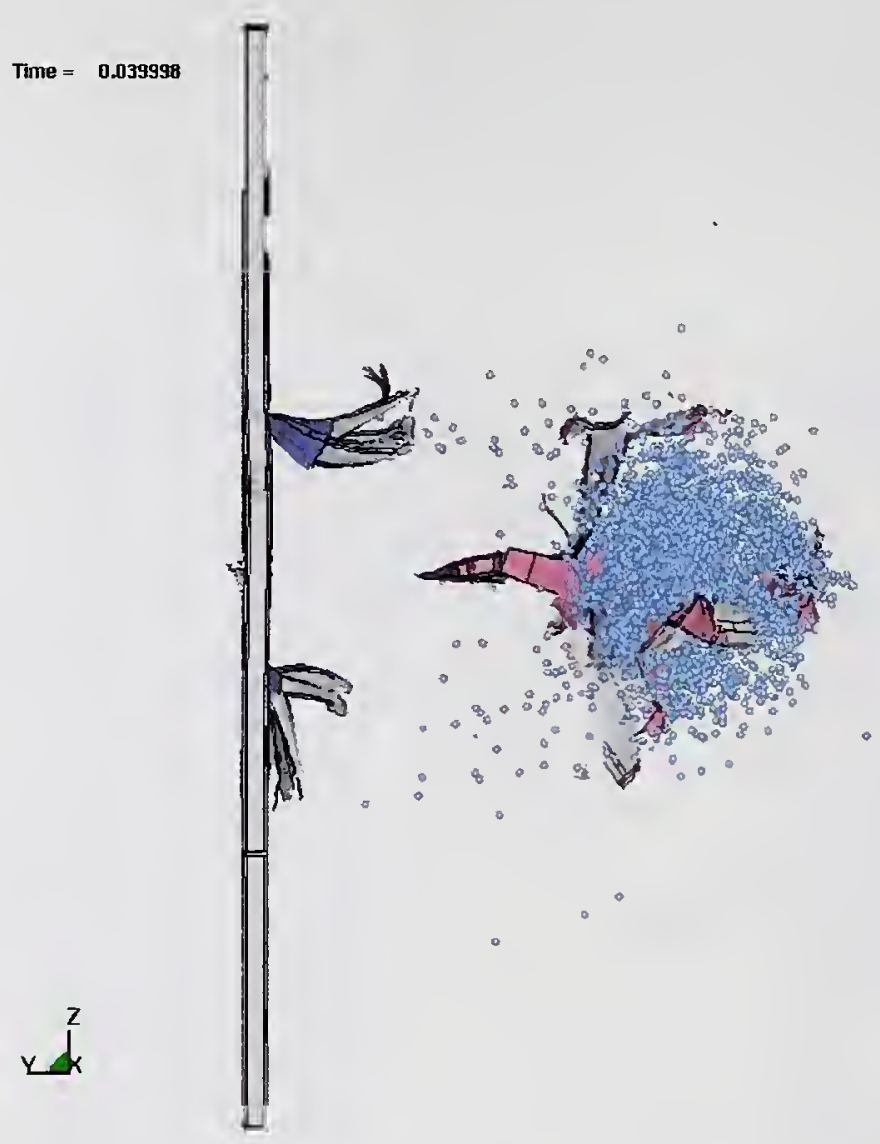

Figure C-66. SPH analysis of structural damage and fuel dispersion (side view).

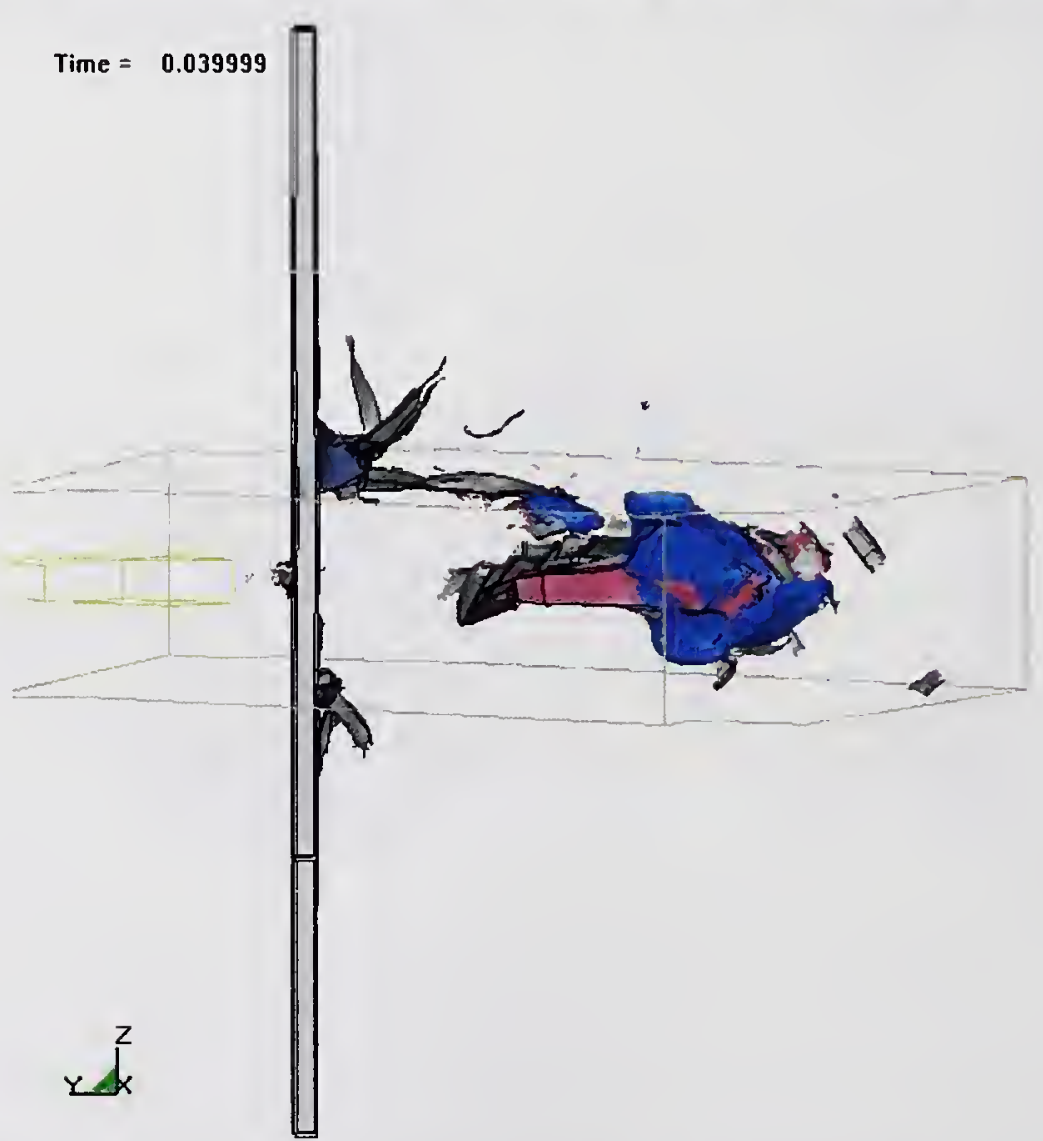

Figure C-67. ALE analysis of structural damage and fuel dispersion (side view).

$$
\text { C-56 }
$$




\section{Bolted Connection Modeling}

There are a wide variety of different connections required for the assembly of the towers and aircraft. Wherever possible, evidence gathered from WTC steel will be applied to determine the importance of including connection details in the model and failure modes of those connections. For example, photographic and structural debris evidence clearly demonstrated that the external column connections played a significant role in the mode of column failure and extent of the external damage.

Two connections are of particular interest to the impact analysis of the aircraft into the WTC towers and are modeled in this section. These include the bolted connections at exterior column butt plates and the bolted spandrel connections. The objective of connection component analyses is to develop connection models for the global impact analyses that accurately capture the capacity and failure modes of the connection. Various connection component models developed include both fine models of these complex connection components (e.g., 3-D brick element models of bolts), to simple models such as beam element bolt models and tied constraints with failure. The constitutive behavior of the beam element bolt was described previously in Section C.2.1. A tied constraint with failure requires that two nodes or a node and a surface segment (shell element or solid element face) have tied degrees of freedom until a failure criterion is exceeded.

The coarse component models utilize many of the simplified connection and element types available in LS-DYNA to approximate the behavior observed in the fine models. For example, in the exterior column bolted connections, the bolts were modeled with elastic-plastic beam elements calibrated to match the fine model. Bolted joints, such as in the spandrel connections, were approximated with tied node algorithm that constrains degrees of freedom of adjacent nodes and element faces. Various options are investigated in these component analyses and final selections of the modeling methodology are based on both the fidelity and efficiency of the modeling approaches.

Component modeling of the exterior column butt plate connections has been completed. As shown in Fig. C-68 the detailed model includes individual bolts modeled with solid brick elements. The simplified model uses coarse brick butt plates joined by beam element representations of the bolts. A dynamic analysis was carried out to calibrate the beam element bolt model. The loading condition was a dynamic separation of the two butt plates. The velocity profile used to separate the butt plates was obtained from a preliminary engine impact analysis against the exterior wall similar to those described in the next subsection. The profile is a linearly increasing separation velocity between the butt plates with an initial velocity of zero and a velocity of $43 \mathrm{ft} / \mathrm{s}(13 \mathrm{~m} / \mathrm{s})$ at a time of $5.0 \mathrm{~ms}$.

Failure strain in the beam models was calibrated such that the beam bolts failed at the same time as the brick element bolts. Failure of the bolts occurs at a time of approximately $3.0 \mathrm{~ms}$. These connection models were used in the corresponding brick and shell models of the exterior column component impact analyses shown previously in Fig. C-59. Connection failure at the column ends was quite similar in both cases.

The spandrel connections consist of an overlapping splice plate across a spandrel joint with a row of bolts on either side of the joint. Typical failure of these spandrel joints in the impact zone resulted from bolt bearing shear failures, typically in the spandrel plate, as shown in the photographs in Fig. C-69. A common configuration in the impact zone would have six bolts on either side of the joint. The bolt bearing shear failure mechanism would be difficult to model using a beam element bolt as applied 
previously to the exterior column bolted connections. In the exterior columns, the bolts fail primarily in tension and details of the contact between bolts and butt plates are not as important for capturing the failure behavior. As a result, an alternate modeling approach was required for the spandrel splice failures.

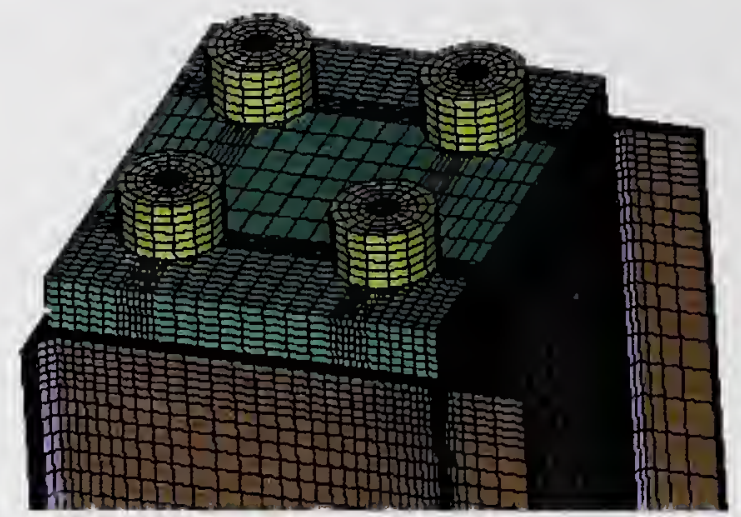

(a) Brick element bolts

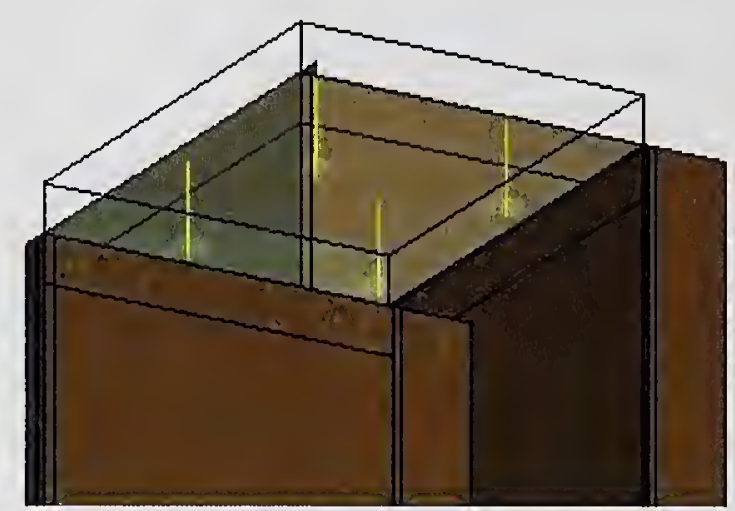

(b) Beam element bolts (butt plates shown as transparent)

Figure C-68. Exterior column end connection modeling.
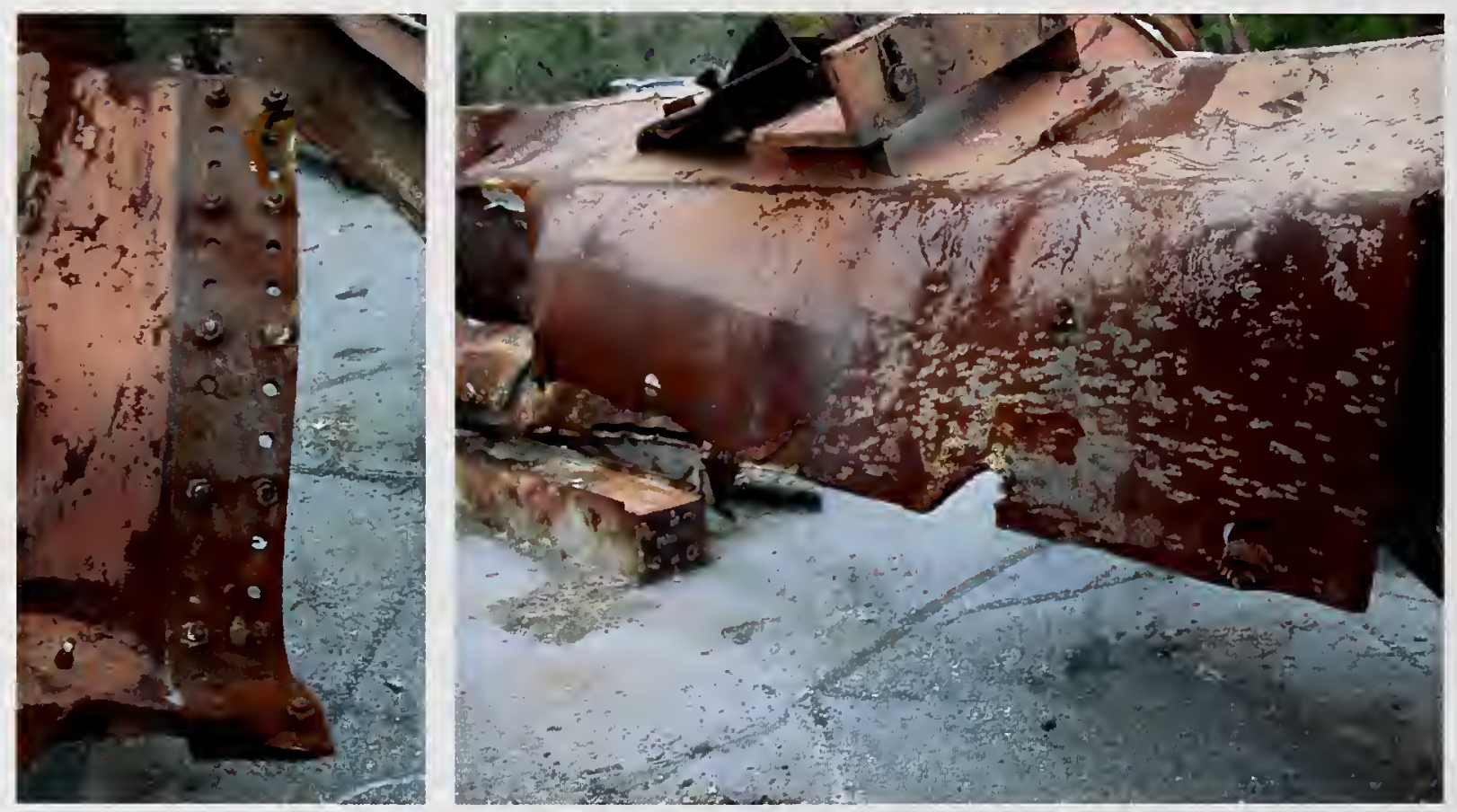

Figure $\mathrm{C}-69$. Typical bolt bearing shear failures of spandrel connections.

Spandrel connections are modeled using a splice plate made up of shell elements, as shown in Fig. C-70. Connections corresponding to individual bolts are treated by tying single nodes on the splice plates (center of green squares in Fig. C-70) to the spandrels. Two material definitions are used to make up the splice plate to allow for contact between the splice plates and the spandrels as well as having tied contact. The first splice plated material definition (shown in green in Fig. C-70) is used to allow the center node tied constraint (representing the bolt connection) to be aligned with the center of the spandrel plate. Since this material includes the tied constraint, it is not included in the automatic contact definition. The second material definition in the splice plate (shown in red in Fig. C-70) has a standoff distance equal to one half of the combined thickness of the spandrel and splice plate and is included in the automatic contact definition. Both material definitions have the same constitutive properties; however, 
using a single material definition would sometimes result in a numerical instability due to conflicting constraint and interface algorithms on those segments. The application of the spandrel splice plate connection model is demonstrated in the engine impact component analyses below.

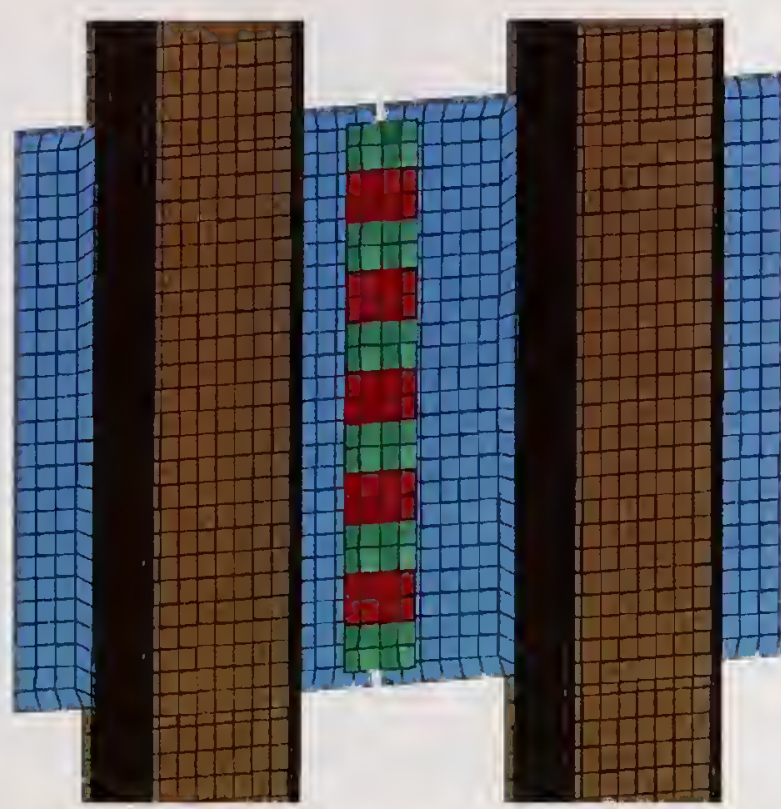

(a) Detail of spandrel connection

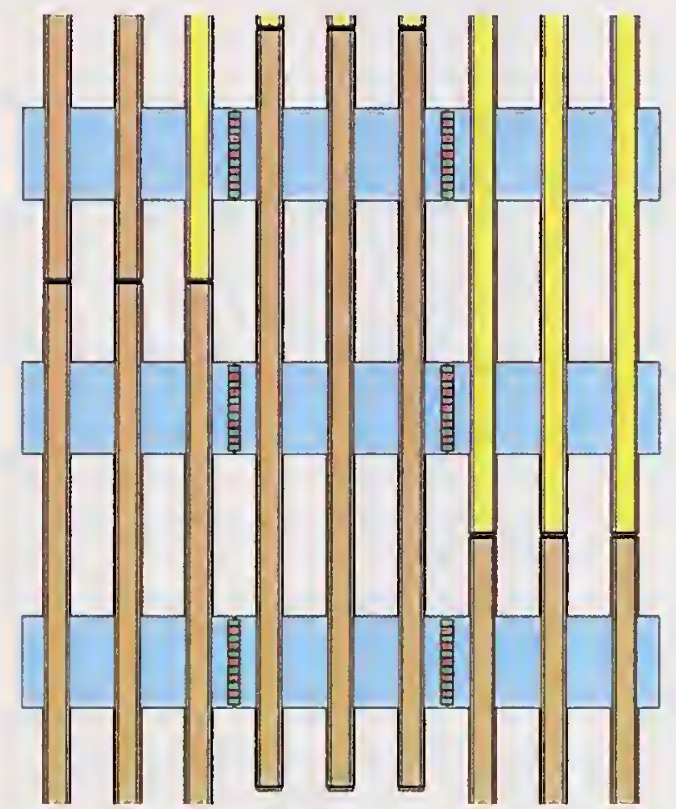

(b) Multiple panel connections

Figure C-70. Bolted spandrel connection modeling.

\section{Engine Impact Analysis}

An example of an engine impacting an assembly of exterior panels is shown in Fig. C-71. The analysis includes an engine impacting an exterior panel of WTC 1 and is centered on panel 124 at floor 96 (the impact is centered on the middle spandrel). The exterior wall model does not contain any boundary conditions or components to represent the truss floor behind the panels. The initial engine speed was $500 \mathrm{mph}(223 \mathrm{~m} / \mathrm{s})$. In this example, a medium mesh density shell element panel was used. Columns were connected with beam element models of individual bolts. Spandrels were merged together in this model-splice plates were not used. Fixed butt plates were bolted at the free column end and no boundary conditions were applied to represent the floors. Velocity time-histories for representative engine materials are shown in Fig. C-72. The plot shows an overall reduction in speed of about 13 percent after impact with the exterior wall.

A second engine impact analysis was performed with similar conditions except the impact location was moved downward by one half floor to create an impact centered between spandrels. A comparison of the two calculated impact behaviors is shown in Fig. C-73. In both analyses the engine breaks through the exterior wall with relatively little breakup of the engine core. The impact centered between spandrels results in a reduction in the velocity of the engine core of $56 \mathrm{mph}(25 \mathrm{~m} / \mathrm{s})$. 


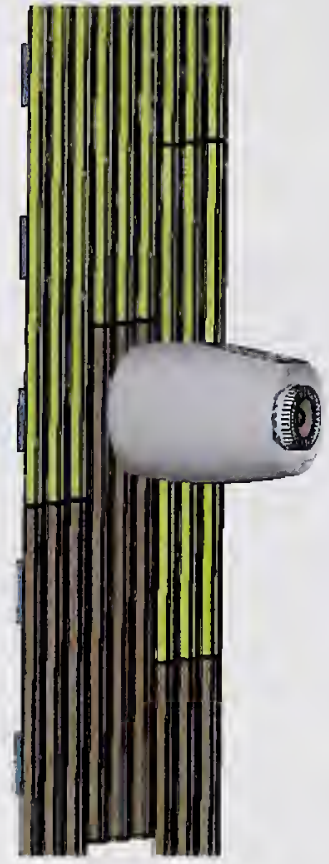

(a) Initial configuration

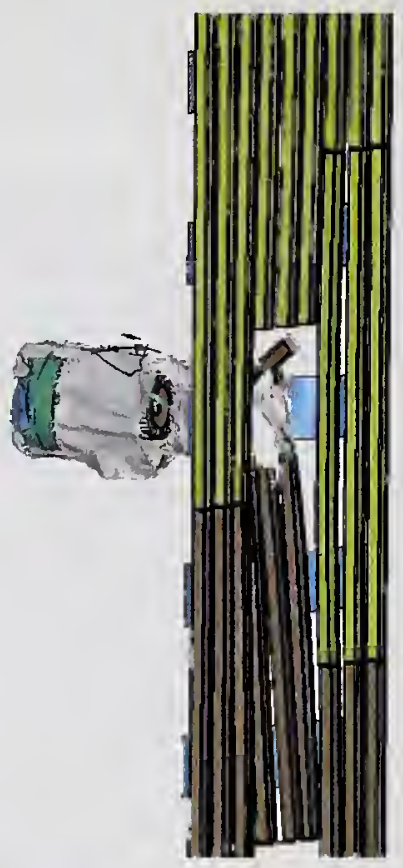

(b) Impact response at $\mathbf{4 0} \mathrm{ms}$

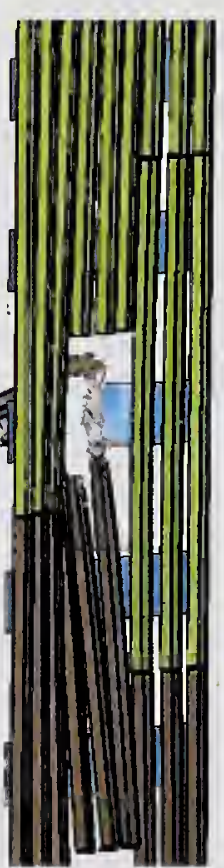

(c) Impact response at $80 \mathrm{~ms}$

Figure $\mathrm{C}-71$. Example engine impact analysis with exterior columns. 


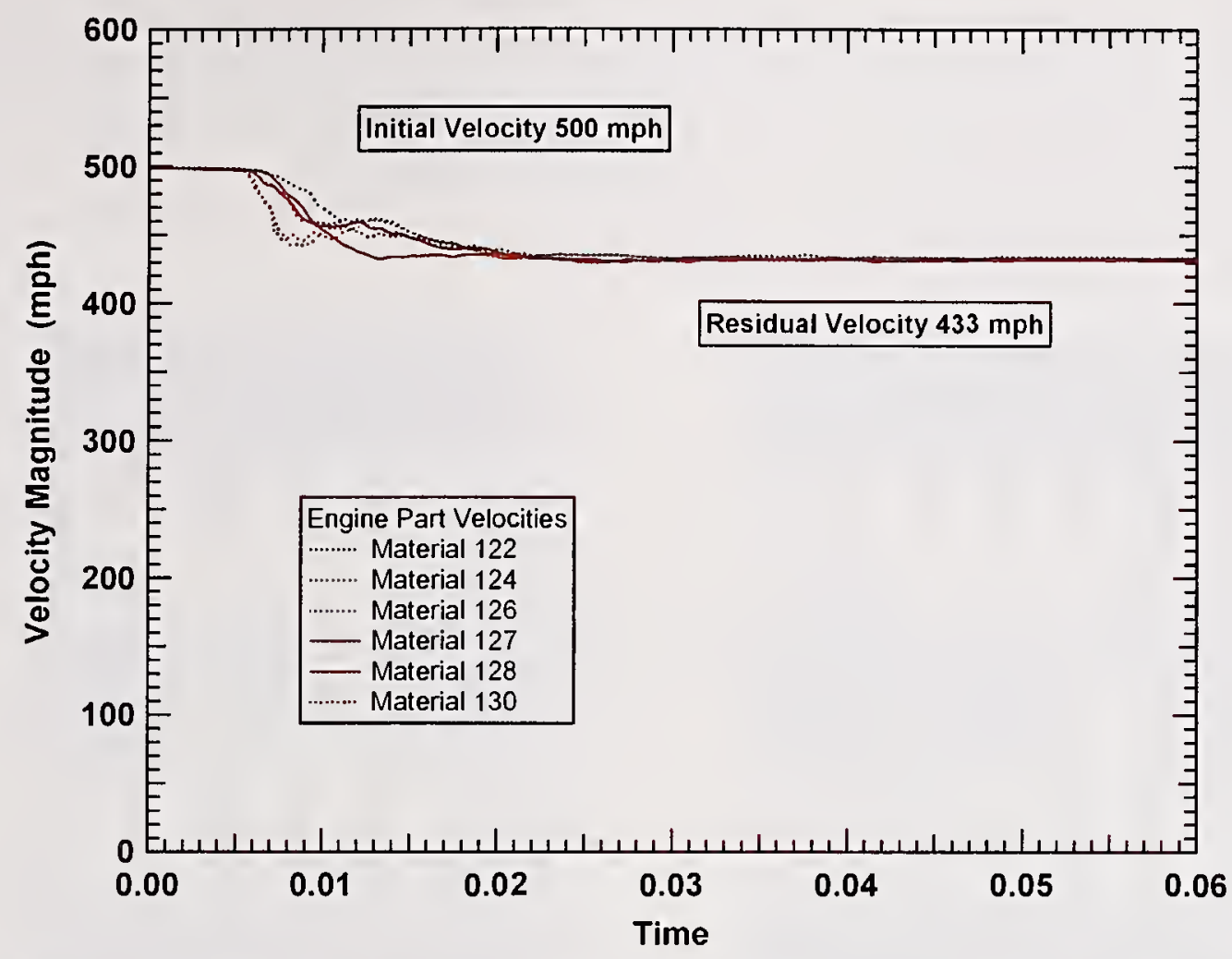

Figure C-72. Engine velocity history for the exterior wall impact.

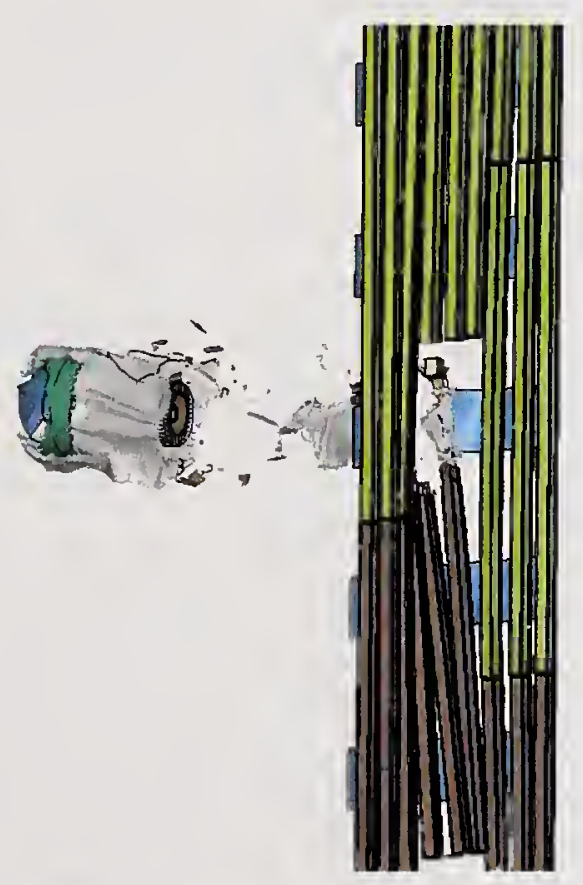

(a) Spandrel centered impact

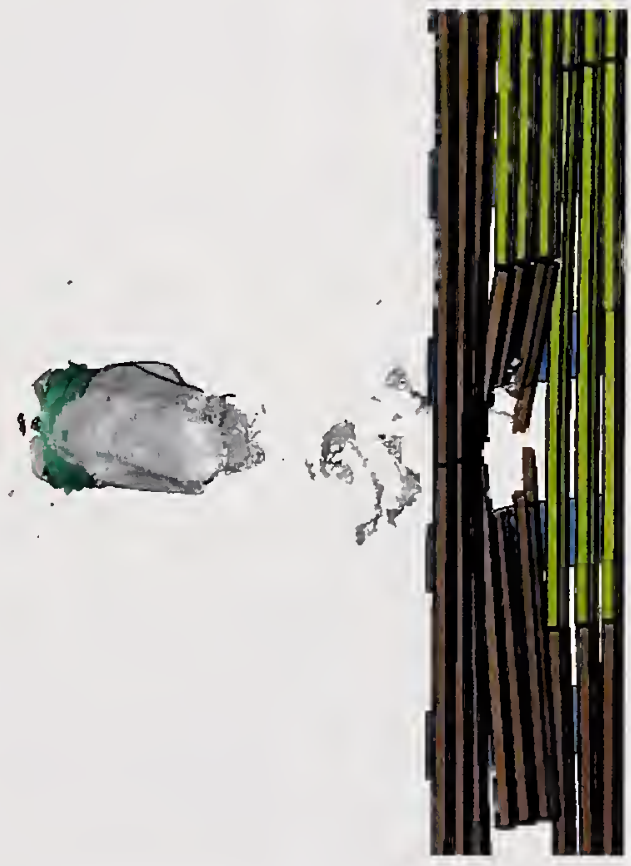

(b) Between-spandrel impact

Figure C-73. Example engine impact analysis with different impact locations.

A final revision of the above analysis included adding splice plates at the spandrel connections as explained in the previous subsection. Figure $\mathrm{C}-74$ presents a comparison of both models. The figure shows exterior wall damage as seen from the outside without engine components. Contours of plastic strain are shown in the plot with blue being zero strain and red being at the failure strain threshold (20 percent in this case). Material exceeding the maximum failure strain is eroded and no longer shown 
in Fig. C-74. The analyses differ most in spandrel failure modes. Spandrels fail at the column connection in the merged spandrel case, while the connection fails in the splice plate case. In the latter case, a realistic bearing stress type tear-out mode is seen in the splice plate. Engine core velocities for the three engine impact analyses are compared in Fig. $\mathrm{C}-75$ for a single representative engine component. The splice plate model resulted in a $74 \mathrm{mph}(33 \mathrm{~m} / \mathrm{s})$ velocity reduction of the engine core. The splice model results in the largest reduction in velocity in the engine.

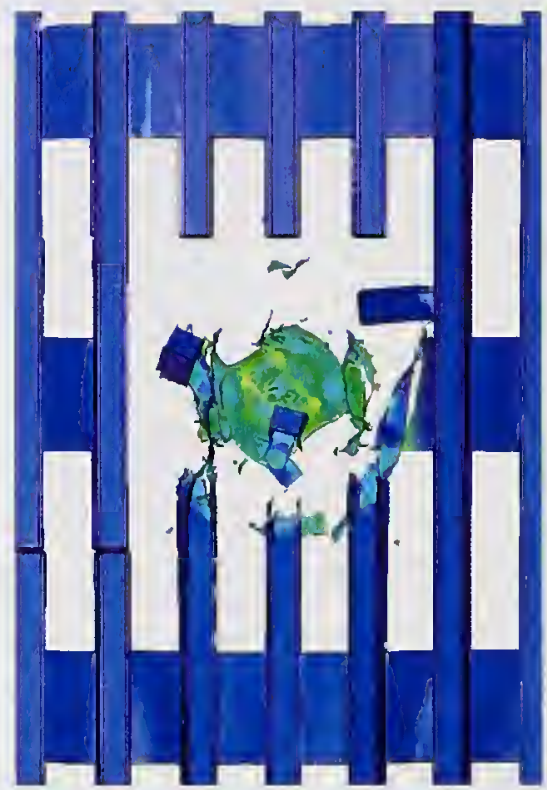

(a) Merged spandrel analysis

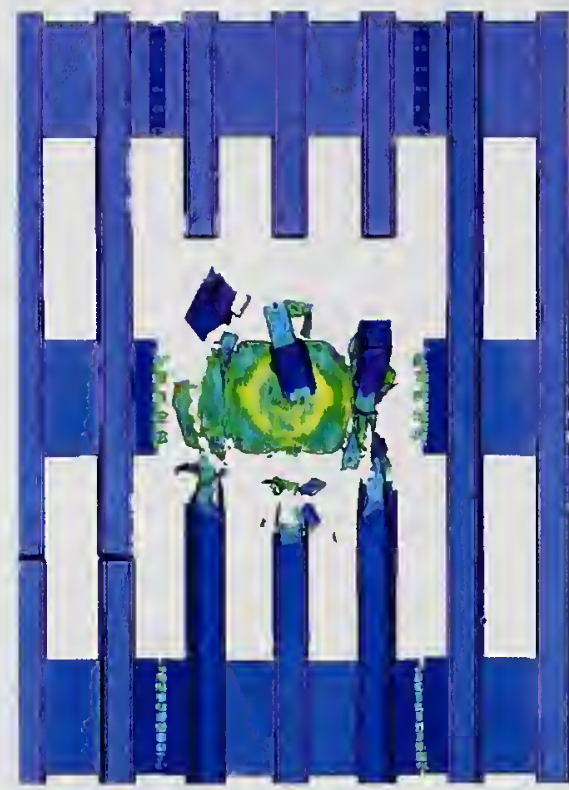

(b) Spliced spandrel analysis

Figure $\mathrm{C}-74$. Example engine impact analysis with different spandrel connection treatments.

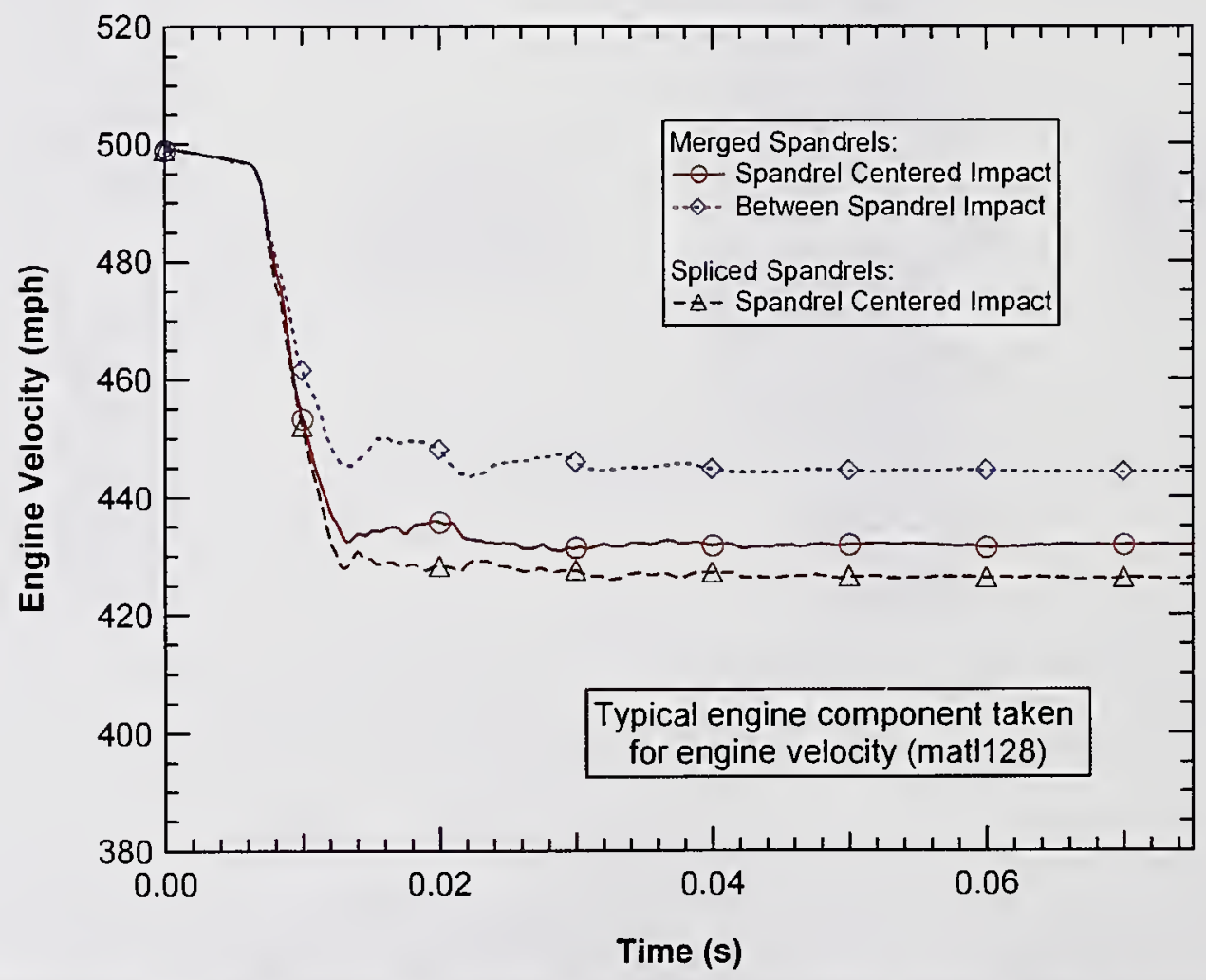

Figure C-75. Engine velocity history for the exterior wall impact. 
The above comparison suggests that the splice plate has a relatively small influence on the exterior wall strength. The addition of the splice plate has approximately a 10 percent effect on the change in engine velocity during impact and penetration of the exterior wall. However, the spandrel connection model does not introduce a large computational cost and results in a more appropriate failure mode for the spandrels in the impact zone. Therefore, the spandrel splice connections will be maintained in subsequent impact analyses.

\section{C.4.3 Core Column Impact Analyses}

\section{Engine Impact Analysis}

Preliminary analyses of an engine impacting a single core column indicated that the impact load was sufficient to penetrate and overwhelm the column. Subsequent analyses of an engine impacting core columns have included multiple impacts and will be reported later along with the subassembly analysis and the uncertainty analyses.

\section{Wing Section with Fuel Impact Analysis}

Component analyses for core columns impacted by fuel-filled wing sections were conducted for both wide flange and box type columns (Figs. $\mathrm{C}-76$ through $\mathrm{C}-79$ ). Similar to exterior column analyses, the primary purpose was to progress from the initial finely meshed brick element models to coarser shell element models. Figure C-76 (wide flange core column) and Fig. C-78 (box section core column) compare the fine brick model and coarser shell model response under the same loading conditions. Figures $\mathrm{C}-77$ and $\mathrm{C}-79$ show corresponding displacement and kinetic energy comparisons for, respectively, the wide flange and box section core column models. The figures indicate that the response of the coarser shell models is very similar to that of the fine brick models. Therefore, the shell element formulation and mesh refinement of the coarse model are sufficient to capture the impact damage mechanisms in this component impact scenario.

\section{C.4.4 Combined Engine Impact Analyses}

An example of engine impact analysis is presented in this section to demonstrate the damage response to both exterior and interior columns. The impact configuration is an engine impacting at $560 \mathrm{mph}$ $(250 \mathrm{~m} / \mathrm{s})$ against a set of exterior columns in a single exterior panel, an interior box column, and an interior wide flange column. The columns are modeled using shell elements. The spacing between exterior and core columns was reduced to shorten the run time necessary for the complete impact scenario. The simulation included three external panels stacked vertically such that the impacted column was bolted to additional panels both above and below. The core columns models were several floors tall to reduce the influence of the clamped boundary conditions at the ends. 


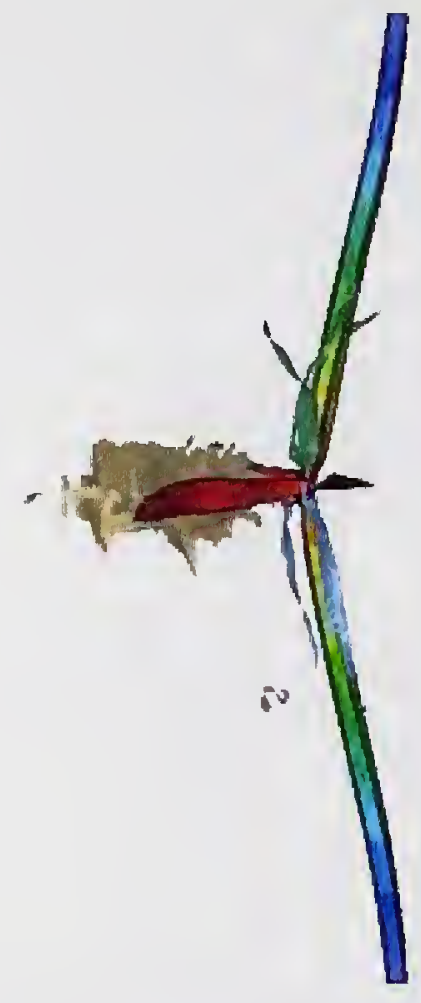

(a) Fine brick element column

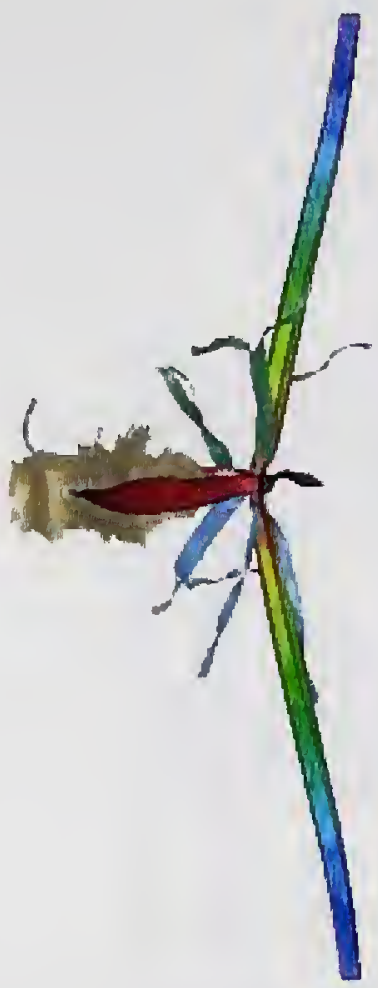

(b) Coarse shell element column

Figure $\mathrm{C}-76$. Wide flange core column response comparison, showing contours of the displacement magnitude (in.).
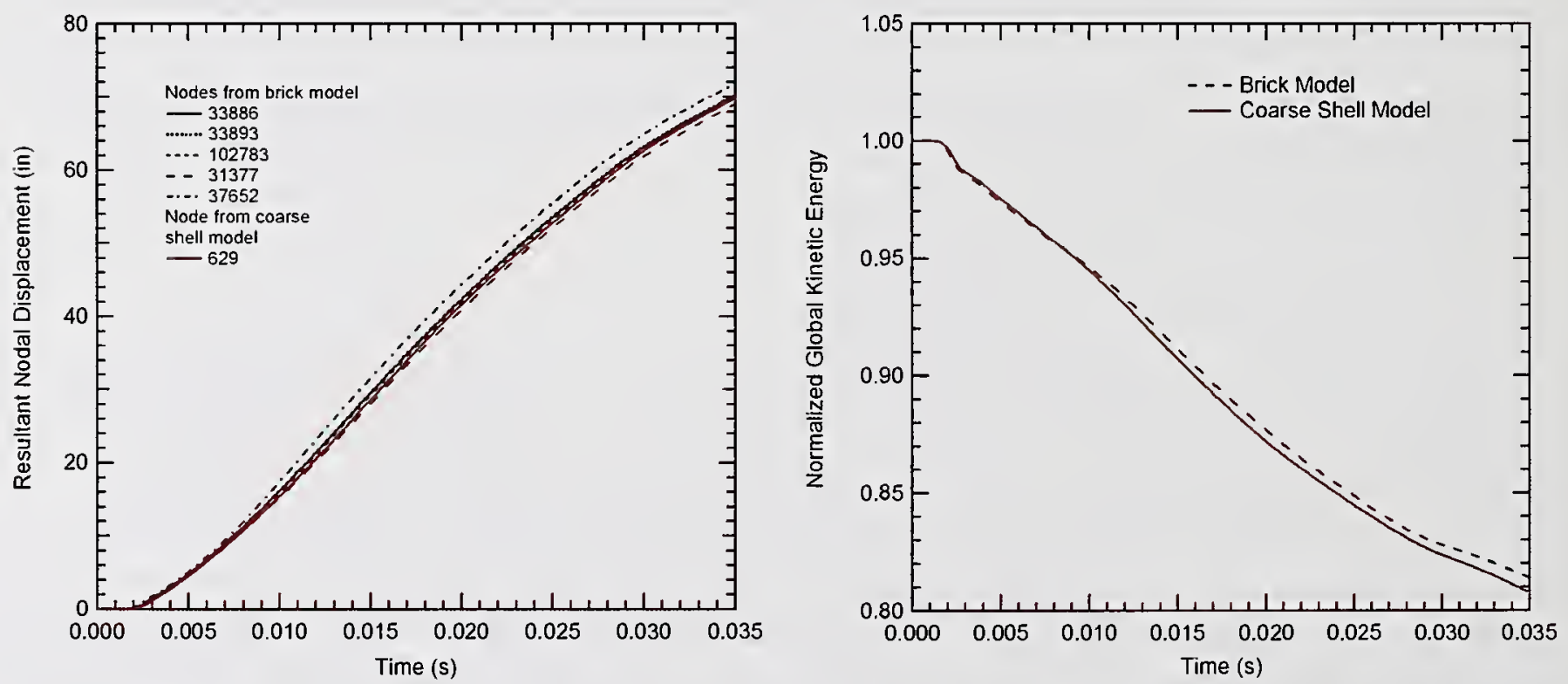

Figure C-77. Displacement and kinetic energy comparison for wide flange core column wing impact analysis. 


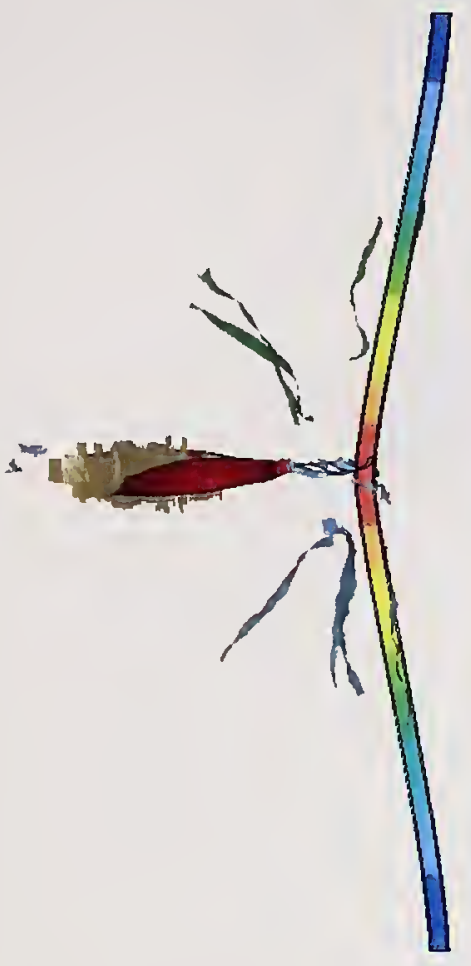

(a) Fine brick element column

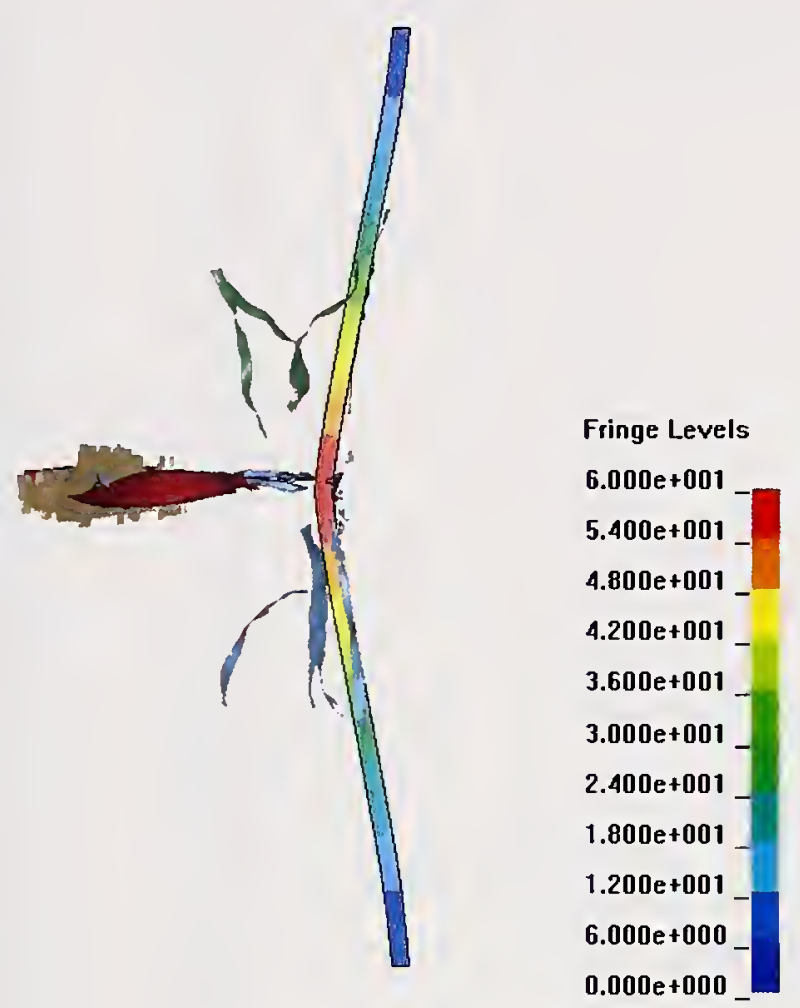

(b) Coarse shell element column

Figure C-78. Box core column response comparison, showing contours of the displacement magnitude (in.).
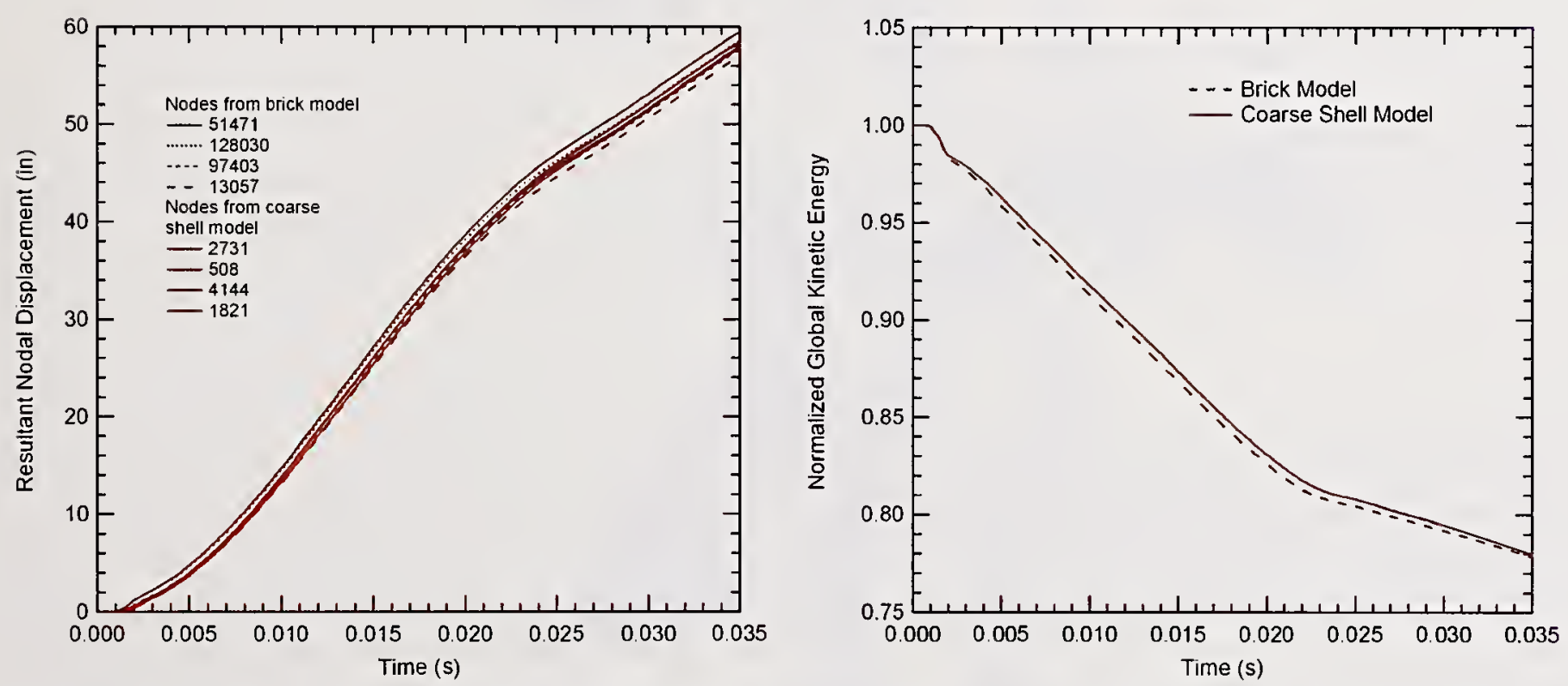

Figure C-79. Displacement and kinetic energy comparison for box core column wing impact analysis.

The impact scenario is illustrated in Fig. C-80 (a). The calculated impact damage is shown at a time of $90 \mathrm{~ms}$ in Fig. C-80 (b). The calculated engine impact response completely fails all of the columns with a residual velocity of the engine of approximately $224 \mathrm{mph}(100 \mathrm{~m} / \mathrm{s})$. The deformations of the column include large lateral displacements which would be significantly reduced if the constraint effects of the concrete floor slab were added. The deceleration profile of the major engine debris fragment is given in 


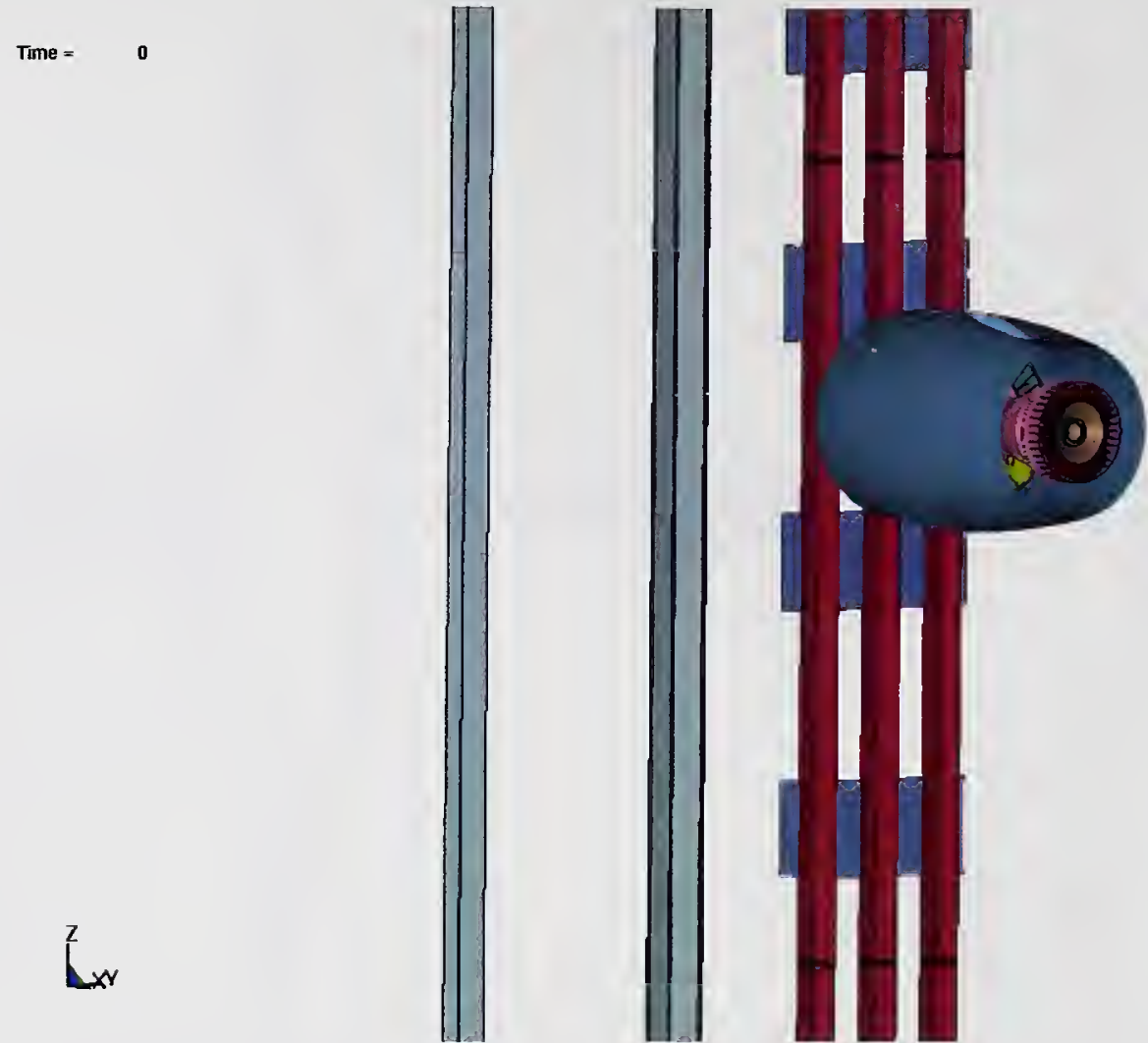

(a) Initial configuration

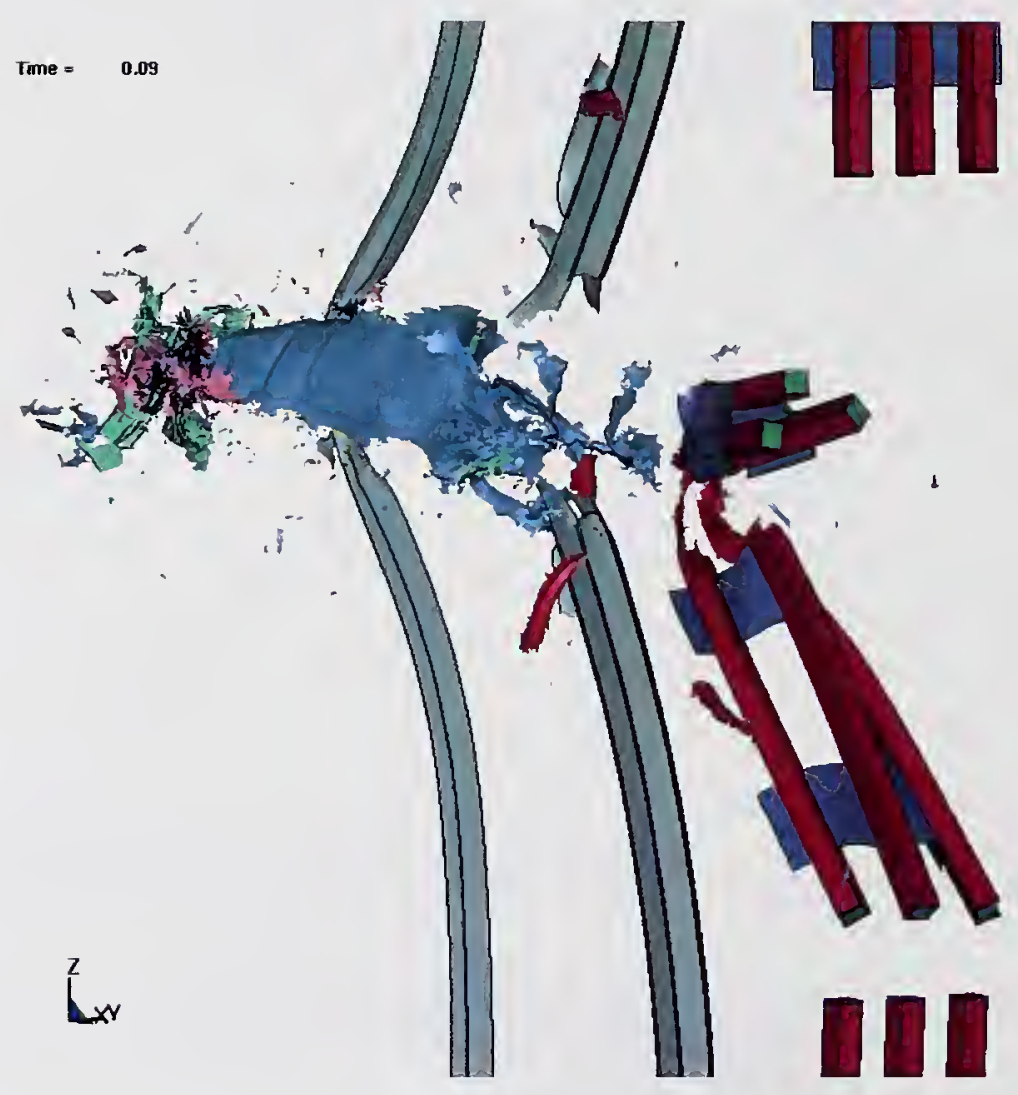

(b) Impact response at $90 \mathrm{~ms}$

Figure C-80. Example engine impact analysis with interior and exterior columns. 
Fig. C-81. The majority of the engine structure has been broken into fragments by the combination of the three impacts. The resulting size, strength, and velocity of the engine debris are not likely to produce severe impact damage or failure to a subsequent core column.

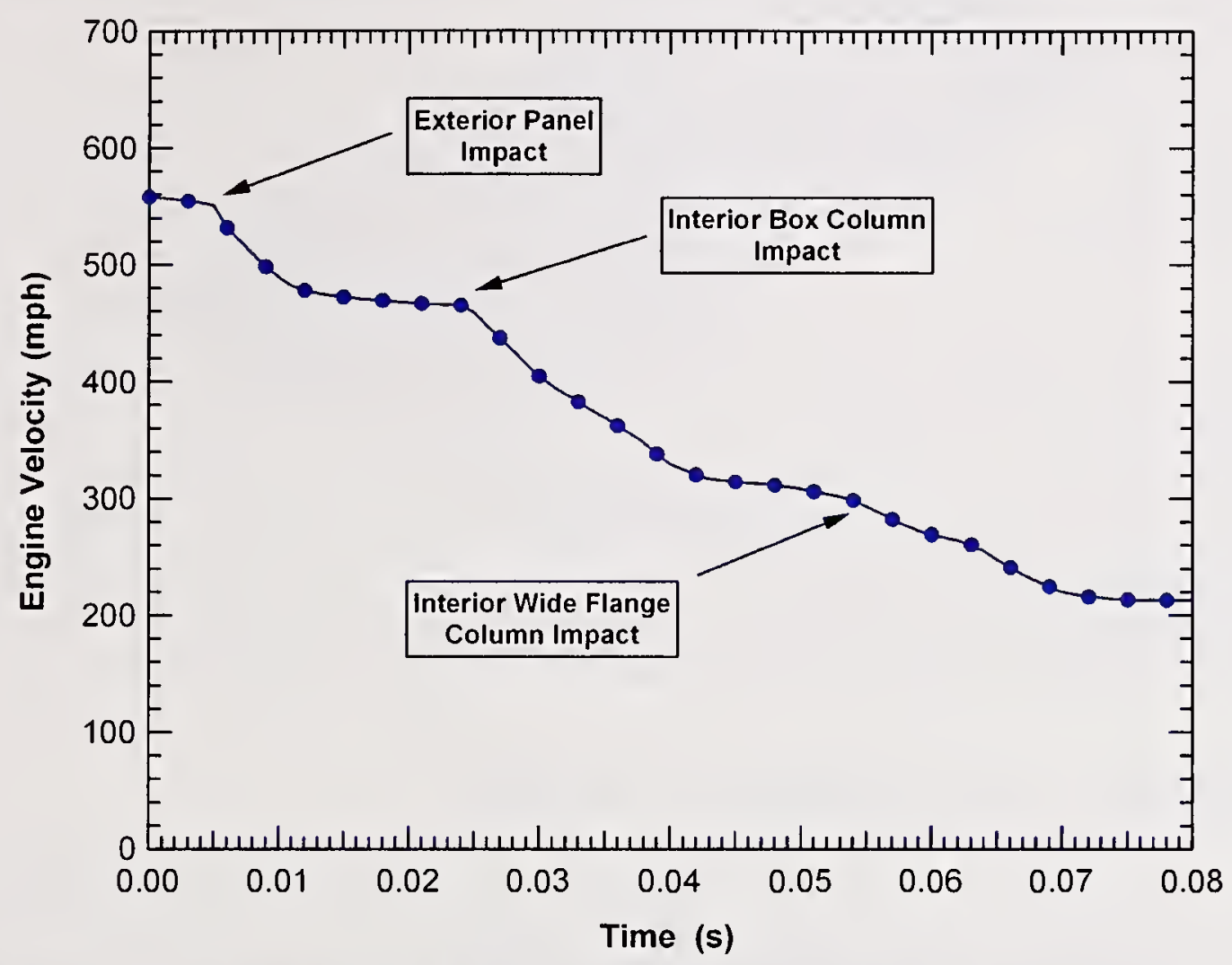

Figure C-81. Example engine impact analysis with interior and exterior columns.

This example illustrates the large level of damage produced by a massive aircraft component, such as an engine, at high impact velocity. The impact energy is sufficient to overwhelm a single core column and, therefore, makes it difficult to determine the effects of column component modeling parameters on the impact response using this impact scenario.

\section{C.4.5 Floor Assembly Component Analyses}

An additional component model analyzed is the truss floor assembly. The failure and penetration of the floor structures is important for assessing the extent of damage and the spread of fuel and debris through the structure. The integrity of the floor structures could also be significant in the analysis of the subsequent fire behavior in the towers. Loading of the floor structure was achieved by direct impact by the engine and a simplified impactor.

Component models of a section of the composite floor assembly outside the core were generated and used in various impact analyses. Initial floor component models used the detailed combination of brick, shell, and beam elements. Subsequent floor assembly models were less refined with shell and beam elements only. A comparison of the two floor system models and analyses is given in Table $\mathrm{C}-7$. The modifications have reduced the size of the model by an order of magnitude and the run times by more than 80 percent. 
Table C-7. Truss floor assembly component analyses comparison.

\begin{tabular}{|l|c|c|}
\hline \multicolumn{1}{|c|}{ Model Type } & Fine Brick Model & Coarse Shell Model \\
\hline Number of beam elements & 6,928 & 3,440 \\
\hline Number of brick elements & 230,778 & 0 \\
\hline Number of shell elements & 148,256 & 39,000 \\
\hline Total nodes & 372,084 & 48,971 \\
\hline CPU time & $16,796 \mathrm{~s}(4.7 \mathrm{~h})$ & $2,482 \mathrm{~s}(0.7 \mathrm{~h})$ \\
\hline Elapsed time & $26,553 \mathrm{~s}(7.3 \mathrm{~h})$ & $4,454 \mathrm{~s}(1.2 \mathrm{~h})$ \\
\hline
\end{tabular}

The impactor used in the initial component modeling is a simplified plow type impactor which promotes repeatable damage, not complicated by all the debris and randomness associated with an engine-floor impact. The weight of the plow impactor is comparable to an engine and the impact velocity was $500 \mathrm{mph}$. An example of a plow impactor analysis with the fine mesh floor model is shown in Fig. C-82. The calculated impact damage with a corresponding shell element floor system model is shown in Fig. C-83. This component impact configuration is useful for comparing the differences in response with changes in the modeling methods or refinement. Additional simulations with an engine impactor are being performed to validate the modeling approach and will be reported at a later date.

\section{C.5 SUMMARY AND PRELIMINARY FINDINGS}

The objectives of this project are to calculate the aircraft impact response of the WTC towers, including damage to WTC tower structural systems, acceleration environment, and fuel and debris dispersion. The impact analyses are conducted at various levels, including: (1) the component level, (2) the subassembly level, and (3) the global level to estimate the probable damage to the towers due to aircraft impact. The analyses also include simplified and approximate methods. Analysis of uncertainties using the component, subassembly, global, and simplified analyses will also be conducted to assess the effect of variability associated with various parameters on the damage estimates.

Significant progress has been made to identify the proper constitutive relationships, including high strainrate effects and failure criteria for the various materials included in the analysis of aircraft impacts into the WTC towers. These materials include steels used in the exterior walls and core columns of the towers, weldment, bolts, reinforced concrete, and aircraft materials.

The development of the Boeing 767 aircraft model for impact analysis is nearing completion. The engine and wing models have been completed and are being used in the component and subassembly analyses. Work is underway to finalize the model of the fuselage, nose, tail, and nonstructural components of the aircraft.

The WTC towers and Boeing 767 aircraft are extremely complex structural systems, and a large database of detailed structural information has been collected on both the towers and the aircraft. In the model development process, the objective was to include all of the structural components and details of both the aircraft and towers that would influence the impact response and damage. This approach results in very large models for the tower and aircraft. The application of the models in the component and subassembly analyses were used to determine model simplifications that can reduce the overall model size while maintaining fidelity in determination of the impact damage. 


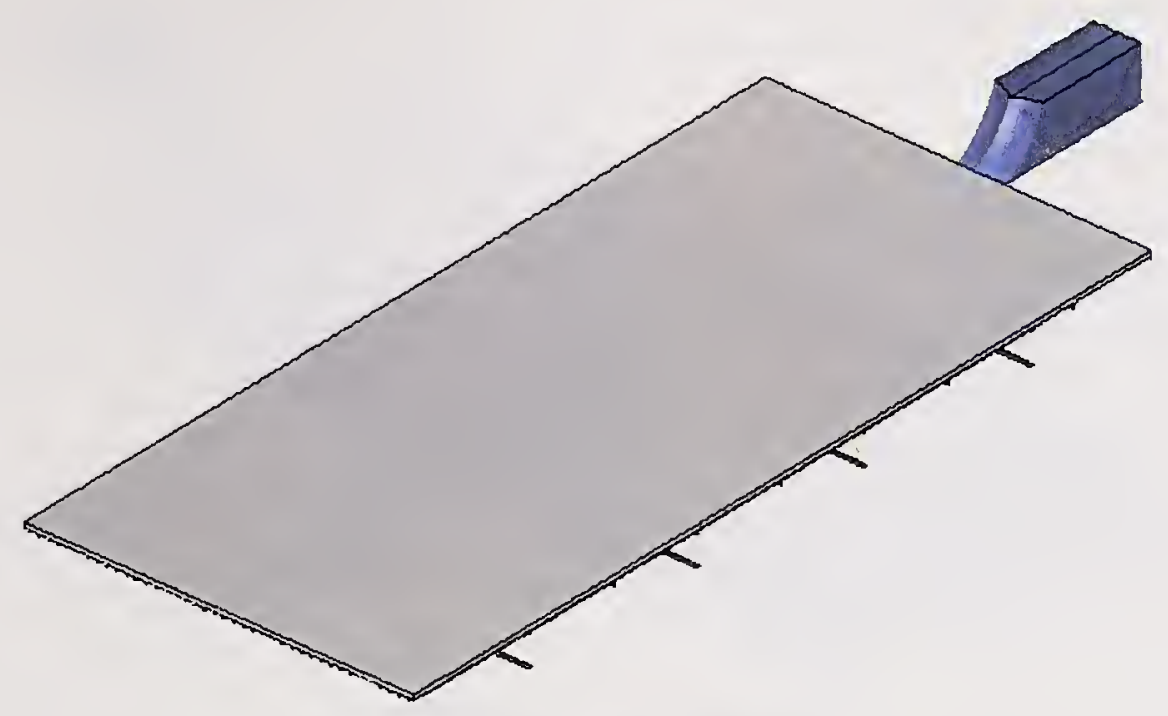

(a) Initial configuration

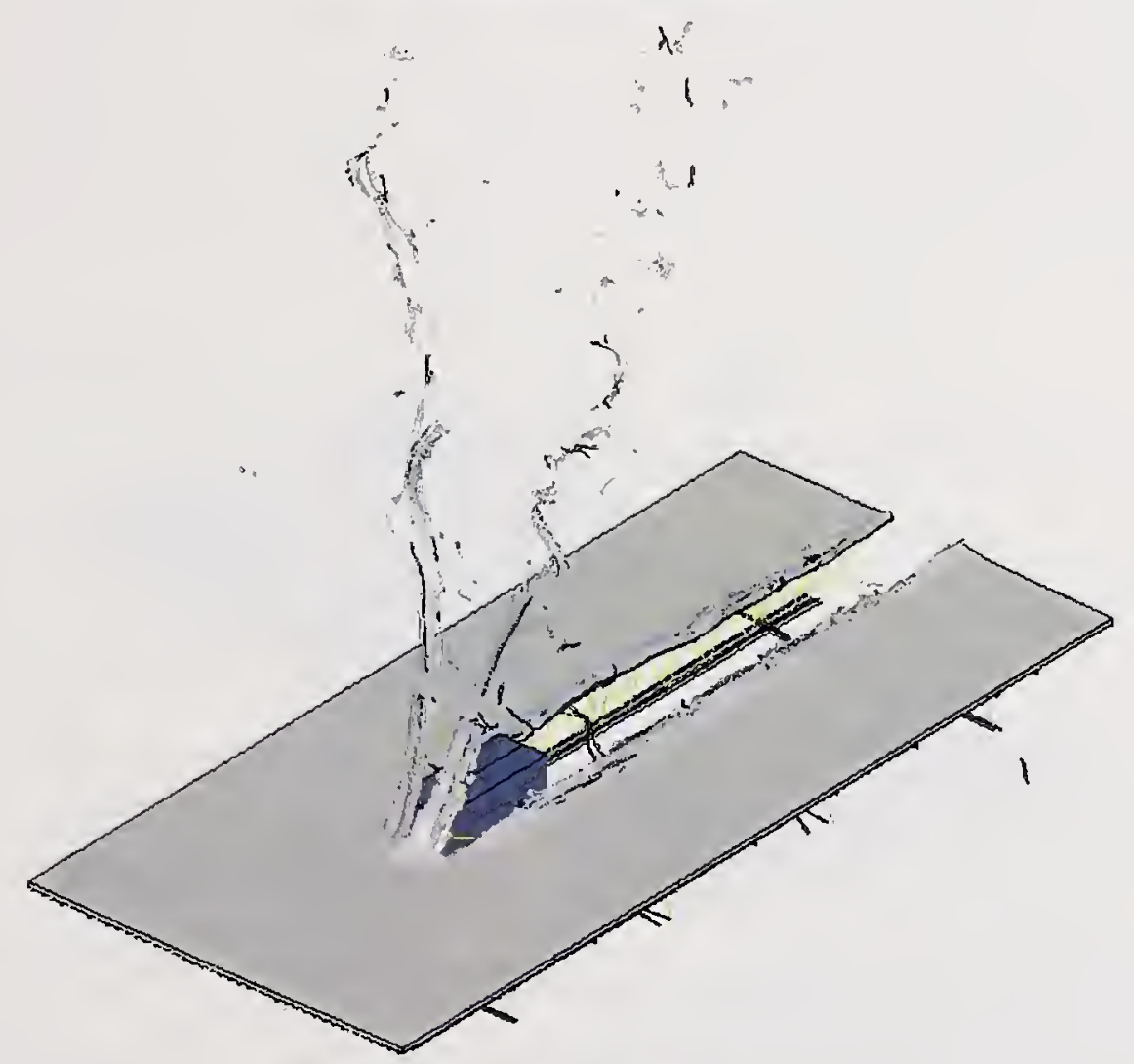

(b) Impact response at $0.10 \mathrm{~s}$

Figure C-82. Floor assembly impact analysis with brick element concrete slab. 


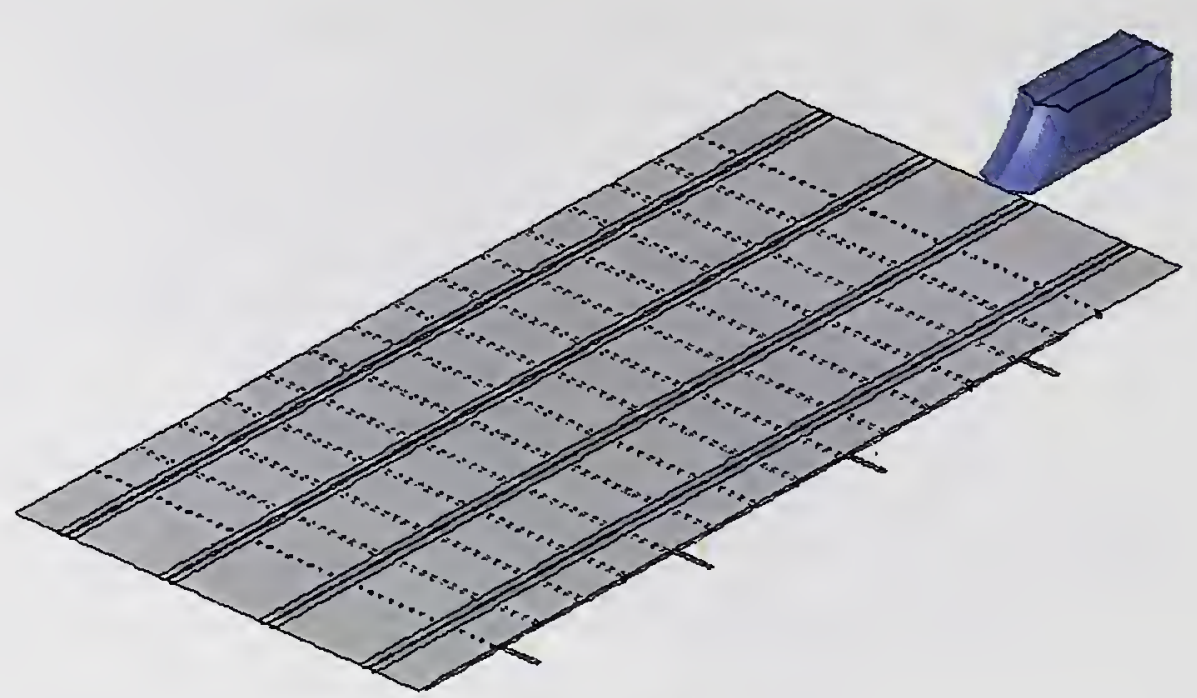

(a) Initial configuration

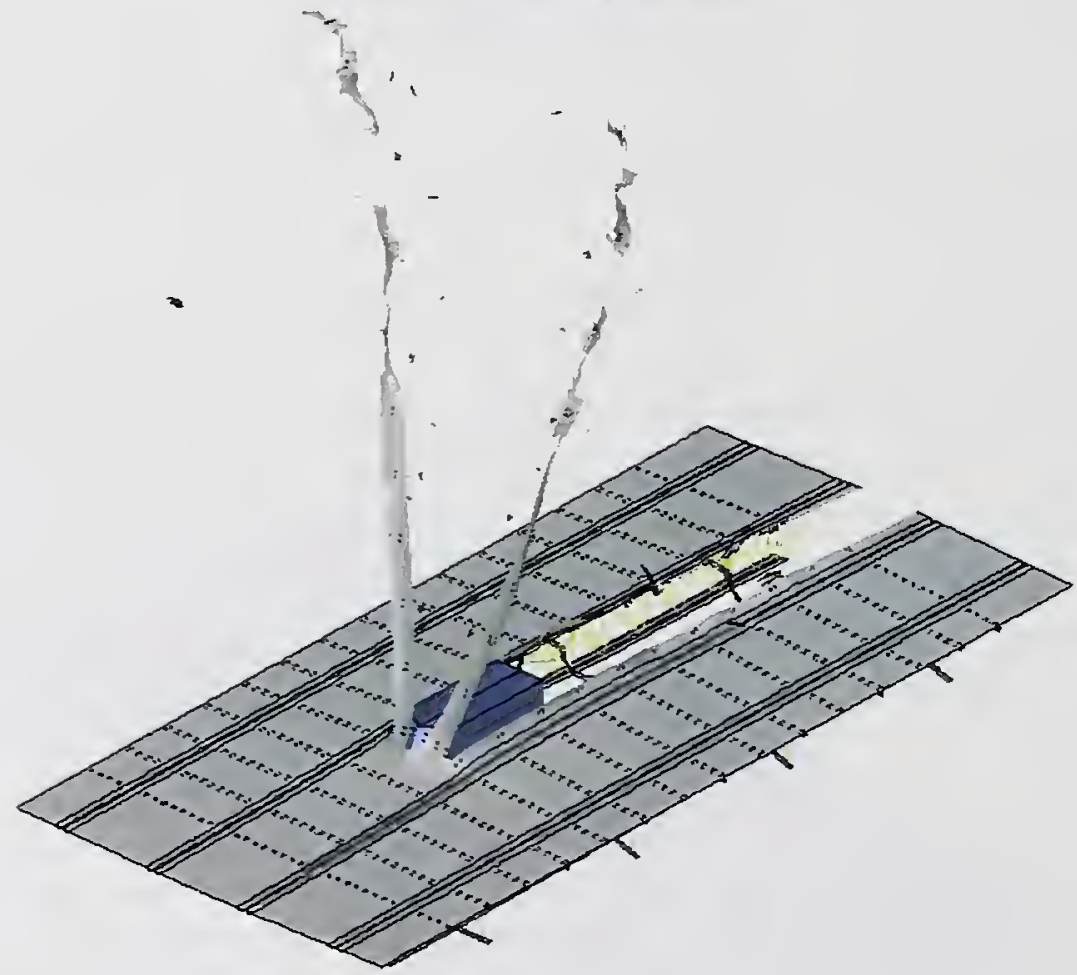

(b) Impact response at $0.10 \mathrm{~s}$

Figure C-83. Floor assembly impact analysis with shell element concrete slab.

A series of component impact analyses were performed using models of tower exterior and core columns with wing section and engine component models as impactors. These models are used to develop the simulation techniques required for the global analysis of the aircraft impacts into the WTC towers. The following results were obtained from the component impact analyses:

- A $500 \mathrm{mph}(223 \mathrm{~m} / \mathrm{s})$ engine impact against an exterior wall panel results in a penetration of the exterior wall and failure of impacted exterior columns. If the engine does not impact a floor slab, the majority of the engine core will remain intact through the exterior wall penetration with a reduction in velocity between 10 percent and 20 percent. The residual velocity and mass of the engine after penetration of the exterior wall is sufficient to fail a core 
column in a direct impact condition. Interaction with additional interior building contents prior to impact or a misaligned impact against the core column could change this result.

- A normal impact of the exterior wall by an empty wing segment from the wing tip region will produce significant damage to the exterior columns but not necessarily complete failure. This is consistent with photographs showing the exterior damage to the towers due to impact. Specific details of the damage will depend on details of the impact orientation and locations of internal wing components such as control surface actuators and arms.

- A fuel-filled wing section impact results in extensive damage to the external including complete failure of the exterior columns. This is also consistent with photographs of the exterior damage. The resulting debris propagating into the building maintains the majority of the initial momentum prior to impact.

- Three different numerical techniques were investigated for modeling impact effects and dispersion of fuel: (1) standard Lagrangian finite element analysis with erosion, (2) Smoothed Particle Hydrodynamics (SPH) analysis, and (3) Arbitrary-Lagrangian-Eulerian (ALE) analysis. Of these approaches, SPH analyses appear to offer the greatest potential for modeling fuel in the global impact analysis due to the combination of both computational efficiency and modeling fidelity.

\section{C.6 REFERENCES}

ASTM Designation A 370 - 03a. 2003. "Standard Test Methods and Definitions for Mechanical Testing of Steel Products," Approved June 10.

Brown, W. F. Jr., H. Mindlin, and C. Y. Ho. eds. 1991. Aerospace Structural Metals Handbook. CINDAS/Purdue University Publishers, vol. $3 \& 4$.

Kirkpatrick, S. W., J. H. Giovanola, and J. W. Simons. 1996. DYNA3D analysis of dynamic fracture of weldments, IA'96, Proceedings of International Seminar on Quasi-Impulsive Analysis.

November 20-22, Osaka, Japan, pp. A6.1-15.

LS-DYNA Keyword User's Manual. 2003. Livermore Software Technology Corporation, version 970. April.

Mackenzie, A. C., J. W. Hancock, and D. K. Brown. 1977. On the influence of state of stress on ductile failure initiation in high-strength steels, Eng. Fracture Mechanics, 9, 167-188.

Military Handbook. 1987. Metallic Materials and Elements for Aerospace Vehicle Structures. U.S. Department of Defense, MIL-HDBK-5F.

Mudry, F. 1985. Methodology and applications of local criteria for prediction of ductile tearing, ElasticPlastic Fracture Mechanics. L.H. Larson, ed. ECSC, EEC, EAEC, Brussels and Luxembourg, Belgium, pp. 263-283. 
Rice, J.R., and D.M. Tracey. 1969. On the ductile enlargement of voids in triaxial stress fields, J. Mech. Phys. Solids, 17, 201-217.

Wischers, G. 1978. Application of effects of compressive loads on concrete, Betontech, nos. 2 and 3. Berlin.

XYZ Scientific Applications, Inc. 2001. TrueGrid Manual, version 2.1.0. September. 

